\title{
Effect of Binder Modification and Aggregate Size on Modulus and Fatigue of Asphalt Concrete
}

\author{
Elizabeth Bashiti \\ West Virginia University, elbashiti@mix.wvu.edu
}

Follow this and additional works at: https://researchrepository.wvu.edu/etd

Part of the Civil Engineering Commons, and the Transportation Engineering Commons

\section{Recommended Citation}

Bashiti, Elizabeth, "Effect of Binder Modification and Aggregate Size on Modulus and Fatigue of Asphalt Concrete" (2020). Graduate Theses, Dissertations, and Problem Reports. 7985.

https://researchrepository.wvu.edu/etd/7985

This Thesis is protected by copyright and/or related rights. It has been brought to you by the The Research Repository @ WVU with permission from the rights-holder(s). You are free to use this Thesis in any way that is permitted by the copyright and related rights legislation that applies to your use. For other uses you must obtain permission from the rights-holder(s) directly, unless additional rights are indicated by a Creative Commons license in the record and/ or on the work itself. This Thesis has been accepted for inclusion in WVU Graduate Theses, Dissertations, and Problem Reports collection by an authorized administrator of The Research Repository @ WVU. For more information, please contact researchrepository@mail.wvu.edu. 
Elizabeth Bashiti

Follow this and additional works at: https://researchrepository.wvu.edu/etd

Part of the Civil Engineering Commons, and the Transportation Engineering Commons 


\title{
Effect of Binder Modification and Aggregate Size on Modulus and Fatigue of Asphalt Concrete
}

\author{
Elizabeth Bashiti \\ Thesis submitted to the \\ Benjamin Statler College of Engineering and Mineral Resources \\ at West Virginia University \\ in partial fulfillment of the requirements for the degree of \\ Master of Science in Civil Engineering
}

John P. Zaniewski, Ph. D., P.E., Chair

Fei Dai, Ph. D.

YooJung Yoon, Ph. D.

Department of Civil and Environmental Engineering

Morgantown, West Virginia

2020

Keywords: Asphalt Concrete, Modified Binders Fatigue, Dynamic Modulus, AMPT, CoreLok, Copyright 2020 Elizabeth Bashiti 


\title{
ABSTRACT \\ Evaluating the Effect of Binder Grade on Fatigue of Asphalt Concrete
}

\author{
Elizabeth Bashiti
}

Asphalt concrete is one of the main ingredients used in the paving of roadways across the globe. These roadways have been deteriorating from overuse, under design, and a lack of understanding of the engineering properties. In the asphalt community, it is agreed upon that polymer modifiers and aggregate size have comparable impacts on the performance of a pavement, such as, low creep at high temperatures, high ductility at low temperatures, high toughness, resistance to moisture and temperature, high cohesive and adhesive strength. With all of these advantages, it has been often assumed that polymer modifiers extend/improve the expected life of pavements. Currently, test methods to accurately predict performance of a pavement based on binder type and aggregate size have not been widely accepted in the pavement design community. This research aimed to evaluate the effect of polymer modifiers and aggregate size on the performance of a pavement, specifically the modulus and fatigue properties.

Six different hot-mix asphalt mixtures were evaluated in this research that were combinations of three (3) binder types; a PG 70-22, PG 70-22 Polymer Modified (PM), and PG 76-22 PM and two (2) different nominal maximum aggregate sizes (NMAS); $9.5 \mathrm{~mm}$ and 12.5 $\mathrm{mm}$. Prior to testing the samples for their performance properties. three methods of measuring bulk specific gravity were used to evaluate air distribution within the samples: Saturated SurfaceDry, CoreLok, and Dimensional (volumetric mass density).

Finally, to evaluate samples for performance properties the Asphalt Mixture Performance Tester (AMPT) was utilized. The AMPT is a relatively new method to measure the performance of a mixture by measuring fatigue, dynamic modulus, and flow number. Only fatigue and dynamic modulus were measured in this research. To evaluate the data collected from the AMPT, both the Mastersolver Version 2.2 developed by Bonaquist and Asphalt Pavement Hierarchical Analysis Toolbox - Fatigue Program (Alpha-FatigueTM software) developed by Kim were used. 


\section{ACKNOWLEDGEMENT}

I would like to thank my advisor, Dr. John Zaniewski, for constantly providing encouragement and guidance throughout this research and providing me the opportunity to further my education.

I would also like to thank my committee members, Dr. Fei Dai, and Dr. YooJung Yoon, for reviewing this thesis and serving on my committee.

I would also like to thank my mom, dad, stepdad, and sister for their unwavering and unconditional support throughout my undergraduate and graduate education.

Next, I would like to extend a wholehearted thanks to my fellow graduate students, Justin Pentz and Elbert Rohrbough for all of their assistance, insight, and support throughout my research. This research would not be what it is without your help.

Finally, I would like to thank my statistics professor, Dr. Casey Jelsema for consulting me on my statistical analysis within this thesis even though I am no longer his student. I really appreciate you taking time away from your busy schedule to consult with me. 


\section{Table of Contents}

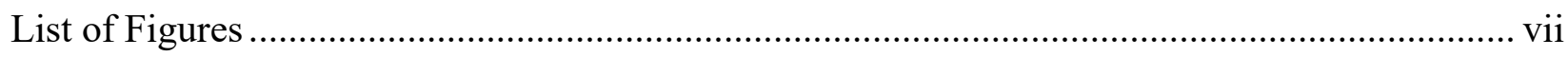

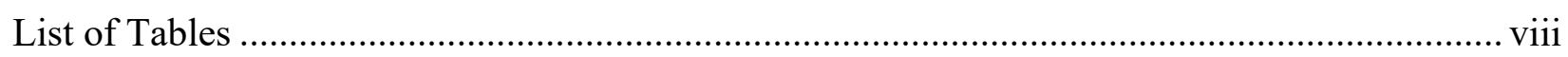

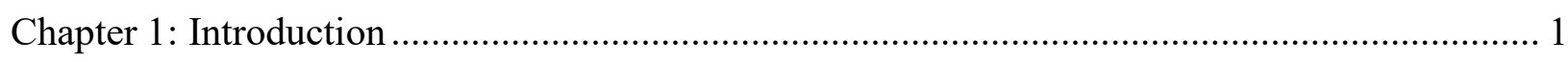

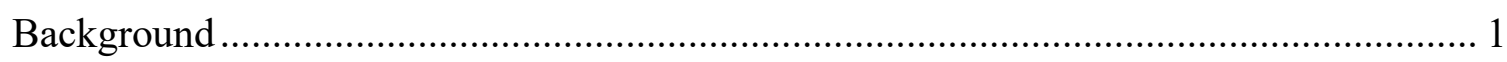

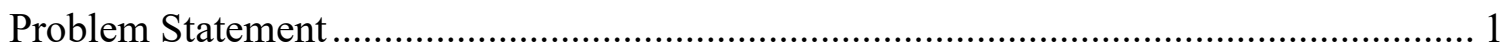

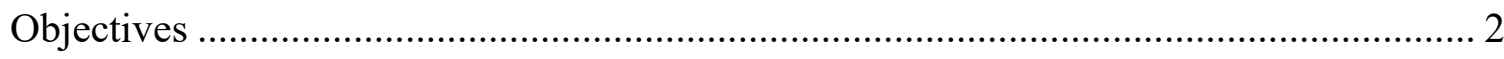

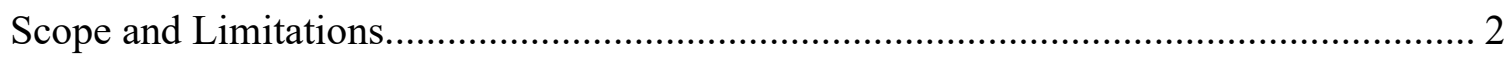

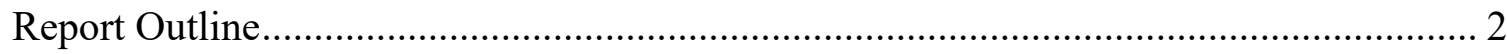

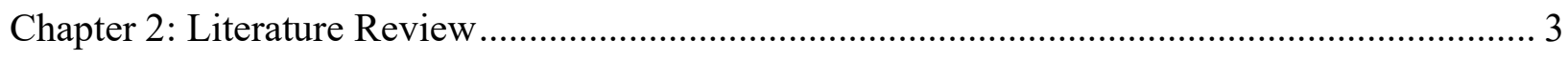

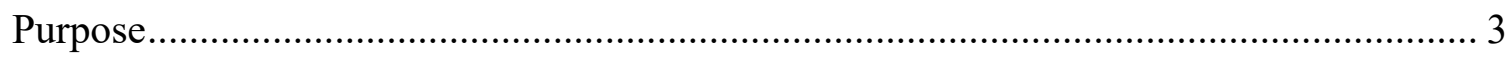

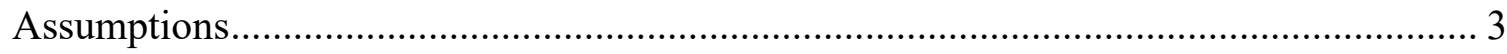

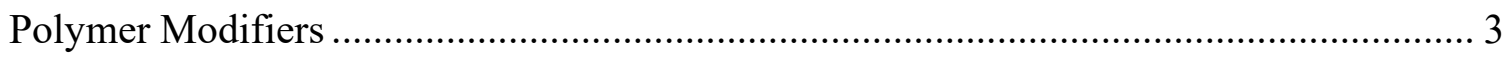

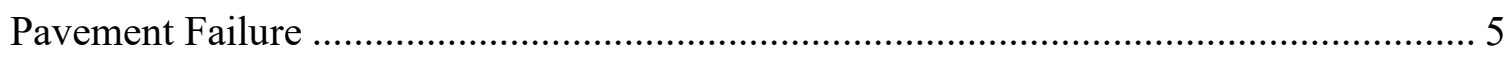

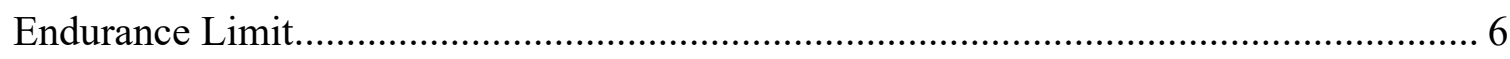

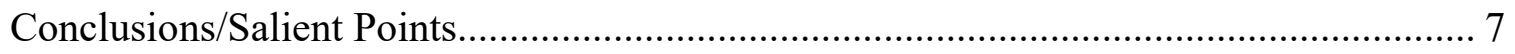

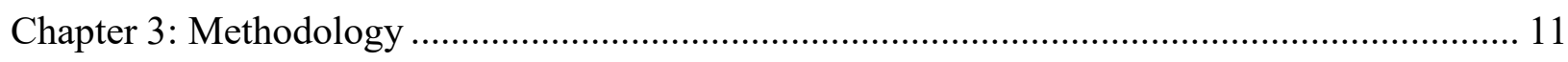

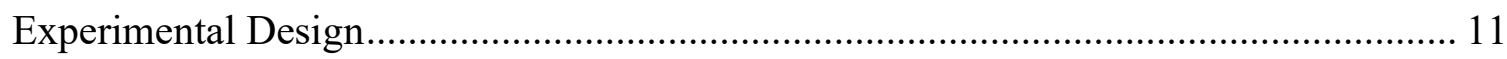

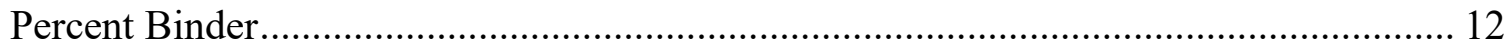

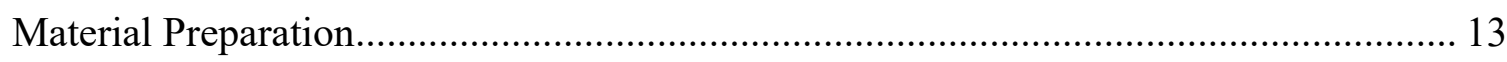

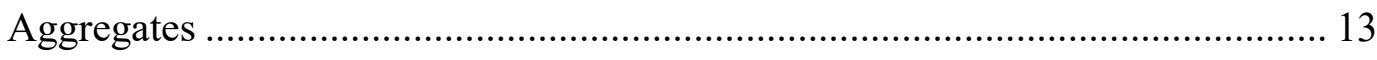

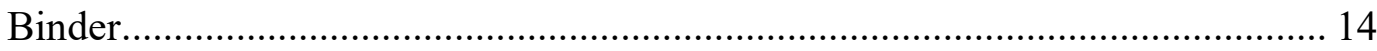

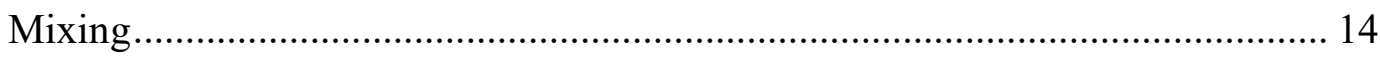

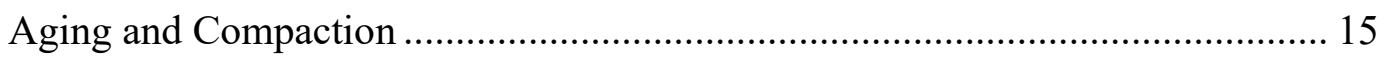

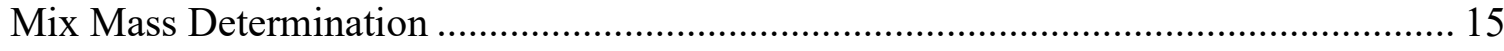

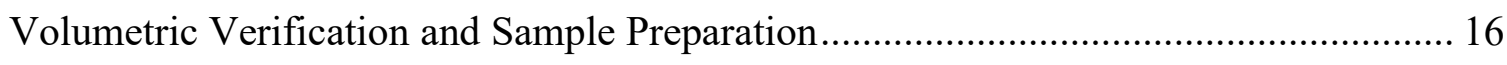

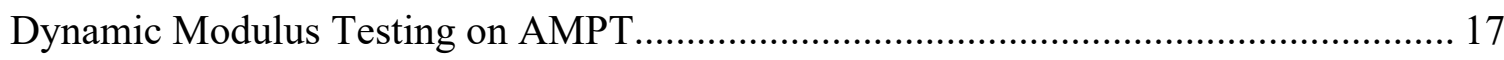

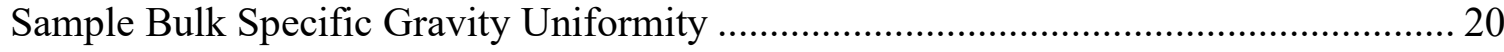

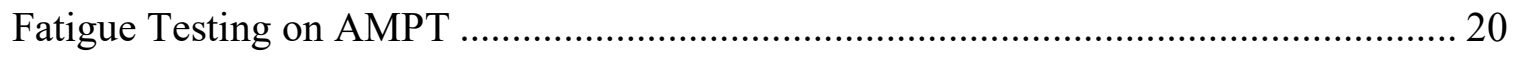

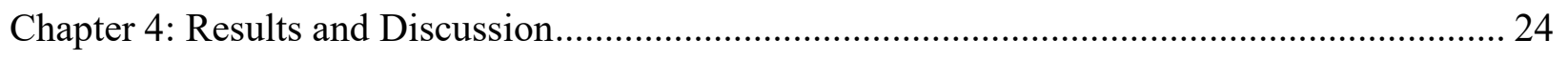

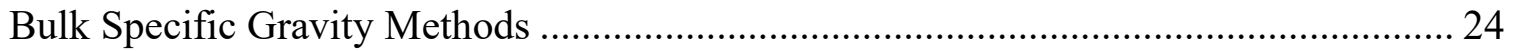


Bulk Specific Gravity Uniformity of Dynamic Modulus Samples............................... 26

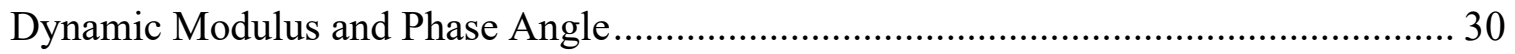

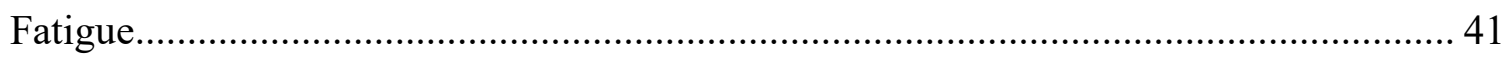

Air Voids Effect on Performance ...................................................................... 52

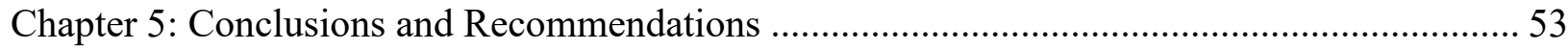

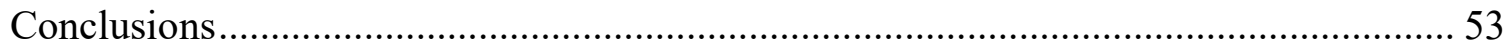

Sample Uniformity and Air Voids .......................................................... 53

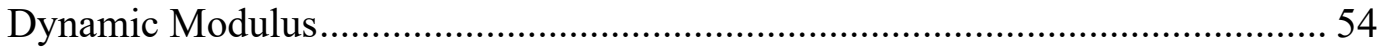

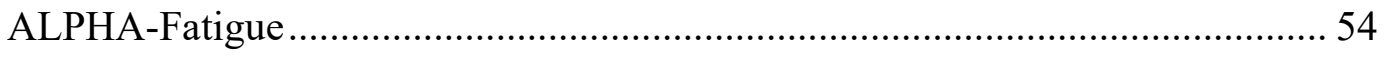

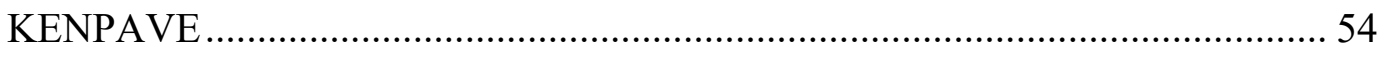

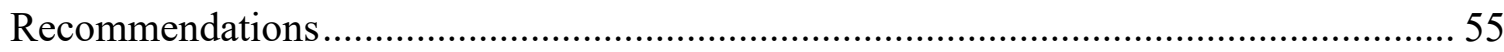

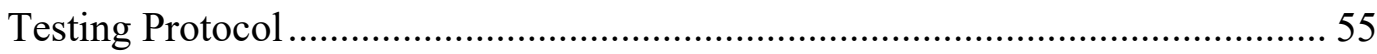

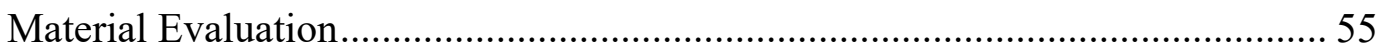

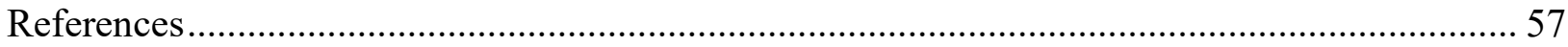

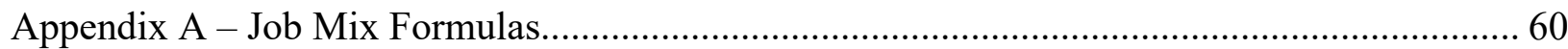

Appendix B - Performance Sample Volumetrics .............................................................. 62

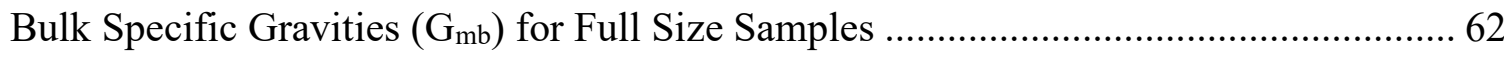

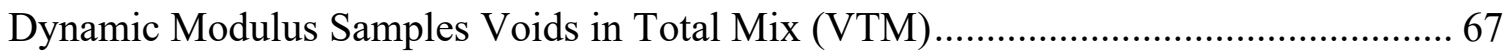

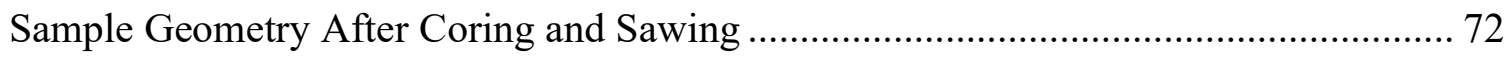

Appendix C - Cut Sample Volumetrics.................................................................... 75

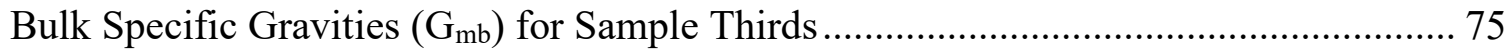

Sample Thirds Voids in Total Mix (VTM) .......................................................... 78

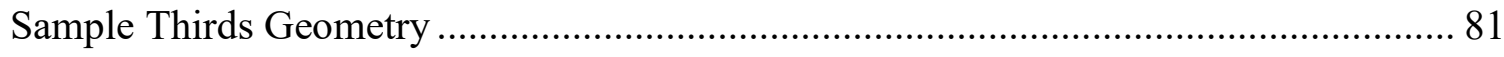

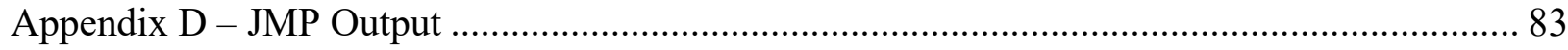

Air Void Distribution Analysis by Section and Method............................................ 83

Robust Fit of Dynamic Modulus versus CoreLok ${ }^{\circledR}$ VTM After.................................. 87

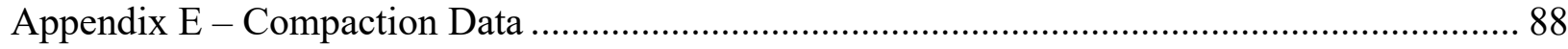

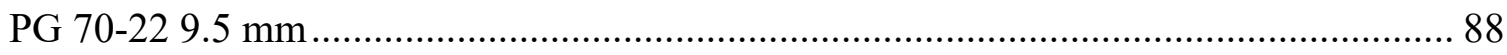

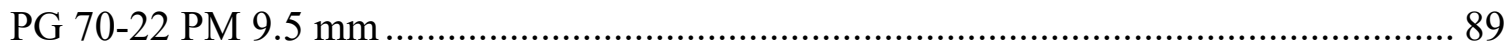

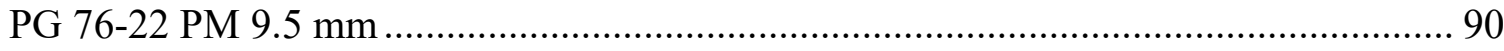

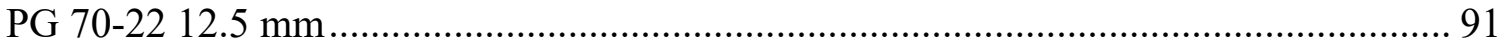




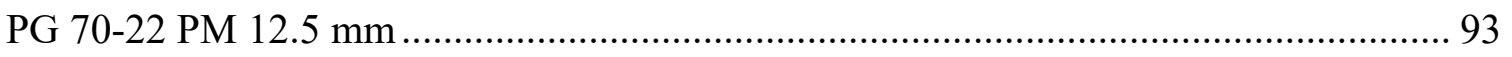

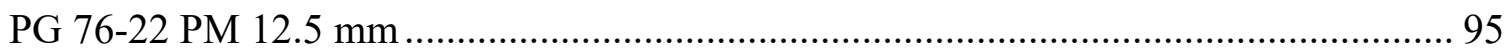

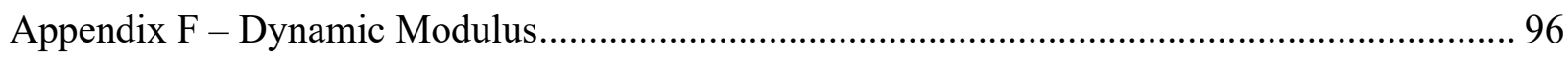

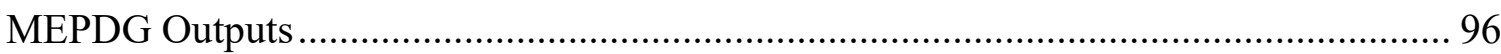

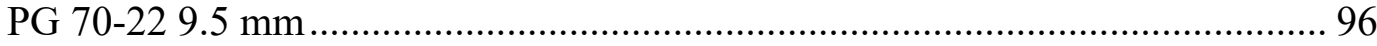

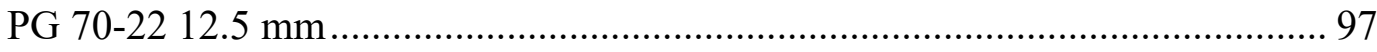

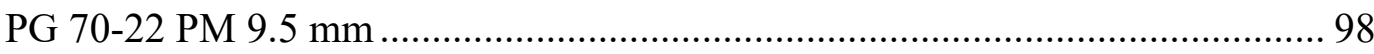

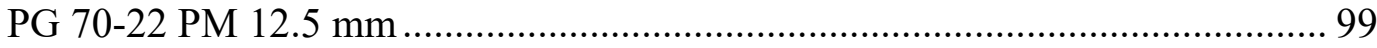

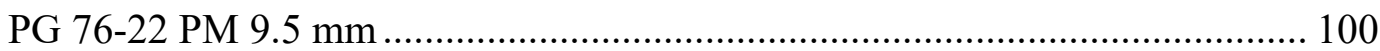

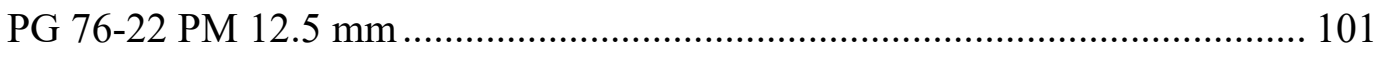

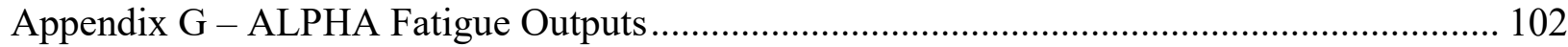

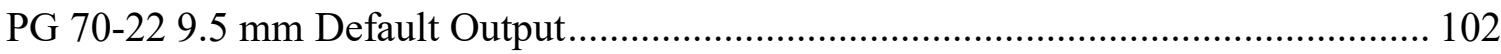

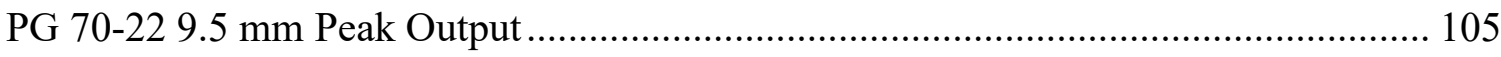

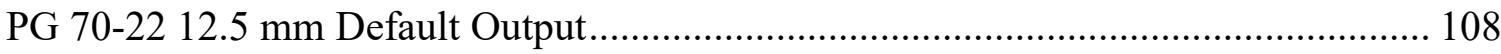

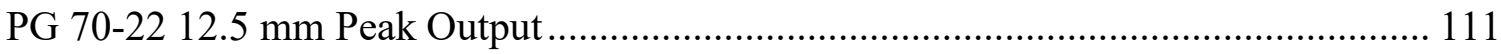

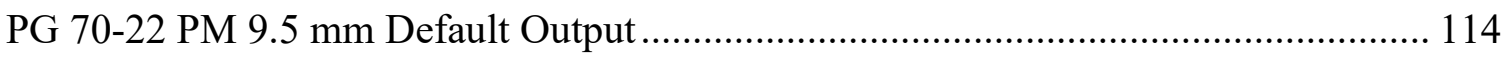

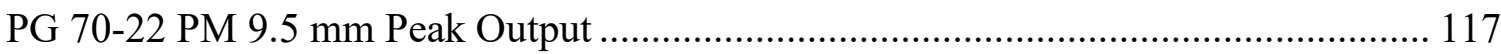

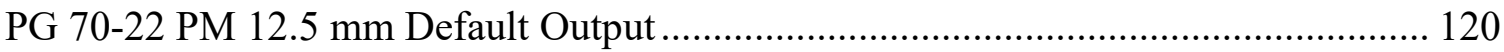

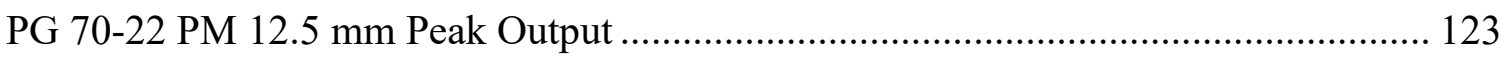

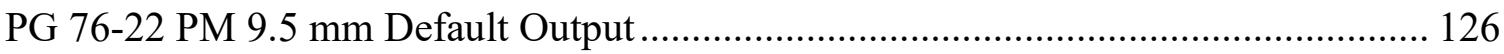

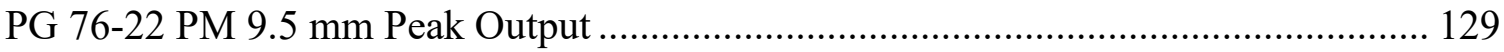

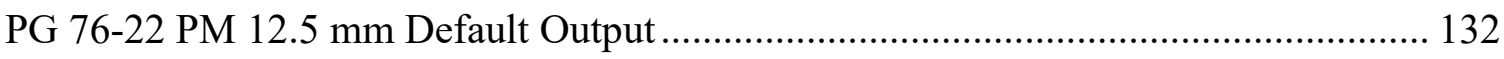

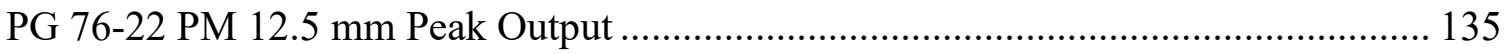




\section{List of Figures}

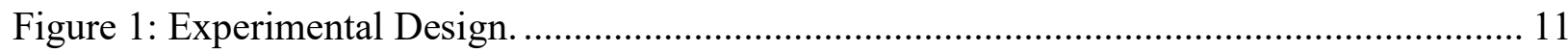

Figure 2: Comparison between blend gradations for $9.5 \mathrm{~mm}$ and $12.5 \mathrm{~mm}$ mix designs. ............. 13

Figure 3: Funnel used to insert mix into the Superpave compaction molds................................. 15

Figure 4: Gluing jig for gage points used for dynamic modulus samples. ................................. 17

Figure 5: Dynamic modulus sample with gage points attached ready to be conditioned for

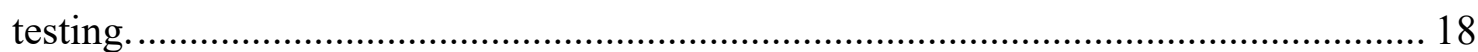

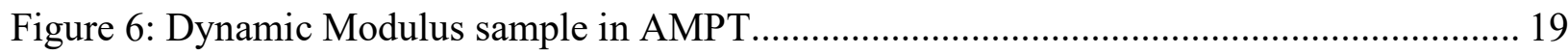

Figure 7: Fatigue end platen gluing jig with sample in place.................................................... 21

Figure 8: Line of Equality Chart for SSD versus CoreLok ${ }^{\circledR}$ Methods ......................................... 24

Figure 9: Line of Equality Chart for SSD versus Dimensional Methods ..................................... 25

Figure 10: Line of Equality Chart for Dimensional versus CoreLok® Methods .......................... 25

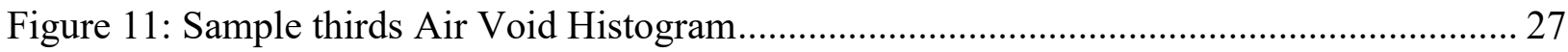

Figure 12: Average Dynamic Modulus at the lowest testing temperature, or $4^{\circ} \mathrm{C} \ldots \ldots \ldots \ldots \ldots \ldots \ldots . . . . . .36$

Figure 13: Average Dynamic Modulus at the intermediate testing temperature, or $20^{\circ} \mathrm{C}$. .......... 37

Figure 14: Average Dynamic Modulus at the highest testing temperature, which was $40^{\circ} \mathrm{C}$ for PG 70-22 and PG 70-22 PM binder types, and $45^{\circ} \mathrm{C}$ for the PG 76-22 PM binder type.

Figure 15: Dynamic Modulus Master Curves created using a reference temperature of $20^{\circ} \mathrm{C} \ldots .40$

Figure 16: Plot of fatigue equations using peak analyzed K-values and collected Dynamic

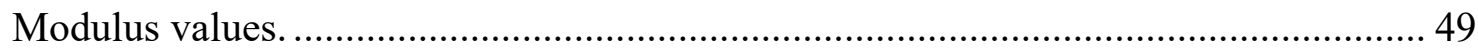

Figure 17: Full-Depth and Conventional Pavement Structures used in KENPAVE analysis. ..... 50

Figure 18: Modulus versus Strain for Convention and Full-Depth pavement models. ................. 51

Figure 19: Air Voids versus Number of Cycles to Failure during fatigue testing........................ 52 


\section{List of Tables}

Table 1 : Summary of research studies and findings. ....................................................... 9

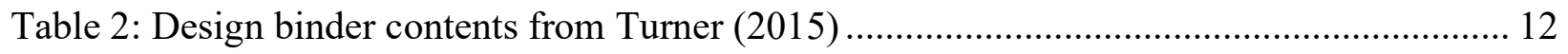

Table 3: Mixture and compaction temperature provided by binder supplier............................ 14

Table 4: Test specimen tolerances for Dynamic Modulus and Fatigue testing ......................... 17

Table 5: Dynamic Modulus sample testing order. Testing temperature was kept in the following order, low (4), medium (20), and high (40 or 45)................................................. 19

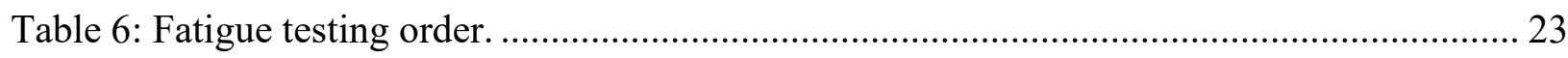

Table 7: On-specimen strain adjustment for second and third fatigue samples ....................... 23

Table 8: Averages for $\mathrm{G}_{\mathrm{mb}}$ thirds by test method................................................................. 27

Table 9: $\mathrm{t}-\mathrm{Statistic}$ for $\mathrm{G}_{\mathrm{mb}}$ thirds for CoreLok results...................................................... 28

Table 10: P-values from JMP output for equivalency test of $\mathrm{G}_{\mathrm{mb}}$ between sections.................. 28

Table 11: Comparison of Sample Third Air Void Averages to Full Sample Air Void ............... 29

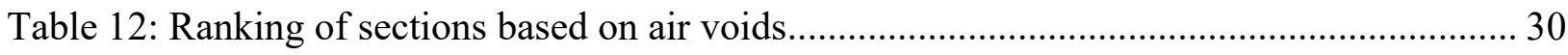

Table 13: Dynamic Modulus values at each test temperature. .............................................. 32

Table 14: Dynamic Modulus averages, standard deviations, and coefficients of variation ......... 33

Table 15: Phase Angle averages, standard deviations, and coefficients of variation ................. 34

Table 16: Master Curve final parameters................................................................................ 39

Table 17: Dynamic Modulus values calculated................................................................. 41

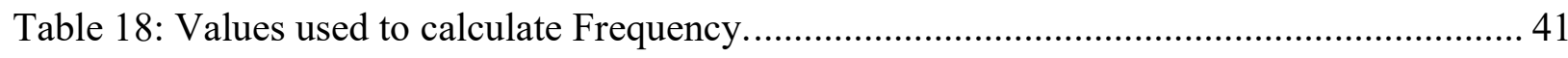

Table 19: Fatigue testing compilation for PG 70-22 binder type. ........................................ 43

Table 20: Fatigue testing compilation for PG 70-22 PM binder type..................................... 44

Table 21: Fatigue testing compilation for PG 76-22 PM binder type..................................... 45

Table 22: Damage Model Coefficients for both analysis failure criteria................................... 46

Table 23: Endurance Limits from ALPHA-Fatigue Outputs.................................................... 47

Table 24: K-Values from ALPHA-Fatigue in units of psi................................................... 49

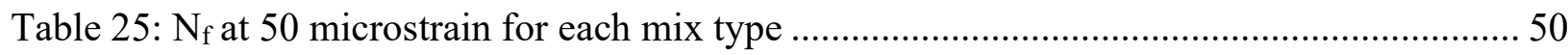

Table 26: KENPAVE Full-Depth and Conventional $\mathrm{N}_{\mathrm{f}}$ values............................................... 51 


\section{Chapter 1: Introduction}

\section{Background}

Asphalt concrete has a primary use in the paving of roadways. These roadways have been deteriorating from overuse, under design, and a lack of understanding of the engineering properties. While there are many modes of pavement failure two structural failures are considered critical for design using mechanistic-empirical design methods (ARA, Inc., 2004): fatigue cracking and rutting (Miller and Bellinger, 2003) (Mohammad et al., 2014). The Superpave mixture design method developed during the Strategic Highway Research Program (SHRP) is used for proportioning asphalt concrete mixtures (FHWA, 2010). However, as implemented, the Superpave method lacks a method to quantitatively evaluate the quality of the asphalt concrete properties relative to fatigue cracking and rutting (FHWA, 2010).

The lack of a practical performance test for Superpave mixtures lead to the development of the Asphalt Mixture Performance Tester (AMPT) (Bonaquist, 2011a, Witczak et al., 2002). The research completed for the National Cooperative Highway Research Program (NCHRP) focused mainly on testing and evaluating dynamic modulus, fatigue, and flow number. The fatigue testing protocol was further enhanced by Kim et al. (2008) using uniaxial direct tension testing and visco-elastic continuum (VECD) damage theory.

These developments provide a methodology for evaluating the mechanistic behavior, and hence the expected field performance of asphalt concrete.

\section{Problem Statement}

This research was performed to evaluate and compare three different binder types and two different nominal maximum aggregate sizes (NMAS) using the Uniaxial Fatigue Test and Dynamic Modulus Test on the AMPT. The three binder types that were tested were PG (Performance Graded) 70-22 Neat, PG 70-22 Polymer Modified (PM), and a PG 76-22 PM ${ }^{1}$. For each of the binder types, two different NMAS's were tested: a $9.5 \mathrm{~mm}$ and a $12.5 \mathrm{~mm}$. In total, 72 AMPT specimens were tested: 54 S-VECD fatigue and 18 dynamic modulus samples. Results from the AMPT were analyzed using the Asphalt Pavement Hierarchical Analysis Toolbox-

${ }^{1}$ When this research was performed the original Performance Grade binder specifications were in place. These have subsequently been replaced with AASHTO M332. The PG 70-22 would now be specified as PG 64H-22 and the PG 76-22 would be specified as PG 64V-22. 
Fatigue Program (ALPHA-F) (ALPHA-F User Guide, 2014), the Mastersolver workbook published by Bonaquist (2011b), in conjunction with other statistical methods. These results were then used to develop an expected life expectancy of the pavements which would provide a deeper insight into the performance in the field.

\section{Objectives}

The main objectives for this research are: 1) compare the effect of binder type on fatigue properties of asphalt concrete mixes with two aggregate structures, and 2) compare effects of binder type on dynamic modulus. The results of the laboratory evaluation were used with a mechanistic-empirical analysis to estimate expected pavement performance.

In addition, the samples were used to evaluate the air void distribution within samples, determine a correlation between the saturated surface dry, CoreLok ${ }^{\circledR}$, and dimensional methods for bulk specific gravity, and AMPT sample height as well as the air void loss when the samples were cored and sawed.

\section{Scope and Limitations}

All samples were prepared, mixed and tested to meet the specifications set by the American Association of State Highways and Transportation Officials (AASHTO). All recommendations made within the specifications were also considered, though not all were applied. Randomization was performed wherever possible to reduce bias throughout mixing and testing. Also, all testing and preparation was limited to the equipment available to the Asphalt Technology Laboratory at West Virginia University. Materials were also limited to local asphalt plants in order to ensure that all mixes could realistically be mixed and paved in West Virginia.

\section{Report Outline}

This report is divided into five chapters. Chapter 1 consists of an introduction, background information, objectives, problem statement and scope and limitations. Chapter 2 contains a review of literature on other research performed on similar topics. Chapter 3 presents the methodology used throughout the research. Chapter 4 presents the analysis performed on the data. Chapter 5 presents conclusions and recommendations based on the results and analysis collected from this research. Lastly, appendices present the data collected during the research. 


\section{Chapter 2: Literature Review}

\section{Purpose}

Approximately $94 \%$ of the 2.3 -million miles of paved roads and highways across the nation have been paved using asphalt concrete in the form of hot mix asphalt (HMA) (Zhao, 2011). A combination of 3 ingredients make up HMA; binder, aggregates, and air. Finding the optimal balance between these three components while maintaining the strength properties required for the pavement is paramount to the design. The asphalt industry is a multi-billiondollar industry that has various stakeholders. These stakeholders depend on higher quality pavements. This dependence greatly increases the value of furthering knowledge about asphalt material properties and the impacts different variations in the mix have on pavement performance.

\section{Assumptions}

Due to the visco-elastic nature of asphalt pavements in order to analyze the impact that variations have on the fatigue life of the pavement, any analysis must consider both rutting and fracture energy required to combat failure. Finding a method for predicting the impact of using a modifier in a pavement's mix design performance has a large value and though no method has been standardized or incorporated into the Superpave mix design, it is generally accepted that modifiers have the ability to improve the performance against rutting and fatigue. Key research performed on these failure modes as well as their conclusions were evaluated. Conclusions from these research articles were considered during the development of the methodology used for this report.

\section{Polymer Modifiers}

One of the key developments in improving the fatigue life in asphalt pavements is through the use of polymer modifiers. In the asphalt community, it is agreed upon that polymer modifiers have various advantages, such as, low creep at high temperatures, high ductility at low temperatures, high toughness, resistance to moisture and temperature, high cohesive and adhesive strength (Bhurke, 1999). Even with all the benefits of polymer modifiers, while developing the Superpave method which is heavily used in the industry, focused mostly on unmodified binders (Zhai, 2001). Without knowing the specific effects of choosing to utilize a modified binder over unmodified, this leaves a gap in the design process. Since the inception of 
the Superpave specification, there has been extensive research on the comparison between modified and unmodified binders as well as the methodology to recommend ways to incorporate modified binders into the specification. The following paragraphs discuss a few examples of the research performed on modified binders.

Bhurke (1999) researched the effect that polymer modifiers had on an asphalt pavement mixture. Bhurke kept all binder contents at $5.7 \%$ in order to reduce the variables influencing performance of the asphalt concrete. Bhurke (1999) measured the fracture toughness and lapshear adhesive strength to evaluate polymer modifier's impact on pavement performance. Specifically, the fracture toughness of the material can provide a valuable insight as it is strongly dependent on and correlated to the average thickness of the asphalt film between aggregates. Since fracture toughness is a method to determine the number of cycles a pavement can withstand before a fracture occurs, it is heavily related to the fatigue performance. Bhurke (1999) observed two forms of failure modes; adhesive and cohesive, where adhesive is where the crack propagation occurs at the asphalt binder-aggregate interface and cohesive is where the crack propagates only through the asphalt binder. Bhurke (1999) noted that in order to compare the effects that polymer modification had on the adhesion failure in different systems, the fracture toughness tests should be performed at temperatures relative to the glass transition of the asphalt binders. It was found that at temperatures above $0^{\circ} \mathrm{C}$ polymer modification does not significantly affect the properties of asphalt concrete as detected by lap shear tests (Bhurke, 1999). Bhurke's research is just an example of research performed utilizing a constant binder content to determine effects of binders on a mixture's performance.

Zhai (2001) focused his research on modifying the Superpave mix design method to evaluate fatigue damage behavior under repeated cyclic loading, accumulated permanent deformation under repeated loading, and storage stability of modified asphalts. Zhai (2001) hypothesized that the two primary factors that would affect fatigue response were asphalt content and air void content. For this reason, considering the upper and lower limits of asphalt content, as well as the role the gradation plays, are crucial in the mix design process. Zhai (2001) found that binder modification has a comparable impact on improving the performance of the pavement as the aggregate gradation meaning both of these factors are as crucial in the design process and analysis of pavement performance. 
Bahia, et al (2001) researched the applicability of the Superpave specification and protocols developed for asphalt cements to modified asphalt binders. Bahia, et al (2001) assumed that binder behavior is independent of film thickness and sample geometry, as well as that binder should be evaluated based on properties within the linear viscoelastic range where behavior is independent of the strain or stress levels. It was found that classifying the modified binders as simple or complex was unnecessary as all binders should be screened for particulate additives and storage stability in order to be included in the performance-grading system. Simple binders are defined by Bahia, et al (2001) as asphalt binders that exhibit rheologically simple behavior which does not violate the following assumptions which the PG system is based on; independence of strain, non-thixotropy, isotropy, and independence of sample geometry.

\section{Pavement Failure}

The two key modes of failure in asphalt pavements are fatigue and rutting. Fatigue cracking is defined as when a repeated load is applied, and interconnected cracks occur at the surface. This cracking phenomenon has been found to initiate at both the top of the pavement (top down cracking) and the bottom of the pavement (bottom down cracking). Rutting, on the other hand, occurs when there is a permanent deformation in the pavement. Knowing the methods of failure provides insight to the material and the factors that lead to failure which may not be apparent.

In order for Bahia, et al (2001) to fully be able to expand the current Superpave specification to include modified asphalt binders, a study into the fatigue performance had to be completed. As stated by Bahia et al (2001), fatigue is believed by many researchers to be a pavement structure problem, while others believe it to be a mixture problem, however fatigue cracking starts then propagates in the binder. While collecting data from the Repeated Shear at Constant Height (RSCH) test, Bahia, et al (2001) found that the first 10 cycles highly influence the lack of fit of the model, therefore these first 10 cycles were not included in further analysis. Further Bahia, et al (2001) found that changing the binder modification had comparable effects as changing the aggregate gradation. This finding was also found by Zhai (2001). From studying the fatigue performance, Bahia, et al (2001) confirmed that fatigue life is sensitive to both the aggregate type and binder type during the Beam Fatigue Test.

Further research performed by Tsai, et al (2005) tested nine different binders in order to define their rheological response over a range in temperatures and times of loading as well as 
studying and analyzing the simulated fatigue performance of the mixes by performing tests on mixes containing the binders. Similar to Bhurke (1999), Tsai et al (2005) held a constant asphalt content of $5 \%$ and a target air void content of $6 \pm 0.5 \%$. However, different from Bhurke (1999), Tsai et al (2005) applied different tests and parameters to evaluate the fatigue performance including not only testing the fatigue performance of mixes, but binders as well. Utilizing mastercurves at a reference temperature of $25^{\circ} \mathrm{C}$ as well as other various tests, it was found that there seemed to be no relationship between the loss of stiffness of the binder $\left(\mathrm{G}^{*} \sin \delta\right)$ and ESALs for fatigue cracking. This finding supports the common industry conclusion that $\mathrm{G}^{*} \sin \delta$ should be replaced with another parameter to accurately evaluate fatigue performance.

Saboo and Kumar (2016) used four different asphalt binders and three different asphalt mixes to evaluate fatigue performance of elastomeric and plastomeric binders. Specifically, Saboo and Kumar (2016) evaluated the loss of stiffness parameter $\left(\mathrm{G}^{*} \sin \delta\right)$ similar to Tsai et al (2005) and agreed that this parameter does not accurately evaluate the fatigue performance. This study found that elastomeric modified binders and the mixes that used them, gave the best performance under fatigue loading where as plastomeric modification was found to be highly susceptible to strain and resulted in poor performance under fatigue. This finding was expected by Saboo and Kumar (2016) due to the properties of elastomers versus plastomers. While the research performed in this report did not evaluate the Superpave mix design process, the ideas presented in this research are highly applicable to pavement performance analysis.

\section{Endurance Limit}

In addition to the research performed on polymer modification and its impact on performance are the methods to evaluate the pavement's performance, and methods to extend the life of pavements. Witczak (2013) extended research from previous studies which indicated that if a strain level of 70 microstrain or less were maintained, they could guarantee a structural design will perform in the region of extended fatigue life, providing a "no damage" performance. This "limit" is known in the asphalt community as the endurance limit of a pavement and a pathway to designing perpetual pavements. The hypothesis of the research performed by Witczak (2013) was that endurance limit in hot mix asphalt is not a single value but will change based on the loading and environmental conditions. Witczak (2013) chose six main factors to evaluate the endurance limit, they were, binder type, binder content, air voids in the mix, testing temperature, amount of rest period applied between each loading cycle, and the number of cycles 
till failure for the test without rest period $\left(\mathrm{N}_{\mathrm{f}}\right)$. It is important to note that Witczak's research only used un-modified binders and that softer binder mixtures had higher endurance limit values than stiffer binder mixtures. The highest endurance limit values in Witczak's research came from high binder contents with low air void contents. While this concept is partially intuitive due to the fact that it would inherently increase the film thickness of the binder, which has been found to be correlated to the fracture toughness (Bhurke, 1999), it also seems to prioritize the binder content in evaluating performance of a pavement.

In addition to Witczak's research exploring the endurance limits of asphalt pavements, it was necessary to also explore the way asphalt mixes recover to some extent after a loading cycle as the result of asphalt relaxation. Pavement researchers and engineers rarely give any attention to healing; however, it is a common topic in polymer engineering, for example Prager and Tirrell which are cited by Witczak (2013) for their description of the healing phenomenon. This healing process is to credit that intermittent loading has a less damaging effect than continuous loading, though some researchers believe the rest period only leads to a temporary modulus recovery without extending the fatigue life. Other researchers have alternatively found that the modulus recovery does extend the fatigue life by a certain amount. Witczak (2013) cited research performed by Monismith, et al. which indicated that increasing the rest period from 1 to 19 seconds has no effect on fatigue performance, though this contradicts many other later research results which showed an increase in fatigue life due to rest periods. Similar to the research performed by Monismith et al, Witczak (2013) found that the rest period in some cases resulted in faster damage and lower fatigue life than the tests without a rest period.

\section{Conclusions/Salient Points}

- Fracture toughness is a valuable tool in understanding the failure mechanisms in asphalt pavements.

- Zhai (2001), Tsai et al (2005), and Witczak (2013) all considered asphalt content and air void content as primary factors in the fatigue performance and expected life of the pavement. In addition to these primary factors, both Zhai (2001) and Bahia, et al (2001) found that binder modification and aggregate gradation have comparable impacts and are equally as critical in the design process and analysis of pavement performance. 
- In studies performed by both Tsai et al (2005) and Bhurke (1999) the binder content was held constant in order to minimize variables. Neither of these studies confirmed if keeping the binder content constant did minimize the variables in the analysis. Though not discussed, based on the other conclusions from these studies it can be implied that keeping the binder content constant achieved the goal of minimizing variables.

- The loss of stiffness of the binder $(G * \sin \delta)$ parameter currently used in the specifications for fatigue cracking has been shown to not correlate to actual performance in fatigue.

- Previous research on the existence of an endurance limit indicated that if a strain level of 70 microstrain or less were maintained, then it could be guaranteed that the fatigue life would be extended and provide a "no damage" performance. Further research into endurance limits has found that in the case of unmodified binders, mixtures that utilize softer binders had higher endurance limit values than stiffer mixtures

- It is believed by some researchers that allowing a mixture to have a rest period in loading only leads to a temporary modulus recovery and does not actually extend the fatigue life. 
Table 1 : Summary of research studies and findings.

\begin{tabular}{|c|c|c|c|}
\hline Researcher & Binder Studied & Test Method & Conclusions \\
\hline $\begin{array}{l}\text { Bahia, et al } \\
(2001)\end{array}$ & $\begin{array}{l}\text { PG 82-22 SBS Radial } \\
\text { PG 82-22 SBR LMW } \\
\text { PG 58-40 SB Di-block } \\
\text { PG 82-22 PE Stabilized } \\
\text { PG 76-22 EthyleneTerpoly } \\
\text { PG 58-40 SBS Linear } \\
\text { PG 82-22 Steam Distilled } \\
\text { PG 76-22 Oxidized } \\
\text { PG 52-40 Oxidized }\end{array}$ & $\begin{array}{l}\text { RSCH Test } \\
\text { Beam Fatigue Test }\end{array}$ & $\begin{array}{l}\text { classifying modified binders as simple or } \\
\text { complex is unnecessary } \\
\text { all binders should be screened for } \\
\text { particulate additives and storage stability to } \\
\text { to be included in the PG system }\end{array}$ \\
\hline Bhurke (1999) & $\begin{array}{l}\text { Viscosity Graded Binders (AC5 } \\
\text { and AC10) }\end{array}$ & $\begin{array}{l}\text { Measure Fracture } \\
\text { Toughness and Lap- } \\
\text { Shear Adhesive } \\
\text { Strength }\end{array}$ & $\begin{array}{l}\text { Polymer modification does not significantly } \\
\text { affect properties of asphalt concrete }\end{array}$ \\
\hline $\begin{array}{l}\text { Saboo \& } \\
\text { Kumar (2016) }\end{array}$ & $\begin{array}{l}\text { VG } 20 \\
\text { VG } 30 \\
\text { PMB (E) } \\
\text { PMB (S) }\end{array}$ & $\begin{array}{l}\text { Linear Amplitude } \\
\text { Sweep } \\
\text { Four Point Beam } \\
\text { Bending } \\
\text { Marshall Stability } \\
\text { Indirect Tensile } \\
\text { Strength }\end{array}$ & $\begin{array}{l}\text { elastomeric modified binders/mixes had the } \\
\text { best performance under fatigue loading } \\
\text { plastomeric modification is highly } \\
\text { susceptible to strain and resulted in poor } \\
\text { fatigue performance }\end{array}$ \\
\hline
\end{tabular}




\begin{tabular}{|c|c|c|c|}
\hline Researcher & Binder Studied & Test Method & Conclusions \\
\hline $\begin{array}{l}\text { Tsai \& King } \\
(2005)\end{array}$ & $\begin{array}{l}\text { AR-4000 (California Valley } \\
\text { Sourced) } \\
\text { AR-4000 (California Coastal } \\
\text { Sourced) } \\
\text { AC20P polymer modified } \\
\text { PBA-6a (modified binder) } \\
\text { PG 70-28 (modified binder) } \\
\text { PG 52-28 } \\
\text { PG 64-22 } \\
\text { PG 64-28 } \\
\text { PG 76-16 }\end{array}$ & $\begin{array}{l}\text { AASHTO MP-1 } \\
\text { requirements } \\
\text { Determine G*sin } \delta \\
\text { Observe molecular } \\
\text { weight distributions } \\
\text { using size exclusion } \\
\text { chromatography }\end{array}$ & $\begin{array}{l}\text { no relationship between the loss of stiffness } \\
\text { of the binder }\left(\mathrm{G}^{*} \sin \delta\right) \text { and ESALs for } \\
\text { fatigue cracking }\end{array}$ \\
\hline $\begin{array}{l}\text { Witczak } \\
(2013)\end{array}$ & Unmodified binders & & $\begin{array}{l}\text { softer binder mixtures had higher endurance } \\
\text { limit values than stiffer binder mixtures } \\
\text { high binder contents with low air void } \\
\text { contents had highest endurance limit values }\end{array}$ \\
\hline Zhai (2001) & $\begin{array}{l}\text { PG 82-22 SBS Radial } \\
\text { PG 82-22 PE Stabilized } \\
\text { PG 82-22 Steam Distilled } \\
\text { PG 82-22 SBR LMW } \\
\text { PG 76-22 Ethylene Terpoly } \\
\text { PG76-22 Oxidized (Straight Run) } \\
\text { PG 58-40 SB Diblock } \\
\text { PG 58-40 SBS Linear } \\
\text { PG 52-40 Oxidized (Back Blend) }\end{array}$ & $\begin{array}{l}\text { Laboratory Asphalt } \\
\text { Stability Test (LAST) } \\
\text { Method }\end{array}$ & $\begin{array}{l}\text { Binder modification has a comparable } \\
\text { impact on improving the performance of the } \\
\text { pavement as the aggregate gradation }\end{array}$ \\
\hline
\end{tabular}




\section{Chapter 3: Methodology}

To achieve the objectives stated in Chapter 1 and ensure the AMPT produced reasonable results, samples were carefully prepared, and all testing protocols were followed. This chapter outlines the methodology followed for sample and material preparation and testing protocol. These samples were prepared for two performance tests, fatigue and dynamic modulus.

\section{Experimental Design}

Sample preparation and testing was designed to evaluate three different asphalt binders: PG 70-22, PG 70-22 polymer modified (PM), and PG 76-22 PM, and two nominal maximum aggregate size (NMAS) gradations; a $9.5 \mathrm{~mm}$ and a $12.5 \mathrm{~mm}$.

Figure 1 shows the sample types for each binder type. The sample configuration in this figure was repeated for each of the three binders. Three replicates were tested for each of the combination of factors and levels. In the dynamic modulus protocol, test results are obtained for each sample, so three samples were sufficient to provide the three replicates. The fatigue testing protocol requires three test results to provide a single result. Hence, it was necessary to make nine samples for each combination of factors and levels. Samples used for the dynamic modulus test were not used for the fatigue testing. In total, 72 samples were tested.

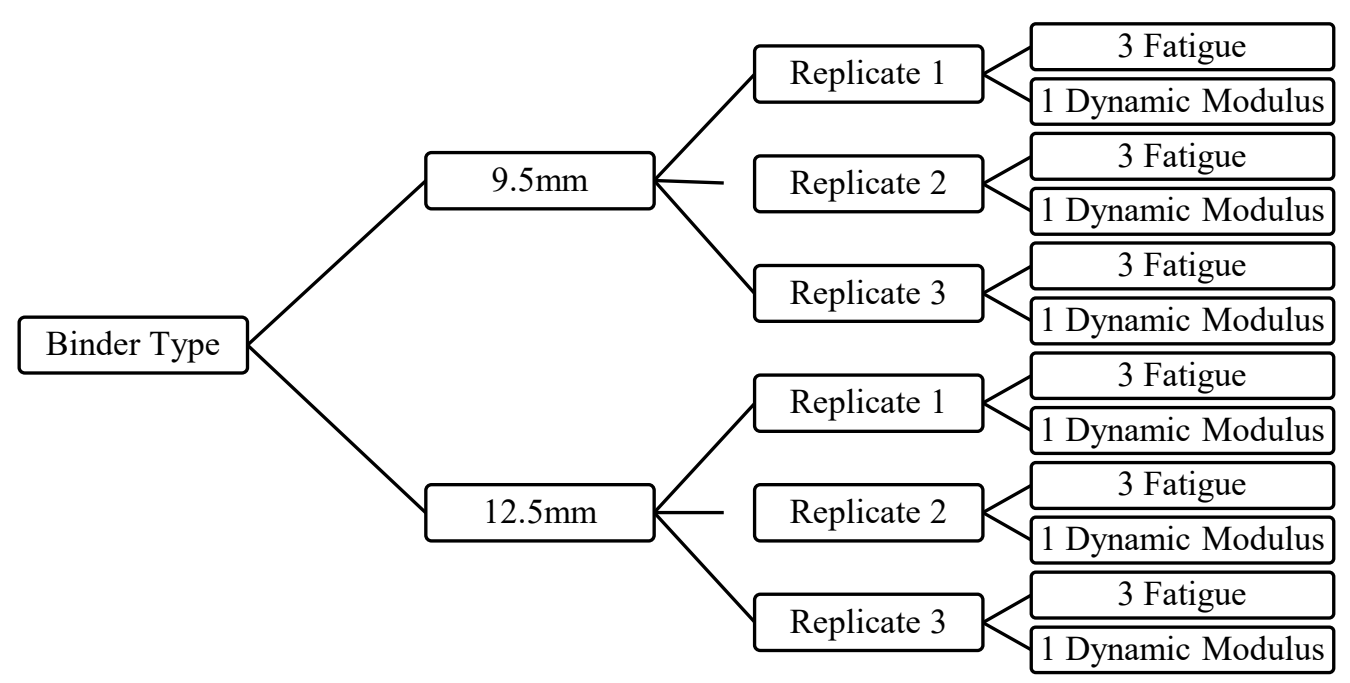

Figure 1: Experimental Design. 


\section{Percent Binder}

The mixes used in this research are based on mix designs produced by Greer Industries, Morgantown, WV. The Job Mix Formula (JMF) sheets submitted by the contractor and approved by the WVDOH are provided in Appendix A. The mix designs were for a PG 76-22 PM binder. Under the current WVDOH mix design process, polymer modified mixes are compacted using 65 gyrations while mixes with non-modified binders are compacted using 80 gyrations. Per the JMF the design binder contents were 6.2 and 5.9 percent for the 9.5 and 12.5 mixes respectively.

Turner (2015) tested similar mixes for dynamic modulus and flow number. Design binder contents were determined using WVDOH procedures. For the unmodified PG 70-22 the compaction effort was 80 gyrations. For the polymer modified PG 70-22 both 65 and 80 gyrations were used. The resulting design binder contents are shown in Table 2. The design binder content determined by Turner (2015) was lower than the JMF binder contents for the PG 76-22 PM binder. The binder contents for the PG 70-22 PM binder was virtually identical for compaction efforts of 65 and 80 gyrations.

Table 2: Design binder contents from Turner (2015)

\begin{tabular}{|c|c|c|c|}
\hline \multirow{2}{*}{ Binder Type } & \multirow{2}{*}{ NMAS } & \multirow{2}{*}{$N_{\text {design }}$} & Design Percent Binder \\
\cline { 3 - 4 } & & & Turner (2015) \\
\hline \multirow{2}{*}{ PG 70-22 } & $9.5 \mathrm{~mm}$ & 80 & $6.2 \%$ \\
\cline { 2 - 4 } & $12.5 \mathrm{~mm}$ & 80 & $5.6 \%$ \\
\hline \multirow{2}{*}{ PG 70-22 PM } & $9.5 \mathrm{~mm}$ & 65 & $6.1 \%$ \\
\cline { 2 - 4 } & $12.5 \mathrm{~mm}$ & 65 & $5.4 \%$ \\
\hline \multirow{2}{*}{ PG 70-22 PM } & $9.5 \mathrm{~mm}$ & 80 & $6.2 \%$ \\
\cline { 2 - 4 } & $12.5 \mathrm{~mm}$ & 80 & $5.4 \%$ \\
\hline \multirow{2}{*}{ PG 76-22 PM } & $9.5 \mathrm{~mm}$ & 65 & $5.9 \%$ \\
\cline { 2 - 4 } & $12.5 \mathrm{~mm}$ & 65 & $5.2 \%$ \\
\hline
\end{tabular}

Verification of the mix designs agreed with the contractor's results rather than Turner's. A constant binder content of 6.1 percent was selected for this research. It was expected that the binder content for the $9.5 \mathrm{~mm}$ mixes would be a little higher than for the $12.5 \mathrm{~mm}$ mixes. However, the gradation for the $9.5 \mathrm{~mm}$ and $12.5 \mathrm{~mm}$ mixes, shown in Figure 2, are almost identical for the aggregate finer than the $4.75 \mathrm{~mm}$ sieve. The surface areas of the aggregate blends, using the procedure described by Roberts et al. (1996) were 23.9 and $24.2 \mathrm{ft}^{2} / \mathrm{lb}$ for the 9.5 and $12.5 \mathrm{~mm}$ mixes respectively. This is a strong indication that the binder content of the mixes should be about the same. A constant binder was used in order to eliminate the 
confounding variables that surfaced during the verification process. Because the binder content, gradation, and VTM are held relatively constant, binder type is the only variable tested.

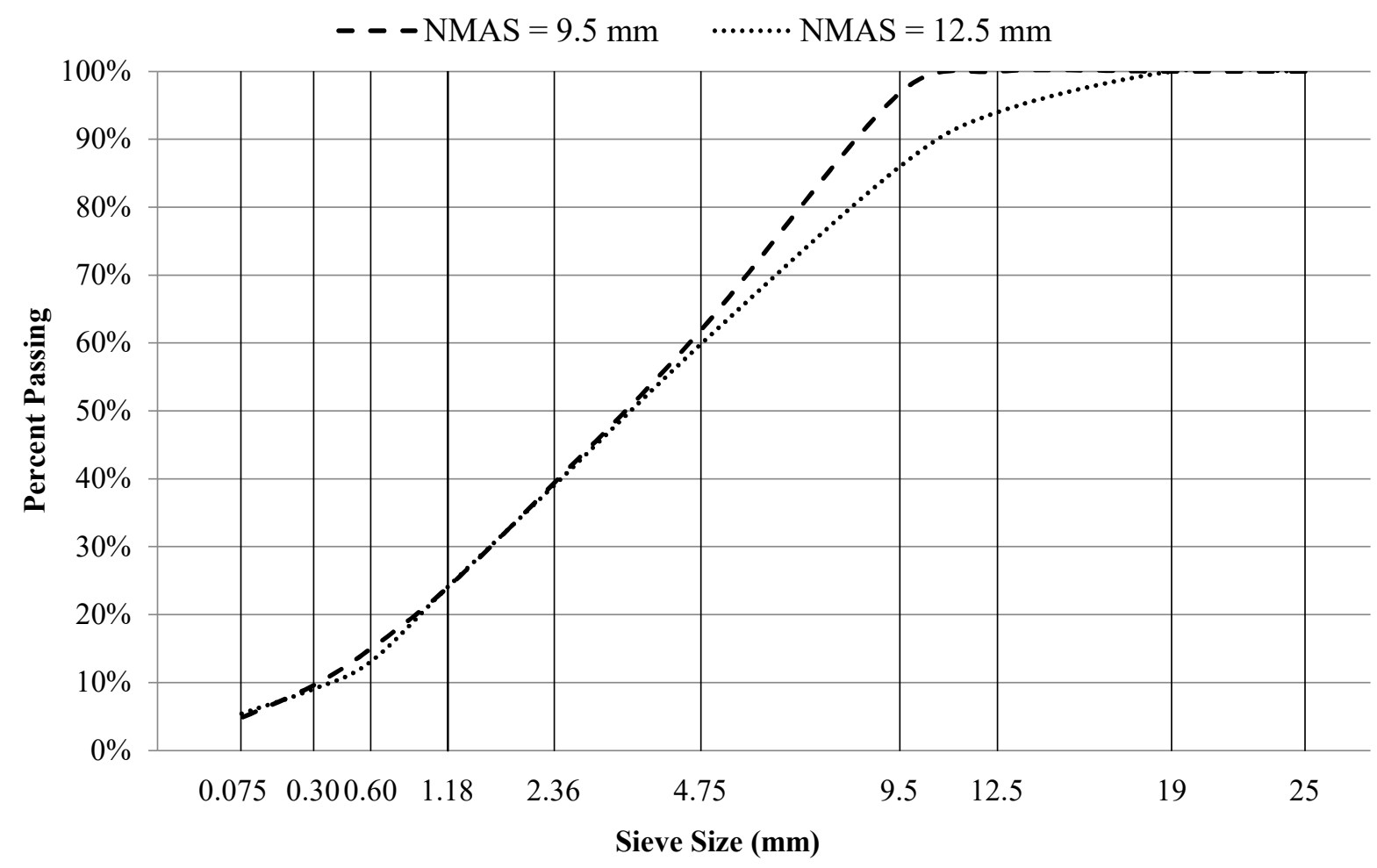

Figure 2: Comparison between blend gradations for $9.5 \mathrm{~mm}$ and $12.5 \mathrm{~mm}$ mix designs.

\section{Material Preparation}

Aggregates

Aggregates used in the mix design process and sample preparation were from the Greer and Buckeye plants in Morgantown, West Virginia from the Buckeye 7, Buckeye 8, Greer Sand, and West Virginia (Buckeye) Sand stockpiles. Following collection, all aggregates were prepared using the following procedure.

1. Initial oven drying for 10 hours at $110^{\circ} \mathrm{C}$

2. Initial sieving for 10 minutes

3. Wash aggregates

4. Final drying for 10 hours at $110^{\circ} \mathrm{C}$

5. Final sieving for approximately 10 minutes

6. Separate and store by sieve size in sealed gallon zip lock bags

7. Batch using a blend gradation matching the Job Mix Formulas in Appendix A 
During batching, each sample was divided into two one-gallon bags that were numbered to ensure that each mixture was consistent. Once batched, samples were mixed using randomly selected batched aggregates. Mixing order was randomized by binder type to ensure zero bias or contamination from the bucket in mixing. During mixing, samples were randomly assigned a sample designation based on the test in which they would be evaluated. Testing order was also randomized.

Extra samples were batched for determining the mass of material needed to produce samples with the correct air voids and for replacement samples in case of an error encountered during testing.

Binder

Asphalt binder was delivered in gallon cans. The binder was split into quart size cans with a mass about 100 grams over the expected mass of binder needed to mix one performance sample. The binder was heated at $100^{\circ} \mathrm{C}$ then poured into quart containers. This splitting process greatly reduced risk of excessive heating and cooling cycles and reduced the amount of wasted asphalt binder.

Mixing

Once aggregates were washed, batched, and assigned a random number, mixing could begin. A "dummy" sample was batched and mixed in order to "prime" the mixing bucket and paddle. The aggregates were heated overnight at the midpoint of the mixing temperature range, Table 3. At least three hours before mixing, ovens holding the asphalt binder, mixing bucket and paddle were heated to the midpoint of the mixing temperature range. Ovens holding the Superpave molds, the transfer funnel (Figure 3), and pans for aging were set to the midpoint of the compaction temperature. All other tools used for mixing were also heated to ensure minimal heat loss during mixing and compaction.

Table 3: Mixture and compaction temperature provided by binder supplier.

\begin{tabular}{|c|c|c|c|c|}
\hline \multirow{2}{*}{ Binder Grade } & \multicolumn{2}{|c|}{ Mixture Temperature $\left({ }^{\circ} \mathrm{C}\right)$} & \multicolumn{2}{c|}{ Compaction Temperature $\left({ }^{\circ} \mathrm{C}\right)$} \\
\cline { 2 - 5 } & Minimum & Maximum & Minimum & Maximum \\
\hline PG 70-22 & 163 & 169 & 152 & 157 \\
\hline PG 70-22 PM & 165 & 171 & 146 & 163 \\
\hline PG 76-22 PM & 165 & 171 & 146 & 163 \\
\hline
\end{tabular}




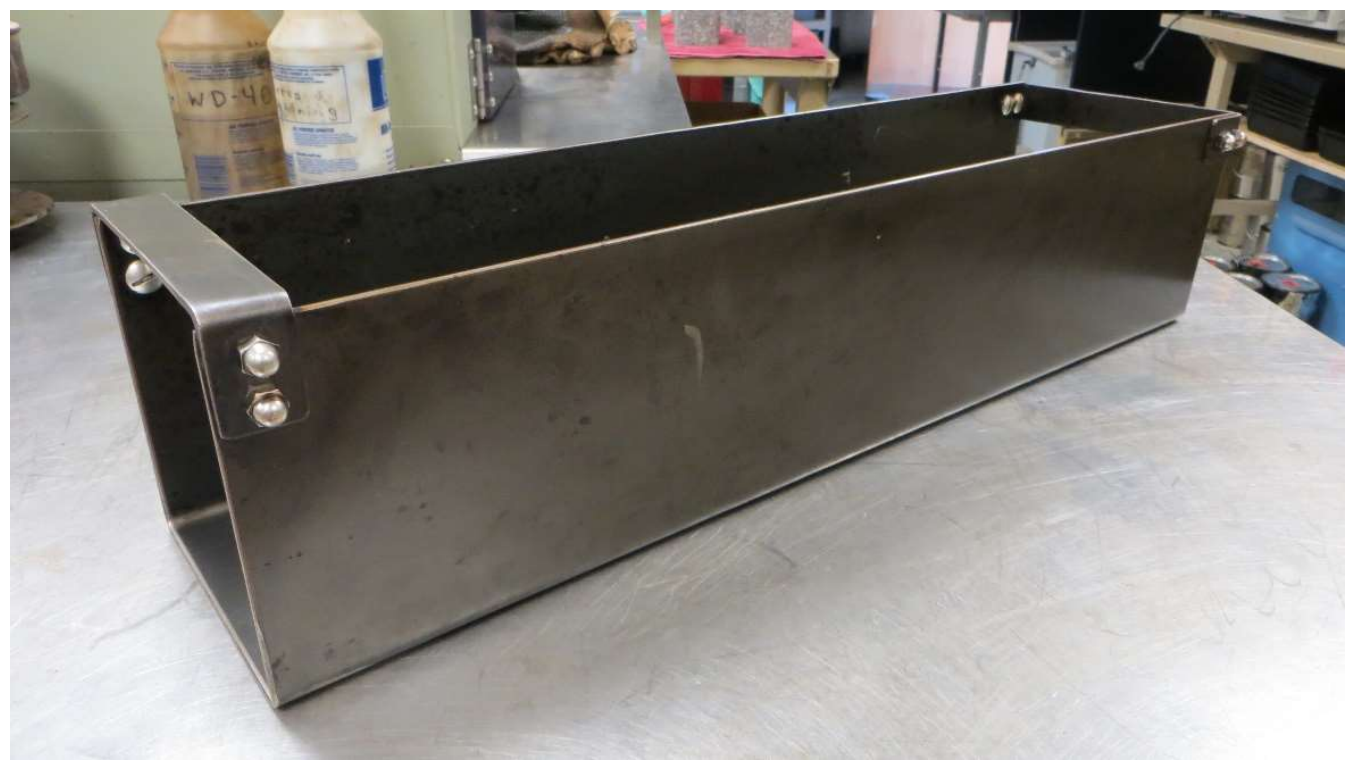

Figure 3: Funnel used to insert mix into the Superpave compaction molds.

\section{Aging and Compaction}

After the samples were thoroughly mixed, the needed amount of material was weighed into pans and placed in an oven at the compaction temperature, Table 3, for two hours; with mixing after one hour. After, the samples were transferred to the mold and compacted with a Superpave Gyratory Compactor (SGC).

After compaction, the molds were removed from the compactor and left for a minimum of 30 minutes to allow the sample to become firm enough for handling. All samples were labeled on the bottom for consistency. Samples were then left overnight to cool before running bulk specific gravity testing using both the CoreLok ${ }^{\circledR}$ and SSD methods. This is an optional step in AASHTO PP 60 as it may identify an improperly made sample. None of the samples prepared for this research were rejected for this reason.

\section{Mix Mass Determination}

Before compacting performance samples, some samples were prepared to determine the mass of mix required to compact a $180 \mathrm{~mm}$ tall sample with $7 \% \pm 0.5 \%$ air voids per AASHTO PP 60.

From previous WVU laboratory experience (Smith, 2015 \& Turner, 2015 \& Dalton, 2016) all samples to be used in performance testing were compacted to $150 \mathrm{~mm}$ diameter and 180mm height, which satisfied both AASHTO PP 61 and TP 107 minimum height requirements. 
Equation 1 was used to determine an initial estimate for mass of mix required to reach $7 \% \pm 0.5 \%$ air voids. A higher and lower mass of mix were compacted. If required, an adjusted mass was then calculated using Equation 2. The mass used in Equations 1 and 2 was based on the mass that was compacted in the Superpave Gyratory Compactor, while the air void levels were based on the cored and sawed VTM values for a dynamic modulus sample computed from $\mathrm{G}_{\mathrm{mb}}$ results from the CoreLok ${ }^{\circledR}$ test.

$$
\text { Mass }=\left[\frac{100\left(V_{a t}+F\right)}{100}\right] \times G_{m m} \times(176.7147) \times H
$$

Where:

Mass = estimated mass of mixture needed $(\mathrm{g})$

$V_{a t}=$ target air void content of the specimen (\%)

$G_{m m}=$ Theoretical maximum specific gravity

$H=$ height of the gyratory compacted sample (mm)

$F=$ air void adjustment factor, 1.5 for $9.5 \mathrm{~mm}$ mixes and 1.0 for $12.5 \mathrm{~mm}$ mixes

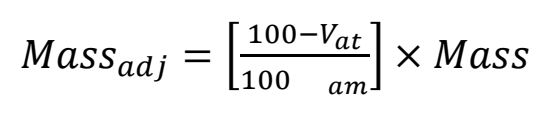

Where:

$$
\begin{aligned}
& \text { Massadj }=\text { adjusted mass of mixture needed }(\mathrm{g}) \\
& V_{a t}=\text { target air void content of the specimen (\%) } \\
& V_{a m}=\text { measured trial test specimen air void content (\%) } \\
& \text { Mass }=\text { mass used to prepare the trial test specimen }(\mathrm{g})
\end{aligned}
$$

Mass corrections were made, and samples were prepared for the experimental testing. Samples were cored and sawed to meet the dimension requirements for the Dynamic Modulus and Fatigue tests. All samples were compacted to a $180 \mathrm{~mm}$ height. However, trimmed samples for fatigue tests are shorter than the Dynamic Modulus samples. It was assumed this would not affect the air voids of the trimmed samples.

\section{Volumetric Verification and Sample Preparation}

The CoreDry ${ }^{\circledR}$ machine was used to remove water from the coring and sawing process. The $\mathrm{G}_{\mathrm{mb}}$ of each sample was determined using the CoreLok ${ }^{\circledR}$. Subsequently, the sample was dried once again and then the SSD method for $\mathrm{G}_{\mathrm{mb}}$ was performed.

Performance samples were measured for their geometry and checked for end flatness and perpendicularity specifications provided in Table 4 . All samples complied with these 
requirements. Samples were also labeled after coring and sawing, noting the top and bottom of the sample from compaction. This labeling was done to keep the top, middle, and bottom consistent from compaction through testing. The samples were tested within two weeks of trimming as recommended by AASHTO PP 60.

Table 4: Test specimen tolerances for Dynamic Modulus and Fatigue testing

\begin{tabular}{|c|c|c|}
\hline & Dynamic Modulus & Fatigue \\
\hline Average Diameter & 98 to $104 \mathrm{~mm}$ & 98 to $104 \mathrm{~mm}$ \\
\hline Standard Deviation of Diameter & $\leq 1.0 \mathrm{~mm}$ & $\leq 1.0 \mathrm{~mm}$ \\
\hline Height & 147.5 to $152.5 \mathrm{~mm}$ & 127.5 to $132.5 \mathrm{~mm}$ \\
\hline End Flatness & $\leq 0.5 \mathrm{~mm}$ & $\leq 0.5 \mathrm{~mm}$ \\
\hline End Perpendicularity & $\leq 1.0 \mathrm{~mm}$ & $\leq 1.0 \mathrm{~mm}$ \\
\hline
\end{tabular}

Dynamic Modulus Testing on AMPT

After the samples had been measured for air voids, dimensional, flatness and perpendicularity specifications, dynamic modulus samples were stored until gage points were glued on using the jig shown in Figure 4, which ensured proper spacing of the LVDT's on the sample. The six gage points were attached using Devcon 5-minute epoxy at $120^{\circ}$ intervals around the sample. The specimen was left in the gluing jig to cure for at least one hour prior to temperature conditioning. An example of a specimen prepared for conditioning is shown in Figure 5. The samples were oriented to match the way they were compacted, e.g. the top of the sample when compacted was the top of the sample when tested. Each sample was first tested at the low temperature followed by the medium then high temperature.

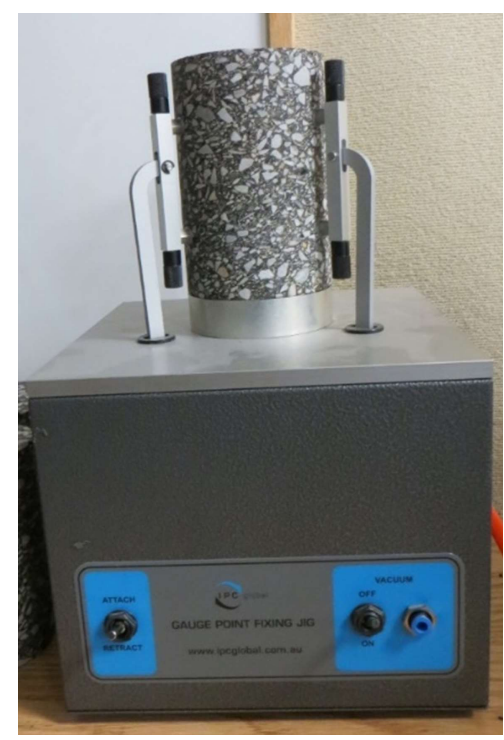

Figure 4: Gluing jig for gage points used for dynamic modulus samples. 


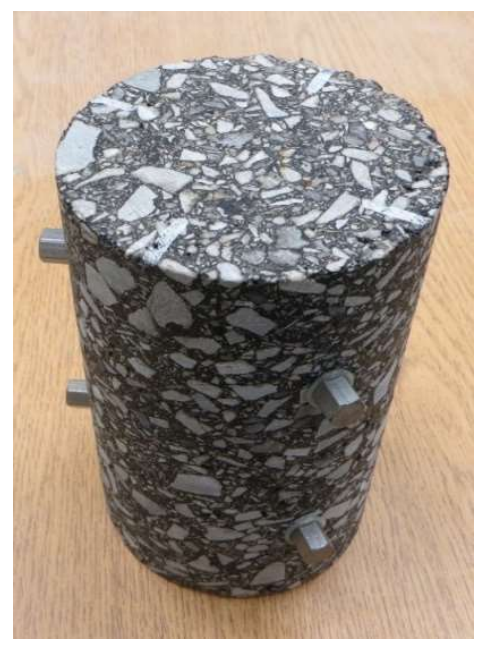

Figure 5: Dynamic modulus sample with gage points attached ready to be conditioned for testing.

During conditioning, a "dummy" sample with an internal thermometer was conditioned with the performance sample to ensure that the testing temperature was achieved. All samples were left in the conditioning chamber with a "dummy" sample for a minimum of 6 hours as this was found to be a sufficient time period for conditioning. It should be noted that samples mixed with the PG 70-22 PM binder type were tested at $40^{\circ} \mathrm{C}$, unlike in the research performed by Turner (2015). This was done in order to compare it to the unmodified binder with the same PG rating. Table 5 shows the order for Dynamic Modulus testing. Samples were labeled with the designation number, NMAS, and binder grade. All samples were tested in accordance with AASHTO TP 79.

Once the specimen had been properly conditioned, it was quickly removed from the conditioning chamber and placed into the AMPT between two end platens with Teflon spacers in between the platens and the specimen. The LVDT's were attached and adjusted to zero displacement using the levels tool within the AMPT software from Instro Tek ${ }^{\circledR}$. After the LVDTs were attached to the sample and adjusted, the testing chamber was closed, and temperature allowed to stabilize before starting the test. The test set up for Dynamic Modulus is provided in Figure 6. 
Table 5: Dynamic Modulus sample testing order. Testing temperature was kept in the following order, low (4), medium (20), and high (40 or 45).

\begin{tabular}{|c|c|c|c|}
\hline Test Number & Sample Designation & NMAS & Binder Grade \\
\hline 1 & DM 1 & $12.5 \mathrm{~mm}$ & PG 70-22 \\
\hline 2 & DM 1 & $9.5 \mathrm{~mm}$ & PG 76-22 PM \\
\hline 3 & DM 1 & $12.5 \mathrm{~mm}$ & PG 76-22 PM \\
\hline 4 & DM 1 & $9.5 \mathrm{~mm}$ & PG 70-22 \\
\hline 5 & DM 2 & $9.5 \mathrm{~mm}$ & PG 76-22 PM \\
\hline 6 & DM 1 & $9.5 \mathrm{~mm}$ & PG 70-22 PM \\
\hline 7 & DM 1 & $12.5 \mathrm{~mm}$ & PG 70-22 PM \\
\hline 8 & DM 2 & $9.5 \mathrm{~mm}$ & PG 70-22 \\
\hline 9 & DM 2 & $12.5 \mathrm{~mm}$ & PG 70-22 PM \\
\hline 10 & DM 3 & $12.5 \mathrm{~mm}$ & PG 70-22 PM \\
\hline 11 & DM 3 & $12.5 \mathrm{~mm}$ & PG 76-22 PM \\
\hline 12 & DM 2 & $9.5 \mathrm{~mm}$ & PG 70-22 PM \\
\hline 13 & DM 3 & $9.5 \mathrm{~mm}$ & PG 70-22 \\
\hline 14 & DM 3 & $12.5 \mathrm{~mm}$ & PG 70-22 \\
\hline 15 & DM 3 & $9.5 \mathrm{~mm}$ & PG 70-22 PM \\
\hline 16 & DM 2 & $12.5 \mathrm{~mm}$ & PG 76-22 PM \\
\hline 17 & DM 3 & $9.5 \mathrm{~mm}$ & PG 76-22 PM \\
\hline 18 & DM 2 & $12.5 \mathrm{~mm}$ & PG 70-22 \\
\hline
\end{tabular}

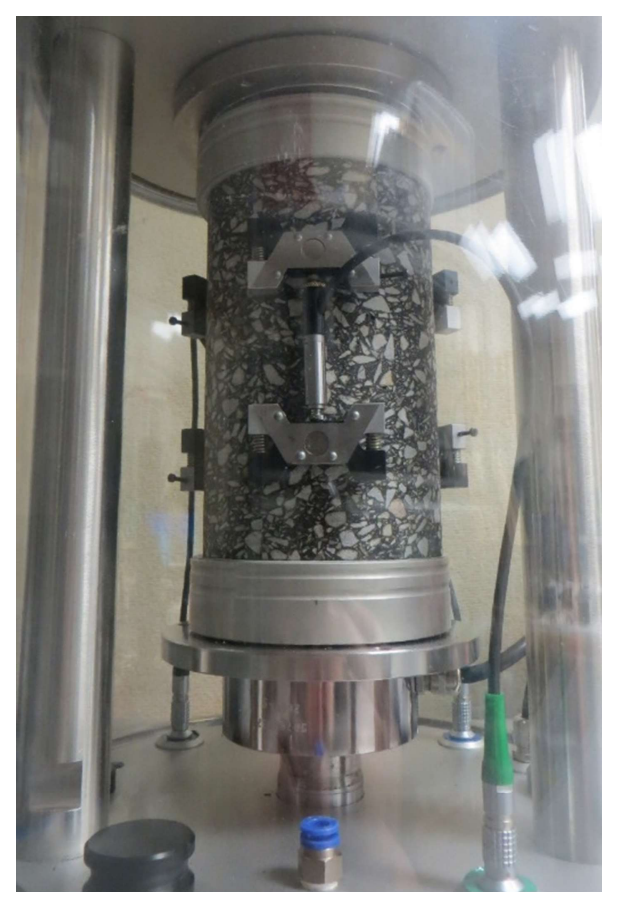

Figure 6: Dynamic Modulus sample in AMPT. 
Temperature was carefully monitored through the levels tool and attached gage within the testing chamber. The software used for dynamic modulus testing was the UTS006, which automatically applies the loads at the desired frequency while collecting the required data for analysis. Once the test was complete, the sample was removed from the testing chamber and conditioned for the next temperature level. After a sample had been tested at all required frequencies and temperatures, the gage points were carefully removed and soaked in acetone to remove the epoxy for future use.

Once testing was completed, the data was exported to an Excel file that could be used in the MasterSolver worksheet developed by Bonaquist (2011b).

\section{Sample Bulk Specific Gravity Uniformity}

Samples tested for dynamic modulus were also evaluated for bulk specific gravity, $\mathrm{G}_{\mathrm{mb}}$, uniformity by sawing the sample into thirds per AASHTO PP 60. This method specifies a target air void content of 5.0 $\pm 0.5 \%$. However, the Dynamic Modulus tests in this research have air void target of $7.0 \pm 0.5 \%$. It was decided that testing at the actual air void target is more beneficial since this is the actual VTM used for testing the material. Each sample was cut into three slices, approximately $50 \mathrm{~mm}$ thick. The air voids of the top, middle and bottom slices were measured using the saturated surface dry, CoreLok ${ }^{\circledR}$ and dimensional methods. Complete results of these tests, including bulk specific gravities $\left(\mathrm{G}_{\mathrm{mb}}\right)$ and air voids (VTM), are provided in Appendix B.

\section{Fatigue Testing on AMPT}

All samples were produced in accordance with AASHTO PP 60 and AASHTO TP 107. Fatigue sample preparation was a similar process as dynamic modulus, but samples are cut shorter, $130 \mathrm{~mm}$. The gluing jig for fatigue gage points is the same device as dynamic modulus apart from the base platen. The base platen for fatigue is taller to ensure that the gage points were located at the third points of the height of the sample. Gage points are attached using 5-minute epoxy.

Fatigue samples require end platens to be attached using Devcon 10110 (steel putty). Following previous failures in other research involving the end platens breaking off of the sample during fatigue testing, it was recommended to heat the end platens to $40^{\circ} \mathrm{C}$ before attaching them. Steel putty was cured for 4 hours on the gluing jig shown in Figure 7. After 
initially curing, samples were carefully removed from the jig and set aside for an additional 12 hours of curing before temperature conditioning.

All fatigue samples were tested at a temperature of $15^{\circ} \mathrm{C}$ based on values from the LongTerm Pavement Performance Binder (LTPP Bind) software. This temperature was determined by selecting the high and low temperature range for the performance grade binder from LTTP Bind for the station at Morgantown Municipal Airport in Morgantown, West Virginia. With a reliability of $98 \%$, the binder grade was PG 58-22, which yields a testing temperature of $15^{\circ} \mathrm{C}$ using Equation 3.

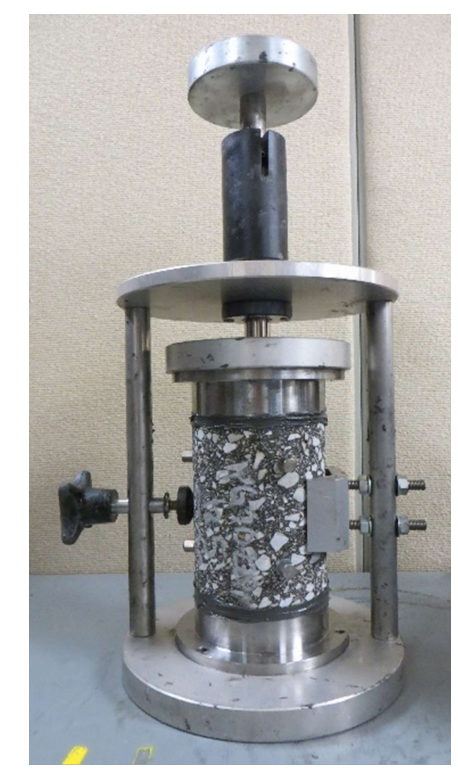

Figure 7: Fatigue end platen gluing jig with sample in place.

$$
\text { Test Temperature }=\frac{\text { High } P G+L \quad P G}{2}-3
$$

The conditioning chamber used for fatigue samples was set to $15^{\circ} \mathrm{C}$. Similar to dynamic modulus, a dummy sample containing an internal thermometer was placed in the conditioning chamber.

Following the conditioning process, the sample was quickly transferred to the testing chamber. The metal ball placed on the top end platen to minimize eccentricity, and the bottom platen was bolted to the bottom actuator. All bolts were tightened to six-foot-pounds using a torque wrench. Once the actuator is raised with an applied seating load of $0.09 \mathrm{kN}$, the top end platen was bolted in place with six-foot-pounds of torque. Then the LVDTs are attached and adjusted to slightly above the minimum displacement allowed (typically around $-0.3 \mathrm{~mm}$ ). The 
displacement levels are monitored within the levels tool within the software. Because fatigue is a tensile test, the LVDTs were adjusted to a minimum displacement to allow for more range during measurements. Once the LVDTs were adjusted, the chamber was closed. The temperature of the chamber was allowed to stabilize at the testing temperature before beginning the test, typically, 45 minutes to an hour. In order to begin the test, the load was zeroed and a Dynamic Modulus Fingerprint test was started. Following the Dynamic Modulus Fingerprint test, there was a rest period of 20 minutes. After this rest period, the fatigue test automatically started.

Samples were tested within two weeks of coring and sawing. Table 6 displays the order of testing. The test protocol requires three samples to provide a single test result. The three samples required for a test result were tested in sequence. The first sample of the set is tested at $\varepsilon_{\mathrm{os} 1}=300$ microstrain, and the following two samples' microstrain, $\varepsilon_{\mathrm{os} 2}$ and $\varepsilon_{\mathrm{os}} 3$ are determined based on the number of cycles to failure $\left(\mathrm{N}_{\mathrm{f}}\right)$ of the first sample; the adjustments are provided in Table 7 per AASHTO TP 107.

Once the testing was complete, the gage points were carefully removed from the sample and cleaned for use on future samples. Once the gage points were removed, the sample was placed in the oven at $100^{\circ} \mathrm{C}$ for at least an hour to soften the steel putty for removal and cleaning of the end platens. End platens were cleaned with acetone to ensure that there was no residue left behind. Samples were discarded. 
Table 6: Fatigue testing order.

\begin{tabular}{|c|c|c|c|}
\hline $\begin{array}{c}\text { Test } \\
\text { sequence no. }\end{array}$ & $\begin{array}{c}\text { Sample } \\
\text { Designation }\end{array}$ & NMAS & Binder Grade \\
\hline 1 & FT 3 & $9.5 \mathrm{~mm}$ & PG 76-22 PM \\
\hline 2 & FT 1 & $9.5 \mathrm{~mm}$ & PG 76-22 PM \\
\hline 3 & FT 3 & $9.5 \mathrm{~mm}$ & PG 70-22 \\
\hline 4 & FT 2 & $12.5 \mathrm{~mm}$ & PG 76-22 PM \\
\hline 5 & FT 1 & $9.5 \mathrm{~mm}$ & PG 70-22 \\
\hline 6 & FT 2 & $9.5 \mathrm{~mm}$ & PG 76-22 PM \\
\hline 7 & FT 1 & $9.5 \mathrm{~mm}$ & PG 70-22 PM \\
\hline 8 & FT 3 & $9.5 \mathrm{~mm}$ & PG 70-22 PM \\
\hline 9 & FT 2 & $12.5 \mathrm{~mm}$ & PG 70-22 \\
\hline 10 & FT 3 & $12.5 \mathrm{~mm}$ & PG 70-22 \\
\hline 11 & FT 3 & $12.5 \mathrm{~mm}$ & PG 76-22 PM \\
\hline 12 & FT 1 & $12.5 \mathrm{~mm}$ & PG 76-22 PM \\
\hline 13 & FT 3 & $12.5 \mathrm{~mm}$ & PG 70-22 PM \\
\hline 14 & FT 2 & $9.5 \mathrm{~mm}$ & PG 70-22 PM \\
\hline 15 & FT 1 & $12.5 \mathrm{~mm}$ & PG 70-22 \\
\hline 16 & FT 2 & $9.5 \mathrm{~mm}$ & PG 70-22 \\
\hline 17 & FT 1 & $12.5 \mathrm{~mm}$ & PG 70-22 PM \\
\hline 18 & FT 2 & $12.5 \mathrm{~mm}$ & PG 70-22 PM \\
\hline
\end{tabular}

Table 7: On-specimen strain adjustment for second and third fatigue samples

\begin{tabular}{|c|c|c|}
\hline Case & $\boldsymbol{\varepsilon}_{\text {os2 }}$ & $\boldsymbol{\varepsilon}_{\text {os } 3}$ \\
\hline $500<\mathrm{N}_{\mathrm{f} 1}<1,000$ & $\varepsilon_{\mathrm{os} 1}-100$ & $\varepsilon_{\mathrm{os} 1}-150$ \\
\hline $1,000<\mathrm{N}_{\mathrm{f} 1}<5,000$ & $\varepsilon_{\mathrm{os} 1}-50$ & $\varepsilon_{\mathrm{os} 1}-100$ \\
\hline $5,000<\mathrm{N}_{\mathrm{f} 1}<20,000$ & $\varepsilon_{\mathrm{os} 1}+50$ & $\varepsilon_{\mathrm{os} 1}-50$ \\
\hline $20,000<\mathrm{N}_{\mathrm{f} 1}<100,000$ & $\varepsilon_{\mathrm{os} 1}+100$ & $\varepsilon_{\mathrm{os} 1}+50$ \\
\hline $100,000<\mathrm{N}_{\mathrm{f} 1}$ & $\varepsilon_{\mathrm{os} 1}+150$ & $\varepsilon_{\mathrm{os} 1}+100$ \\
\hline
\end{tabular}




\section{Chapter 4: Results and Discussion}

This chapter describes the results collected and analyses performed on samples in regard to the effect of binder type on the air void distribution, dynamic modulus and fatigue testing.

\section{Bulk Specific Gravity Methods}

Although the volumetric parameters used in this research are based on the CoreLok ${ }^{\circledR}$ method, the $\mathrm{G}_{\mathrm{mb}}$ was also determined with the SSD and volumetric methods. Similar to Dalton (2016), line of equality graphs were produced in order to compare the three methods. Figures 8-

10 display these plots as well as the lines of "best fit" for both before and after coring and sawing as well as an $\mathrm{R}^{2}$ value for each of these best fit lines.

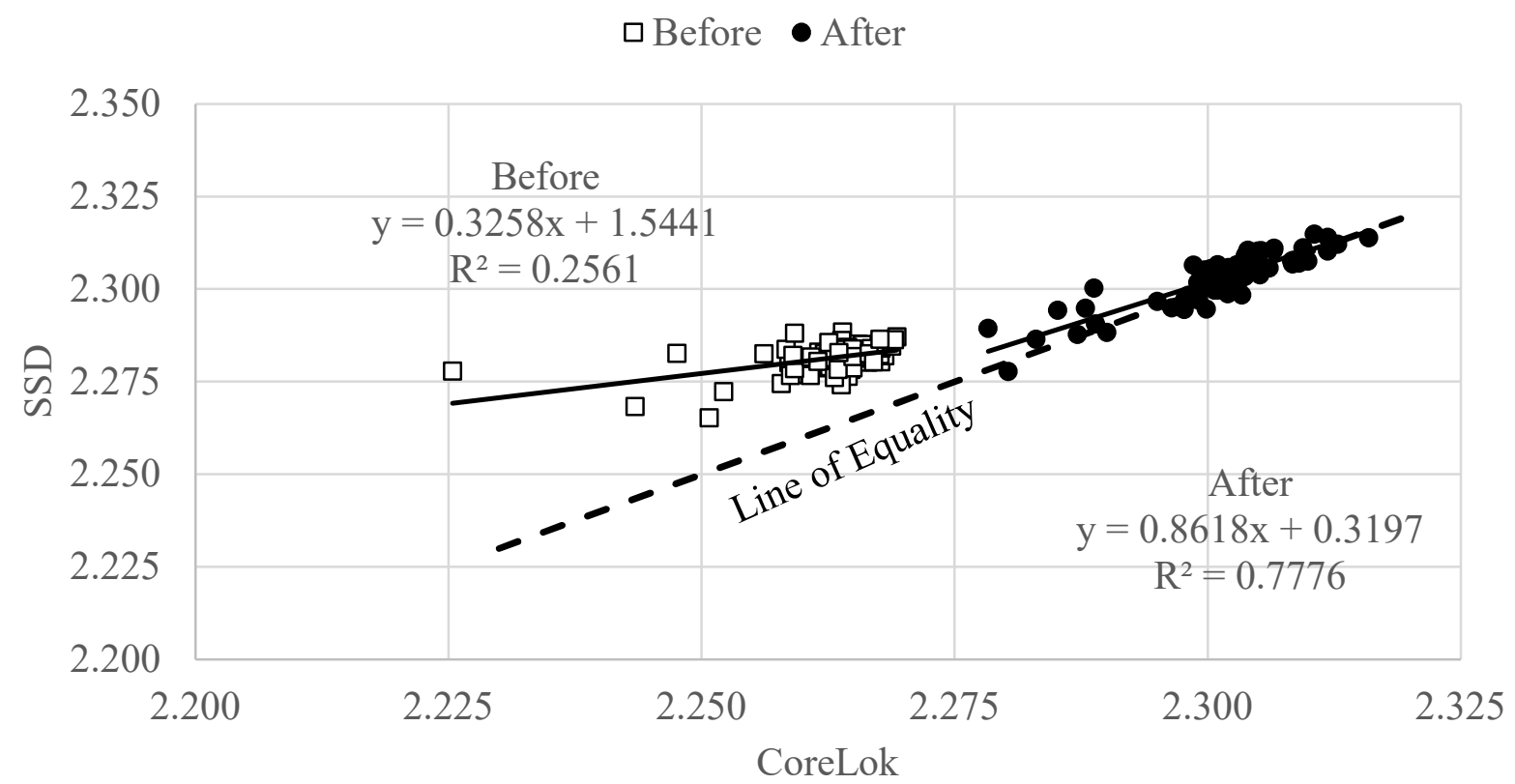

Figure 8: Line of Equality Chart for SSD versus CoreLok® Methods 


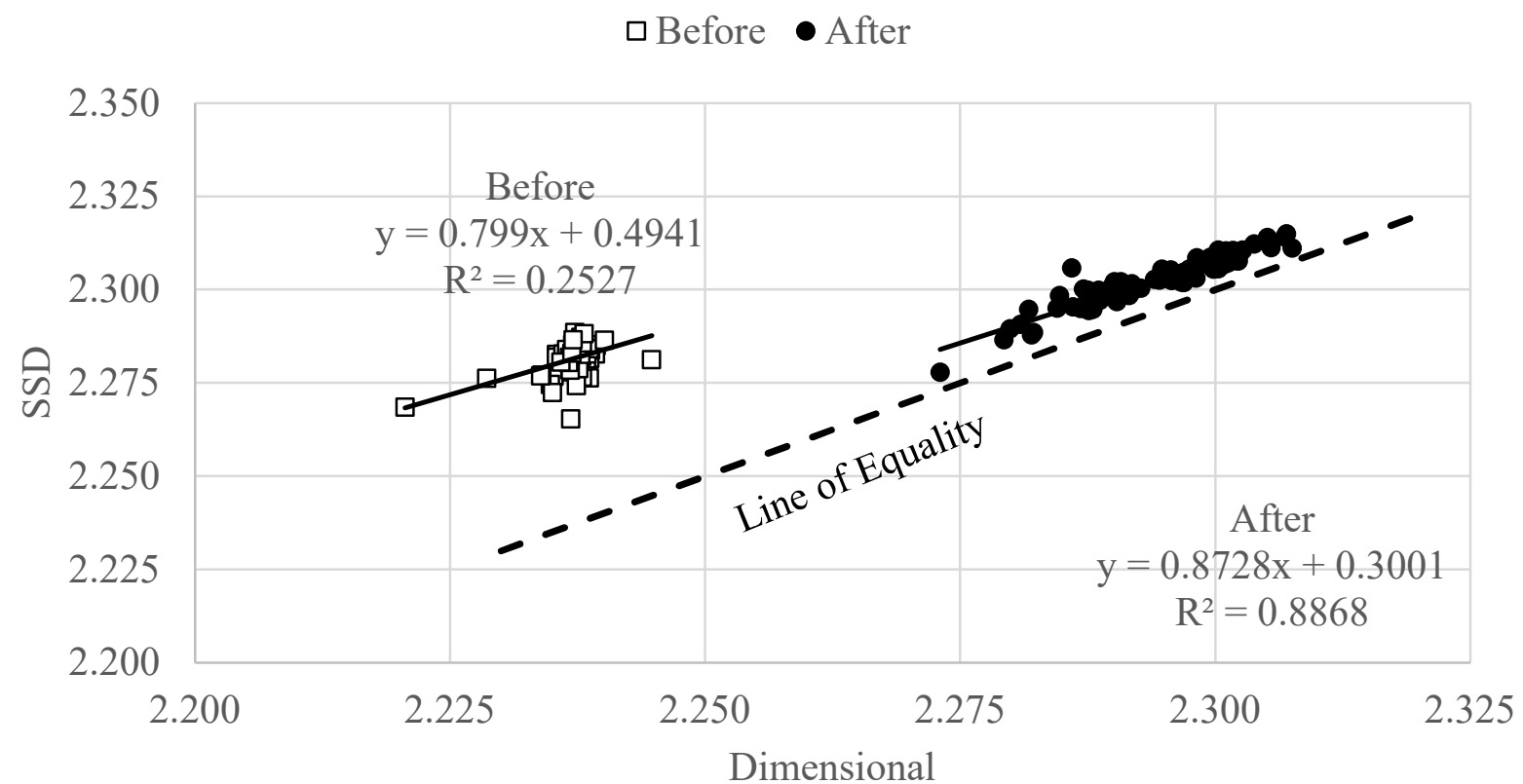

Figure 9: Line of Equality Chart for SSD versus Dimensional Methods

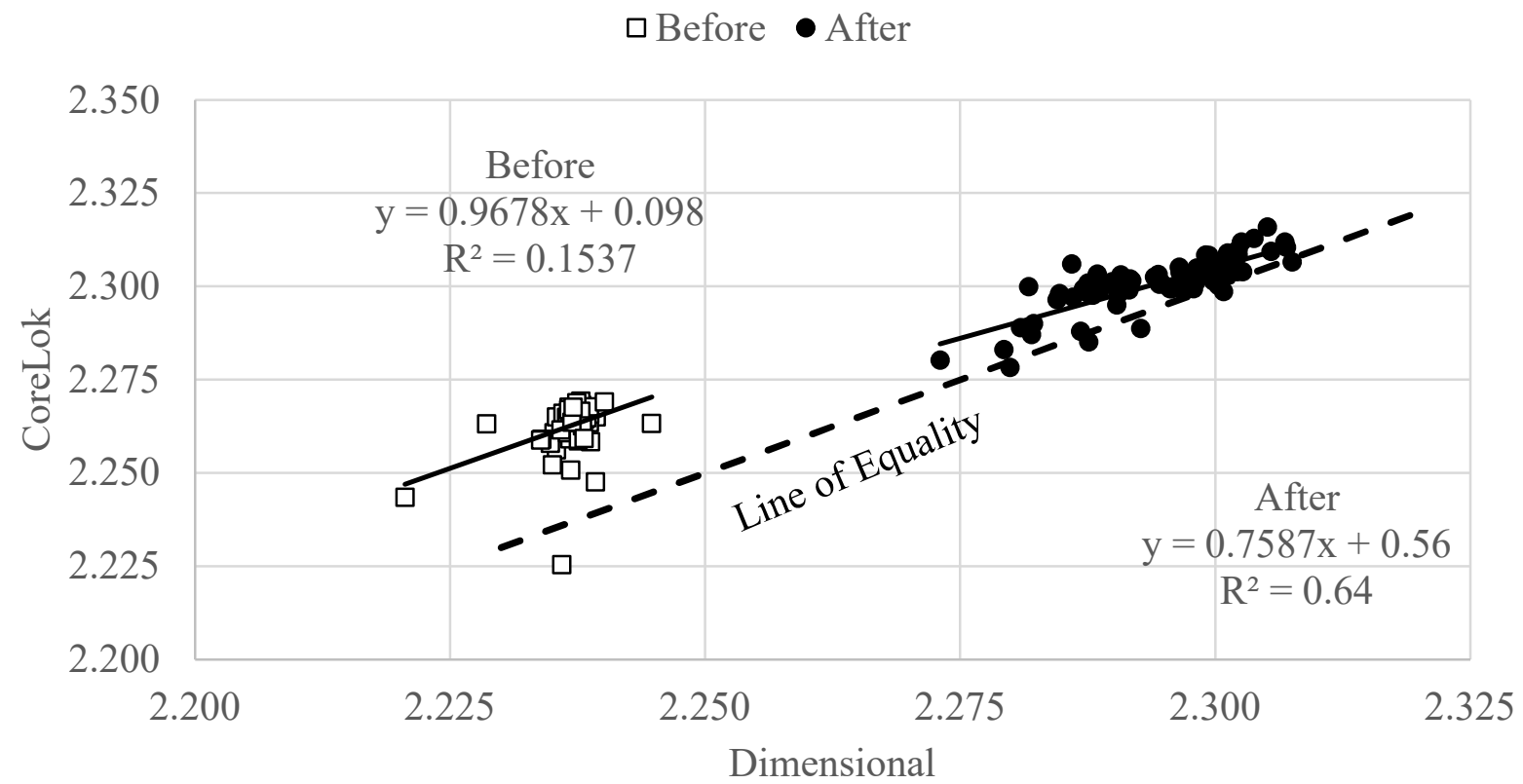

Figure 10: Line of Equality Chart for Dimensional versus CoreLok® Methods

From these figures, it is obvious that all of the methods had a very low correlation before coring and sawing but a much higher correlation after. The Dimensional vs. CoreLok ${ }^{\circledR}$ methods was almost parallel to the line of equality, though it had the lowest $\mathrm{R}^{2}$ value. These plots do not 
lead to the conclusion that the results of each test are comparable in a laboratory setting. SSD compared to the dimensional method resulted in the highest $\mathrm{R}^{2}$ after coring and sawing which was similar to the research performed by Dalton (2016). These results also are comparable to the conclusion that Griffith (2009) determined, which was that the difference between SSD and CoreLok ${ }^{\circledR}$ methods $\mathrm{G}_{\mathrm{mb}}$ values diverge at higher air void contents. High air void contents are defined by Griffith (2009) as being in the range of 5\% to 8\%. All samples within this research were qualified as high air voids by Griffith (2009).

\section{Bulk Specific Gravity Uniformity of Dynamic Modulus Samples}

The means and standard deviations for the uniformity tests are presented in Table 8. Per AASHTO T 31, Bulk Specific Gravity and Density of Compacted HMA using Automatic Vacuum Sealing Method, the standard deviation of replicate samples tested by one technician in one lab should be less than 0.0124 . As shown by bolded numbers in Table 8 , six of the mixes had larger standard deviations. Figure 11 is a histogram of the average air voids for the three slices of each of the mixes. Air voids are used on this figure since $\mathrm{G}_{\mathrm{mm}}$ varies with binder type limiting the utility of comparing $\mathrm{G}_{\mathrm{mb}}$. All but the PG 76-22 PM - $12.5 \mathrm{~mm}$ mix show the top and bottom slices are similar and have a higher $\mathrm{G}_{\mathrm{mb}}$ and lower air voids than the middle slice. AASHTO PP 60 prescribes the t-test for comparing the $\mathrm{G}_{\mathrm{mb}}$ of the top to middle and the middle to bottom slices. The method does not call for comparing the top to bottom slices; this comparison is included in the analysis herein. The test analysis results are presented in Table 9. To conclude that the bulk specific gravity between each third were equal ${ }^{2}$, the t-statistic must be lower than 2.78. As indicated by the bold values in Table 9, for half the mixes the null hypothesis of equal means was rejected. None of the comparisons of the top to bottom slices indicated a problem.

\footnotetext{
${ }^{2}$ This is based on the terminology stated in AASHTO PP 60. The word "equal" is used to mean there is insufficient evidence to reject the null hypothesis of equal means.
} 
Table 8: Averages for $G_{m b}$ thirds by test method

\begin{tabular}{|c|c|c|c|c|}
\hline Mix Type & & Top & Middle & Bottom \\
\hline PG 70-22 & Mean & 2.301 & 2.270 & 2.295 \\
\cline { 2 - 5 } $9.5 \mathrm{~mm}$ & Standard Deviation & 0.005 & 0.008 & 0.004 \\
\hline \multirow{2}{*}{ PG 70-22 } & Mean & 2.296 & 2.266 & 2.289 \\
12.5mm & Standard Deviation & 0.007 & 0.007 & 0.007 \\
\hline PG 70-22 PM & Mean & 2.300 & 2.271 & 2.307 \\
\cline { 2 - 5 } $9.5 \mathrm{~mm}$ & Standard Deviation & 0.006 & 0.003 & 0.003 \\
\hline PG 70-22 PM & Mean & 2.298 & 2.258 & 2.296 \\
\cline { 2 - 5 } $12.5 \mathrm{~mm}$ & Standard Deviation & $\mathbf{0 . 0 1 4}$ & $\mathbf{0 . 0 3 1}$ & 0.010 \\
\hline PG 76-22 PM & Mean & 2.298 & 2.256 & 2.296 \\
\cline { 2 - 5 } $9.5 \mathrm{~mm}$ & Standard Deviation & $\mathbf{0 . 0 1 6}$ & $\mathbf{0 . 0 2 5}$ & $\mathbf{0 . 0 1 8}$ \\
\hline PG 76-22 PM & Mean & 2.248 & 2.276 & 2.299 \\
\cline { 2 - 5 } $12.5 \mathrm{~mm}$ & Standard Deviation & $\mathbf{0 . 0 7 0}$ & 0.009 & 0.012 \\
\hline
\end{tabular}

घTop $\square$ Middle $\boldsymbol{\square}$ Bottom

$10.0 \%$

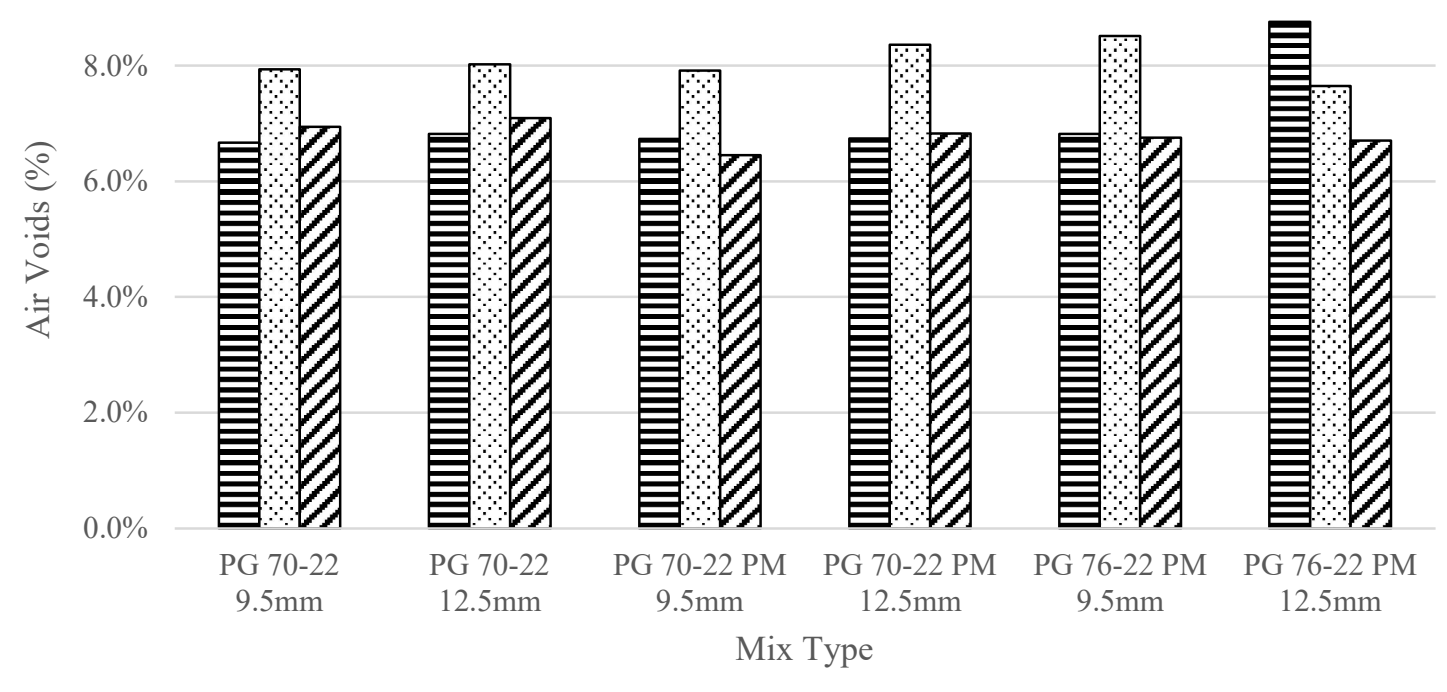

Figure 11: Sample thirds Air Void Histogram 
Table 9: $t$-Statistic for $G_{m b}$ thirds for CoreLok results

\begin{tabular}{|c|c|c|c|}
\hline Mix Type & T-M & B-M & T-B \\
\hline $\begin{array}{c}\text { PG 70-22 } \\
9.5 \mathrm{~mm}\end{array}$ & $\mathbf{5 . 4 7}$ & $\mathbf{4 . 7 3}$ & 1.55 \\
\hline $\begin{array}{c}\text { PG 70-22 } \\
12.5 \mathrm{~mm}\end{array}$ & $\mathbf{5 . 0 7}$ & $\mathbf{3 . 9 4}$ & 1.17 \\
\hline $\begin{array}{c}\text { PG 70-22 PM } \\
9.5 \mathrm{~mm}\end{array}$ & $\mathbf{7 . 0 6}$ & $\mathbf{1 3 . 7 4}$ & 1.66 \\
\hline $\begin{array}{c}\text { PG 70-22 PM } \\
12.5 \mathrm{~mm}\end{array}$ & 2.04 & 2.02 & 0.20 \\
\hline $\begin{array}{c}\text { PG 76-22 PM } \\
9.5 \mathrm{~mm}\end{array}$ & 2.48 & 2.24 & 0.14 \\
\hline $\begin{array}{c}\text { PG 76-22 PM } \\
12.5 \mathrm{~mm}\end{array}$ & 0.69 & 2.68 & 1.24 \\
\hline
\end{tabular}

The equivalence test is an alternative method for a comparative analysis of samples if limits can be established for an acceptable difference between the means. Per AASHTO T 331 the standard deviation of a single operator in a single lab is 0.0124 , for a two-tailed test the means between two similar populations should be different by no more than \pm 2 standard deviations 95 percent of the time. Thus, a threshold of 0.05 was used for performing an equivalency test using an alpha level of 0.05 . The software JMP was use for the analysis. If pvalues were less than the alpha value, we would accept the hypothesis that the sections are equal. A complete output from JMP of the equivalency test is provided in Appendix D and are summarized in Table 10. With an alpha level of 0.05 , the hypothesis of equal means is accepted for all comparisons.

Table 10: P-values from JMP output for equivalency test of $G_{m b}$ between sections.

\begin{tabular}{|c|c|c|c|}
\hline \multirow{2}{*}{} & \multicolumn{3}{|c|}{ CoreLok ${ }^{\circledR}$} \\
\cline { 2 - 4 } & T-M & M-B & T-B \\
\hline Lower Threshold & 0.0004 & $<0.0001$ & $<0.0001$ \\
\hline Upper Threshold & $<0.0001$ & 0.0063 & $<0.0001$ \\
\hline Max of Both & 0.0004 & 0.0063 & $<0.0001$ \\
\hline
\end{tabular}

Another analysis was performed to compare the averages of the samples cut into thirds to the averages of the full or intact samples. Among most of the samples, there was a difference less than $0.5 \%$ VTM between the full sample and when it had been cut into thirds as revealed in Table 11. The only sample that did not fall under $0.5 \%$ difference was the PG 76-22 PM 12.5 
$\mathrm{mm}$, which had an apparent outlier in the data that was possibly attributed to a problem encountered in the CoreLok ${ }^{\circledR}$ test. This issue was not further analyzed; therefore, the reason for this difference is unknown.

Table 11: Comparison of Sample Third Air Void Averages to Full Sample Air Void

\begin{tabular}{|c|c|c|c|c|c|c|c|c|}
\hline \multirow{2}{*}{ Binder Type } & \multirow{2}{*}{ NMAS } & \multirow{2}{*}{ Designation } & \multicolumn{3}{|c|}{ Average } & \multirow[t]{2}{*}{$\begin{array}{c}\text { Thirds } \\
\text { Average }\end{array}$} & \multirow[t]{2}{*}{$\begin{array}{c}\text { Intact } \\
\text { Sample }\end{array}$} & \multirow[t]{2}{*}{ Difference } \\
\hline & & & $\mathrm{T}$ & M & B & & & \\
\hline \multirow{3}{*}{ PG 70-22 } & \multirow{3}{*}{$9.5 \mathrm{~mm}$} & DM 1 & $7.1 \%$ & $8.4 \%$ & $6.8 \%$ & $7.4 \%$ & $7.3 \%$ & $0.1 \%$ \\
\hline & & DM 2 & $6.6 \%$ & $8.0 \%$ & $7.0 \%$ & $7.2 \%$ & $7.0 \%$ & $0.2 \%$ \\
\hline & & DM 3 & $6.4 \%$ & $7.7 \%$ & $7.1 \%$ & $7.0 \%$ & $6.9 \%$ & $0.1 \%$ \\
\hline \multirow{3}{*}{ PG 70-22 } & \multirow{3}{*}{$12.5 \mathrm{~mm}$} & DM 1 & $6.8 \%$ & $8.2 \%$ & $7.3 \%$ & $7.5 \%$ & $7.2 \%$ & $0.2 \%$ \\
\hline & & DM 2 & $6.8 \%$ & $7.7 \%$ & $7.1 \%$ & $7.2 \%$ & $6.8 \%$ & $0.4 \%$ \\
\hline & & DM 3 & $6.7 \%$ & $8.0 \%$ & $6.9 \%$ & $7.2 \%$ & $6.8 \%$ & $0.4 \%$ \\
\hline \multirow{3}{*}{ PG 70-22 PM } & \multirow{3}{*}{$9.5 \mathrm{~mm}$} & DM 1 & $7.0 \%$ & $8.0 \%$ & $6.6 \%$ & $7.2 \%$ & $6.9 \%$ & $0.2 \%$ \\
\hline & & DM 2 & $6.6 \%$ & $7.9 \%$ & $6.5 \%$ & $7.0 \%$ & $7.0 \%$ & $0.0 \%$ \\
\hline & & DM 3 & $6.8 \%$ & $7.5 \%$ & $6.4 \%$ & $6.9 \%$ & $6.8 \%$ & $0.1 \%$ \\
\hline \multirow{3}{*}{ PG 70-22 PM } & \multirow{3}{*}{$12.5 \mathrm{~mm}$} & DM 1 & $7.0 \%$ & $7.7 \%$ & $6.4 \%$ & $7.1 \%$ & $6.9 \%$ & $0.1 \%$ \\
\hline & & DM 2 & $6.3 \%$ & $7.6 \%$ & $7.0 \%$ & $7.0 \%$ & $6.8 \%$ & $0.2 \%$ \\
\hline & & DM 3 & $6.7 \%$ & $8.3 \%$ & $7.2 \%$ & $7.4 \%$ & $7.0 \%$ & $0.4 \%$ \\
\hline \multirow{3}{*}{ PG 76-22 PM } & \multirow{3}{*}{$9.5 \mathrm{~mm}$} & DM 1 & $7.6 \%$ & $9.0 \%$ & $7.4 \%$ & $8.0 \%$ & $7.7 \%$ & $0.3 \%$ \\
\hline & & $\mathrm{DM} 2$ & $6.7 \%$ & $7.9 \%$ & $6.0 \%$ & $6.9 \%$ & $6.8 \%$ & $0.0 \%$ \\
\hline & & DM 3 & $6.3 \%$ & $7.6 \%$ & $6.6 \%$ & $6.8 \%$ & $6.7 \%$ & $0.1 \%$ \\
\hline \multirow{3}{*}{ PG 76-22 PM } & \multirow{3}{*}{$12.5 \mathrm{~mm}$} & DM 1 & $7.1 \%$ & $7.8 \%$ & $7.1 \%$ & $7.3 \%$ & $7.2 \%$ & $0.1 \%$ \\
\hline & & DM 2 & $7.0 \%$ & $7.9 \%$ & $6.7 \%$ & $7.2 \%$ & $7.0 \%$ & $0.2 \%$ \\
\hline & & DM 3 & $8.5 \%$ & $7.5 \%$ & $6.4 \%$ & $7.4 \%$ & $6.7 \%$ & $0.7 \%$ \\
\hline
\end{tabular}

Apart from the analysis comparing the thirds to the intact samples, further analysis of the thirds was performed on the distribution. Previous research performed in the West Virginia University Asphalt Technology Laboratory yielded various results in terms of the air void distribution. This research aimed to collect more data and provide a comparison to the research performed by Dalton (2016). Based on the air voids of each section, a rank was assigned for each sample, for example, the third assigned with a 1 had the highest air voids, and -1 had the lowest air voids. Table 12 displays the results of this ranking analysis. 
Table 12: Ranking of sections based on air voids

\begin{tabular}{|c|c|c|c|c|c|}
\hline \multirow{2}{*}{ Binder Type } & \multirow{2}{*}{ NMAS } & \multirow{2}{*}{ Designation } & \multicolumn{3}{|c|}{ Ranking } \\
\hline & & & $\mathrm{T}$ & M & B \\
\hline \multirow{3}{*}{ PG 70-22 } & \multirow{3}{*}{$9.5 \mathrm{~mm}$} & DM 1 & 0 & 1 & -1 \\
\hline & & DM 2 & -1 & 1 & 0 \\
\hline & & DM 3 & -1 & 1 & 0 \\
\hline \multirow{3}{*}{ PG 70-22 } & \multirow{3}{*}{$12.5 \mathrm{~mm}$} & DM 1 & -1 & 1 & 0 \\
\hline & & DM 2 & -1 & 1 & 0 \\
\hline & & DM 3 & -1 & 1 & 0 \\
\hline \multirow{3}{*}{ PG 70-22 PM } & \multirow{3}{*}{$9.5 \mathrm{~mm}$} & DM 1 & 0 & 1 & -1 \\
\hline & & DM 2 & 0 & 1 & -1 \\
\hline & & DM 3 & 0 & 1 & -1 \\
\hline \multirow{3}{*}{ PG 70-22 PM } & \multirow{3}{*}{$12.5 \mathrm{~mm}$} & DM 1 & 0 & 1 & -1 \\
\hline & & DM 2 & -1 & 1 & 0 \\
\hline & & DM 3 & -1 & 1 & 0 \\
\hline \multirow{3}{*}{ PG 76-22 PM } & \multirow{3}{*}{$9.5 \mathrm{~mm}$} & DM 1 & 0 & 1 & -1 \\
\hline & & DM 2 & 0 & 1 & -1 \\
\hline & & DM 3 & -1 & 1 & 0 \\
\hline \multirow{3}{*}{ PG 76-22 PM } & \multirow{3}{*}{$12.5 \mathrm{~mm}$} & DM 1 & -1 & 1 & 0 \\
\hline & & DM 2 & 0 & 1 & -1 \\
\hline & & DM 3 & 1 & 0 & -1 \\
\hline \multirow{3}{*}{\multicolumn{2}{|c|}{ Total }} & 1 's & 1 & 17 & 0 \\
\hline & & 0 's & 8 & 1 & 9 \\
\hline & & -1 's & 9 & 0 & 9 \\
\hline
\end{tabular}

In 17 of the 18 samples, the middle section had the highest air voids. The only exception had an apparent outlier in the CoreLok ${ }^{\circledR}$ data which possibly affected this result. About half of the tops had the lowest air voids and half of the time the bottoms had the lowest air voids. This suggests that the top and bottom thirds of the samples get similar compaction effort while the middle third is not as well compacted.

\section{Dynamic Modulus and Phase Angle}

Dynamic Modulus testing was performed as per AASHTO TP 79 on the AMPT. All testing was run and data was collected and analyzed. Tables containing the output from MEPDG are provided in Appendix F and are sorted by mix type. 
All dynamic modulus in MPa obtained through testing on the AMPT were tabulated in Table 13. The averages, standard deviation and coefficients of variation were calculated and tabulated in Table 14. Along with the dynamic modulus, Phase Angle values were also collected from the dynamic modulus testing. Table 15 displays the average, standard deviation, and coefficient of variance of Phase Angle based on the testing temperature and frequency. Since dynamic modulus is not considered to be a destructive test, each sample was run at all temperatures and frequencies.

The dynamic modulus decreases based on frequency and testing temperature as expected. Standard deviation of the dynamic modulus decreased as temperature increased and frequency decreased suggesting these results are more accurate. The coefficient of variation did not seem to have any obvious trends but remained relatively low in most cases and never exceeded 23 percent.

Phase angle typically increased with testing temperature and decreased based on frequency. This result was expected based on previous knowledge of asphalt concrete properties as well as previous dynamic modulus testing (Dalton, 2016, Smith, 2015, Turner 2015). The standard deviations did not show any obvious trends just as in dynamic modulus. A coefficient of variation was calculated for the phase angles, these values never exceeded $15.9 \%$, but again, were typically much lower. 
Table 13: Dynamic Modulus values at each test temperature.

\begin{tabular}{|c|c|c|c|c|c|c|c|c|c|c|c|c|c|c|c|}
\hline \multirow[b]{2}{*}{ Mix Type } & \multirow[b]{2}{*}{ Sample } & \multicolumn{3}{|c|}{$4^{\circ} \mathrm{C}$} & \multicolumn{3}{|c|}{$20^{\circ} \mathrm{C}$} & \multicolumn{4}{|c|}{$40^{\circ} \mathrm{C}^{*}$} & \multicolumn{4}{|c|}{$45^{\circ} \mathrm{C}^{*}$} \\
\hline & & 10 & 1.0 & 0.1 & 10 & 1.0 & 0.1 & 10 & 1.0 & 0.1 & 0.01 & 10 & 1.0 & 0.1 & 0.01 \\
\hline \multirow{3}{*}{$\begin{array}{l}\text { PG } 70-22 \\
9.5 \mathrm{~mm}\end{array}$} & DM 1 & 12,459 & 9,144 & 6,124 & 6,249 & 3,562 & 1,810 & 1,786 & 760 & 315 & 147 & & & & \\
\hline & $\mathrm{DM} 2$ & 13,199 & 9,825 & 6,671 & 5,613 & 3,123 & 1,539 & 1,436 & 605 & 258 & 128 & & & & \\
\hline & DM 3 & 13,939 & 10,173 & 6,770 & 6,134 & 3,404 & 1,678 & 1,594 & 672 & 283 & 139 & & & & \\
\hline \multirow{3}{*}{$\begin{array}{c}\text { PG 70-22 } \\
12.5 \mathrm{~mm}\end{array}$} & DM 1 & 11,342 & 8,061 & 5,204 & 3,754 & 1,895 & 894 & 972 & 393 & 169 & 95 & & & & \\
\hline & DM 2 & 12,283 & 8,589 & 5,487 & 4,429 & 2,285 & 1,088 & 1,011 & 412 & 178 & 99 & & & & \\
\hline & DM 3 & 12,505 & 9,122 & 6,078 & 5,142 & 2,769 & 1,359 & 1,195 & 508 & 222 & 113 & & & & \\
\hline \multirow{3}{*}{$\begin{array}{c}\text { PG 70-22 PM } \\
\quad 9.5 \mathrm{~mm}\end{array}$} & DM 1 & 10,243 & 7,342 & 4,795 & 4,275 & 2,260 & 1,081 & 874 & 366 & 172 & 102 & & & & \\
\hline & $\mathrm{DM} 2$ & 12,295 & 8,681 & 5,584 & 4,754 & 2,510 & 1,214 & 924 & 391 & 185 & 114 & & & & \\
\hline & DM 3 & 11,024 & 7,941 & 5,222 & 4,357 & 2,320 & 1,121 & 949 & 407 & 195 & 119 & & & & \\
\hline \multirow{3}{*}{$\begin{array}{c}\text { PG } 70-22 \mathrm{PM} \\
12.5 \mathrm{~mm}\end{array}$} & DM 1 & 11,232 & 7,964 & 5,150 & 4,502 & 2,391 & 1,165 & 996 & 429 & 210 & 128 & & & & \\
\hline & $\mathrm{DM} 2$ & 11,168 & 7,860 & 5,048 & 4,373 & 2,292 & 1,086 & 943 & 401 & 193 & 117 & & & & \\
\hline & DM 3 & 10,142 & 7,242 & 4,688 & 3,832 & 1,979 & 935 & 869 & 365 & 173 & 106 & & & & \\
\hline \multirow{3}{*}{$\begin{array}{c}\text { PG 76-22 PM } \\
\quad 9.5 \mathrm{~mm}\end{array}$} & DM 1 & 9,788 & 6,850 & 4,381 & 3,252 & 1,607 & 763 & & & & & 664 & 297 & 165 & 113 \\
\hline & $\mathrm{DM} 2$ & 11,857 & 8,518 & 5,600 & 5,013 & 2,735 & 1,364 & & & & & 1,039 & 472 & 252 & 156 \\
\hline & DM 3 & 11,717 & 8,307 & 5,353 & 4,340 & 2,243 & 1,079 & & & & & 751 & 337 & 185 & 124 \\
\hline \multirow{3}{*}{$\begin{array}{c}\text { PG 76-22 PM } \\
12.5 \mathrm{~mm}\end{array}$} & DM 1 & 10,110 & 7,130 & 4,597 & 3,549 & 1,762 & 840 & & & & & 641 & 288 & 160 & 111 \\
\hline & $\mathrm{DM} 2$ & 11,063 & 7,763 & 4,984 & 3,852 & 1,958 & 949 & & & & & 770 & 343 & 195 & 131 \\
\hline & DM 3 & 10,324 & 7,295 & 4,709 & 3,895 & 1,995 & 958 & & & & & 737 & 338 & 187 & 121 \\
\hline
\end{tabular}

*Per the test protocol the highest temperature for the PG 76-22 PM samples was $45^{\circ} \mathrm{C}$ rather than $40^{\circ} \mathrm{C}$ used for the other samples. 
Table 14: Dynamic Modulus averages, standard deviations, and coefficients of variation

\begin{tabular}{|c|c|c|c|c|c|c|c|c|c|c|c|c|c|c|c|}
\hline \multirow[b]{3}{*}{ Mix Type } & & \multicolumn{14}{|c|}{ Test Temperature } \\
\hline & & \multicolumn{3}{|c|}{$4^{\circ} \mathrm{C}$} & \multicolumn{3}{|c|}{$20^{\circ} \mathrm{C}$} & \multicolumn{4}{|c|}{$40^{\circ} \mathrm{C}^{*}$} & \multicolumn{4}{|c|}{$45^{\circ} \mathrm{C}^{*}$} \\
\hline & & 10 & 1 & 0.1 & 10 & 1 & 0.1 & 10 & 1 & 0.1 & 0.01 & 10 & 1 & 0.1 & 0.01 \\
\hline \multirow{3}{*}{$\begin{array}{l}\text { PG 70-22 } \\
9.5 \mathrm{~mm}\end{array}$} & Avg. & 13,199 & 9,714 & 6,522 & 5,999 & 3,363 & 1,676 & 1,605 & 679 & 285 & 138 & & & & \\
\hline & $\mathrm{SD}$ & 604 & 427 & 284 & 277 & 182 & 111 & 143 & 63 & 23 & 8 & & & & \\
\hline & CV (\%) & $4.6 \%$ & $4.4 \%$ & $4.4 \%$ & $4.6 \%$ & $5.4 \%$ & $6.6 \%$ & $8.9 \%$ & $9.4 \%$ & $8.2 \%$ & $5.7 \%$ & & & & \\
\hline \multirow{3}{*}{$\begin{array}{c}\text { PG } 70-22 \\
12.5 \mathrm{~mm}\end{array}$} & Avg. & 12,043 & 8,591 & 5,590 & 4,442 & 2,316 & 1,114 & 1,059 & 438 & 190 & 102 & & & & \\
\hline & $\mathrm{SD}$ & 504 & 433 & 364 & 567 & 357 & 191 & 97 & 51 & 23 & 8 & & & & \\
\hline & CV (\%) & $4.2 \%$ & $5.0 \%$ & $6.5 \%$ & $12.8 \%$ & $15.4 \%$ & $17.1 \%$ & $9.2 \%$ & $11.6 \%$ & $12.1 \%$ & $7.6 \%$ & & & & \\
\hline \multirow{3}{*}{$\begin{array}{c}\text { PG } 70-22 \text { PM } \\
9.5 \mathrm{~mm}\end{array}$} & Avg. & 11,187 & 7,988 & 5,200 & 4,462 & 2,363 & 1,139 & 916 & 388 & 184 & 111 & & & & \\
\hline & SD & 846 & 548 & 322 & 209 & 107 & 56 & 31 & 17 & 9 & 7 & & & & \\
\hline & CV (\%) & $7.6 \%$ & $6.9 \%$ & $6.2 \%$ & $4.7 \%$ & $4.5 \%$ & $4.9 \%$ & $3.4 \%$ & $4.4 \%$ & $5.1 \%$ & $6.6 \%$ & & & & \\
\hline \multirow{3}{*}{$\begin{array}{c}\text { PG 70-22 PM } \\
12.5 \mathrm{~mm}\end{array}$} & Avg. & 10,847 & 7,689 & 4,962 & 4,236 & 2,221 & 1,062 & 936 & 398 & 192 & 117 & & & & \\
\hline & SD & 499 & 319 & 198 & 290 & 176 & 95 & 52 & 26 & 15 & 9 & & & & \\
\hline & CV (\%) & $4.6 \%$ & $4.1 \%$ & $4.0 \%$ & $6.9 \%$ & $7.9 \%$ & $9.0 \%$ & $5.6 \%$ & $6.6 \%$ & $7.8 \%$ & $7.7 \%$ & & & & \\
\hline \multirow{3}{*}{$\begin{array}{c}\text { PG 76-22 PM } \\
9.5 \mathrm{~mm}\end{array}$} & Avg. & 11,121 & 7,892 & 5,111 & 4,202 & 2,195 & 1,069 & & & & & 818 & 369 & 201 & 131 \\
\hline & SD & 944 & 742 & 526 & 726 & 462 & 246 & & & & & 160 & 75 & 37 & 18 \\
\hline & CV (\%) & $8.5 \%$ & $9.4 \%$ & $10.3 \%$ & $17.3 \%$ & $21.0 \%$ & $23.0 \%$ & & & & & $19.6 \%$ & $20.3 \%$ & $18.6 \%$ & $13.8 \%$ \\
\hline \multirow{3}{*}{$\begin{array}{c}\text { PG 76-22 PM } \\
12.5 \mathrm{~mm}\end{array}$} & Avg. & 10,499 & 7,396 & 4,763 & 3,765 & 1,905 & 916 & & & & & 716 & 323 & 180 & 121 \\
\hline & SD & 408 & 268 & 163 & 154 & 102 & 54 & & & & & 55 & 25 & 15 & 8 \\
\hline & CV $(\%)$ & $3.9 \%$ & $3.6 \%$ & $3.4 \%$ & $4.1 \%$ & $5.4 \%$ & $5.9 \%$ & & & & & $7.6 \%$ & $7.7 \%$ & $8.1 \%$ & $6.7 \%$ \\
\hline
\end{tabular}

*Per the test protocol the highest temperature for the PG 76-22 PM samples was $45^{\circ} \mathrm{C}$ rather than $40^{\circ} \mathrm{C}$ used for the other samples. 
Table 15: Phase Angle averages, standard deviations, and coefficients of variation

\begin{tabular}{|c|c|c|c|c|c|c|c|c|c|c|c|c|c|c|c|}
\hline \multirow[b]{3}{*}{ Binder Type } & & \multicolumn{14}{|c|}{ Test Temperature } \\
\hline & & \multicolumn{3}{|c|}{$4^{\circ} \mathrm{C}$} & \multicolumn{3}{|c|}{$20^{\circ} \mathrm{C}$} & \multicolumn{4}{|c|}{$40^{\circ} \mathrm{C}^{*}$} & \multicolumn{4}{|c|}{$45^{\circ} \mathrm{C}^{*}$} \\
\hline & & 10 & 1 & 0.1 & 10 & 1 & 0.1 & 10 & 1 & 0.1 & 0.01 & 10 & 1 & 0.1 & 0.01 \\
\hline \multirow{3}{*}{$\begin{array}{l}\text { PG } 70-22 \\
9.5 \mathrm{~mm}\end{array}$} & Avg. & 10.89 & 14.53 & 19.36 & 21.59 & 27.20 & 31.10 & 33.88 & 32.72 & 29.29 & 24.70 & & & & \\
\hline & SD & 0.29 & 0.42 & 0.46 & 0.83 & 0.95 & 0.78 & 1.74 & 1.48 & 0.87 & 0.50 & & & & \\
\hline & $\mathrm{CV}(\%)$ & $2.6 \%$ & $2.9 \%$ & $2.4 \%$ & $3.9 \%$ & $3.5 \%$ & $2.5 \%$ & $5.1 \%$ & $4.5 \%$ & $3.0 \%$ & $2.0 \%$ & & & & \\
\hline \multirow{3}{*}{$\begin{array}{c}\text { PG 70-22 } \\
12.5 \mathrm{~mm}\end{array}$} & Avg. & 11.88 & 15.75 & 20.73 & 25.35 & 30.31 & 32.41 & 35.51 & 32.92 & 28.46 & 23.31 & & & & \\
\hline & SD & 0.47 & 0.71 & 0.85 & 1.44 & 1.34 & 0.92 & 0.52 & 0.16 & 0.49 & 0.99 & & & & \\
\hline & CV (\%) & $3.9 \%$ & $4.5 \%$ & $4.1 \%$ & $5.7 \%$ & $4.4 \%$ & $2.8 \%$ & $1.5 \%$ & $0.5 \%$ & $1.7 \%$ & $4.3 \%$ & & & & \\
\hline \multirow{3}{*}{$\begin{array}{c}\text { PG } 70-22 \text { PM } \\
9.5 \mathrm{~mm}\end{array}$} & Avg. & 12.28 & 16.07 & 20.85 & 24.58 & 29.15 & 31.14 & 34.78 & 31.52 & 26.79 & 22.31 & & & & \\
\hline & SD & 0.17 & 0.16 & 0.20 & 0.10 & 0.08 & 0.13 & 0.10 & 0.17 & 0.15 & 0.38 & & & & \\
\hline & CV (\%) & $1.3 \%$ & $1.0 \%$ & $1.0 \%$ & $0.4 \%$ & $0.3 \%$ & $0.4 \%$ & $0.3 \%$ & $0.5 \%$ & $0.5 \%$ & $1.7 \%$ & & & & \\
\hline \multirow{3}{*}{$\begin{array}{c}\text { PG } 70-22 \text { PM } \\
12.5 \mathrm{~mm}\end{array}$} & Avg. & 12.68 & 16.61 & 21.41 & 25.13 & 29.56 & 31.37 & 34.89 & 31.41 & 26.50 & 21.78 & & & & \\
\hline & SD & 0.14 & 0.11 & 0.17 & 0.49 & 0.49 & 0.46 & 0.27 & 0.28 & 0.18 & 0.44 & & & & \\
\hline & CV $(\%)$ & $1.1 \%$ & $0.7 \%$ & $0.8 \%$ & $2.0 \%$ & $1.7 \%$ & $1.5 \%$ & $0.8 \%$ & $0.9 \%$ & $0.7 \%$ & $2.0 \%$ & & & & \\
\hline \multirow{3}{*}{$\begin{array}{c}\text { PG 76-22 PM } \\
9.5 \mathrm{~mm}\end{array}$} & Avg. & 12.39 & 16.26 & 20.90 & 25.15 & 29.32 & 30.67 & & & & & 34.09 & 30.06 & 28.44 & 20.70 \\
\hline & SD & 0.38 & 0.56 & 0.67 & 1.57 & 1.37 & 0.72 & & & & & 0.50 & 0.23 & 4.53 & 0.40 \\
\hline & $\mathrm{CV}(\%)$ & $3.1 \%$ & $3.4 \%$ & $3.2 \%$ & $6.2 \%$ & $4.7 \%$ & $2.4 \%$ & & & & & $1.5 \%$ & $0.8 \%$ & $15.9 \%$ & $2.0 \%$ \\
\hline \multirow{3}{*}{$\begin{array}{c}\text { PG 76-22 PM } \\
12.5 \mathrm{~mm}\end{array}$} & Avg. & 12.87 & 16.84 & 21.58 & 26.35 & 30.41 & 31.30 & & & & & 33.85 & 29.89 & 24.97 & 20.42 \\
\hline & $\mathrm{SD}$ & 0.14 & 0.16 & 0.27 & 0.46 & 0.48 & 0.37 & & & & & 0.90 & 0.99 & 0.64 & 0.63 \\
\hline & CV $(\%)$ & $1.1 \%$ & $0.9 \%$ & $1.2 \%$ & $1.7 \%$ & $1.6 \%$ & $1.2 \%$ & & & & & $2.7 \%$ & $3.3 \%$ & $2.6 \%$ & $3.1 \%$ \\
\hline
\end{tabular}

*Per the test protocol the highest temperature for the PG 76-22 PM samples was $45^{\circ} \mathrm{C}$ rather than $40^{\circ} \mathrm{C}$ used for the other samples. 
The average dynamic modulus for the replicate samples were calculated based on frequency and mix type, then plotted by temperature. These plots are provided in Figures 12 through 14. From these plots, it is easy to compare the mix types by temperature and frequency. At higher frequencies, all mix types obviously had higher dynamic modulus values. This trend was expected and has been found in most testing that has been performed in the WVU Asphalt Technology Laboratory (Dalton, 2016) (Smith, 2015) (Turner, 2015). It is also apparent that at all testing temperatures, the PG 70-22 $9.5 \mathrm{~mm}$ mix type had the highest dynamic modulus, while the PG 76-22 PM $12.5 \mathrm{~mm}$ had the lowest. As discussed in the literature review, it is generally accepted that modifiers can improve performance against rutting and fatigue and therefore should also demonstrate an improvement in dynamic modulus testing. This result is contradictory to what was expected due to the differences in binder grades, as well as the addition of polymer modifiers. The research performed by Turner (2015) exhibited expected results of the non-modified binder having lower dynamic modulus than the PG 76-22 PM binder type.

All samples were further analyzed by mix type using the Mastersolver Version 2.2 workbook that was published by Bonaquist (2011b). This workbook requires entering data collected from the exported files from the AMPT software. Excel's solver tool is then used to generate the master curves. The final curve uses a reduced frequency and five parameters; $\beta, \gamma$, $\mathrm{E}_{\min }, \mathrm{E}_{\max }$, and $\Delta \mathrm{EA}$. These five parameters are provided in Table 16 based on mix type. Along with the parameters used to develop the MasterCurves, a goodness of fit output is displayed as well. 
Low Temperature $4^{\circ} \mathrm{C}$

-

- - PG 70-22 PM 12.5 mm Average
$-\square-P G$ 70-22 $12.5 \mathrm{~mm}$ Average

$\neg$-PG 76-22 PM 9.5 mm Average
-PG 70-22 PM 9.5 mm Average $\triangle-$ PG 76-22 PM $12.5 \mathrm{~mm}$ Average

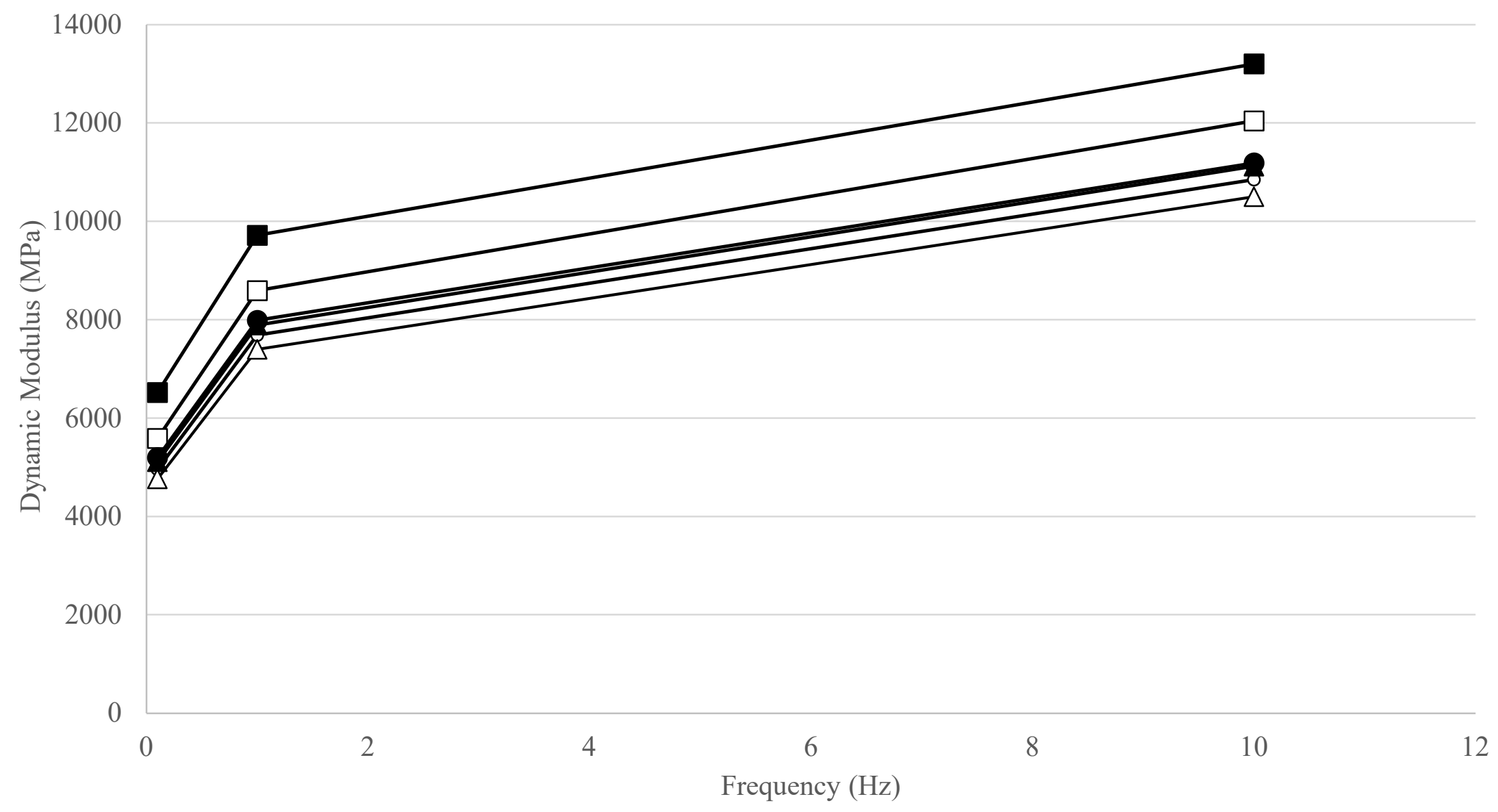

Figure 12: Average Dynamic Modulus at the lowest testing temperature, or $4^{\circ} \mathrm{C}$. 


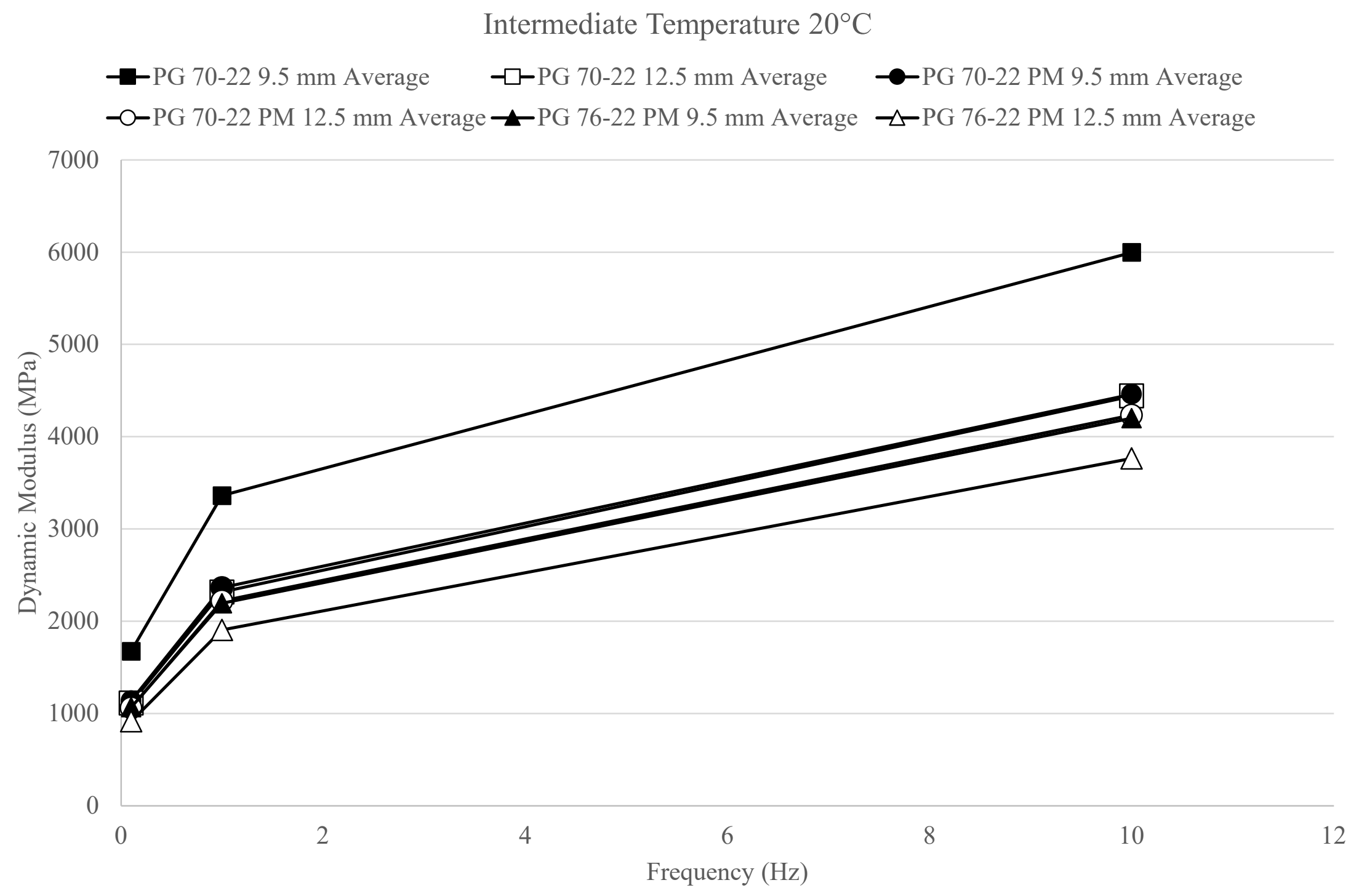

Figure 13: Average Dynamic Modulus at the intermediate testing temperature, or $20^{\circ} \mathrm{C}$. 


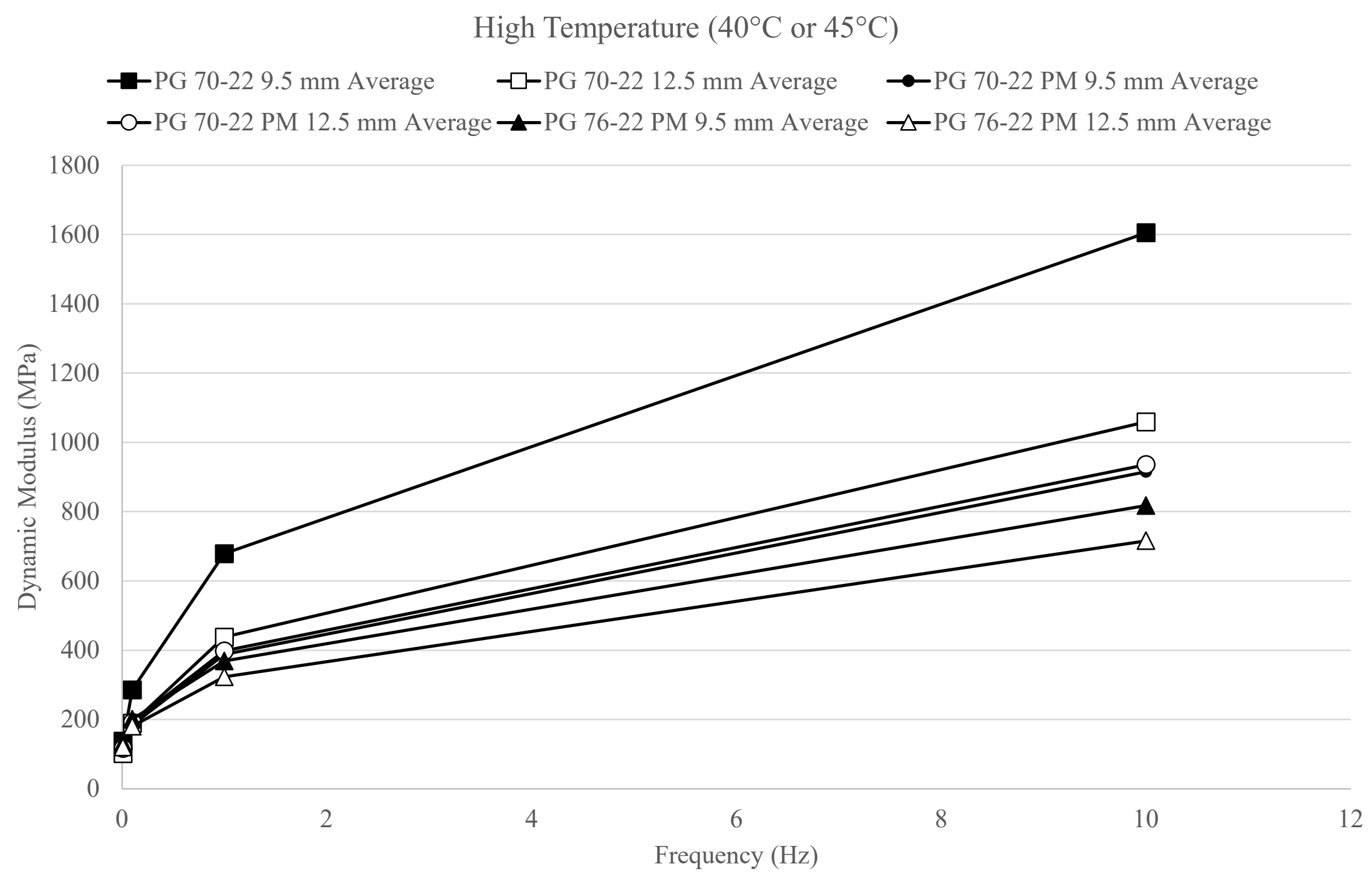

Figure 14: Average Dynamic Modulus at the highest testing temperature, which was $40^{\circ} \mathrm{C}$ for PG 70-22 and PG 70-22 PM binder types, and $45^{\circ} \mathrm{C}$ for the $P G$ 76-22 PM binder type. 
Table 16: Master Curve final parameters

\begin{tabular}{|c|c|c|c|c|c|c|c|c|}
\hline & \multicolumn{2}{|c|}{ Goodness of Fit } \\
\hline Binder Type & NMAS & $\begin{array}{c}\text { Max E* } \\
(\mathrm{ksi})\end{array}$ & $\begin{array}{c}\text { Min } E^{*} \\
(\mathrm{ksi})\end{array}$ & $\beta$ & $\gamma$ & $\Delta \mathrm{EA}$ & $\mathrm{R}^{2}$ & $\mathrm{~S}_{\mathrm{e}} / \mathrm{S}_{\mathrm{y}}$ \\
\hline \multirow{2}{*}{ PG 70-22 } & 9.5 & 3114.2 & 3.5 & -1.02615 & -0.50489 & 186518 & 0.9978 & 0.03 \\
\hline & 12.5 & 3123.4 & 3.9 & -0.76526 & -0.51003 & 193866 & 0.9934 & 0.06 \\
\hline \multirow{2}{*}{ PG 70-22 PM } & 9.5 & 3123.8 & 4.3 & -0.70157 & -0.48597 & 206527 & 0.9986 & 0.03 \\
\hline & 12.5 & 3126.7 & 5 & -0.63605 & -0.49319 & 199898 & 0.9976 & 0.03 \\
\hline \multirow{2}{*}{ PG 76-22 PM } & 9.5 & 3111.5 & 8.9 & -0.52479 & -0.52602 & 184575 & 0.9912 & 0.07 \\
\hline & 12.5 & 3121.3 & 8.8 & -0.43464 & -0.52658 & 186385 & 0.9887 & 0.08 \\
\hline
\end{tabular}

All Master Curves for a reference temperature of $20^{\circ} \mathrm{C}$ were consolidated into one plot for comparison, Figure 15. All curves are very consistent with little to no variation between binder type or NMAS. Similar to the results found by Dalton (2016), there is a higher variation at lower frequencies and converging at the higher frequencies. 


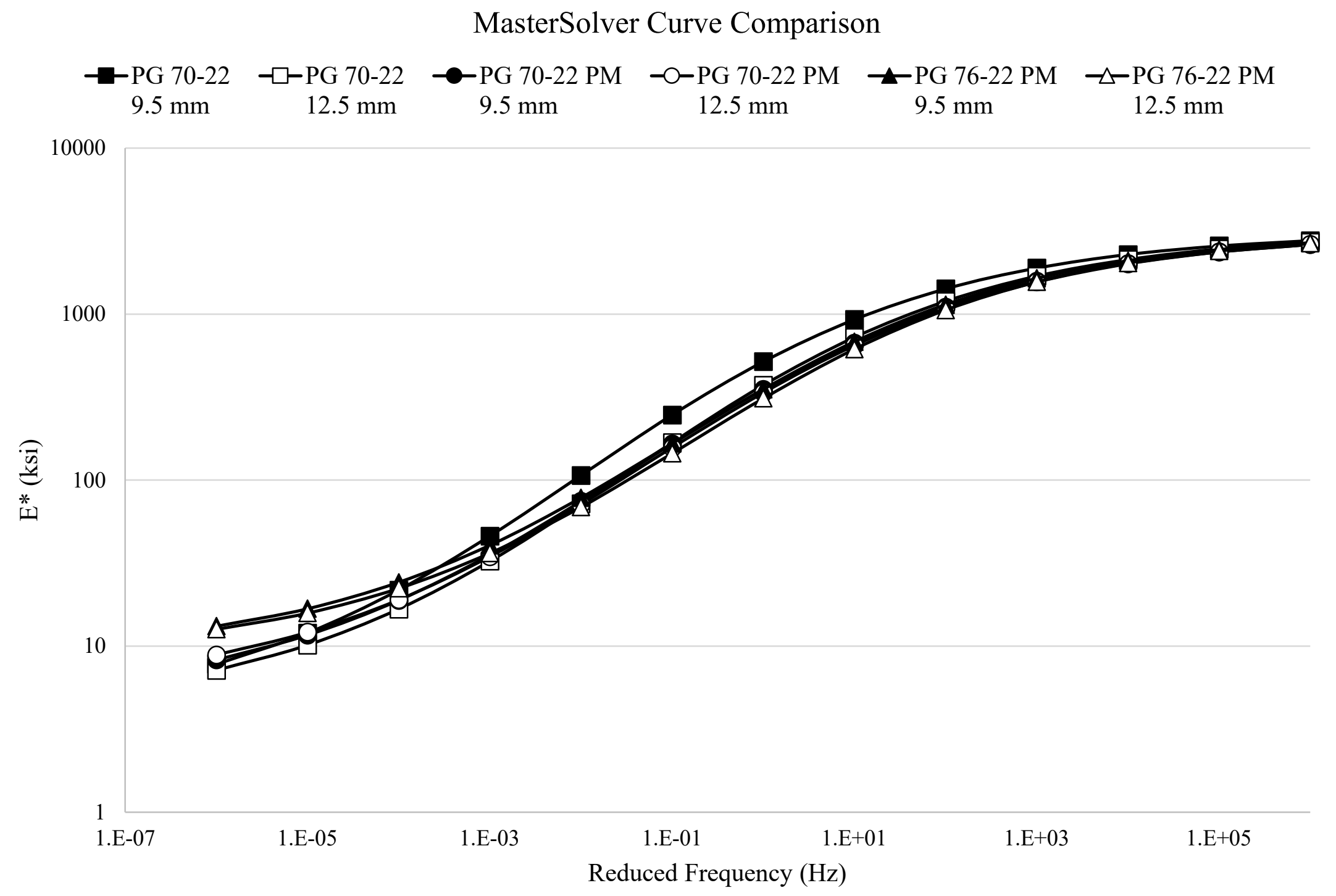

Figure 15: Dynamic Modulus Master Curves created using a reference temperature of $20^{\circ} \mathrm{C}$. 
To determine the dynamic modulus from the mastercurves, a frequency must be calculated using the inverse of the duration equation which is provided as Equation 4 (Huang, 2004). The parameters used in this equation are defined as a dual axle loading with a 4,500pound load per tire (18-kip ESAL) and 110 psi tire pressure. The contact radius is 3.61 inches, and the vehicle was assumed to be traveling at a speed of $55 \mathrm{mph}$. This equation yields a frequency of $1.866 \mathrm{~Hz}$. The values calculated are provided in Table 17. The parameters used to calculate the frequency are provided in Table 18.

$$
d=\frac{12 a}{s}
$$

Where:

$$
\begin{aligned}
& d=\text { duration (seconds) } \\
& a=\text { contact radius (in) } \\
& s=\operatorname{speed~(ft/s)}
\end{aligned}
$$

Table 17: Dynamic Modulus values calculated.

\begin{tabular}{|c|c|c|c|}
\hline Binder Type & NMAS & $\mathbf{E}^{*}(\mathbf{k s i})$ & $\mathbf{E}^{*}(\mathbf{M P a})$ \\
\hline PG70-22 & $9.5 \mathrm{~mm}$ & 616 & 4252 \\
\hline PG70-22 & $12.5 \mathrm{~mm}$ & 454 & 3130 \\
\hline PG70-22 PM & $9.5 \mathrm{~mm}$ & 425 & 2932 \\
\hline PG70-22 PM & $12.5 \mathrm{~mm}$ & 407 & 2807 \\
\hline PG76-22 PM & $9.5 \mathrm{~mm}$ & 427 & 2946 \\
\hline PG76-22 PM & $12.5 \mathrm{~mm}$ & 378 & 2608 \\
\hline
\end{tabular}

Table 18: Values used to calculate Frequency.

\begin{tabular}{|c|rl|}
\hline Axle Type & Dual Axle \\
\hline Load & 4,500 & lbs. \\
\hline Tire Pressure & 110 & Psi \\
\hline Contact Radius & 3.61 & Inches \\
\hline Speed & 55 & $\mathrm{Mph}$ \\
\hline Frequency & 1.866 & $\mathrm{~Hz}$ \\
\hline
\end{tabular}

\section{Fatigue}

The fatigue test protocol (as embodied in the software purchased from InstroTek $\mathbb{C}$ used in this research terminates the testing when one of three failure criterion is achieved:

1) $10 \%$ of the initial dynamic modulus is reached,

2) an increase in phase angle followed by an immediate drop, or

$3)$ the number of cycles exceeding 100,000. 
The test can be prematurely terminated due to testing issues such as an LVDT signal error or separation of the sample from the platen.

A summary of fatigue testing is displayed in Tables 19 through 21. Most samples either met the maximum number of cycles or ten percent modulus. One sample had an LVDT error and another had end platen separation. However, both these samples met the phase angle drop criteria before the issue occurred. Therefore, their results were kept in the data set.

Only two replicates of the PG 76-22 PM 9.5 mm mix type were tested as the VTM of one sample was outside of the accepted range for air voids. It was decided that introducing new materials would possibly create more variability to the results, therefore a replacement sample was not made. Not analyzing this replicate may have impacted the accuracy of the analysis when compared to the other mix types but will not be further explored. A replacement sample was not prepared due to time and material constraints. 
Table 19: Fatigue testing compilation for PG 70-22 binder type.

\begin{tabular}{|c|c|c|c|c|c|c|c|}
\hline Mix Type & $\begin{array}{c}\text { Sample } \\
\text { Designation }\end{array}$ & $\begin{array}{c}\text { Air } \\
\text { Voids } \\
(\%) \\
\end{array}$ & $\mu($ strain $)$ & $\begin{array}{c}\text { Cycles at } \\
\text { Failure }\end{array}$ & $\begin{array}{c}\text { Initial } \\
\text { Dynamic } \\
\text { Modulus }\end{array}$ & $\begin{array}{c}\text { Final Dynamic } \\
\text { Modulus }\end{array}$ & Notes \\
\hline \multirow{9}{*}{$\begin{array}{l}\text { PG 70-22 } \\
9.5 \mathrm{~mm}\end{array}$} & FT 1A & 6.6 & 300 & 26,360 & 7,623 & $1,100.0$ & LVDT \#2 Signal Error. Phase Angle drop. \\
\hline & FT 1B & 6.7 & 400 & 7,800 & 5,194 & $3,504.0$ & Bottom End Platen broke off. Phase Angle drop. \\
\hline & FT 1C & 6.6 & 350 & 20,280 & 5,570 & 550.1 & Completed 10\% Modulus criteria. \\
\hline & FT 2A & 6.8 & 300 & 35,480 & 6,419 & 636.6 & Completed 10\% Modulus criteria. \\
\hline & FT 2B & 6.6 & 400 & 8,980 & 5,694 & 564.8 & Completed 10\% Modulus criteria. \\
\hline & FT $2 \mathrm{C}$ & 6.5 & 350 & 13,280 & 6,990 & 685.1 & Completed 10\% Modulus criteria. \\
\hline & FT 3A & 6.5 & 300 & 47,100 & 5,770 & 573.4 & Completed 10\% Modulus criteria. \\
\hline & FT 3B & 6.7 & 400 & 3,510 & 6,618 & 625.3 & Bottom End Platen had to be re-glued. \\
\hline & FT 3C & 6.7 & 350 & 16,460 & 5,767 & 571.8 & Completed 10\% Modulus criteria. \\
\hline \multirow{9}{*}{$\begin{array}{l}\text { PG } 70-22 \\
12.5 \mathrm{~mm}\end{array}$} & FT 1A & 6.6 & 300 & 24,680 & 7,449 & 740.1 & Completed 10\% Modulus criteria. \\
\hline & FT 1B & 6.0 & 400 & 5,530 & 6,844 & 668.0 & Completed 10\% Modulus criteria. \\
\hline & FT 1C & 6.3 & 350 & 13,570 & 7,187 & 704.3 & Completed 10\% Modulus criteria. \\
\hline & FT 2A & 6.6 & 300 & 32,150 & 6,280 & 623.9 & Completed $10 \%$ Modulus criteria. \\
\hline & FT 2B & 6.7 & 400 & 2,940 & 6,558 & 648.8 & Completed 10\% Modulus criteria. \\
\hline & FT $2 \mathrm{C}$ & 6.7 & 350 & 10,140 & 7,008 & 693.9 & Completed 10\% Modulus criteria. \\
\hline & FT 3A & 7.1 & 300 & 37,200 & 5,984 & 596.2 & Completed 10\% Modulus criteria. \\
\hline & FT 3B & 6.5 & 400 & 4,560 & 6,666 & 644.9 & Completed 10\% Modulus criteria. \\
\hline & FT 3C & 7.3 & 350 & 16,510 & 5,678 & 561.0 & Completed 10\% Modulus criteria. \\
\hline
\end{tabular}


Table 20: Fatigue testing compilation for PG 70-22 PM binder type.

\begin{tabular}{|c|c|c|c|c|c|c|c|}
\hline Mix Type & $\begin{array}{c}\text { Sample } \\
\text { Designation }\end{array}$ & $\begin{array}{l}\text { Air Voids } \\
\quad(\%)\end{array}$ & $\mu($ strain $)$ & $\begin{array}{l}\text { Cycles at } \\
\text { Failure }\end{array}$ & $\begin{array}{c}\text { Initial } \\
\text { Dynamic } \\
\text { Modulus }\end{array}$ & $\begin{array}{c}\text { Final Dynamic } \\
\text { Modulus }\end{array}$ & Notes \\
\hline \multirow{9}{*}{$\begin{array}{c}\text { PG 70-22 PM } \\
9.5 \mathrm{~mm}\end{array}$} & FT 1A & 6.6 & 300 & 99,610 & 5,581 & 557.9 & Completed $10 \%$ Modulus criteria. \\
\hline & FT 1B & 6.8 & 400 & 17,780 & 5,122 & 511.0 & Completed $10 \%$ Modulus criteria. \\
\hline & FT $1 \mathrm{C}$ & 7.2 & 350 & 36,950 & 5,341 & 530.6 & Completed 10\% Modulus criteria. \\
\hline & FT 2A & 6.8 & 300 & 99,810 & 5,436 & 542.2 & Completed 10\% Modulus criteria. \\
\hline & FT 2B & 6.6 & 400 & 16,450 & 4,991 & 496.0 & Completed $10 \%$ Modulus criteria. \\
\hline & FT $2 \mathrm{C}$ & 6.3 & 350 & 24,050 & 5,631 & 558.0 & Completed $10 \%$ Modulus criteria. \\
\hline & FT 3A & 6.7 & 300 & 83,370 & 5,687 & 568.7 & Completed $10 \%$ Modulus criteria. \\
\hline & FT 3B & 6.8 & 400 & 15,570 & 5,359 & 535.1 & Completed 10\% Modulus criteria. \\
\hline & FT 3C & 6.8 & 350 & 25,140 & 5,719 & 568.9 & Completed 10\% Modulus criteria. \\
\hline \multirow{9}{*}{$\begin{array}{c}\text { PG 70-22 PM } \\
12.5 \mathrm{~mm}\end{array}$} & FT 1A & 6.6 & 300 & 93,380 & 5,393 & 538.3 & Completed $10 \%$ Modulus criteria. \\
\hline & FT 1B & 6.2 & 400 & 18,220 & 5,234 & 519.9 & Completed 10\% Modulus criteria. \\
\hline & FT $1 \mathrm{C}$ & 6.6 & 350 & 29,310 & 5,405 & 536.8 & Completed $10 \%$ Modulus criteria. \\
\hline & FT 2A & 6.6 & 300 & 86,640 & 5,205 & 518.8 & Completed $10 \%$ Modulus criteria. \\
\hline & FT 2B & 6.7 & 400 & 18,100 & 5,302 & 526.8 & Completed $10 \%$ Modulus criteria. \\
\hline & FT $2 \mathrm{C}$ & 7.5 & 350 & 61,290 & 4,802 & 479.4 & Completed 10\% Modulus criteria. \\
\hline & FT 3A & 6.7 & 300 & 94,390 & 5,229 & 521.5 & Completed 10\% Modulus criteria. \\
\hline & FT 3B & 6.7 & 400 & 15,770 & 5,165 & 512.3 & Completed $10 \%$ Modulus criteria. \\
\hline & FT 3C & 7.3 & 350 & 31,250 & 5,076 & 506.7 & Completed $10 \%$ Modulus criteria. \\
\hline
\end{tabular}


Table 21: Fatigue testing compilation for PG 76-22 PM binder type.

\begin{tabular}{|c|c|c|c|c|c|c|c|}
\hline Mix Type & $\begin{array}{c}\text { Sample } \\
\text { Designation }\end{array}$ & $\begin{array}{c}\text { Air Voids } \\
\quad(\%)\end{array}$ & $\mu($ strain $)$ & $\begin{array}{l}\text { Cycles at } \\
\text { Failure }\end{array}$ & $\begin{array}{c}\text { Initial Dynamic } \\
\text { Modulus }\end{array}$ & $\begin{array}{c}\text { Final } \\
\text { Dynamic } \\
\text { Modulus }\end{array}$ & Notes \\
\hline \multirow{9}{*}{$\begin{array}{c}\text { PG 76-22 PM } \\
9.5 \mathrm{~mm}\end{array}$} & FT 1A2 & 6.8 & 300 & 100,000 & 5,941 & $1,550.0$ & Completed $10 \%$ Modulus criteria. \\
\hline & FT 1B2 & 6.6 & 450 & 7,630 & 5,298 & 526.7 & Completed $10 \%$ Modulus criteria. \\
\hline & FT 1C & 6.6 & 400 & 21,440 & 5,457 & 544.0 & Completed $10 \%$ Modulus criteria. \\
\hline & FT 2A & 6.3 & 300 & 88,680 & 6,356 & 634.9 & Completed $10 \%$ Modulus criteria. \\
\hline & FT 2B & 6.2 & & & & & Sample not tested. \\
\hline & FT 2C & 6.6 & 350 & 77,670 & 5,239 & 523.0 & Completed $10 \%$ Modulus criteria. \\
\hline & FT 3A & 6.5 & 300 & 100,000 & 5,634 & $2,013.0$ & Completed $10 \%$ Modulus criteria. \\
\hline & FT 3B & 6.5 & 450 & 12,800 & 4,910 & 488.0 & Completed $10 \%$ Modulus criteria. \\
\hline & FT 3C & 6.5 & 400 & 19,100 & 5,338 & 532.7 & Completed 10\% Modulus criteria. \\
\hline \multirow{9}{*}{$\begin{array}{c}\text { PG 76-22 PM } \\
12.5 \mathrm{~mm}\end{array}$} & FT 1A & 6.3 & 300 & 100,000 & 5,415 & $1,934.0$ & Completed 10\% Modulus criteria. \\
\hline & FT 1B & 6.5 & 450 & 11,270 & 4,919 & 491.1 & Completed $10 \%$ Modulus criteria. \\
\hline & FT 1C & 6.3 & 400 & 20,320 & 5,479 & 547.0 & Completed 10\% Modulus criteria. \\
\hline & FT 2A & 6.4 & 300 & 100,000 & 5,939 & $1,230.0$ & Completed 10\% Modulus criteria. \\
\hline & FT 2B & 6.2 & 450 & 19,600 & 4,886 & 488.3 & Completed $10 \%$ Modulus criteria. \\
\hline & FT 2C & 6.3 & 400 & 22,460 & 5,401 & 538.2 & Completed $10 \%$ Modulus criteria. \\
\hline & FT 3A & 6.9 & 300 & 100,000 & 5,152 & $2,218.0$ & Completed 10\% Modulus criteria. \\
\hline & FT 3B & 6.6 & 450 & 11,500 & 5,042 & 501.5 & Completed 10\% Modulus criteria. \\
\hline & FT 3C & 6.3 & 400 & 27,210 & 4,938 & 492.1 & Completed $10 \%$ Modulus criteria. \\
\hline
\end{tabular}




\section{ALPHA-Fatigue}

The damage model parameters used for the S-VECD and $\mathrm{G}^{\mathrm{R}}$ models are given in Table 22. Results are provided for both the default and peak phase angle method of identifying the number of cycles to failure. These parameters are provided for potential use by future researchers.

Table 22: Damage Model Coefficients for both analysis failure criteria

\begin{tabular}{|c|c|c|c|c|c|c|c|c|c|}
\hline \multirow{2}{*}{ Method } & \multicolumn{2}{|c|}{$\mathbf{a}$} & \multicolumn{2}{|c|}{ b } & \multirow{2}{*}{$\alpha$} & \multicolumn{2}{|c|}{$\mathbf{r}$} & \multicolumn{2}{|c|}{$\mathbf{s}$} \\
\hline & Default & Peak & Default & Peak & & Default & Peak & Default & Peak \\
\hline $\begin{array}{l}\text { PG 70-22 } \\
9.5 \mathrm{~mm}\end{array}$ & $-1.29 \mathrm{E}-04$ & $-1.05 \mathrm{E}-04$ & 0.77 & 0.79 & 3.701 & $1.01 \mathrm{E}+05$ & $7.58 \mathrm{E}+05$ & -0.53 & -0.73 \\
\hline $\begin{array}{c}\text { PG 70-22 } \\
12.5 \mathrm{~mm}\end{array}$ & $-3.43 \mathrm{E}-04$ & $-2.28 \mathrm{E}-04$ & 0.69 & 0.74 & 3.694 & $9.99 \mathrm{E}+04$ & $5.65 \mathrm{E}+05$ & -0.58 & -0.75 \\
\hline $\begin{array}{c}\text { PG } 70-22 \mathrm{PM} \\
9.5 \mathrm{~mm}\end{array}$ & $-1.19 \mathrm{E}-04$ & $-1.45 \mathrm{E}-04$ & 0.79 & 0.77 & 3.866 & $2.83 \mathrm{E}+04$ & $1.03 \mathrm{E}+06$ & -0.28 & -0.73 \\
\hline $\begin{array}{c}\text { PG 70-22 PM } \\
12.5 \mathrm{~mm}\end{array}$ & $-1.62 \mathrm{E}-04$ & $-1.55 \mathrm{E}-04$ & 0.76 & 0.77 & 3.883 & $2.80 \mathrm{E}+04$ & $9.30 \mathrm{E}+05$ & -0.28 & -0.72 \\
\hline $\begin{array}{c}\text { PG 76-22 PM } \\
9.5 \mathrm{~mm}\end{array}$ & $-2.69 \mathrm{E}-04$ & $-2.36 \mathrm{E}-04$ & 0.71 & 0.72 & 3.947 & $3.19 \mathrm{E}+04$ & $6.79 \mathrm{E}+05$ & -0.30 & -0.64 \\
\hline $\begin{array}{c}\text { PG 76-22 PM } \\
12.5 \mathrm{~mm}\end{array}$ & $-2.31 \mathrm{E}-04$ & $-2.25 \mathrm{E}-04$ & 0.72 & 0.73 & 3.929 & $2.29 \mathrm{E}+04$ & $4.52 \mathrm{E}+05$ & -0.24 & -0.57 \\
\hline
\end{tabular}

The ALPHA-fatigue estimates of endurance limits, in microstrain, are given in Table 23. Though the AMPT fatigue test was run at $15^{\circ} \mathrm{C}, \mathrm{ALPHA}-$ Fatigue uses transfer functions to estimate the endurance limits at other temperatures. A common trend between all mixes and analysis methods is an increase in endurance limit as the temperature increases. Default output values are also much lower than the values obtained with the peak method. The PG 70-22 PM 9.5mm mix type had the highest overall peak values for endurance limit, while the PG 76-22 PM $12.5 \mathrm{~mm}$ had the lowest. This ranking of microstrain is not consistent between the peak and default methods. The only values that compare to accepted ranges were obtained through the peak analysis, therefore, from here forth, only the peak method values will be considered. 
Table 23: Endurance Limits from ALPHA-Fatigue Outputs

\begin{tabular}{|c|c|c|c|c|c|c|c|c|c|c|}
\hline & \multicolumn{7}{|c|}{ Default } & \multicolumn{5}{c|}{ Peak } \\
\hline & $5^{\circ} \mathrm{C}$ & $10^{\circ} \mathrm{C}$ & $15^{\circ} \mathrm{C}$ & $20^{\circ} \mathrm{C}$ & $25^{\circ} \mathrm{C}$ & $5^{\circ} \mathrm{C}$ & $10^{\circ} \mathrm{C}$ & $15^{\circ} \mathrm{C}$ & $20^{\circ} \mathrm{C}$ & $25^{\circ} \mathrm{C}$ \\
\hline $\begin{array}{c}\text { PG 70-22 } \\
9.5 \mathrm{~mm}\end{array}$ & 16 & 17 & 20 & 23 & 29 & 66 & 73 & 89 & 107 & 146 \\
\hline $\begin{array}{c}\text { PG 70-22 } \\
12.5 \mathrm{~mm}\end{array}$ & 19 & 21 & 26 & 31 & 43 & 65 & 77 & 96 & 123 & 179 \\
\hline $\begin{array}{c}\text { PG 70-22 } \\
\text { PM } \\
9.5 \mathrm{~mm}\end{array}$ & 5 & 5 & 6 & 7 & 9 & 85 & 104 & 132 & 174 & 260 \\
\hline $\begin{array}{c}\text { PG 70-22 } \\
\text { PM } \\
12.5 \mathrm{~mm}\end{array}$ & 5 & 5 & 6 & 6 & 8 & 80 & 97 & 125 & 163 & 242 \\
\hline $\begin{array}{c}\text { PG 76-22 } \\
\text { PM } \\
9.5 \mathrm{~mm}\end{array}$ & 4 & 4 & 4 & 5 & 6 & 58 & 67 & 85 & 106 & 149 \\
\hline $\begin{array}{c}\text { PG 76-22 } \\
\text { PM } \\
12.5 \mathrm{~mm}\end{array}$ & 4 & 4 & 5 & 6 & 7 & 39 & 45 & 57 & 71 & 99 \\
\hline
\end{tabular}

A range of strain values, dynamic modulus values from the mastercurves as described previously in Table 17, and the K-values provided in Table 24 were applied to the fatigue failure equation displayed in Equation 5. The plot in Figure 16 and data in Table 25 were produced. The purpose of Figure 16 is to compare life cycles of the different mix types. Along with each of the six mix types, the Asphalt Institute values were also plotted in this method for comparison. The suggested limit of 50 million cycles by Underwood et.al (2012) was included in Figure 16 as a comparison for endurance limit values.

$$
N_{f}=K_{1}\left(\frac{1}{\varepsilon_{t}}\right)^{K_{2}}(E)^{K_{3}}
$$

Where:

$$
\begin{aligned}
& K_{1}, K_{2}, K_{3}=\text { constants } \\
& \varepsilon_{t}=\text { strain } \\
& E=\text { dynamic modulus }
\end{aligned}
$$

While most of the mixes are consistently close to this limitation, the PG 70-22 PM 9.5 mm mix type reached this endurance limitation around 100 microstrain which approximately corresponds to ALPHA-Fatigue's $10^{\circ} \mathrm{C}$ prediction value from the peak method. Not all mixes corresponded to the values that ALPHA-Fatigue gave as a prediction, for example, the PG 76-22 PM $12.5 \mathrm{~mm}$ mix type doesn't cross the endurance limit line at all in this plotted range, 
therefore, the value is below 50 microstrain which is lower than the peak values displayed in Table 24. It should also be noted that almost all mixes begin higher than the Asphalt Institute line, but all of them fall below it at the highest microstrain plotted. This shows that the Asphalt Institute's values may not be exact, but on average, they may be a good indication of the mix design's performance.

\section{KENPAVE Pavement Life Prediction}

Similar to Dalton (2016) and Smith (2015), the dynamic modulus and fatigue data was also analyzed in comparison to results using the KENPAVE software. Following these analyses, modulus versus strain graphs were created for a range of moduli using both conventional and full-depth pavement models which are provided in Figure 17. Subbase material modulus were assumed based on past knowledge and the pavement was analyzed as linear rather than viscoelastic.

The plot of strain versus dynamic modulus for both the conventional and full-depth pavement models are provided in Figure 18. For the conventional pavement the entire surface layer was assumed to be uniform material of each mix type. This assumption was also applied to the full depth pavement. This is a concerning limitation the analysis of the base of the full depth pavement should be a different mix with a larger nominal maximum aggregate size.

The dynamic modulus values from Table 17 were used with Figure 18 to determine the critical fatigue strain for each mix. These strains and dynamic modulus values were used with the peak fatigue $\mathrm{K}$ values from Table 24 in Equation 5 to compute the fatigue life of each pavement. The resulting strain and life expectancy are provided in Table 26.

Calculated values for the full-depth pavement are much lower than the accepted value for perpetual pavements of 70 micro-strain (Witczak et al., 2013). From these values, the full-depth analysis indicates that only the PG 70-22 $9.5 \mathrm{~mm}$ mix design would be considered a perpetual pavement. With an expected fatigue life greater than 5 million ESALS the pavements would be considered suitable for most roads in the state of West Virginia other than interstates. Full-depth pavements consistently had higher fatigue life expectancies than the conventional. 
Table 24: K-Values from ALPHA-Fatigue in units of psi

\begin{tabular}{|c|c|c|c|c|c|c|}
\hline & \multicolumn{3}{|c|}{ Default } & \multicolumn{3}{c|}{ Peak } \\
\cline { 2 - 7 } & $\mathrm{K} 1$ & $\mathrm{~K} 2$ & $\mathrm{~K} 3$ & $\mathrm{~K} 1$ & $\mathrm{~K} 2$ & $\mathrm{~K} 3$ \\
\hline $\begin{array}{c}\text { PG 70-22 } \\
9.5 \mathrm{~mm}\end{array}$ & $3.21 \mathrm{E}+06$ & 3.058 & -2.245 & $5.79 \mathrm{E}+14$ & 5.579 & -4.899 \\
\hline $\begin{array}{c}\text { PG 70-22 } \\
12.5 \mathrm{~mm}\end{array}$ & $1.69 \mathrm{E}+08$ & 3.591 & -2.886 & $1.61 \mathrm{E}+16$ & 6.196 & -5.588 \\
\hline $\begin{array}{c}\text { PG 70-22 PM } \\
9.5 \mathrm{~mm}\end{array}$ & $1.09 \mathrm{E}+05$ & 1.306 & -0.971 & $9.26 \mathrm{E}+16$ & 5.715 & -5.280 \\
\hline $\begin{array}{c}\text { PG 70-22 PM } \\
12.5 \mathrm{~mm}\end{array}$ & $1.35 \mathrm{E}+05$ & 1.291 & -0.978 & $1.36 \mathrm{E}+16$ & 5.428 & -4.990 \\
\hline $\begin{array}{c}\text { PG 76-22 PM } \\
9.5 \mathrm{~mm}\end{array}$ & $2.66 \mathrm{E}+05$ & 1.391 & -1.083 & $3.49 \mathrm{E}+12$ & 4.179 & -3.681 \\
\hline $\begin{array}{c}\text { PG 76-22 PM } \\
12.5 \mathrm{~mm}\end{array}$ & $1.02 \mathrm{E}+05$ & 1.054 & -0.816 & $1.97 \mathrm{E}+10$ & 3.287 & -2.821 \\
\hline
\end{tabular}

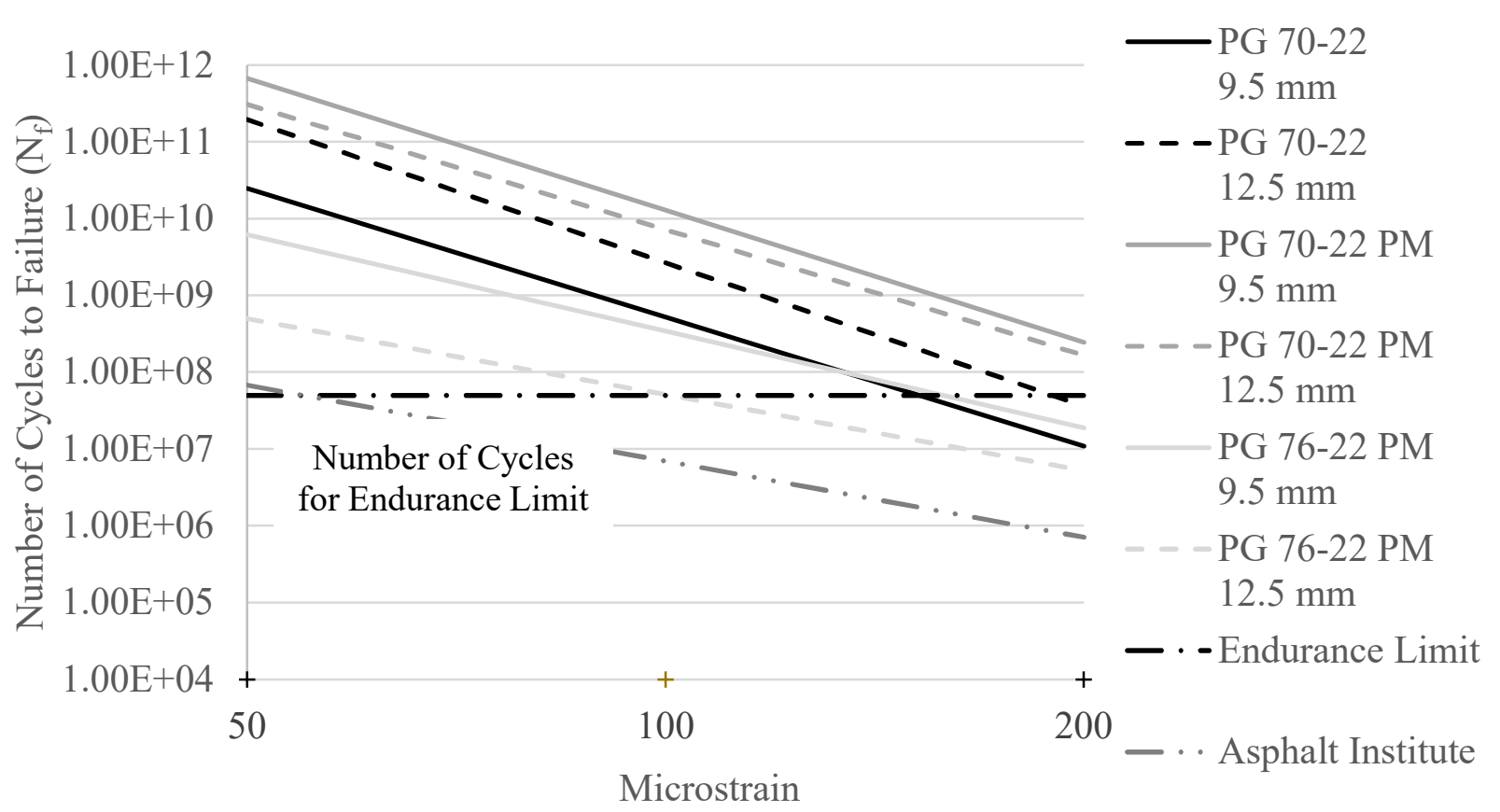

Figure 16: Plot of fatigue equations using peak analyzed K-values and collected Dynamic Modulus values. 
Table 25: $N_{f}$ at 50 microstrain for each mix type

\begin{tabular}{|c|c|}
\hline Mix Type & $\mathbf{N}_{\mathbf{f}}$ \\
\hline $\begin{array}{c}\text { PG 70-22 } \\
9.5 \mathrm{~mm}\end{array}$ & $6.16 \mathrm{E}+08$ \\
\hline $\begin{array}{c}\text { PG 70-22 } \\
12.5 \mathrm{~mm}\end{array}$ & $5.27 \mathrm{E}+08$ \\
\hline $\begin{array}{c}\text { PG 70-22 PM } \\
9.5 \mathrm{~mm}\end{array}$ & $1.77 \mathrm{E}+09$ \\
\hline $\begin{array}{c}\text { PG 70-22 PM } \\
12.5 \mathrm{~mm}\end{array}$ & $9.00 \mathrm{E}+08$ \\
\hline $\begin{array}{c}\text { PG 76-22 PM } \\
9.5 \text { mm }\end{array}$ & $9.98 \mathrm{E}+07$ \\
\hline $\begin{array}{c}\text { PG 76-22 PM } \\
12.5 \text { mm }\end{array}$ & $1.50 \mathrm{E}+07$ \\
\hline Asphalt Institute & $6.78 \mathrm{E}+07$ \\
\hline Shell & $5.91 \mathrm{E}+08$ \\
\hline Illinois DOT & $4.00 \mathrm{E}+07$ \\
\hline TRRL & $6.32 \mathrm{E}+08$ \\
\hline
\end{tabular}
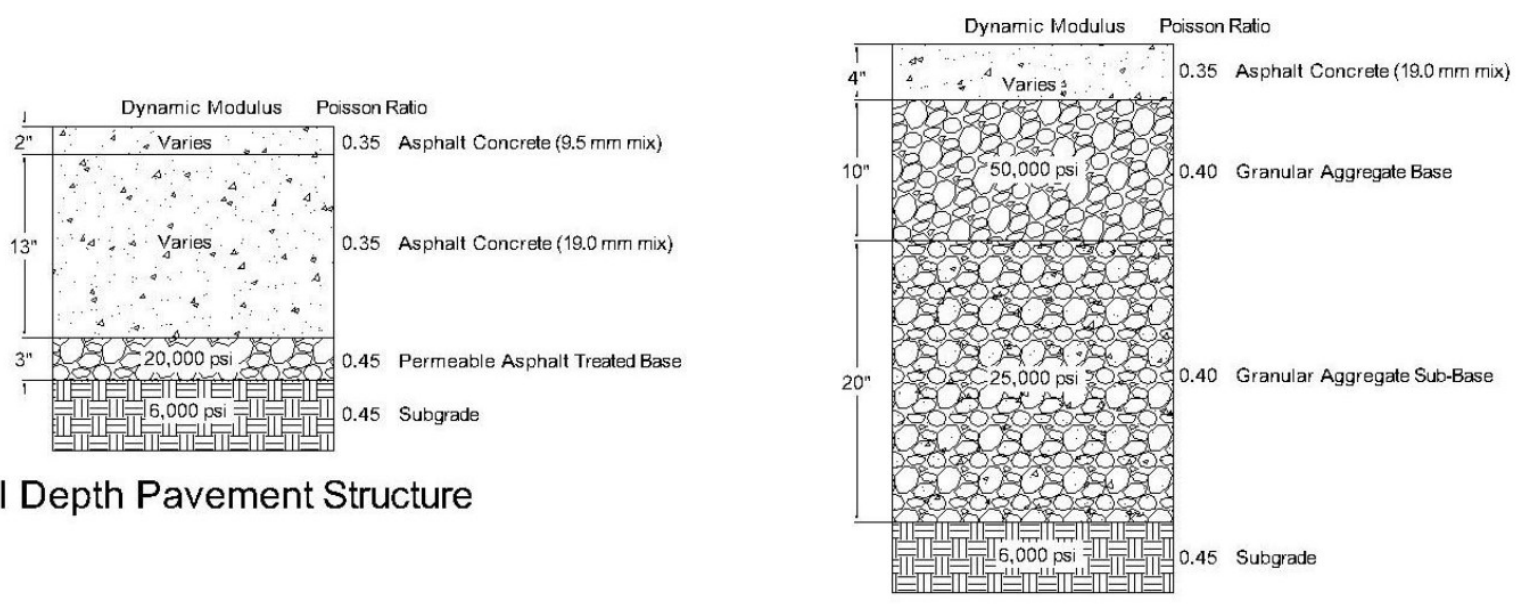

Conventional Pavement Structure

Figure 17: Full-Depth and Conventional Pavement Structures used in KENPAVE analysis. 


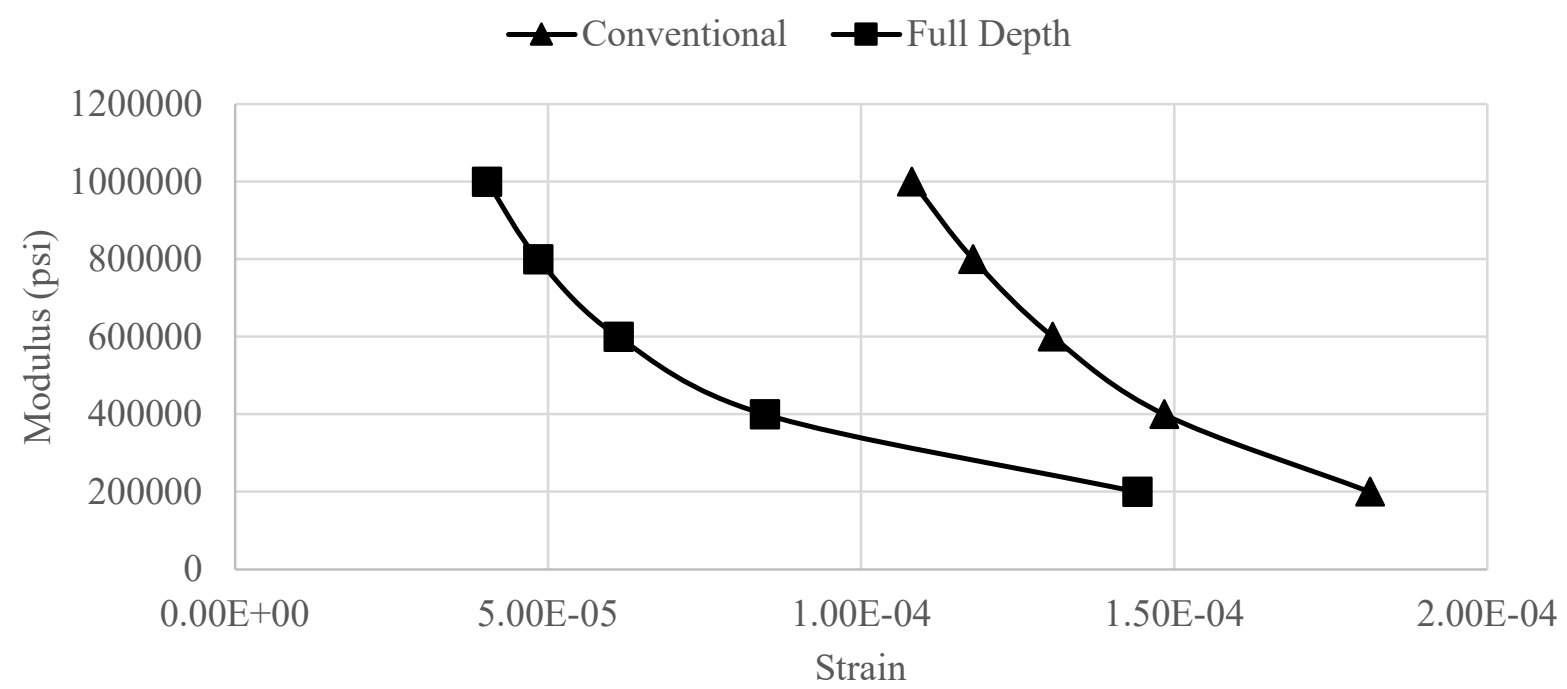

Figure 18: Modulus versus Strain for Convention and Full-Depth pavement models.

Table 26: KENPAVE Full-Depth and Conventional $N_{f}$ values

\begin{tabular}{|c|c|c|c|c|c|}
\cline { 2 - 6 } Mix Type & E (ksi) & $\begin{array}{c}\text { Strain } \\
\text { (Microstrain) }\end{array}$ & $\mathbf{N}_{\mathbf{f}}$ & $\begin{array}{c}\text { Strain } \\
\text { (Microstrain) }\end{array}$ & $\mathbf{N}_{\mathbf{f}}$ \\
\hline $\begin{array}{c}\text { PG 70-22 } \\
9.5 \mathrm{~mm}\end{array}$ & 616 & 127 & $1.39 \mathrm{E}+08$ & 60 & $9.18 \mathrm{E}+09$ \\
\hline $\begin{array}{c}\text { PG 70-22 } \\
12.5 \mathrm{~mm}\end{array}$ & 453 & 140 & $3.04 \mathrm{E}+08$ & 76 & $1.30 \mathrm{E}+10$ \\
\hline $\begin{array}{c}\text { PG 70-22 PM } \\
9.5 \mathrm{~mm}\end{array}$ & 424 & 143 & $1.69 \mathrm{E}+09$ & 80 & $4.54 \mathrm{E}+10$ \\
\hline $\begin{array}{c}\text { PG 70-22 PM } \\
12.5 \mathrm{~mm}\end{array}$ & 406 & 145 & $9.67 \mathrm{E}+08$ & 83 & $1.97 \mathrm{E}+10$ \\
\hline $\begin{array}{c}\text { PG 76-22 PM } \\
9.5 \mathrm{~mm}\end{array}$ & 426 & 142 & $7.81 \mathrm{E}+07$ & 80 & $8.73 \mathrm{E}+08$ \\
\hline $\begin{array}{c}\text { PG 76-22 PM } \\
12.5 \mathrm{~mm}\end{array}$ & 377 & 148 & $1.41 \mathrm{E}+07$ & 88 & $7.79 \mathrm{E}+07$ \\
\hline
\end{tabular}




\section{Air Voids Effect on Performance}

Due to the variation in air voids just below $6.5 \%$, an analysis on the impact air voids had on the number of cycles to failure was performed. Figure 19 displays a plot of measured air voids in percent versus the measured number of cycles to failure measured during fatigue testing for the respective sample. Measured data points were used since the predicted values using the $G^{R}$ method has been found to be extremely accurate to the measured AMPT data (Underwood et al., 2012). There are no obvious trends in the data and an extremely low coefficient of determination. This data implies that the impact of air voids on fatigue performance is not statistically significant. Due to this analysis, it was decided to continue using the data collected on these samples for their respective test's analysis even though they did not meet the AASHTO air void specification of $7.0 \% \pm 0.5 \%$.

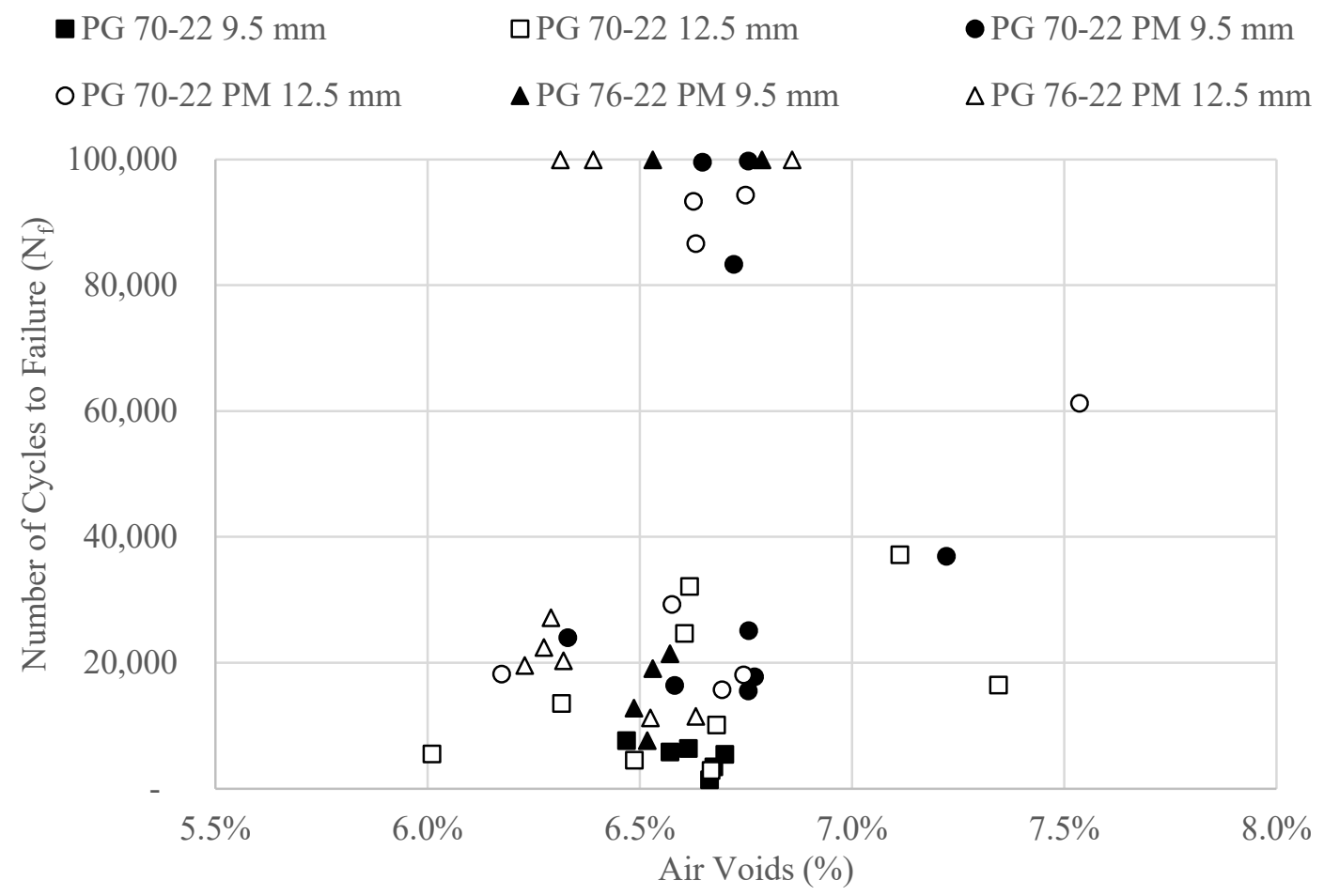

Figure 19: Air Voids versus Number of Cycles to Failure during fatigue testing. 


\section{Chapter 5: Conclusions and Recommendations}

\section{Conclusions}

\section{Sample Uniformity and Air Voids}

All samples made for Dynamic Modulus testing were also tested for their air void uniformity. Fatigue samples were not tested for uniformity for two reasons. The first being that in order to remove the end platens, the samples would have to be heated until the asphalt was essentially liquid, and the sample could no longer maintain its cylindrical shape. The second reason is that the fatigue samples can be assumed to have the same air void distribution as the dynamic modulus samples due to the randomization of the mixing and compacting process.

By analyzing the sections, it was found that there was a much higher variation than the specification allows, however one possible explanation for the samples falling outside of the specified range is that all samples had very low variances and small replicate sample sizes. It was also found that though there was high variation statistically within the samples, none of them were outside of accepted ranges of $\mathrm{G}_{\mathrm{mb}}$ as found in the equivalency test. There was also a slight difference between the average of the sections and the intact samples just as found by Dalton (2016).

Weak correlations were found between the three $G_{m b}$ methods tested (CoreLok ${ }^{\circledR}, S S D$, and Dimensional), though the correlation was stronger with samples after coring and sawing. The reasoning for the weak correlations between methods was unexpected and unexplainable. Dalton (2016) found that the dimensional method was the most accurate for samples with cut faces and also recommended that this process be included in AASHTO PP60 as a requirement. This research points to the $\operatorname{CoreLok}{ }^{\circledR}$ method, not the dimensional, as the most accurate for cored and sawed samples.

When testing for uniformity, both plots containing the SSD method had higher correlations, though the SSD versus dimensional after coring and sawing had the highest correlation at 0.89 . Visually, the SSD versus CoreLok ${ }^{\circledR}$ data points were the closest to the line of equality, though the coefficient of determination was rather low at 0.78 . This conclusion contradicts the findings of Dalton (2016) who found that the Dimensional method was the most accurate. 


\section{Dynamic Modulus}

Both Dynamic Modulus and Phase Angle values fell within an expected range of values and coefficient of variations, more so at the lower testing temperatures. The low coefficient of variation leads to the conclusion that the AMPT can produce reliable and repeatable data from the dynamic modulus test.

All MasterCurves produced using the worksheet developed by Bonaquist (2011b) followed a similar fit and trends. All data tended to vary at lower reduced frequencies, then converged at higher frequencies, just as Dalton (2016) discovered. It was also found that binder type and nominal maximum aggregate size (NMAS) does not have an obvious impact on the mastercurves fit or trends. The PG 70-22 9.5 mm mix type had higher average modulus values while PG 76-22 PM $12.5 \mathrm{~mm}$ mix type had the lowest. This trend should be explored further since this result contradicts other research on modifier's impact on Dynamic Modulus.

\section{ALPHA-Fatigue}

As previously mentioned, all fatigue data was analyzed using both the default and user selected peak failure point methods and the exponential model within the ALPHA-Fatigue software. The peak criteria typically resulted in reasonable microstrain endurance limits, while the default method resulted in much lower values. Against previous knowledge of binder types, the PG 70-22 PM binder typically resulted in higher predicted endurance limits, while, again, the PG 76-22 PM had lower values.

It was also found that when compared to the Asphalt Institute K-values, most of the mixes had higher cycles to failure at lower strain values, but at higher strain values, all mixes fell below the Asphalt Institute's predicted values.

\section{KENPAVE}

Following previous research using KENPAVE values, it was found that the full-depth pavement yielded values implying that almost all pavements met the criteria for a perpetual pavement with respect to fatigue by having low strain values and higher estimates for fatigue life. Conventional pavements however yielded much greater strain values than the full depth which is why they were used in further analysis.

It was also found that using the ALPHA-Fatigue K-values gave higher fatigue life estimates than the results using the Asphalt Institute values in all cases. Most importantly, it was 
found that the only mix type that met the qualifications to be considered a perpetual pavement by Witczak et al. (2013) was the PG 70-22 9.5mm. All of the other mix types did not qualify as perpetual pavements by the full depth method and none of the mix types qualified per the conventional method.

\section{Recommendations}

\section{Testing Protocol}

Effects of air voids on dynamic modulus and fatigue should be further evaluated to determine a definitive effect of lower air voids on fatigue life. Better methods of evaluating air voids and sample uniformity should also be explored as the test methods and t-statistic analysis in use now do not account for low variances and replicate sample sizes.

More data needs to be collected using the AMPT and analyzed using the ALPHA-Fatigue software. Data collected and analyzed in this research as well as other projects in the WVU Asphalt Technology Laboratory not been very consistent with the Asphalt Institute. In terms of the ALPHA-Fatigue software, more development needs to be addressed, especially in the terms of ease of use. A common problem within the software is that, when running multiple replicates, there is no way to change just one selection such as the selection of a failure point or which model to analyze.

\section{Material Evaluation}

The PG 70-22 $9.5 \mathrm{~mm}$ mix type performed better than the others in the dynamic modulus test, and the PG 76-22 PM binder type overall did the worst in both the dynamic modulus and fatigue tests. This conclusion goes against the expected outcome based on the fact that the worst performing binder was rated for higher temperatures and contains modifiers that should stiffen the binder causing an increase in dynamic modulus and fatigue life. More data should be collected on this relationship to determine whether it was the binder type's effect that lowered dynamic modulus and fatigue resistance, or if it was simply the effect of having a richer mix than optimum.

Though the PG 70-22 binder type had higher dynamic modulus values, it performed slightly worse in the fatigue testing overall than its modified counterpart. Turner (2015) discovered a similar relationship in the dynamic modulus test between the PG 70-22 neat and polymer modified binder types. 
A further designed experiment should be performed analyzing more binder types and nominal maximum aggregate sizes with varying percent binders, gradations, and air voids to eliminate all factors that could statistically affect the mix. Considering all of these factors and performing all of these tests would also increase the database of measured samples allowing a deeper understanding of the data collected and analyzed from the AMPT in ALPHA-Fatigue and MasterSolver.

Another suggestion is that during the mixing process, the mix should be quartered and remixed directly before compaction to avoid segregation of the mix which would give a more precise air void distribution. 


\section{References}

ALPHA-F User Guide. (2014). Raleigh, NC: IPC Global.

ARA, Inc. (2004). Guide for Mechanistic-Empirical Design of New and Rehabilitated Pavement Structures. ERES Division. NCHRP. Retrieved from http://onlinepubs.trb.org/onlinepubs/archive/mepdg/guide.htm

Bahia, H. U., Hanson, D. I., Zeng, M., Zhai, H., Khatri, M. A., \& Anderson, R. M. (2001). NCHRP Report 459: Characterization of Modified Asphalt Binders in Superpave Mix Design. Washington, D.C.: Transportation Research Board - National Research Council.

Bhurke, A. S. (1999). Effect of Polymer Modification on the Properties of Asphalt Concrete. Thesis, Michigan State University, Ann Arbor, MI.

Bonaquist, R. (2011a). MasterSolver: Version 2.2 [Software]. Retrieved from http://onlinepubs.trb.org/onlinepubs/nchrp/docs/NCHRP09-29_mastersolver2-2.xls

Bonaquist, R. (2011b). Precision of the Dynamic Modulus and Flow Number Tests Conducted with the Asphalt Mixture Performance Tester. Advanced Asphalt Technoogies, LLC. Washington, D.C.: Transportation Research Board.

Dalton, L. (2016). Evaluating the Protocol of the Spectrum of Hot Mix Asphalt Mixes Produced in West Virginia. MS Thesis, West Virginia University, Morgantown, WV.

FHWA. (2010). Superpave Mix Design and Gyratory Compaction Levels. FHWA TechBrief. Retrieved from http://www.fhwa.dot.gov/pavement/materials/pubs/hif1 1031/hif1 1031.pdf

Griffith, F. (2009, December). Investigation of the Measurement of Bulk Specific Gravity of Compacted Specimens By Various Methods. MS thesis, University of Arkansas, Fayetteville.

Huang, Y. (2004). Pavement Analysis and Design (2nd ed.). Upper Saddle River, NJ: Pearson Education.

Kim, Y. R., Baek, C., Underwood, S., Subramanian, V., Guddati, M. N., \& Lee, K. (2008). Applications of Viscoelastic Continuum Damage Model Based Finite Element Analysis to Predict the Fatigue Performance of Asphalt Pavements. KSCE Journal of Civil Enineering, 12(2), 109-120.

Miller, J. S., \& Bellinger, W. Y. (2003). Distress Identification Manuals for the Long-Term Pavement Performance Program (Fourth Revised Edition ed.). Springfield, VA: National Technical Information Service. Retrieved from https://www.fhwa.dot.gov/publications/research/infrastructure/pavements/ltpp/reports/03 031/03031.pdf

Mohammad, L., Kim, M., Raghavendra, A., \& Obulareddy, S. (2014). Characterization of Louisiana Asphalt Mixtures Using Simple Performance Tests and MEPDG. Baton Rouge, LA. 
Saboo, N., \& Kumar, P. (2016). Performance Characterization of Polymer Modified Asphalt Binders and Mixes. Research Article, Indian Institute of Technology.

Smith, L. (2015). Comparison of the Fatigue Characteristics of Recycled Asphalt Pavements. MS Thesis, West Virginia University, Morgantown, WV.

Tsai, B.-W., \& Monismith, C. L. (2005). Influence of Asphalt Binder Properties on the Fatigue Performance of Asphalt Concrete Pavements. Long Beach, CA: ResearchGate.

Turner, K. (2015). Evaluation of Asphalt Mixture Performance Tester. MS Thesis, West Virginia University, Morgantown, WV.

Underwood, S., Baek, C., \& Kim, Y. R. (2012). Simplified Viscoelastic Continuum Damage Model as Platform for Asphalt Concrete Fatigue Analysis. Journal of Transportation Research Board, 36-45.

Witczak, M. W., Kaloush, K., Pellinen, T., \& El-Basyouny, M. (2002). Simple Performance Test for Superpave Mix Design. Washington, D.C.: Transportation Research Board - National Research Council.

Witczak, M., Mamlouk, M., Souliman, M., \& Zeiada, W. (2013). Validating an Endurance Limit for Hot-Mix Asphalt (HMA) Pavements: Laboratory Experiment and Algorithm Development. National Cooperative Highway Research Program Transportation Research Board.

Zhai, H. (2001). Superpave Protocols for Modified Asphalt Binders. PhD Thesis, University of Wisconsin - Madison, Madison, WI.

Zhao, W. (2011). The Effects of Fundamental Mixture Parameters on Hot-Mix Asphalt Performance Properties. PhD Thesis, Clemson University, Clemson, SC.

List of Test Methods Used

AASHTO PP 60: Preparation of Cylindrical Performance Test Specimens Using the Superpave Gyratory Compactor. Washington, DC: American Association of State Highway and Transportation Officials, 2015.

AASHTO PP 61: Developing Dynamic Modulus Master Curves using AMPT. Washington, DC: American Association of State Highway and Transportation Officials, 2015.

AASHTO TP 79: Standard Method of Test for Determining the Dynamic Modulus and Flow Number for Asphalt Mixture Performance Tester (AMPT) Washington, DC: American Association of State Highway and Transportation Officials, 2013.

AASHTO TP 107: Determining the Damage Characteristics Curve of Asphalt Mixtures from Direct Tension Cyclic Fatigue Tests. Washington, DC: American Association of State Highway and Transportation Officials, 2015.

AASHTO T 166: Bulk Specific Gravity of Compacted Hot Mix Asphalt (HMA) Using Saturated Surface-Dry Specimens. Washington, DC: American Association of State Highway and Transportation Officials, 2015. 
AASHTO T 209: Theoretical Maximum Specific Gravity (Gmm) and Density of Hot Mix Asphalt (HMA). Washington, DC: American Association of State Highway and Transportation Officials, 2015.

AASHTO T 269: Percent of Air Voids in Compacted Dense and Open Asphalt Mixtures. Washington, DC: American Association of State Highway and Transportation Officials, 2015.

AASHTO T 312: Preparing and Determining the Density of Hot Mix Asphalt (HMA) by Means of the Superpave Gyratory Compactor. Washington, DC: American Association of State Highway Transportation Officials, 2015.

AASHTO T 331: Bulk Specific Gravity and Density of Compacted Hot Mix Asphalt (HMA) Using Automatic Vacuum Sealing Method. Washington, DC: American Association of State Highway and Transportation Officials, 2015.

AASHTO T 342: Determining Dynamic Modulus of Hot Mix Asphalt. Washington, DC: American Association of State Highway and Transportation Officials, 2015. 


\section{Appendix A - Job Mix Formulas}

T400 SP

04-10

\section{WEST VIRGINIA DIVISION OF HIGHWAYS \\ JOB MIX FORMULA FOR SUPERPAVE HOT-MIX ASPHALT}

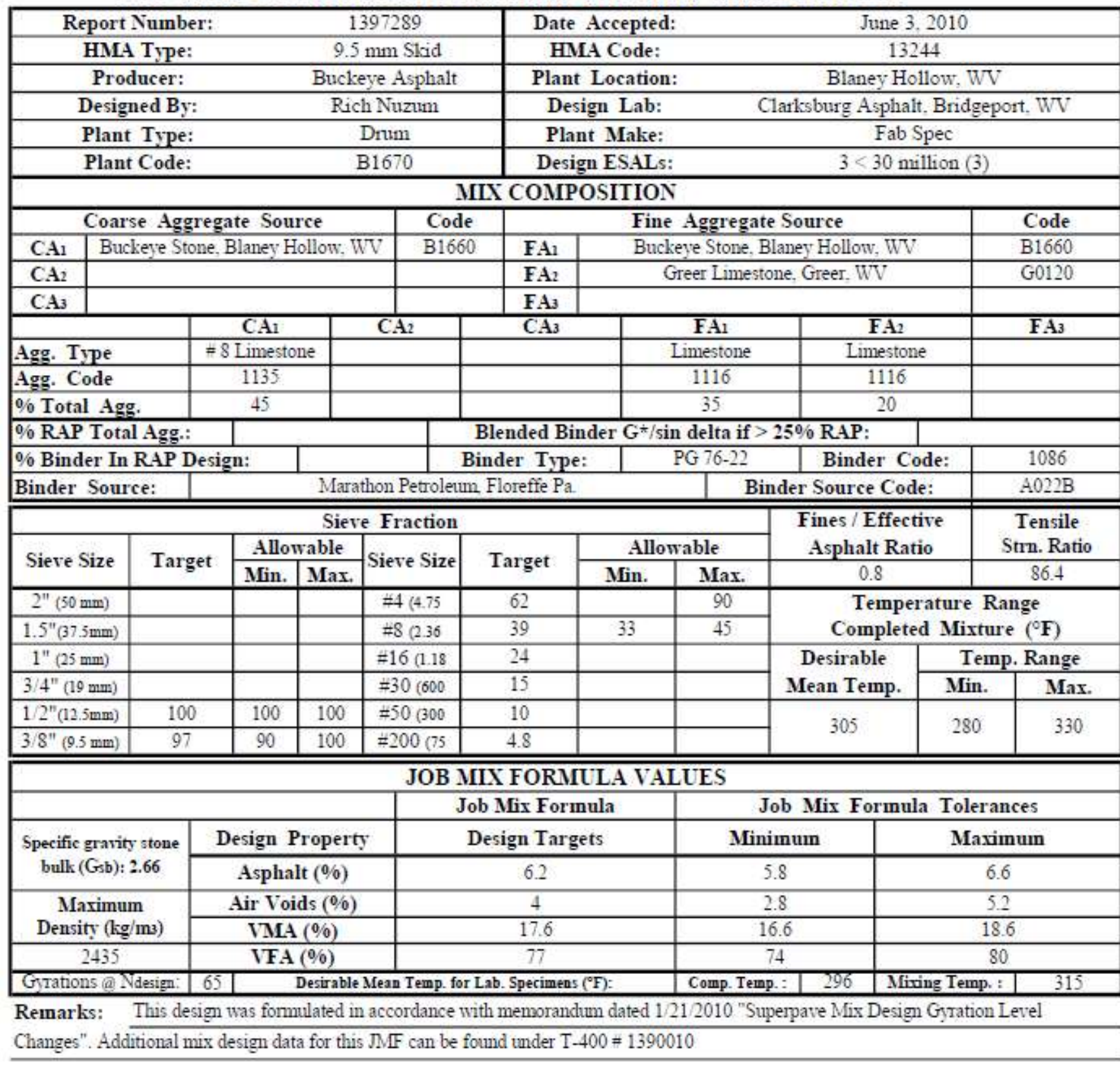




\section{JOB MIX FORMULA FOR SUPERPAVE HOT-MIX ASPHALT}

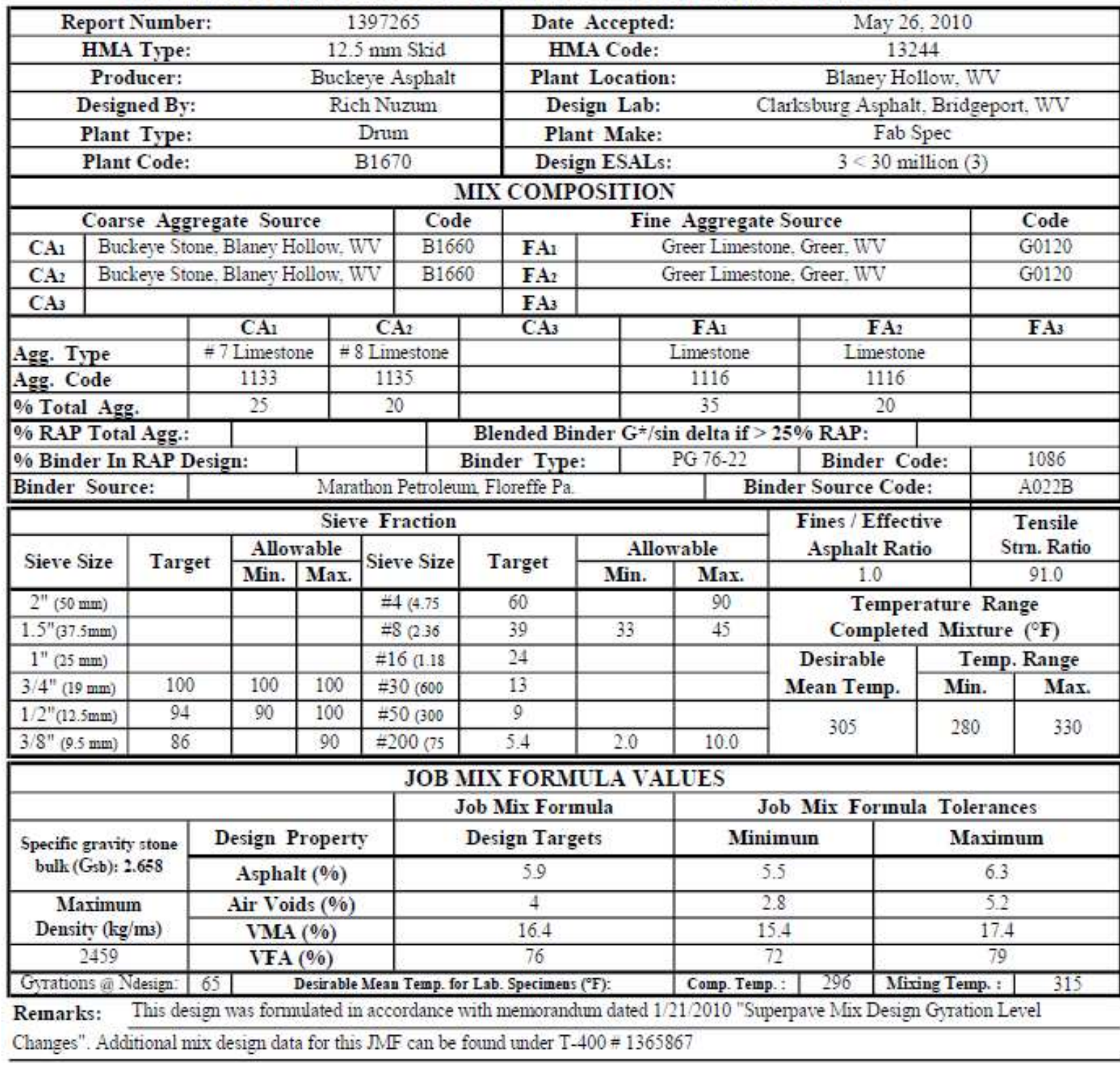




\section{Appendix B - Performance Sample Volumetrics}

Bulk Specific Gravities $\left(G_{m b}\right)$ for Full Size Samples

\begin{tabular}{|c|c|c|c|c|c|c|c|c|}
\hline \multirow[b]{2}{*}{ Binder Type } & \multirow[b]{2}{*}{ NMAS } & \multirow[b]{2}{*}{$\begin{array}{c}\text { Sample } \\
\text { Designation }\end{array}$} & \multicolumn{3}{|c|}{ Before } & \multicolumn{3}{|c|}{ After } \\
\hline & & & SSD & CoreLok & Dimensional & SSD & CoreLok & Dimensional \\
\hline PG 70-22 & $9.5 \mathrm{~mm}$ & FT 1A & 2.278 & 2.265 & 2.238 & 2.307 & 2.303 & 2.298 \\
\hline PG 70-22 & $9.5 \mathrm{~mm}$ & FT 1B & 2.279 & 2.263 & 2.236 & 2.305 & 2.301 & 2.300 \\
\hline PG 70-22 & $9.5 \mathrm{~mm}$ & FT 1C & 2.280 & 2.259 & 2.238 & 2.308 & 2.304 & 2.302 \\
\hline PG 70-22 & $9.5 \mathrm{~mm}$ & FT 2A & 2.283 & 2.262 & 2.237 & 2.300 & 2.299 & 2.287 \\
\hline PG 70-22 & $9.5 \mathrm{~mm}$ & FT 2B & 2.283 & 2.266 & 2.237 & 2.303 & 2.303 & 2.294 \\
\hline PG 70-22 & $9.5 \mathrm{~mm}$ & FT 2C & 2.285 & 2.265 & 2.239 & 2.304 & 2.305 & 2.296 \\
\hline PG 70-22 & $9.5 \mathrm{~mm}$ & FT 3A & 2.281 & 2.264 & 2.237 & 2.311 & 2.306 & 2.300 \\
\hline PG 70-22 & $9.5 \mathrm{~mm}$ & FT 3B & 2.283 & 2.256 & 2.235 & 2.305 & 2.302 & 2.297 \\
\hline PG 70-22 & $9.5 \mathrm{~mm}$ & FT 3C & 2.279 & 2.263 & 2.236 & 2.306 & 2.301 & 2.295 \\
\hline PG 70-22 & $9.5 \mathrm{~mm}$ & DM 1 & 2.278 & 2.225 & 2.236 & 2.291 & 2.289 & 2.281 \\
\hline PG 70-22 & $9.5 \mathrm{~mm}$ & DM 2 & 2.281 & 2.263 & 2.245 & 2.298 & 2.298 & 2.285 \\
\hline PG 70-22 & $9.5 \mathrm{~mm}$ & DM 3 & 2.283 & 2.248 & 2.239 & 2.300 & 2.301 & 2.288 \\
\hline
\end{tabular}




\begin{tabular}{|c|c|c|c|c|c|c|c|c|}
\cline { 3 - 8 } \multicolumn{2}{c}{ Binder Type } & NMAS & $\begin{array}{c}\text { Sample } \\
\text { Designation }\end{array}$ & SSD & CoreLok & Dimensional & \multirow{2}{*}{ SSD } & \multirow{2}{*}{ CoreLok } \\
& & Dimensional & Defore \\
\hline PG 70-22 & $12.5 \mathrm{~mm}$ & FT 1A & 2.285 & 2.268 & 2.238 & 2.303 & 2.301 \\
\hline PG 70-22 & $12.5 \mathrm{~mm}$ & FT 1B & 2.289 & 2.264 & 2.237 & 2.314 & 2.316 & 2.305 \\
\hline PG 70-22 & $12.5 \mathrm{~mm}$ & FT 1C & 2.280 & 2.266 & 2.237 & 2.307 & 2.308 & 2.299 \\
\hline PG 70-22 & $12.5 \mathrm{~mm}$ & FT 2A & 2.280 & 2.268 & 2.238 & 2.307 & 2.301 & 2.301 \\
\hline PG 70-22 & $12.5 \mathrm{~mm}$ & FT 2B & 2.276 & 2.263 & 2.239 & 2.305 & 2.300 & 2.296 \\
\hline PG 70-22 & $12.5 \mathrm{~mm}$ & FT 2C & 2.277 & 2.265 & 2.238 & 2.304 & 2.299 & 2.296 \\
\hline PG 70-22 & $12.5 \mathrm{~mm}$ & FT 3A & 2.283 & 2.266 & 2.237 & 2.300 & 2.289 & 2.293 \\
\hline PG 70-22 & $12.5 \mathrm{~mm}$ & FT 3B & 2.285 & 2.266 & 2.238 & 2.308 & 2.304 & 2.302 \\
\hline PG 70-22 & $12.5 \mathrm{~mm}$ & FT 3C & 2.265 & 2.251 & 2.237 & 2.287 & 2.283 & 2.279 \\
\hline PG 70-22 & $12.5 \mathrm{~mm}$ & DM 1 & 2.277 & 2.261 & 2.235 & 2.288 & 2.287 & 2.282 \\
\hline PG 70-22 & $12.5 \mathrm{~mm}$ & DM 2 & 2.285 & 2.265 & 2.237 & 2.298 & 2.303 & 2.288 \\
\hline PG 70-22 & $12.5 \mathrm{~mm}$ & DM 3 & 2.287 & 2.268 & 2.238 & 2.301 & 2.301 & 2.290 \\
\hline
\end{tabular}

\begin{tabular}{|c|c|c|c|c|c|c|c|c|}
\cline { 3 - 8 } \multicolumn{2}{c}{} & \multicolumn{3}{c|}{ Before } & \multicolumn{2}{c|}{ After } \\
\hline Binder Type & NMAS & $\begin{array}{c}\text { Sample } \\
\text { Designation }\end{array}$ & SSD & CoreLok & Dimensional & SSD & CoreLok & \multirow{2}{*}{ Dimensional } \\
\hline PG 70-22 PM & $9.5 \mathrm{~mm}$ & FT 1A & 2.281 & 2.265 & 2.238 & 2.306 & 2.302 & 2.300 \\
\hline PG 70-22 PM & $9.5 \mathrm{~mm}$ & FT 1B & 2.275 & 2.258 & 2.235 & 2.302 & 2.299 & 2.297 \\
\hline PG 70-22 PM & $9.5 \mathrm{~mm}$ & FT 1C & 2.272 & 2.252 & 2.235 & 2.295 & 2.288 & 2.287 \\
\hline PG 70-22 PM & $9.5 \mathrm{~mm}$ & FT 2A & 2.278 & 2.264 & 2.237 & 2.302 & 2.299 & 2.297 \\
\hline PG 70-22 PM & $9.5 \mathrm{~mm}$ & FT 2B & 2.282 & 2.266 & 2.239 & 2.304 & 2.304 & 2.297 \\
\hline PG 70-22 PM & $9.5 \mathrm{~mm}$ & FT 2C & 2.281 & 2.265 & 2.238 & 2.308 & 2.310 & 2.302 \\
\hline PG 70-22 PM & $9.5 \mathrm{~mm}$ & FT 3A & 2.274 & 2.264 & 2.237 & 2.306 & 2.300 & 2.300 \\
\hline PG 70-22 PM & $9.5 \mathrm{~mm}$ & FT 3B & 2.281 & 2.265 & 2.238 & 2.302 & 2.299 & 2.296 \\
\hline PG 70-22 PM & $9.5 \mathrm{~mm}$ & FT 3C & 2.277 & 2.259 & 2.234 & 2.304 & 2.299 & 2.298 \\
\hline PG 70-22 PM & $9.5 \mathrm{~mm}$ & DM 1 & 2.283 & 2.262 & 2.236 & 2.297 & 2.299 & 2.289 \\
\hline PG 70-22 PM & $9.5 \mathrm{~mm}$ & DM 2 & 2.276 & 2.263 & 2.229 & 2.297 & 2.298 & 2.288 \\
\hline PG 70-22 PM & $9.5 \mathrm{~mm}$ & DM 3 & 2.282 & 2.263 & 2.237 & 2.302 & 2.302 & 2.929 \\
\hline
\end{tabular}




\begin{tabular}{|c|c|c|c|c|c|c|c|c|}
\hline \multirow[b]{2}{*}{ Binder Type } & \multirow[b]{2}{*}{ NMAS } & \multirow[b]{2}{*}{$\begin{array}{c}\text { Sample } \\
\text { Designation }\end{array}$} & \multicolumn{3}{|c|}{ Before } & \multicolumn{3}{|c|}{ After } \\
\hline & & & SSD & CoreLok & Dimensional & SSD & CoreLok & Dimensional \\
\hline PG 70-22 PM & $12.5 \mathrm{~mm}$ & FT 1A & 2.285 & 2.268 & 2.239 & 2.301 & 2.301 & 2.292 \\
\hline PG 70-22 PM & $12.5 \mathrm{~mm}$ & FT 1B & 2.286 & 2.264 & 2.238 & 2.310 & 2.312 & 2.303 \\
\hline PG 70-22 PM & $12.5 \mathrm{~mm}$ & FT 1C & 2.277 & 2.259 & 2.234 & 2.299 & 2.302 & 2.292 \\
\hline PG 70-22 PM & $12.5 \mathrm{~mm}$ & FT 2A & 2.284 & 2.267 & 2.238 & 2.300 & 2.301 & 2.291 \\
\hline PG 70-22 PM & $12.5 \mathrm{~mm}$ & FT 2B & 2.282 & 2.265 & 2.235 & 2.298 & 2.298 & 2.290 \\
\hline PG 70-22 PM & $12.5 \mathrm{~mm}$ & FT 2C & 2.279 & 2.259 & 2.237 & 2.290 & 2.278 & 2.280 \\
\hline PG 70-22 PM & $12.5 \mathrm{~mm}$ & FT 3A & 2.282 & 2.264 & 2.237 & 2.295 & 2.298 & 2.288 \\
\hline PG 70-22 PM & $12.5 \mathrm{~mm}$ & FT 3B & 2.285 & 2.266 & 2.237 & 2.298 & 2.299 & 2.292 \\
\hline PG 70-22 PM & $12.5 \mathrm{~mm}$ & FT 3C & 2.282 & 2.261 & 2.237 & 2.294 & 2.285 & 2.288 \\
\hline PG 70-22 PM & $12.5 \mathrm{~mm}$ & DM 1 & 2.282 & 2.268 & 2.238 & 2.295 & 2.297 & 2.286 \\
\hline PG 70-22 PM & $12.5 \mathrm{~mm}$ & DM 2 & 2.282 & 2.265 & 2.237 & 2.300 & 2.301 & 2.289 \\
\hline PG 70-22 PM & $12.5 \mathrm{~mm}$ & DM 3 & 2.284 & 2.258 & 2.239 & 2.295 & 2.300 & 2.282 \\
\hline
\end{tabular}




\begin{tabular}{|c|c|c|c|c|c|c|c|c|}
\cline { 3 - 8 } \multicolumn{2}{c|}{} & \multicolumn{3}{c|}{ Before } & \multicolumn{2}{c|}{ After } \\
\hline Binder Type & NMAS & $\begin{array}{c}\text { Sample } \\
\text { Designation }\end{array}$ & SSD & CoreLok & Dimensional & \multirow{2}{*}{ SSD } & CoreLok & Dimensional \\
\hline PG 76-22 PM & $9.5 \mathrm{~mm}$ & FT 1A & 2.282 & 2.268 & 2.237 & 2.309 & 2.305 & 2.299 \\
\hline PG 76-22 PM & $9.5 \mathrm{~mm}$ & FT 1A2 & 2.283 & 2.266 & 2.236 & 2.307 & 2.299 & 2.301 \\
\hline PG 76-22 PM & $9.5 \mathrm{~mm}$ & FT 1B & 2.282 & 2.259 & 2.238 & 2.310 & 2.305 & 2.302 \\
\hline PG 76-22 PM & $9.5 \mathrm{~mm}$ & FT 1B2 & 2.284 & 2.264 & 2.238 & 2.309 & 2.304 & 2.301 \\
\hline PG 76-22 PM & $9.5 \mathrm{~mm}$ & FT 1C & 2.284 & 2.267 & 2.238 & 2.311 & 2.304 & 2.303 \\
\hline PG 76-22 PM & $9.5 \mathrm{~mm}$ & FT 2A & 2.284 & 2.264 & 2.237 & 2.314 & 2.312 & 2.307 \\
\hline PG 76-22 PM & $9.5 \mathrm{~mm}$ & FT 2B & 2.283 & 2.265 & 2.237 & 2.312 & 2.313 & 2.304 \\
\hline PG 76-22 PM & $9.5 \mathrm{~mm}$ & FT 2C & 2.281 & 2.264 & 2.237 & 2.307 & 2.304 & 2.300 \\
\hline PG 76-22 PM & $9.5 \mathrm{~mm}$ & FT 3A & 2.283 & 2.265 & 2.238 & 2.309 & 2.305 & 2.298 \\
\hline PG 76-22 PM & $9.5 \mathrm{~mm}$ & FT 3B & 2.279 & 2.265 & 2.238 & 2.306 & 2.306 & 2.286 \\
\hline PG 76-22 PM & $9.5 \mathrm{~mm}$ & FT 3C & 2.278 & 2.263 & 2.237 & 2.310 & 2.305 & 2.301 \\
\hline PG 76-22 PM & $9.5 \mathrm{~mm}$ & DM 1 & 2.268 & 2.243 & 2.221 & 2.278 & 2.280 & 2.273 \\
\hline PG 76-22 PM & $9.5 \mathrm{~mm}$ & DM 2 & 2.284 & 2.265 & 2.236 & 2.302 & 2.300 & 2.290 \\
\hline PG 76-22 PM & $9.5 \mathrm{~mm}$ & DM 3 & 2.282 & 2.265 & 2.237 & 2.303 & 2.303 & 2.294 \\
\hline
\end{tabular}




\begin{tabular}{|c|c|c|c|c|c|c|c|c|}
\cline { 3 - 8 } \multicolumn{2}{c}{ Binder Type } & \multirow{2}{*}{ NMAS } & $\begin{array}{c}\text { Sample } \\
\text { Designation }\end{array}$ & SSD & CoreLok & Dimensional & \multirow{2}{*}{ SSD } & \multirow{2}{*}{ CoreLok } \\
& & FT 1A & 2.286 & 2.268 & 2.238 & 2.308 & 2.308 & 2.302 \\
\hline PG 76-22 PM & $12.5 \mathrm{~mm}$ & Dimensional \\
\hline PG 76-22 PM & $12.5 \mathrm{~mm}$ & FT 1B & 2.287 & 2.269 & 2.238 & 2.305 & 2.303 & 2.297 \\
\hline PG 76-22 PM & $12.5 \mathrm{~mm}$ & FT 1C & 2.284 & 2.268 & 2.239 & 2.308 & 2.308 & 2.299 \\
\hline PG 76-22 PM & $12.5 \mathrm{~mm}$ & FT 2A & 2.285 & 2.269 & 2.237 & 2.311 & 2.307 & 2.308 \\
\hline PG 76-22 PM & $12.5 \mathrm{~mm}$ & FT 2B & 2.283 & 2.267 & 2.238 & 2.315 & 2.311 & 2.307 \\
\hline PG 76-22 PM & $12.5 \mathrm{~mm}$ & FT 2C & 2.280 & 2.267 & 2.237 & 2.311 & 2.309 & 2.305 \\
\hline PG 76-22 PM & $12.5 \mathrm{~mm}$ & FT 3A & 2.281 & 2.261 & 2.236 & 2.297 & 2.295 & 2.290 \\
\hline PG 76-22 PM & $12.5 \mathrm{~mm}$ & FT 3B & 2.286 & 2.263 & 2.238 & 2.303 & 2.301 & 2.295 \\
\hline PG 76-22 PM & $12.5 \mathrm{~mm}$ & FT 3C & 2.286 & 2.269 & 2.240 & 2.307 & 2.309 & 2.301 \\
\hline PG 76-22 PM & $12.5 \mathrm{~mm}$ & DM 1 & 2.283 & 2.264 & 2.237 & 2.288 & 2.290 & 2.282 \\
\hline PG 76-22 PM & $12.5 \mathrm{~mm}$ & DM 2 & 2.288 & 2.259 & 2.238 & 2.295 & 2.296 & 2.285 \\
\hline PG 76-22 PM & $12.5 \mathrm{~mm}$ & DM 3 & 2.287 & 2.268 & 2.237 & 2.302 & 2.303 & 2.291 \\
\hline
\end{tabular}


Dynamic Modulus Samples Voids in Total Mix (VTM)

\begin{tabular}{|c|c|c|c|c|c|c|c|c|}
\cline { 3 - 8 } Binder Type & NMAS & $\begin{array}{c}\text { Sample } \\
\text { Designation }\end{array}$ & SSD & CoreLok & Dimensional & \multirow{2}{*}{ SSD } & CoreLok & \multirow{2}{*}{ Dimensional } \\
\hline PG 70-22 & $9.5 \mathrm{~mm}$ & FT 1A & $7.6 \%$ & $8.2 \%$ & $9.3 \%$ & $6.5 \%$ & $6.6 \%$ & $6.8 \%$ \\
\hline PG 70-22 & $9.5 \mathrm{~mm}$ & FT 1B & $7.6 \%$ & $8.2 \%$ & $9.3 \%$ & $6.5 \%$ & $6.7 \%$ & $6.7 \%$ \\
\hline PG 70-22 & $9.5 \mathrm{~mm}$ & FT 1C & $7.5 \%$ & $8.4 \%$ & $9.3 \%$ & $6.4 \%$ & $6.6 \%$ & $6.6 \%$ \\
\hline PG 70-22 & $9.5 \mathrm{~mm}$ & FT 2A & $7.4 \%$ & $8.3 \%$ & $9.3 \%$ & $6.7 \%$ & $6.8 \%$ & $7.3 \%$ \\
\hline PG 70-22 & $9.5 \mathrm{~mm}$ & FT 2B & $7.4 \%$ & $8.1 \%$ & $9.3 \%$ & $6.6 \%$ & $6.6 \%$ & $7.0 \%$ \\
\hline PG 70-22 & $9.5 \mathrm{~mm}$ & FT 2C & $7.3 \%$ & $8.1 \%$ & $9.2 \%$ & $6.6 \%$ & $6.5 \%$ & $6.9 \%$ \\
\hline PG 70-22 & $9.5 \mathrm{~mm}$ & FT 3A & $7.5 \%$ & $8.2 \%$ & $9.3 \%$ & $6.3 \%$ & $6.5 \%$ & $6.7 \%$ \\
\hline PG 70-22 & $9.5 \mathrm{~mm}$ & FT 3B & $7.4 \%$ & $8.5 \%$ & $9.3 \%$ & $6.5 \%$ & $6.7 \%$ & $6.8 \%$ \\
\hline PG 70-22 & $9.5 \mathrm{~mm}$ & FT 3C & $7.6 \%$ & $8.2 \%$ & $9.3 \%$ & $6.5 \%$ & $6.7 \%$ & $6.9 \%$ \\
\hline PG 70-22 & $9.5 \mathrm{~mm}$ & DM 1 & $7.6 \%$ & $9.8 \%$ & $9.3 \%$ & $7.1 \%$ & $7.2 \%$ & $7.5 \%$ \\
\hline PG 70-22 & $9.5 \mathrm{~mm}$ & DM 2 & $7.5 \%$ & $8.2 \%$ & $9.0 \%$ & $6.8 \%$ & $6.8 \%$ & $7.4 \%$ \\
\hline PG 70-22 & $9.5 \mathrm{~mm}$ & DM 3 & $7.4 \%$ & $8.9 \%$ & $9.2 \%$ & $6.7 \%$ & $6.7 \%$ & $7.2 \%$ \\
\hline
\end{tabular}




\begin{tabular}{|c|c|c|c|c|c|c|c|c|}
\cline { 3 - 8 } Binder Type & NMAS & $\begin{array}{c}\text { Sample } \\
\text { Designation }\end{array}$ & SSD & CoreLok & Dimensional & \multirow{2}{*}{ SSD } & \multirow{2}{*}{ CoreLok } & \multirow{2}{*}{ Dimensional } \\
\hline PG 70-22 & $12.5 \mathrm{~mm}$ & FT 1A & $7.3 \%$ & $7.9 \%$ & $9.2 \%$ & $6.5 \%$ & $6.6 \%$ \\
\hline PG 70-22 & $12.5 \mathrm{~mm}$ & FT 1B & $7.1 \%$ & $8.1 \%$ & $9.2 \%$ & $6.1 \%$ & $6.0 \%$ & $6.4 \%$ \\
\hline PG 70-22 & $12.5 \mathrm{~mm}$ & FT 1C & $7.5 \%$ & $8.0 \%$ & $9.2 \%$ & $6.4 \%$ & $6.3 \%$ & $6.7 \%$ \\
\hline PG 70-22 & $12.5 \mathrm{~mm}$ & FT 2A & $7.4 \%$ & $8.0 \%$ & $9.2 \%$ & $6.4 \%$ & $6.6 \%$ & $6.6 \%$ \\
\hline PG 70-22 & $12.5 \mathrm{~mm}$ & FT 2B & $7.6 \%$ & $8.1 \%$ & $9.1 \%$ & $6.4 \%$ & $6.7 \%$ & $6.8 \%$ \\
\hline PG 70-22 & $12.5 \mathrm{~mm}$ & FT 2C & $7.6 \%$ & $8.1 \%$ & $9.2 \%$ & $6.5 \%$ & $6.7 \%$ & $6.8 \%$ \\
\hline PG 70-22 & $12.5 \mathrm{~mm}$ & FT 3A & $7.3 \%$ & $8.0 \%$ & $9.2 \%$ & $6.6 \%$ & $7.1 \%$ & $7.0 \%$ \\
\hline PG 70-22 & $12.5 \mathrm{~mm}$ & FT 3B & $7.3 \%$ & $8.0 \%$ & $9.2 \%$ & $6.3 \%$ & $6.5 \%$ & $6.6 \%$ \\
\hline PG 70-22 & $12.5 \mathrm{~mm}$ & FT 3C & $8.1 \%$ & $8.7 \%$ & $9.2 \%$ & $7.2 \%$ & $7.3 \%$ & $7.5 \%$ \\
\hline PG 70-22 & $12.5 \mathrm{~mm}$ & DM 1 & $7.6 \%$ & $8.2 \%$ & $9.3 \%$ & $7.2 \%$ & $7.2 \%$ & $7.4 \%$ \\
\hline PG 70-22 & $12.5 \mathrm{~mm}$ & DM 2 & $7.3 \%$ & $8.1 \%$ & $9.2 \%$ & $6.7 \%$ & $6.5 \%$ & $7.1 \%$ \\
\hline PG 70-22 & $12.5 \mathrm{~mm}$ & DM 3 & $7.2 \%$ & $8.0 \%$ & $9.2 \%$ & $6.6 \%$ & $6.6 \%$ & $7.1 \%$ \\
\hline
\end{tabular}

\begin{tabular}{|c|c|c|c|c|c|c|c|c|}
\hline \multirow[b]{2}{*}{ Binder Type } & \multirow[b]{2}{*}{ NMAS } & \multirow[b]{2}{*}{$\begin{array}{c}\text { Sample } \\
\text { Designation }\end{array}$} & \multicolumn{3}{|c|}{ Before } & \multicolumn{3}{|c|}{ After } \\
\hline & & & SSD & CoreLok & Dimensional & SSD & CoreLok & Dimensional \\
\hline PG 70-22 PM & $9.5 \mathrm{~mm}$ & FT 1A & $7.5 \%$ & $8.2 \%$ & $9.2 \%$ & $6.5 \%$ & $6.6 \%$ & $6.7 \%$ \\
\hline PG 70-22 PM & $9.5 \mathrm{~mm}$ & FT 1B & $7.8 \%$ & $8.4 \%$ & $9.4 \%$ & $6.7 \%$ & $6.8 \%$ & $6.9 \%$ \\
\hline PG 70-22 PM & $9.5 \mathrm{~mm}$ & FT 1C & $7.8 \%$ & $8.7 \%$ & $9.4 \%$ & $6.9 \%$ & $7.2 \%$ & $7.3 \%$ \\
\hline PG 70-22 PM & $9.5 \mathrm{~mm}$ & FT 2A & $7.6 \%$ & $8.2 \%$ & $9.3 \%$ & $6.6 \%$ & $6.8 \%$ & $6.9 \%$ \\
\hline PG 70-22 PM & $9.5 \mathrm{~mm}$ & FT 2B & $7.5 \%$ & $8.1 \%$ & $9.2 \%$ & $6.6 \%$ & $6.6 \%$ & $6.9 \%$ \\
\hline PG 70-22 PM & $9.5 \mathrm{~mm}$ & FT 2C & $7.5 \%$ & $8.2 \%$ & $9.3 \%$ & $6.4 \%$ & $6.3 \%$ & $6.6 \%$ \\
\hline PG 70-22 PM & $9.5 \mathrm{~mm}$ & FT 3A & $7.8 \%$ & $8.2 \%$ & $9.3 \%$ & $6.5 \%$ & $6.7 \%$ & $6.7 \%$ \\
\hline PG 70-22 PM & $9.5 \mathrm{~mm}$ & FT 3B & $7.5 \%$ & $8.1 \%$ & $9.2 \%$ & $6.6 \%$ & $6.8 \%$ & $6.9 \%$ \\
\hline PG 70-22 PM & $9.5 \mathrm{~mm}$ & FT 3C & $7.7 \%$ & $8.4 \%$ & $9.4 \%$ & $6.6 \%$ & $6.8 \%$ & $6.8 \%$ \\
\hline PG 70-22 PM & $9.5 \mathrm{~mm}$ & DM 1 & $7.4 \%$ & $8.3 \%$ & $9.3 \%$ & $6.9 \%$ & $6.8 \%$ & $7.2 \%$ \\
\hline PG 70-22 PM & $9.5 \mathrm{~mm}$ & DM 2 & $7.7 \%$ & $8.2 \%$ & $9.6 \%$ & $6.8 \%$ & $6.8 \%$ & $7.2 \%$ \\
\hline PG 70-22 PM & $9.5 \mathrm{~mm}$ & DM 3 & $7.5 \%$ & $8.2 \%$ & $9.3 \%$ & $6.7 \%$ & $6.7 \%$ & $7.1 \%$ \\
\hline
\end{tabular}




\begin{tabular}{|c|c|c|c|c|c|c|c|c|}
\cline { 3 - 8 } \multicolumn{2}{c}{ Binder Type } & NMAS & $\begin{array}{c}\text { Sample } \\
\text { Designation }\end{array}$ & SSD & CoreLok & Dimensional & \multirow{2}{*}{ SSD } & \multirow{2}{*}{ CoreLok } \\
\cline { 4 - 9 } Dimensional \\
\hline PG 70-22 PM & $12.5 \mathrm{~mm}$ & FT 1A & $7.3 \%$ & $8.0 \%$ & $9.2 \%$ & $6.6 \%$ & $6.6 \%$ & $7.0 \%$ \\
\hline PG 70-22 PM & $12.5 \mathrm{~mm}$ & FT 1B & $7.2 \%$ & $8.1 \%$ & $9.2 \%$ & $6.2 \%$ & $6.2 \%$ & $6.6 \%$ \\
\hline PG 70-22 PM & $12.5 \mathrm{~mm}$ & FT 1C & $7.6 \%$ & $8.3 \%$ & $9.3 \%$ & $6.7 \%$ & $6.6 \%$ & $7.0 \%$ \\
\hline PG 70-22 PM & $12.5 \mathrm{~mm}$ & FT 2A & $7.3 \%$ & $8.0 \%$ & $9.2 \%$ & $6.6 \%$ & $6.6 \%$ & $7.0 \%$ \\
\hline PG 70-22 PM & $12.5 \mathrm{~mm}$ & FT 2B & $7.4 \%$ & $8.1 \%$ & $9.3 \%$ & $6.7 \%$ & $6.7 \%$ & $7.0 \%$ \\
\hline PG 70-22 PM & $12.5 \mathrm{~mm}$ & FT 2C & $7.5 \%$ & $8.3 \%$ & $9.2 \%$ & $7.1 \%$ & $7.5 \%$ & $7.5 \%$ \\
\hline PG 70-22 PM & $12.5 \mathrm{~mm}$ & FT 3A & $7.4 \%$ & $8.1 \%$ & $9.2 \%$ & $6.9 \%$ & $6.7 \%$ & $7.1 \%$ \\
\hline PG 70-22 PM & $12.5 \mathrm{~mm}$ & FT 3B & $7.3 \%$ & $8.0 \%$ & $9.2 \%$ & $6.7 \%$ & $6.7 \%$ & $7.0 \%$ \\
\hline PG 70-22 PM & $12.5 \mathrm{~mm}$ & FT 3C & $7.4 \%$ & $8.2 \%$ & $9.2 \%$ & $6.9 \%$ & $7.3 \%$ & $7.2 \%$ \\
\hline PG 70-22 PM & $12.5 \mathrm{~mm}$ & DM 1 & $7.4 \%$ & $8.0 \%$ & $9.2 \%$ & $6.8 \%$ & $6.8 \%$ & $7.2 \%$ \\
\hline PG 70-22 PM & $12.5 \mathrm{~mm}$ & DM 2 & $7.4 \%$ & $8.1 \%$ & $9.2 \%$ & $6.7 \%$ & $6.6 \%$ & $7.1 \%$ \\
\hline PG 70-22 PM & $12.5 \mathrm{~mm}$ & DM 3 & $7.3 \%$ & $8.3 \%$ & $9.1 \%$ & $6.9 \%$ & $6.7 \%$ & $7.4 \%$ \\
\hline
\end{tabular}




\begin{tabular}{|c|c|c|c|c|c|c|c|c|}
\cline { 4 - 8 } \multicolumn{2}{c}{} & \multicolumn{3}{c|}{ Before } & \multicolumn{3}{c|}{ After } \\
\hline \multirow{2}{*}{ Binder Type } & NMAS & $\begin{array}{c}\text { Sample } \\
\text { Designation }\end{array}$ & SSD & CoreLok & Dimensional & \multirow{2}{*}{ SSD } & CoreLok & Dimensional \\
\hline PG 76-22 PM & $9.5 \mathrm{~mm}$ & FT 1A & $7.4 \%$ & $8.0 \%$ & $9.3 \%$ & $6.4 \%$ & $6.5 \%$ & $6.8 \%$ \\
\hline PG 76-22 PM & $9.5 \mathrm{~mm}$ & FT 1A2 & $7.4 \%$ & $8.1 \%$ & $9.3 \%$ & $6.5 \%$ & $6.8 \%$ & $6.7 \%$ \\
\hline PG 76-22 PM & $9.5 \mathrm{~mm}$ & FT 1B & $7.5 \%$ & $8.4 \%$ & $9.3 \%$ & $6.3 \%$ & $6.5 \%$ & $6.7 \%$ \\
\hline PG 76-22 PM & $9.5 \mathrm{~mm}$ & FT 1B2 & $7.4 \%$ & $8.2 \%$ & $9.2 \%$ & $6.4 \%$ & $6.6 \%$ & $6.7 \%$ \\
\hline PG 76-22 PM & $9.5 \mathrm{~mm}$ & FT 1C & $7.4 \%$ & $8.1 \%$ & $9.2 \%$ & $6.3 \%$ & $6.6 \%$ & $6.6 \%$ \\
\hline PG 76-22 PM & $9.5 \mathrm{~mm}$ & FT 2A & $7.4 \%$ & $8.2 \%$ & $9.3 \%$ & $6.2 \%$ & $6.3 \%$ & $6.5 \%$ \\
\hline PG 76-22 PM & $9.5 \mathrm{~mm}$ & FT 2B & $7.4 \%$ & $8.2 \%$ & $9.3 \%$ & $6.2 \%$ & $6.2 \%$ & $6.6 \%$ \\
\hline PG 76-22 PM & $9.5 \mathrm{~mm}$ & FT 2C & $7.5 \%$ & $8.2 \%$ & $9.3 \%$ & $6.4 \%$ & $6.6 \%$ & $6.7 \%$ \\
\hline PG 76-22 PM & $9.5 \mathrm{~mm}$ & FT 3A & $7.4 \%$ & $8.2 \%$ & $9.2 \%$ & $6.4 \%$ & $6.5 \%$ & $6.8 \%$ \\
\hline PG 76-22 PM & $9.5 \mathrm{~mm}$ & FT 3B & $7.6 \%$ & $8.2 \%$ & $9.3 \%$ & $6.5 \%$ & $6.5 \%$ & $7.3 \%$ \\
\hline PG 76-22 PM & $9.5 \mathrm{~mm}$ & FT 3C & $7.6 \%$ & $8.2 \%$ & $9.3 \%$ & $6.3 \%$ & $6.5 \%$ & $6.7 \%$ \\
\hline PG 76-22 PM & $9.5 \mathrm{~mm}$ & DM 1 & $8.0 \%$ & $9.0 \%$ & $10.0 \%$ & $7.6 \%$ & $7.5 \%$ & $7.8 \%$ \\
\hline PG 76-22 PM & $9.5 \mathrm{~mm}$ & DM 2 & $7.4 \%$ & $8.2 \%$ & $9.3 \%$ & $6.6 \%$ & $6.7 \%$ & $7.1 \%$ \\
\hline PG 76-22 PM & $9.5 \mathrm{~mm}$ & DM 3 & $7.5 \%$ & $8.2 \%$ & $9.3 \%$ & $6.6 \%$ & $6.6 \%$ & $7.0 \%$ \\
\hline
\end{tabular}




\begin{tabular}{|c|c|c|c|c|c|c|c|c|}
\cline { 3 - 8 } \multicolumn{2}{c}{ Binder Type } & NMAS & $\begin{array}{c}\text { Sample } \\
\text { Designation }\end{array}$ & SSD & CoreLok & Dimensional & \multirow{2}{*}{ SSD } & \multirow{2}{*}{ CoreLok } \\
\cline { 4 - 9 } Dimensional \\
\hline PG 76-22 PM & $12.5 \mathrm{~mm}$ & FT 1A & $7.2 \%$ & $7.9 \%$ & $9.2 \%$ & $6.3 \%$ & $6.3 \%$ & $6.6 \%$ \\
\hline PG 76-22 PM & $12.5 \mathrm{~mm}$ & FT 1B & $7.2 \%$ & $7.9 \%$ & $9.2 \%$ & $6.5 \%$ & $6.5 \%$ & $6.8 \%$ \\
\hline PG 76-22 PM & $12.5 \mathrm{~mm}$ & FT 1C & $7.3 \%$ & $8.0 \%$ & $9.1 \%$ & $6.3 \%$ & $6.3 \%$ & $6.7 \%$ \\
\hline PG 76-22 PM & $12.5 \mathrm{~mm}$ & FT 2A & $7.3 \%$ & $7.9 \%$ & $9.2 \%$ & $6.2 \%$ & $6.4 \%$ & $6.4 \%$ \\
\hline PG 76-22 PM & $12.5 \mathrm{~mm}$ & FT 2B & $7.4 \%$ & $8.0 \%$ & $9.2 \%$ & $6.1 \%$ & $6.2 \%$ & $6.4 \%$ \\
\hline PG 76-22 PM & $12.5 \mathrm{~mm}$ & FT 2C & $7.4 \%$ & $8.0 \%$ & $9.2 \%$ & $6.2 \%$ & $6.3 \%$ & $6.4 \%$ \\
\hline PG 76-22 PM & $12.5 \mathrm{~mm}$ & FT 3A & $7.4 \%$ & $8.2 \%$ & $9.3 \%$ & $6.8 \%$ & $6.9 \%$ & $7.0 \%$ \\
\hline PG 76-22 PM & $12.5 \mathrm{~mm}$ & FT 3B & $7.2 \%$ & $8.2 \%$ & $9.2 \%$ & $6.6 \%$ & $6.6 \%$ & $6.9 \%$ \\
\hline PG 76-22 PM & $12.5 \mathrm{~mm}$ & FT 3C & $7.2 \%$ & $7.9 \%$ & $9.1 \%$ & $6.4 \%$ & $6.3 \%$ & $6.6 \%$ \\
\hline PG 76-22 PM & $12.5 \mathrm{~mm}$ & DM 1 & $7.3 \%$ & $8.1 \%$ & $9.2 \%$ & $7.1 \%$ & $7.1 \%$ & $7.4 \%$ \\
\hline PG 76-22 PM & $12.5 \mathrm{~mm}$ & DM 2 & $7.1 \%$ & $8.3 \%$ & $9.2 \%$ & $6.9 \%$ & $6.8 \%$ & $7.3 \%$ \\
\hline PG 76-22 PM & $12.5 \mathrm{~mm}$ & DM 3 & $7.2 \%$ & $8.0 \%$ & $9.2 \%$ & $6.6 \%$ & $6.5 \%$ & $7.0 \%$ \\
\hline
\end{tabular}


Sample Geometry After Coring and Sawing

\begin{tabular}{|c|c|c|c|c|c|c|}
\hline \multirow{2}{*}{ Binder Type } & \multirow{2}{*}{ NMAS } & \multirow{2}{*}{$\begin{array}{c}\text { Sample } \\
\text { Designation }\end{array}$} & \multicolumn{2}{|c|}{ Diameter } & \multicolumn{2}{c|}{ Height } \\
\cline { 5 - 7 } & & & Average & $\begin{array}{c}\text { Standard } \\
\text { Deviation }\end{array}$ & Average & $\begin{array}{c}\text { Standard } \\
\text { Deviation }\end{array}$ \\
\hline PG 70-22 & $9.5 \mathrm{~mm}$ & FT 1A & 100.46 & 0.06 & 129.86 & 0.32 \\
\hline PG 70-22 & $9.5 \mathrm{~mm}$ & FT 1B & 100.43 & 0.02 & 130.85 & 0.24 \\
\hline PG 70-22 & $9.5 \mathrm{~mm}$ & FT 1C & 100.44 & 0.03 & 129.36 & 0.51 \\
\hline PG 70-22 & $9.5 \mathrm{~mm}$ & FT 2A & 100.43 & 0.02 & 129.62 & 0.32 \\
\hline PG 70-22 & $9.5 \mathrm{~mm}$ & FT 2B & 100.41 & 0.03 & 130.93 & 0.24 \\
\hline PG 70-22 & $9.5 \mathrm{~mm}$ & FT 2C & 100.42 & 0.05 & 129.64 & 0.32 \\
\hline PG 70-22 & $9.5 \mathrm{~mm}$ & FT 3A & 100.49 & 0.08 & 131.60 & 0.42 \\
\hline PG 70-22 & $9.5 \mathrm{~mm}$ & FT 3B & 100.47 & 0.05 & 130.14 & 0.48 \\
\hline PG 70-22 & $9.5 \mathrm{~mm}$ & FT 3C & 100.44 & 0.02 & 130.84 & 0.50 \\
\hline PG 70-22 & $9.5 \mathrm{~mm}$ & DM 1 & 100.48 & 0.02 & 150.10 & 0.47 \\
\hline PG 70-22 & $9.5 \mathrm{~mm}$ & DM 2 & 100.43 & 0.13 & 150.21 & 0.38 \\
\hline PG 70-22 & $9.5 \mathrm{~mm}$ & DM 3 & 100.46 & 0.02 & 150.90 & 0.08 \\
\hline
\end{tabular}

\begin{tabular}{|c|c|c|c|c|c|c|}
\hline \multirow{2}{*}{ Binder Type } & \multirow{2}{*}{ NMAS } & \multirow{2}{*}{$\begin{array}{c}\text { Sample } \\
\text { Designation }\end{array}$} & \multicolumn{2}{|c|}{ Diameter } & \multicolumn{2}{|c|}{ Height } \\
\cline { 5 - 7 } & & & & $\begin{array}{c}\text { Standard } \\
\text { Deviation }\end{array}$ & Average & $\begin{array}{c}\text { Standard } \\
\text { Deviation }\end{array}$ \\
\hline PG 70-22 & $12.5 \mathrm{~mm}$ & FT 1A & 100.42 & 0.03 & 129.97 & 0.21 \\
\hline PG 70-22 & $12.5 \mathrm{~mm}$ & FT 1B & 100.43 & 0.02 & 129.13 & 0.59 \\
\hline PG 70-22 & $12.5 \mathrm{~mm}$ & FT 1C & 100.42 & 0.03 & 130.02 & 0.29 \\
\hline PG 70-22 & $12.5 \mathrm{~mm}$ & FT 2A & 100.42 & 0.03 & 129.58 & 0.67 \\
\hline PG 70-22 & $12.5 \mathrm{~mm}$ & FT 2B & 100.43 & 0.04 & 129.70 & 0.47 \\
\hline PG 70-22 & $12.5 \mathrm{~mm}$ & FT 2C & 100.45 & 0.03 & 129.63 & 0.67 \\
\hline PG 70-22 & $12.5 \mathrm{~mm}$ & FT 3A & 100.43 & 0.02 & 129.36 & 0.63 \\
\hline PG 70-22 & $12.5 \mathrm{~mm}$ & FT 3B & 100.43 & 0.03 & 130.32 & 0.43 \\
\hline PG 70-22 & $12.5 \mathrm{~mm}$ & FT 3C & 100.44 & 0.02 & 130.39 & 0.33 \\
\hline PG 70-22 & $12.5 \mathrm{~mm}$ & DM 1 & 100.38 & 0.06 & 151.13 & 0.07 \\
\hline PG 70-22 & $12.5 \mathrm{~mm}$ & DM 2 & 100.45 & 0.06 & 150.17 & 0.09 \\
\hline PG 70-22 & $12.5 \mathrm{~mm}$ & DM 3 & 100.45 & 0.02 & 149.30 & 0.36 \\
\hline
\end{tabular}




\begin{tabular}{|c|c|c|c|c|c|c|}
\hline \multirow{2}{*}{ Binder Type } & \multirow{2}{*}{ NMAS } & \multirow{2}{*}{$\begin{array}{c}\text { Sample } \\
\text { Designation }\end{array}$} & \multicolumn{2}{|c|}{ Diameter } & \multicolumn{2}{c|}{ Height } \\
\cline { 5 - 7 } & & & & $\begin{array}{c}\text { Standard } \\
\text { Deviation }\end{array}$ & Average & $\begin{array}{c}\text { Standard } \\
\text { Deviation }\end{array}$ \\
\hline PG 70-22 PM & $9.5 \mathrm{~mm}$ & FT 1A & 100.44 & 0.01 & 130.50 & 0.43 \\
\hline PG 70-22 PM & $9.5 \mathrm{~mm}$ & FT 1B & 100.43 & 0.02 & 130.15 & 0.42 \\
\hline PG 70-22 PM & $9.5 \mathrm{~mm}$ & FT 1C & 100.43 & 0.04 & 130.13 & 0.36 \\
\hline PG 70-22 PM & $9.5 \mathrm{~mm}$ & FT 2A & 100.41 & 0.04 & 130.21 & 0.38 \\
\hline PG 70-22 PM & $9.5 \mathrm{~mm}$ & FT 2B & 100.41 & 0.03 & 130.27 & 0.37 \\
\hline PG 70-22 PM & $9.5 \mathrm{~mm}$ & FT 2C & 100.44 & 0.02 & 130.32 & 0.48 \\
\hline PG 70-22 PM & $9.5 \mathrm{~mm}$ & FT 3A & 100.41 & 0.02 & 131.02 & 0.50 \\
\hline PG 70-22 PM & $9.5 \mathrm{~mm}$ & FT 3B & 100.42 & 0.04 & 130.93 & 0.45 \\
\hline PG 70-22 PM & $9.5 \mathrm{~mm}$ & FT 3C & 100.43 & 0.03 & 129.93 & 0.52 \\
\hline PG 70-22 PM & $9.5 \mathrm{~mm}$ & DM 1 & 100.46 & 0.05 & 150.39 & 0.24 \\
\hline PG 70-22 PM & $9.5 \mathrm{~mm}$ & DM 2 & 100.47 & 0.05 & 148.50 & 0.08 \\
\hline PG 70-22 PM & $9.5 \mathrm{~mm}$ & DM 3 & 100.46 & 0.04 & 149.87 & 0.31 \\
\hline
\end{tabular}

\begin{tabular}{|c|c|c|c|c|c|c|}
\hline \multirow{2}{*}{ Binder Type } & \multirow{2}{*}{ NMAS } & \multirow{2}{*}{$\begin{array}{c}\text { Sample } \\
\text { Designation }\end{array}$} & Average & $\begin{array}{c}\text { Standard } \\
\text { Deviation }\end{array}$ & Average & $\begin{array}{c}\text { Standard } \\
\text { Deviation }\end{array}$ \\
\cline { 5 - 7 } & & & & 0.05 & 130.07 & 0.18 \\
\hline PG 70-22 PM & $12.5 \mathrm{~mm}$ & FT 1A & 100.43 & 0.03 & 130.87 & 0.32 \\
\hline PG 70-22 PM & $12.5 \mathrm{~mm}$ & FT 1B & 100.41 & 0.02 & 131.26 & 0.22 \\
\hline PG 70-22 PM & $12.5 \mathrm{~mm}$ & FT 1C & 100.41 & 0.04 & 131.03 & 0.28 \\
\hline PG 70-22 PM & $12.5 \mathrm{~mm}$ & FT 2A & 100.42 & 0.03 & 129.31 & 0.25 \\
\hline PG 70-22 PM & $12.5 \mathrm{~mm}$ & FT 2B & 100.42 & 0.03 & 131.34 & 0.26 \\
\hline PG 70-22 PM & $12.5 \mathrm{~mm}$ & FT 2C & 100.44 & 0.04 & 130.21 & 0.35 \\
\hline PG 70-22 PM & $12.5 \mathrm{~mm}$ & FT 3A & 100.41 & 0.05 & 129.84 & 0.33 \\
\hline PG 70-22 PM & $12.5 \mathrm{~mm}$ & FT 3B & 100.42 & 0.43 & 130.18 & 0.52 \\
\hline PG 70-22 PM & $12.5 \mathrm{~mm}$ & FT 3C & 100.43 & 0.03 & 151.16 & 0.16 \\
\hline PG 70-22 PM & $12.5 \mathrm{~mm}$ & DM 1 & 100.47 & 0.02 & 150.22 & 0.49 \\
\hline PG 70-22 PM & $12.5 \mathrm{~mm}$ & DM 2 & 100.47 & 0.05 & 150.95 & 0.57 \\
\hline PG 70-22 PM & $12.5 \mathrm{~mm}$ & DM 3 & 100.50 & 0.05 & & \\
\hline
\end{tabular}




\begin{tabular}{|c|c|c|c|c|c|c|}
\hline \multirow{2}{*}{ Binder Type } & \multirow{2}{*}{ NMAS } & \multirow{2}{*}{$\begin{array}{c}\text { Sample } \\
\text { Designation }\end{array}$} & \multicolumn{2}{|c|}{ Diameter } & \multicolumn{2}{c|}{ Height } \\
\cline { 5 - 7 } & & & & $\begin{array}{c}\text { Standard } \\
\text { Deviation }\end{array}$ & Average & $\begin{array}{c}\text { Standard } \\
\text { Deviation }\end{array}$ \\
\hline PG 76-22 PM & $9.5 \mathrm{~mm}$ & FT 1A & 100.47 & 0.02 & 130.25 & 0.27 \\
\hline PG 76-22 PM & $9.5 \mathrm{~mm}$ & FT 1A2 & 100.43 & 0.03 & 129.39 & 0.36 \\
\hline PG 76-22 PM & $9.5 \mathrm{~mm}$ & FT 1B & 100.45 & 0.05 & 130.91 & 0.36 \\
\hline PG 76-22 PM & $9.5 \mathrm{~mm}$ & FT 1B2 & 100.47 & 0.04 & 129.89 & 0.48 \\
\hline PG 76-22 PM & $9.5 \mathrm{~mm}$ & FT 1C & 100.46 & 0.05 & 131.14 & 0.09 \\
\hline PG 76-22 PM & $9.5 \mathrm{~mm}$ & FT 2A & 100.45 & 0.03 & 130.08 & 0.38 \\
\hline PG 76-22 PM & $9.5 \mathrm{~mm}$ & FT 2B & 100.46 & 0.03 & 130.70 & 0.09 \\
\hline PG 76-22 PM & $9.5 \mathrm{~mm}$ & FT 2C & 100.45 & 0.01 & 130.23 & 0.37 \\
\hline PG 76-22 PM & $9.5 \mathrm{~mm}$ & FT 3A & 100.44 & 0.04 & 130.40 & 0.24 \\
\hline PG 76-22 PM & $9.5 \mathrm{~mm}$ & FT 3B & 100.45 & 0.01 & 131.40 & 0.17 \\
\hline PG 76-22 PM & $9.5 \mathrm{~mm}$ & FT 3C & 100.44 & 0.01 & 131.32 & 0.44 \\
\hline PG 76-22 PM & $9.5 \mathrm{~mm}$ & DM 1 & 100.41 & 0.02 & 151.88 & 0.26 \\
\hline PG 76-22 PM & $9.5 \mathrm{~mm}$ & DM 2 & 100.51 & 0.04 & 150.53 & 0.10 \\
\hline PG 76-22 PM & $9.5 \mathrm{~mm}$ & DM 3 & 100.44 & 0.02 & 151.09 & 0.37 \\
\hline
\end{tabular}

\begin{tabular}{|c|c|c|c|c|c|c|}
\hline \multirow{2}{*}{ Binder Type } & \multirow{2}{*}{ NMAS } & \multirow{2}{*}{$\begin{array}{c}\text { Sample } \\
\text { Designation }\end{array}$} & \multicolumn{2}{|c|}{ Diameter } & \multicolumn{2}{c|}{ Height } \\
\cline { 5 - 7 } & & & Average & $\begin{array}{c}\text { Standard } \\
\text { Deviation }\end{array}$ & Average & $\begin{array}{c}\text { Standard } \\
\text { Deviation }\end{array}$ \\
\hline PG 76-22 PM & $12.5 \mathrm{~mm}$ & FT 1A & 100.43 & 0.03 & 130.57 & 0.17 \\
\hline PG 76-22 PM & $12.5 \mathrm{~mm}$ & FT 1B & 100.43 & 0.04 & 129.74 & 0.45 \\
\hline PG 76-22 PM & $12.5 \mathrm{~mm}$ & FT 1C & 100.46 & 0.02 & 130.40 & 0.22 \\
\hline PG 76-22 PM & $12.5 \mathrm{~mm}$ & FT 2A & 100.44 & 0.02 & 129.99 & 0.35 \\
\hline PG 76-22 PM & $12.5 \mathrm{~mm}$ & FT 2B & 100.44 & 0.01 & 131.20 & 0.26 \\
\hline PG 76-22 PM & $12.5 \mathrm{~mm}$ & FT 2C & 100.42 & 0.02 & 130.34 & 0.32 \\
\hline PG 76-22 PM & $12.5 \mathrm{~mm}$ & FT 3A & 100.43 & 0.02 & 130.04 & 0.52 \\
\hline PG 76-22 PM & $12.5 \mathrm{~mm}$ & FT 3B & 100.44 & 0.02 & 131.82 & 0.18 \\
\hline PG 76-22 PM & $12.5 \mathrm{~mm}$ & FT 3C & 100.42 & 0.01 & 130.18 & 0.44 \\
\hline PG 76-22 PM & $12.5 \mathrm{~mm}$ & DM 1 & 100.42 & 0.04 & 152.04 & 0.20 \\
\hline PG 76-22 PM & $12.5 \mathrm{~mm}$ & DM 2 & 100.46 & 0.03 & 150.11 & 0.23 \\
\hline PG 76-22 PM & $12.5 \mathrm{~mm}$ & DM 3 & 100.46 & 0.02 & 150.31 & 0.53 \\
\hline
\end{tabular}




\section{Appendix C - Cut Sample Volumetrics}

\section{Bulk Specific Gravities $\left(\mathrm{G}_{\mathrm{mb}}\right)$ for Sample Thirds}

\begin{tabular}{|c|c|c|c|c|c|c|}
\hline Binder Type & NMAS & $\begin{array}{c}\text { Sample } \\
\text { Designation }\end{array}$ & Section & SSD & CoreLok & Dimensional \\
\hline PG 70-22 & $9.5 \mathrm{~mm}$ & DM 1 & Top & 2.301 & 2.295 & 2.280 \\
\hline PG 70-22 & $9.5 \mathrm{~mm}$ & DM 1 & Middle & 2.266 & 2.261 & 2.251 \\
\hline PG 70-22 & $9.5 \mathrm{~mm}$ & DM 1 & Bottom & 2.303 & 2.299 & 2.292 \\
\hline PG 70-22 & $9.5 \mathrm{~mm}$ & DM 2 & Top & 2.311 & 2.303 & 2.294 \\
\hline PG 70-22 & $9.5 \mathrm{~mm}$ & DM 2 & Middle & 2.276 & 2.272 & 2.258 \\
\hline PG 70-22 & $9.5 \mathrm{~mm}$ & DM 2 & Bottom & 2.302 & 2.293 & 2.286 \\
\hline PG 70-22 & $9.5 \mathrm{~mm}$ & DM 3 & Top & 2.315 & 2.306 & 2.304 \\
\hline PG 70-22 & $9.5 \mathrm{~mm}$ & DM 3 & Middle & 2.283 & 2.277 & 2.272 \\
\hline PG 70-22 & $9.5 \mathrm{~mm}$ & DM 3 & Bottom & 2.297 & 2.292 & 2.286 \\
\hline
\end{tabular}

\begin{tabular}{|c|c|c|c|c|c|c|}
\hline Binder Type & NMAS & $\begin{array}{c}\text { Sample } \\
\text { Designation }\end{array}$ & Section & SSD & CoreLok & Dimensional \\
\hline PG 70-22 & $12.5 \mathrm{~mm}$ & DM 1 & Top & 2.300 & 2.299 & 2.287 \\
\hline PG 70-22 & $12.5 \mathrm{~mm}$ & DM 1 & Middle & 2.267 & 2.262 & 2.257 \\
\hline PG 70-22 & $12.5 \mathrm{~mm}$ & DM 1 & Bottom & 2.288 & 2.284 & 2.278 \\
\hline PG 70-22 & $12.5 \mathrm{~mm}$ & DM 2 & Top & 2.306 & 2.287 & 2.296 \\
\hline PG 70-22 & $12.5 \mathrm{~mm}$ & DM 2 & Middle & 2.281 & 2.274 & 2.269 \\
\hline PG 70-22 & $12.5 \mathrm{~mm}$ & DM 2 & Bottom & 2.298 & 2.286 & 2.287 \\
\hline PG 70-22 & $12.5 \mathrm{~mm}$ & DM 3 & Top & 2.308 & 2.301 & 2.291 \\
\hline PG 70-22 & $12.5 \mathrm{~mm}$ & DM 3 & Middle & 2.284 & 2.263 & 2.257 \\
\hline PG 70-22 & $12.5 \mathrm{~mm}$ & DM 3 & Bottom & 2.304 & 2.297 & 2.284 \\
\hline
\end{tabular}




\begin{tabular}{|c|c|c|c|c|c|c|}
\hline Binder Type & NMAS & $\begin{array}{c}\text { Sample } \\
\text { Designation }\end{array}$ & Section & SSD & CoreLok & Dimensional \\
\hline PG 70-22 PM & $9.5 \mathrm{~mm}$ & DM 1 & Top & 2.302 & 2.294 & 2.286 \\
\hline PG 70-22 PM & $9.5 \mathrm{~mm}$ & DM 1 & Middle & 2.276 & 2.272 & 2.260 \\
\hline PG 70-22 PM & $9.5 \mathrm{~mm}$ & DM 1 & Bottom & 2.312 & 2.309 & 2.291 \\
\hline PG 70-22 PM & $9.5 \mathrm{~mm}$ & DM 2 & Top & 2.308 & 2.307 & 2.298 \\
\hline PG 70-22 PM & $9.5 \mathrm{~mm}$ & DM 2 & Middle & 2.275 & 2.268 & 2.269 \\
\hline PG 70-22 PM & $9.5 \mathrm{~mm}$ & DM 2 & Bottom & 2.308 & 2.303 & 2.307 \\
\hline PG 70-22 PM & $9.5 \mathrm{~mm}$ & DM 3 & Top & 2.305 & 2.299 & 2.290 \\
\hline PG 70-22 PM & $9.5 \mathrm{~mm}$ & DM 3 & Middle & 2.286 & 2.273 & 2.284 \\
\hline PG 70-22 PM & $9.5 \mathrm{~mm}$ & DM 3 & Bottom & 2.312 & 2.309 & 2.306 \\
\hline
\end{tabular}

\begin{tabular}{|c|c|c|c|c|c|c|}
\hline Binder Type & NMAS & $\begin{array}{c}\text { Sample } \\
\text { Designation }\end{array}$ & Section & SSD & CoreLok & Dimensional \\
\hline PG 70-22 PM & $12.5 \mathrm{~mm}$ & DM 1 & Top & 2.297 & 2.288 & 2.286 \\
\hline PG 70-22 PM & $12.5 \mathrm{~mm}$ & DM 1 & Middle & 2.280 & 2.276 & 2.269 \\
\hline PG 70-22 PM & $12.5 \mathrm{~mm}$ & DM 1 & Bottom & 2.308 & 2.305 & 2.302 \\
\hline PG 70-22 PM & $12.5 \mathrm{~mm}$ & DM 2 & Top & 2.313 & 2.314 & 2.299 \\
\hline PG 70-22 PM & $12.5 \mathrm{~mm}$ & DM 2 & Middle & 2.283 & 2.276 & 2.270 \\
\hline PG 70-22 PM & $12.5 \mathrm{~mm}$ & DM 2 & Bottom & 2.294 & 2.298 & 2.284 \\
\hline PG 70-22 PM & $12.5 \mathrm{~mm}$ & DM 3 & Top & 2.304 & 2.292 & 2.299 \\
\hline PG 70-22 PM & $12.5 \mathrm{~mm}$ & DM 3 & Middle & 2.284 & 2.222 & 2.274 \\
\hline PG 70-22 PM & $12.5 \mathrm{~mm}$ & DM 3 & Bottom & 2.293 & 2.285 & 2.282 \\
\hline
\end{tabular}




\begin{tabular}{|c|c|c|c|c|c|c|}
\hline Binder Type & NMAS & $\begin{array}{c}\text { Sample } \\
\text { Designation }\end{array}$ & Section & SSD & CoreLok & Dimensional \\
\hline PG 76-22 PM & $9.5 \mathrm{~mm}$ & DM 1 & Top & 2.282 & 2.280 & 2.274 \\
\hline PG 76-22 PM & $9.5 \mathrm{~mm}$ & DM 1 & Middle & 2.257 & 2.227 & 2.251 \\
\hline PG 76-22 PM & $9.5 \mathrm{~mm}$ & DM 1 & Bottom & 2.287 & 2.281 & 2.280 \\
\hline PG 76-22 PM & $9.5 \mathrm{~mm}$ & DM 2 & Top & 2.308 & 2.304 & 2.292 \\
\hline PG 76-22 PM & $9.5 \mathrm{~mm}$ & DM 2 & Middle & 2.276 & 2.268 & 2.267 \\
\hline PG 76-22 PM & $9.5 \mathrm{~mm}$ & DM 2 & Bottom & 2.323 & 2.317 & 2.312 \\
\hline PG 76-22 PM & $9.5 \mathrm{~mm}$ & DM 3 & Top & 2.317 & 2.309 & 2.307 \\
\hline PG 76-22 PM & $9.5 \mathrm{~mm}$ & DM 3 & Middle & 2.285 & 2.272 & 2.276 \\
\hline PG 76-22 PM & $9.5 \mathrm{~mm}$ & DM 3 & Bottom & 2.308 & 2.300 & 2.301 \\
\hline
\end{tabular}

\begin{tabular}{|c|c|c|c|c|c|c|}
\hline Binder Type & NMAS & $\begin{array}{c}\text { Sample } \\
\text { Designation }\end{array}$ & Section & SSD & CoreLok & Dimensional \\
\hline PG 76-22 PM & $12.5 \mathrm{~mm}$ & DM 1 & Top & 2.297 & 2.293 & 2.277 \\
\hline PG 76-22 PM & $12.5 \mathrm{~mm}$ & DM 1 & Middle & 2.274 & 2.271 & 2.272 \\
\hline PG 76-22 PM & $12.5 \mathrm{~mm}$ & DM 1 & Bottom & 2.289 & 2.288 & 2.286 \\
\hline PG 76-22 PM & $12.5 \mathrm{~mm}$ & DM 2 & Top & 2.296 & 2.284 & 2.292 \\
\hline PG 76-22 PM & $12.5 \mathrm{~mm}$ & DM 2 & Middle & 2.278 & 2.269 & 2.264 \\
\hline PG 76-22 PM & $12.5 \mathrm{~mm}$ & DM 2 & Bottom & 2.303 & 2.297 & 2.295 \\
\hline PG 76-22 PM & $12.5 \mathrm{~mm}$ & DM 3 & Top & 2.304 & 2.167 & 2.294 \\
\hline PG 76-22 PM & $12.5 \mathrm{~mm}$ & DM 3 & Middle & 2.287 & 2.286 & 2.265 \\
\hline PG 76-22 PM & $12.5 \mathrm{~mm}$ & DM 3 & Bottom & 2.312 & 2.311 & 2.298 \\
\hline
\end{tabular}


Sample Thirds Voids in Total Mix (VTM)

\begin{tabular}{|c|c|c|c|c|c|c|}
\hline Binder Type & NMAS & $\begin{array}{c}\text { Sample } \\
\text { Designation }\end{array}$ & Section & SSD & CoreLok & Dimensional \\
\hline PG 70-22 & $9.5 \mathrm{~mm}$ & DM 1 & Top & $6.7 \%$ & $6.9 \%$ & $7.5 \%$ \\
\hline PG 70-22 & $9.5 \mathrm{~mm}$ & DM 1 & Middle & $8.1 \%$ & $8.3 \%$ & $8.7 \%$ \\
\hline PG 70-22 & $9.5 \mathrm{~mm}$ & DM 1 & Bottom & $6.6 \%$ & $6.8 \%$ & $7.1 \%$ \\
\hline PG 70-22 & $9.5 \mathrm{~mm}$ & DM 2 & Top & $6.3 \%$ & $6.6 \%$ & $7.0 \%$ \\
\hline PG 70-22 & $9.5 \mathrm{~mm}$ & DM 2 & Middle & $7.7 \%$ & $7.9 \%$ & $8.4 \%$ \\
\hline PG 70-22 & $9.5 \mathrm{~mm}$ & DM 2 & Bottom & $6.7 \%$ & $7.0 \%$ & $7.3 \%$ \\
\hline PG 70-22 & $9.5 \mathrm{~mm}$ & DM 3 & Top & $6.1 \%$ & $6.5 \%$ & $6.6 \%$ \\
\hline PG 70-22 & $9.5 \mathrm{~mm}$ & DM 3 & Middle & $7.4 \%$ & $7.6 \%$ & $7.9 \%$ \\
\hline PG 70-22 & $9.5 \mathrm{~mm}$ & DM 3 & Bottom & $6.8 \%$ & $7.1 \%$ & $7.3 \%$ \\
\hline
\end{tabular}

\begin{tabular}{|c|c|c|c|c|c|c|}
\hline Binder Type & NMAS & $\begin{array}{c}\text { Sample } \\
\text { Designation }\end{array}$ & Section & SSD & CoreLok & Dimensional \\
\hline PG 70-22 & $12.5 \mathrm{~mm}$ & DM 1 & Top & $6.7 \%$ & $6.7 \%$ & $7.2 \%$ \\
\hline PG 70-22 & $12.5 \mathrm{~mm}$ & DM 1 & Middle & $8.0 \%$ & $8.2 \%$ & $8.4 \%$ \\
\hline PG 70-22 & $12.5 \mathrm{~mm}$ & DM 1 & Bottom & $7.1 \%$ & $7.3 \%$ & $7.5 \%$ \\
\hline PG 70-22 & $12.5 \mathrm{~mm}$ & DM 2 & Top & $6.4 \%$ & $7.2 \%$ & $6.8 \%$ \\
\hline PG 70-22 & $12.5 \mathrm{~mm}$ & DM 2 & Middle & $7.4 \%$ & $7.7 \%$ & $7.9 \%$ \\
\hline PG 70-22 & $12.5 \mathrm{~mm}$ & DM 2 & Bottom & $6.7 \%$ & $7.2 \%$ & $7.2 \%$ \\
\hline PG 70-22 & $12.5 \mathrm{~mm}$ & DM 3 & Top & $6.3 \%$ & $6.6 \%$ & $7.0 \%$ \\
\hline PG 70-22 & $12.5 \mathrm{~mm}$ & DM 3 & Middle & $7.3 \%$ & $8.2 \%$ & $8.4 \%$ \\
\hline PG 70-22 & $12.5 \mathrm{~mm}$ & DM 3 & Bottom & $6.5 \%$ & $6.8 \%$ & $7.3 \%$ \\
\hline
\end{tabular}




\begin{tabular}{|c|c|c|c|c|c|c|}
\hline Binder Type & NMAS & $\begin{array}{c}\text { Sample } \\
\text { Designation }\end{array}$ & Section & SSD & CoreLok & Dimensional \\
\hline PG 70-22 PM & $9.5 \mathrm{~mm}$ & DM 1 & Top & $6.7 \%$ & $7.0 \%$ & $7.3 \%$ \\
\hline PG 70-22 PM & $9.5 \mathrm{~mm}$ & DM 1 & Middle & $7.7 \%$ & $7.9 \%$ & $8.4 \%$ \\
\hline PG 70-22 PM & $9.5 \mathrm{~mm}$ & DM 1 & Bottom & $6.2 \%$ & $6.4 \%$ & $7.1 \%$ \\
\hline PG 70-22 PM & $9.5 \mathrm{~mm}$ & DM 2 & Top & $6.4 \%$ & $6.5 \%$ & $6.8 \%$ \\
\hline PG 70-22 PM & $9.5 \mathrm{~mm}$ & DM 2 & Middle & $7.8 \%$ & $8.0 \%$ & $8.0 \%$ \\
\hline PG 70-22 PM & $9.5 \mathrm{~mm}$ & DM 2 & Bottom & $6.4 \%$ & $6.6 \%$ & $6.4 \%$ \\
\hline PG 70-22 PM & $9.5 \mathrm{~mm}$ & DM 3 & Top & $6.5 \%$ & $6.8 \%$ & $7.1 \%$ \\
\hline PG 70-22 PM & $9.5 \mathrm{~mm}$ & DM 3 & Middle & $7.3 \%$ & $7.8 \%$ & $7.4 \%$ \\
\hline PG 70-22 PM & $9.5 \mathrm{~mm}$ & DM 3 & Bottom & $6.2 \%$ & $6.4 \%$ & $6.5 \%$ \\
\hline
\end{tabular}

\begin{tabular}{|c|c|c|c|c|c|c|}
\hline Binder Type & NMAS & $\begin{array}{c}\text { Sample } \\
\text { Designation }\end{array}$ & Section & SSD & CoreLok & Dimensional \\
\hline PG 70-22 PM & $12.5 \mathrm{~mm}$ & DM 1 & Top & $6.8 \%$ & $7.1 \%$ & $7.2 \%$ \\
\hline PG 70-22 PM & $12.5 \mathrm{~mm}$ & DM 1 & Middle & $7.5 \%$ & $7.6 \%$ & $7.9 \%$ \\
\hline PG 70-22 PM & $12.5 \mathrm{~mm}$ & DM 1 & Bottom & $6.3 \%$ & $6.5 \%$ & $6.6 \%$ \\
\hline PG 70-22 PM & $12.5 \mathrm{~mm}$ & DM 2 & Top & $6.1 \%$ & $6.1 \%$ & $6.7 \%$ \\
\hline PG 70-22 PM & $12.5 \mathrm{~mm}$ & DM 2 & Middle & $7.3 \%$ & $7.6 \%$ & $7.9 \%$ \\
\hline PG 70-22 PM & $12.5 \mathrm{~mm}$ & DM 2 & Bottom & $6.9 \%$ & $6.8 \%$ & $7.3 \%$ \\
\hline PG 70-22 PM & $12.5 \mathrm{~mm}$ & DM 3 & Top & $6.5 \%$ & $7.0 \%$ & $6.7 \%$ \\
\hline PG 70-22 PM & $12.5 \mathrm{~mm}$ & DM 3 & Middle & $7.3 \%$ & $9.8 \%$ & $7.7 \%$ \\
\hline PG 70-22 PM & $12.5 \mathrm{~mm}$ & DM 3 & Bottom & $6.9 \%$ & $7.3 \%$ & $7.4 \%$ \\
\hline
\end{tabular}




\begin{tabular}{|c|c|c|c|c|c|c|}
\hline Binder Type & NMAS & $\begin{array}{c}\text { Sample } \\
\text { Designation }\end{array}$ & Section & SSD & CoreLok & Dimensional \\
\hline PG 76-22 PM & $9.5 \mathrm{~mm}$ & DM 1 & Top & $7.5 \%$ & $7.5 \%$ & $7.8 \%$ \\
\hline PG 76-22 PM & $9.5 \mathrm{~mm}$ & DM 1 & Middle & $8.5 \%$ & $9.7 \%$ & $8.7 \%$ \\
\hline PG 76-22 PM & $9.5 \mathrm{~mm}$ & DM 1 & Bottom & $7.2 \%$ & $7.5 \%$ & $7.5 \%$ \\
\hline PG 76-22 PM & $9.5 \mathrm{~mm}$ & DM 2 & Top & $6.4 \%$ & $6.6 \%$ & $7.1 \%$ \\
\hline PG 76-22 PM & $9.5 \mathrm{~mm}$ & DM 2 & Middle & $7.7 \%$ & $8.0 \%$ & $8.1 \%$ \\
\hline PG 76-22 PM & $9.5 \mathrm{~mm}$ & DM 2 & Bottom & $5.8 \%$ & $6.0 \%$ & $6.2 \%$ \\
\hline PG 76-22 PM & $9.5 \mathrm{~mm}$ & DM 3 & Top & $6.0 \%$ & $6.4 \%$ & $6.5 \%$ \\
\hline PG 76-22 PM & $9.5 \mathrm{~mm}$ & DM 3 & Middle & $7.4 \%$ & $7.9 \%$ & $7.7 \%$ \\
\hline PG 76-22 PM & $9.5 \mathrm{~mm}$ & DM 3 & Bottom & $6.4 \%$ & $6.7 \%$ & $6.7 \%$ \\
\hline
\end{tabular}

\begin{tabular}{|c|c|c|c|c|c|c|}
\hline Binder Type & NMAS & $\begin{array}{c}\text { Sample } \\
\text { Designation }\end{array}$ & Section & SSD & CoreLok & Dimensional \\
\hline PG 76-22 PM & $12.5 \mathrm{~mm}$ & DM 1 & Top & $6.8 \%$ & $6.9 \%$ & $7.6 \%$ \\
\hline PG 76-22 PM & $12.5 \mathrm{~mm}$ & DM 1 & Middle & $7.7 \%$ & $7.8 \%$ & $7.8 \%$ \\
\hline PG 76-22 PM & $12.5 \mathrm{~mm}$ & DM 1 & Bottom & $7.1 \%$ & $7.1 \%$ & $7.2 \%$ \\
\hline PG 76-22 PM & $12.5 \mathrm{~mm}$ & DM 2 & Top & $6.8 \%$ & $7.3 \%$ & $7.0 \%$ \\
\hline PG 76-22 PM & $12.5 \mathrm{~mm}$ & DM 2 & Middle & $7.5 \%$ & $7.9 \%$ & $8.1 \%$ \\
\hline PG 76-22 PM & $12.5 \mathrm{~mm}$ & DM 2 & Bottom & $6.5 \%$ & $6.8 \%$ & $6.9 \%$ \\
\hline PG 76-22 PM & $12.5 \mathrm{~mm}$ & DM 3 & Top & $6.5 \%$ & $12.0 \%$ & $6.9 \%$ \\
\hline PG 76-22 PM & $12.5 \mathrm{~mm}$ & DM 3 & Middle & $7.2 \%$ & $7.2 \%$ & $8.1 \%$ \\
\hline PG 76-22 PM & $12.5 \mathrm{~mm}$ & DM 3 & Bottom & $6.2 \%$ & $6.2 \%$ & $6.7 \%$ \\
\hline
\end{tabular}


Sample Thirds Geometry

\begin{tabular}{|c|c|c|c|c|c|}
\hline Binder Type & NMAS & $\begin{array}{c}\text { Sample } \\
\text { Designation }\end{array}$ & Section & Diameter & Height \\
\hline PG 70-22 & $9.5 \mathrm{~mm}$ & DM 1 & Top & 100.46 & 51.93 \\
\hline PG 70-22 & $9.5 \mathrm{~mm}$ & DM 1 & Middle & 100.56 & 45.62 \\
\hline PG 70-22 & $9.5 \mathrm{~mm}$ & DM 1 & Bottom & 100.55 & 45.02 \\
\hline PG 70-22 & $9.5 \mathrm{~mm}$ & DM 2 & Top & 100.44 & 47.64 \\
\hline PG 70-22 & $9.5 \mathrm{~mm}$ & DM 2 & Middle & 100.41 & 45.79 \\
\hline PG 70-22 & $9.5 \mathrm{~mm}$ & DM 2 & Bottom & 100.52 & 49.11 \\
\hline PG 70-22 & $9.5 \mathrm{~mm}$ & DM 3 & Top & 100.45 & 46.99 \\
\hline PG 70-22 & $9.5 \mathrm{~mm}$ & DM 3 & Middle & 100.53 & 46.74 \\
\hline PG 70-22 & $9.5 \mathrm{~mm}$ & DM 3 & Bottom & 100.53 & 49.24 \\
\hline
\end{tabular}

\begin{tabular}{|c|c|c|c|c|c|}
\hline Binder Type & NMAS & $\begin{array}{c}\text { Sample } \\
\text { Designation }\end{array}$ & Section & Diameter & Height \\
\hline PG 70-22 & $12.5 \mathrm{~mm}$ & DM 1 & Top & 100.38 & 49.37 \\
\hline PG 70-22 & $12.5 \mathrm{~mm}$ & DM 1 & Middle & 100.48 & 44.30 \\
\hline PG 70-22 & $12.5 \mathrm{~mm}$ & DM 1 & Bottom & 100.55 & 49.70 \\
\hline PG 70-22 & $12.5 \mathrm{~mm}$ & DM 2 & Top & 100.44 & 47.65 \\
\hline PG 70-22 & $12.5 \mathrm{~mm}$ & DM 2 & Middle & 100.58 & 46.99 \\
\hline PG 70-22 & $12.5 \mathrm{~mm}$ & DM 2 & Bottom & 100.57 & 47.79 \\
\hline PG 70-22 & $12.5 \mathrm{~mm}$ & DM 3 & Top & 100.41 & 46.15 \\
\hline PG 70-22 & $12.5 \mathrm{~mm}$ & DM 3 & Middle & 100.51 & 47.89 \\
\hline PG 70-22 & $12.5 \mathrm{~mm}$ & DM 3 & Bottom & 100.58 & 48.07 \\
\hline
\end{tabular}

\begin{tabular}{|c|c|c|c|c|c|}
\hline Binder Type & NMAS & $\begin{array}{c}\text { Sample } \\
\text { Designation }\end{array}$ & Section & Diameter & Height \\
\hline PG 70-22 PM & $9.5 \mathrm{~mm}$ & DM 1 & Top & 100.49 & 49.43 \\
\hline PG 70-22 PM & $9.5 \mathrm{~mm}$ & DM 1 & Middle & 100.51 & 48.87 \\
\hline PG 70-22 PM & $9.5 \mathrm{~mm}$ & DM 1 & Bottom & 100.62 & 44.66 \\
\hline PG 70-22 PM & $9.5 \mathrm{~mm}$ & DM 2 & Top & 100.42 & 48.24 \\
\hline PG 70-22 PM & $9.5 \mathrm{~mm}$ & DM 2 & Middle & 100.42 & 48.22 \\
\hline PG 70-22 PM & $9.5 \mathrm{~mm}$ & DM 2 & Bottom & 100.45 & 44.13 \\
\hline PG 70-22 PM & $9.5 \mathrm{~mm}$ & DM 3 & Top & 100.42 & 47.70 \\
\hline PG 70-22 PM & $9.5 \mathrm{~mm}$ & DM 3 & Middle & 100.45 & 47.15 \\
\hline PG 70-22 PM & $9.5 \mathrm{~mm}$ & DM 3 & Bottom & 100.48 & 47.24 \\
\hline
\end{tabular}




\begin{tabular}{|c|c|c|c|c|c|}
\hline Binder Type & NMAS & $\begin{array}{c}\text { Sample } \\
\text { Designation }\end{array}$ & Section & Diameter & Height \\
\hline PG 70-22 PM & $12.5 \mathrm{~mm}$ & DM 1 & Top & 100.46 & 47.08 \\
\hline PG 70-22 PM & $12.5 \mathrm{~mm}$ & DM 1 & Middle & 100.55 & 49.66 \\
\hline PG 70-22 PM & $12.5 \mathrm{~mm}$ & DM 1 & Bottom & 100.53 & 46.63 \\
\hline PG 70-22 PM & $12.5 \mathrm{~mm}$ & DM 2 & Top & 100.42 & 46.93 \\
\hline PG 70-22 PM & $12.5 \mathrm{~mm}$ & DM 2 & Middle & 100.51 & 47.30 \\
\hline PG 70-22 PM & $12.5 \mathrm{~mm}$ & DM 2 & Bottom & 100.55 & 48.32 \\
\hline PG 70-22 PM & $12.5 \mathrm{~mm}$ & DM 3 & Top & 100.43 & 47.73 \\
\hline PG 70-22 PM & $12.5 \mathrm{~mm}$ & DM 3 & Middle & 100.50 & 47.21 \\
\hline PG 70-22 PM & $12.5 \mathrm{~mm}$ & DM 3 & Bottom & 100.55 & 48.17 \\
\hline
\end{tabular}

\begin{tabular}{|c|c|c|c|c|c|}
\hline Binder Type & NMAS & $\begin{array}{c}\text { Sample } \\
\text { Designation }\end{array}$ & Section & Diameter & Height \\
\hline PG 76-22 PM & $9.5 \mathrm{~mm}$ & DM 1 & Top & 100.39 & 50.77 \\
\hline PG 76-22 PM & $9.5 \mathrm{~mm}$ & DM 1 & Middle & 100.42 & 45.23 \\
\hline PG 76-22 PM & $9.5 \mathrm{~mm}$ & DM 1 & Bottom & 100.48 & 48.18 \\
\hline PG 76-22 PM & $9.5 \mathrm{~mm}$ & DM 2 & Top & 100.42 & 49.95 \\
\hline PG 76-22 PM & $9.5 \mathrm{~mm}$ & DM 2 & Middle & 100.51 & 45.47 \\
\hline PG 76-22 PM & $9.5 \mathrm{~mm}$ & DM 2 & Bottom & 100.45 & 47.50 \\
\hline PG 76-22 PM & $9.5 \mathrm{~mm}$ & DM 3 & Top & 100.35 & 46.64 \\
\hline PG 76-22 PM & $9.5 \mathrm{~mm}$ & DM 3 & Middle & 100.50 & 48.64 \\
\hline PG 76-22 PM & $9.5 \mathrm{~mm}$ & DM 3 & Bottom & 100.47 & 47.98 \\
\hline
\end{tabular}

\begin{tabular}{|c|c|c|c|c|c|}
\hline Binder Type & NMAS & $\begin{array}{c}\text { Sample } \\
\text { Designation }\end{array}$ & Section & Diameter & Height \\
\hline PG 76-22 PM & $12.5 \mathrm{~mm}$ & DM 1 & Top & 100.38 & 47.51 \\
\hline PG 76-22 PM & $12.5 \mathrm{~mm}$ & DM 1 & Middle & 100.38 & 48.09 \\
\hline PG 76-22 PM & $12.5 \mathrm{~mm}$ & DM 1 & Bottom & 100.46 & 48.66 \\
\hline PG 76-22 PM & $12.5 \mathrm{~mm}$ & DM 2 & Top & 100.43 & 47.90 \\
\hline PG 76-22 PM & $12.5 \mathrm{~mm}$ & DM 2 & Middle & 100.45 & 46.48 \\
\hline PG 76-22 PM & $12.5 \mathrm{~mm}$ & DM 2 & Bottom & 100.45 & 48.07 \\
\hline PG 76-22 PM & $12.5 \mathrm{~mm}$ & DM 3 & Top & 100.49 & 44.67 \\
\hline PG 76-22 PM & $12.5 \mathrm{~mm}$ & DM 3 & Middle & 100.45 & 49.62 \\
\hline PG 76-22 PM & $12.5 \mathrm{~mm}$ & DM 3 & Bottom & 100.43 & 48.61 \\
\hline
\end{tabular}




\section{Appendix D - JMP Output}

\section{Air Void Distribution Analysis by Section and Method}

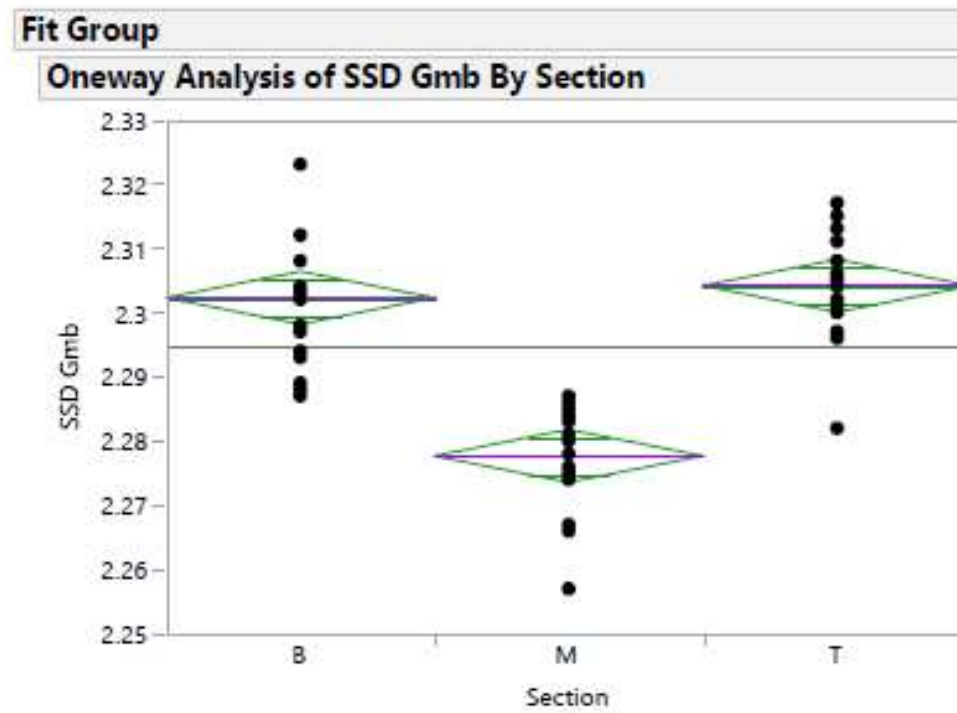

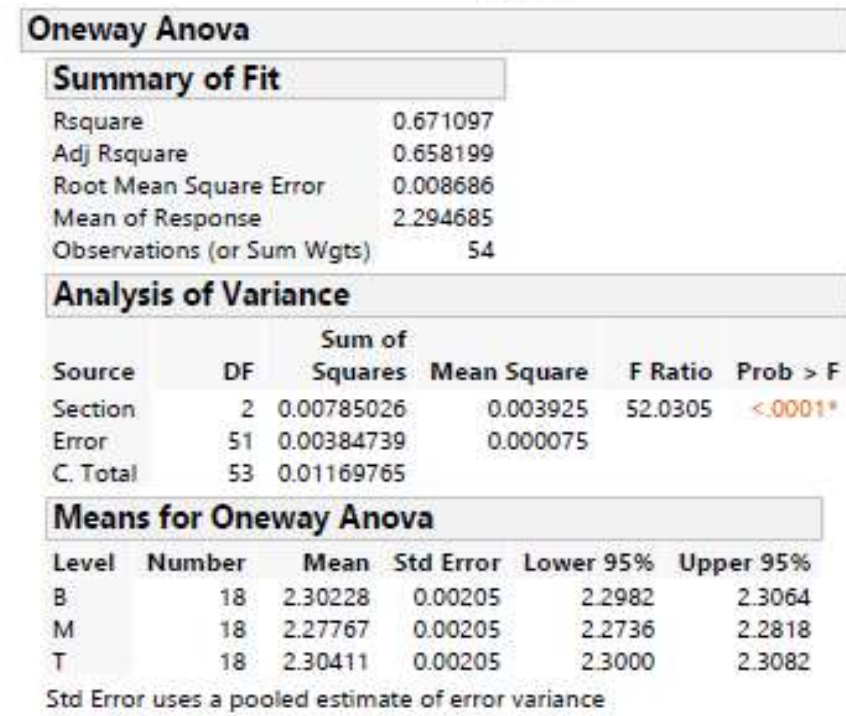

Practical Equivalence between $\mathrm{M}$ and $\mathrm{B}$

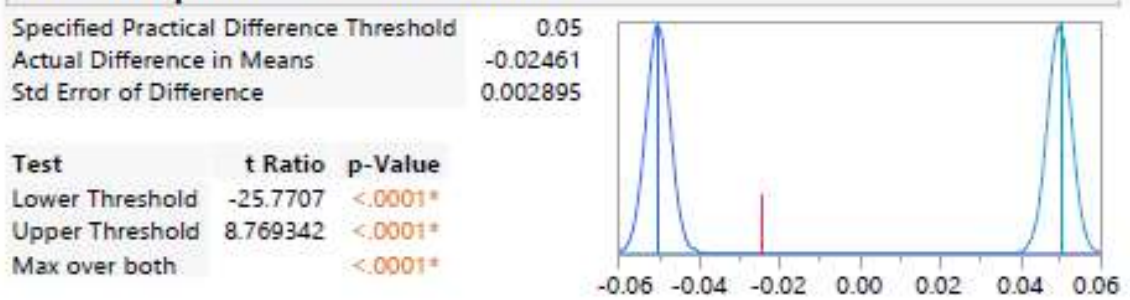




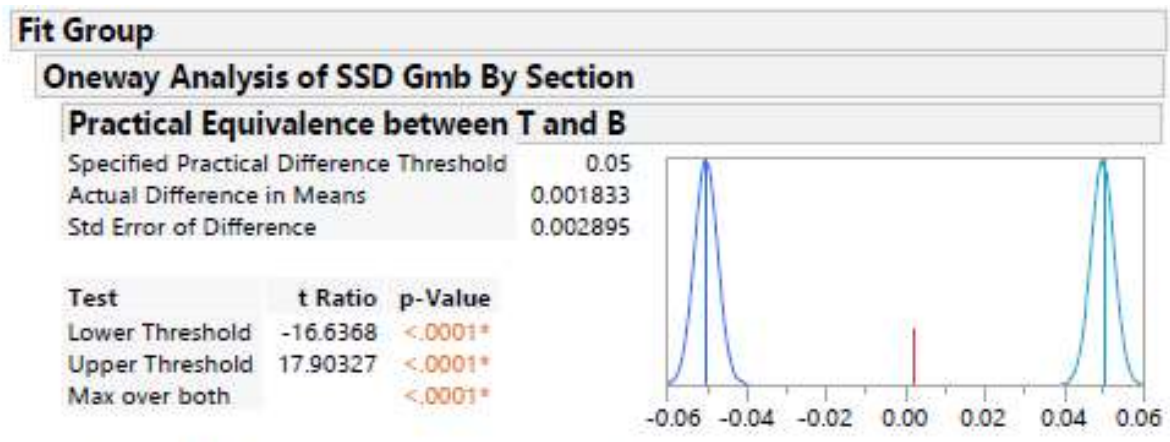

Practical Equivalence between $\mathrm{T}$ and $\mathrm{M}$

Specified Practical Difference Threshold Actual Difference in Means

Std Error of Difference

0.05
0.026444
0.002895

Test

t Ratio p-Value

Lower Threshold $-8.13611<$.000t=

Upper Threshold $26.40397<.0001$ *

Max over both

\section{Robust Fit}

Sigma ChiSquare PValue LogWorth

$0.00855 \quad 124.923<.0001 * \quad 27.1268$

Level Robust Mean Std Error

$\begin{array}{lll}\text { B } & 2.30206 & 0.00228\end{array}$

$\begin{array}{lll}M & 2.27788 & 0.00185\end{array}$

$\begin{array}{lll}\text { T } & 2.30441 & 0.00184\end{array}$

Oneway Analysis of CoreLok Gmb By Section

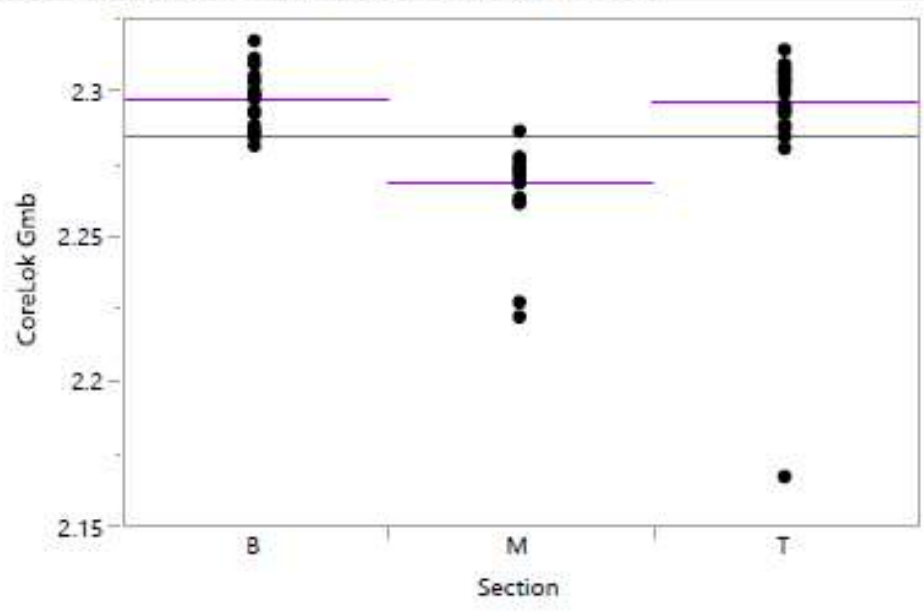




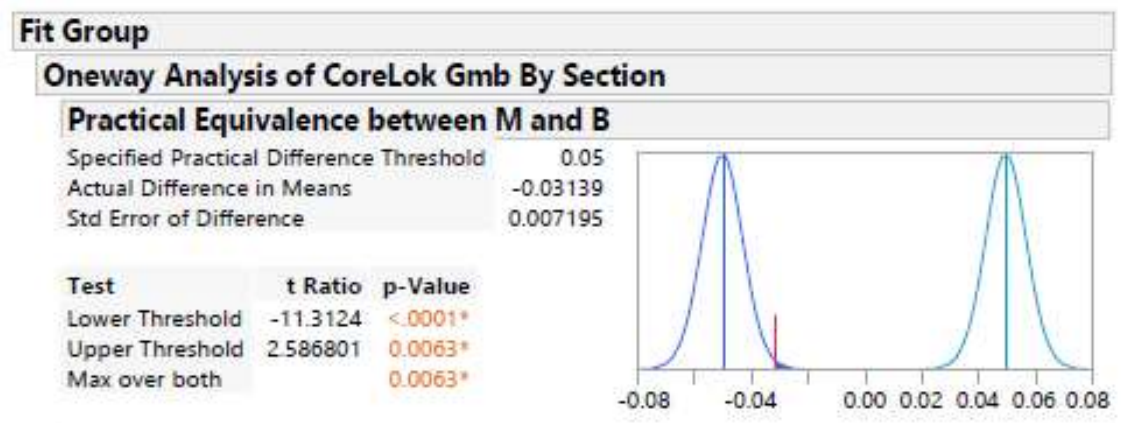

Practical Equivalence between T and B

Specified Practical Difference Threshold

Actual Difference in Means

Std Error of Difference

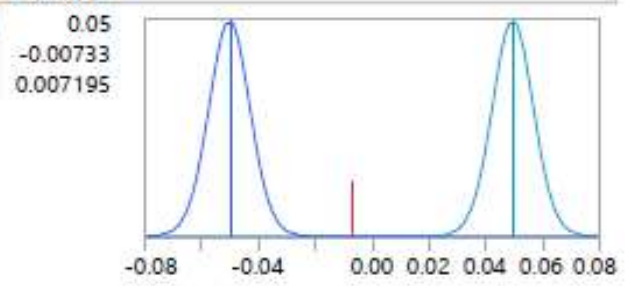

Test

t Ratio p-Value

Lower Threshold $-7.96889<0001$.

Upper Threshold $5.930338<0001$,

Max over both

$<.0001 *$

Practical Equivalence between $\mathrm{T}$ and $\mathrm{M}$

Specified Practical Difference Threshold

Actual Difference in Means

Std Error of Difference

0.05
0.024056

Test

t Ratio p-Value

Lower Threshold -3.606080 .0004 *

Upper Threshold $10.29315<0001 *$

Max over both

$0.0004 *$

\section{Robust Fit}

$\begin{array}{rrrr}\text { Sigma } & \text { ChiSquare } & \text { PValue } & \text { LogWorth } \\ 0.01083 & 79.7409 & <.0001 * & 173155\end{array}$

Level Robust Mean Std Error

$\begin{array}{lll}B & 2.29744 & 0.00236 \\ M & 2.26849 & 0.00281\end{array}$

$\begin{array}{lll}\text { T } & 2.29606 & 0.00271\end{array}$

Oneway Analysis of Dimensional Gmb By Section

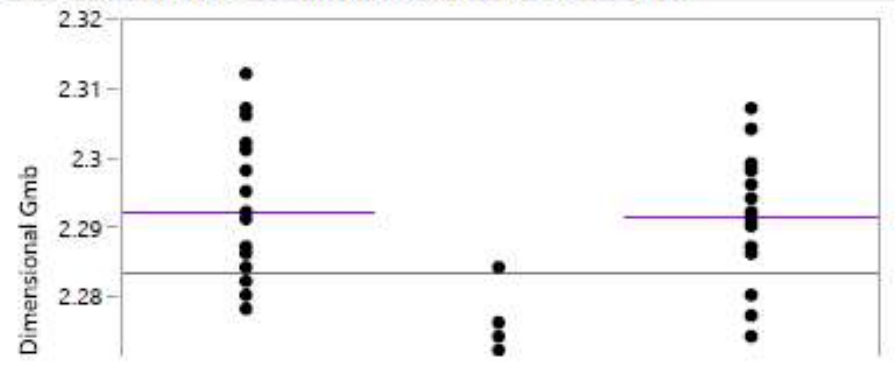




\section{Fit Group}

Oneway Analysis of Dimensional Gmb By Section

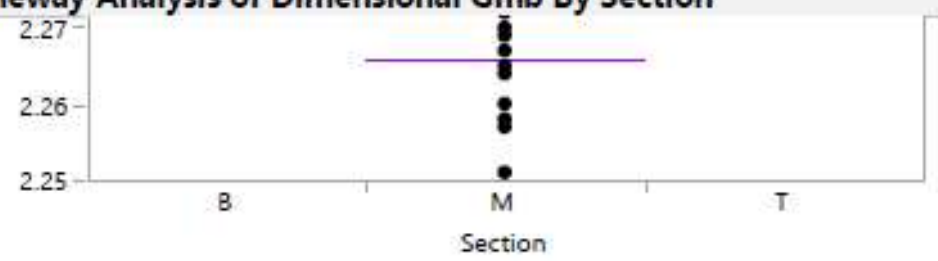

\section{Practical Equivalence between $\mathrm{M}$ and $\mathrm{B}$}

Specified Practical Difference Threshold Actual Difference in Means

Std Error of Difference

0.05
-0.02622
0.003091

Test

t Ratio p-Value

Lower Threshold $-24.6581<.0001$ "

Upper Threshold $7.692169<.0001$ s

Max over both

$<.0001 \%$

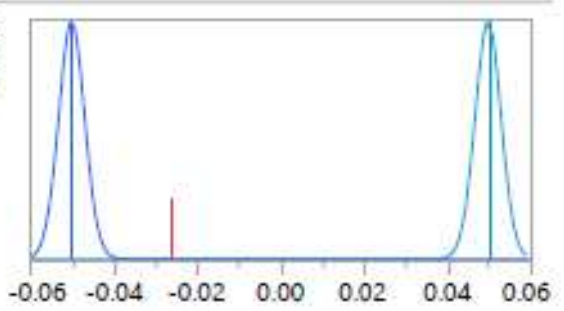

\section{Practical Equivalence between $\mathrm{T}$ and $\mathrm{B}$}

Specified Practical Difference Threshold Actual Difference in Means

Std Error of Difference

-0.00061
0.00309

Test

t Ratio p-Value

Lower Threshold

Upper Threshold

$-16.3728<.0001 \%$

$15.97742<.0001^{*}$

Max over both

$<.0001 *$

0.003091

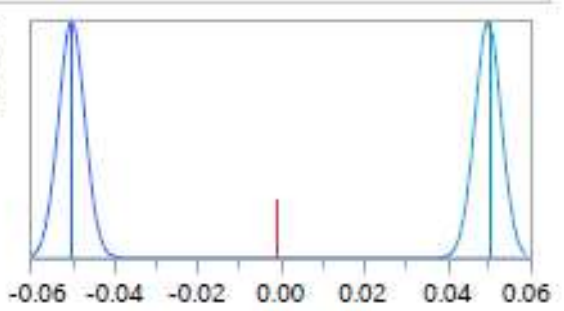

Practical Equivalence between $\mathrm{T}$ and $\mathrm{M}$

Specified Practical Difference Threshold Actual Difference in Means

Std Error of Difference

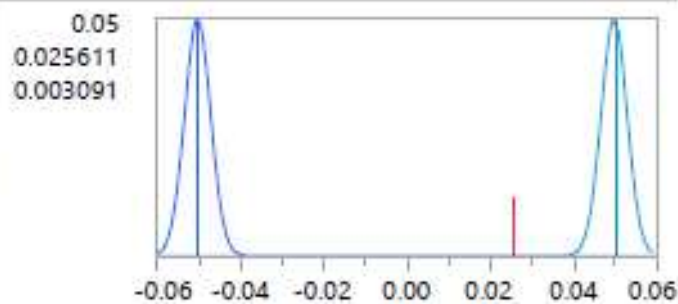

Test

t Ratio p-Value

Lower Threshold -7,88986 $<0001$ *

Upper Threshold $24.46038<.0001=$

Max over both

$\begin{aligned} 24.46038 & <.0001= \\ & <.0001=\end{aligned}$

\section{Robust Fit}

$\begin{array}{lrrr}\text { Sigma } & \text { ChiSquare } & \text { PValue } & \text { LogWorth } \\ 0.00975 & 102.392 & <.0001 * & 22.2341 \\ & & & \\ \text { Level } & \text { Robust Mean } & \text { Std Error } \\ \text { B } & 2.29202 & 0.00249 \\ \text { M } & 2.26583 & 0.00202 \\ \text { T } & 2.29144 & 0.00202\end{array}$




\section{Robust Fit of Dynamic Modulus versus CoreLok® VTM After}

\section{Bivariate Fit of Dynamic Modulus (ksi) By CoreLok VTM After}

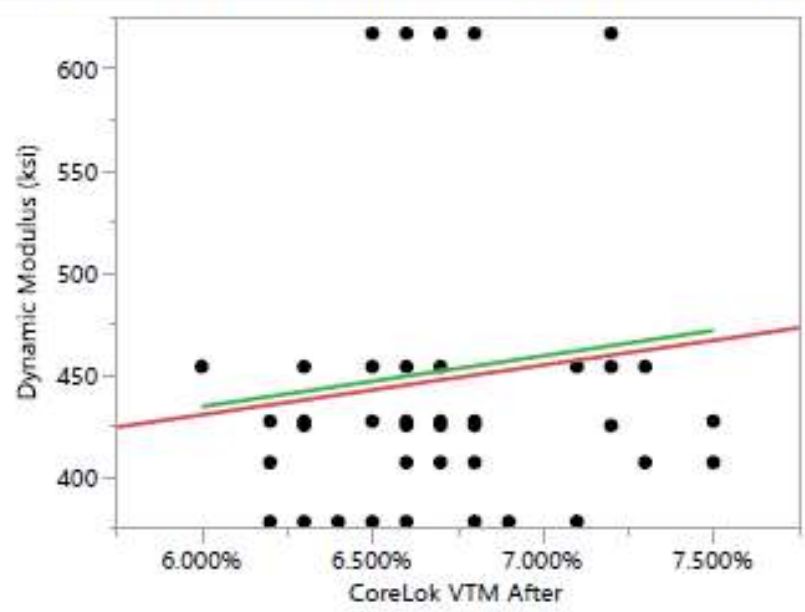

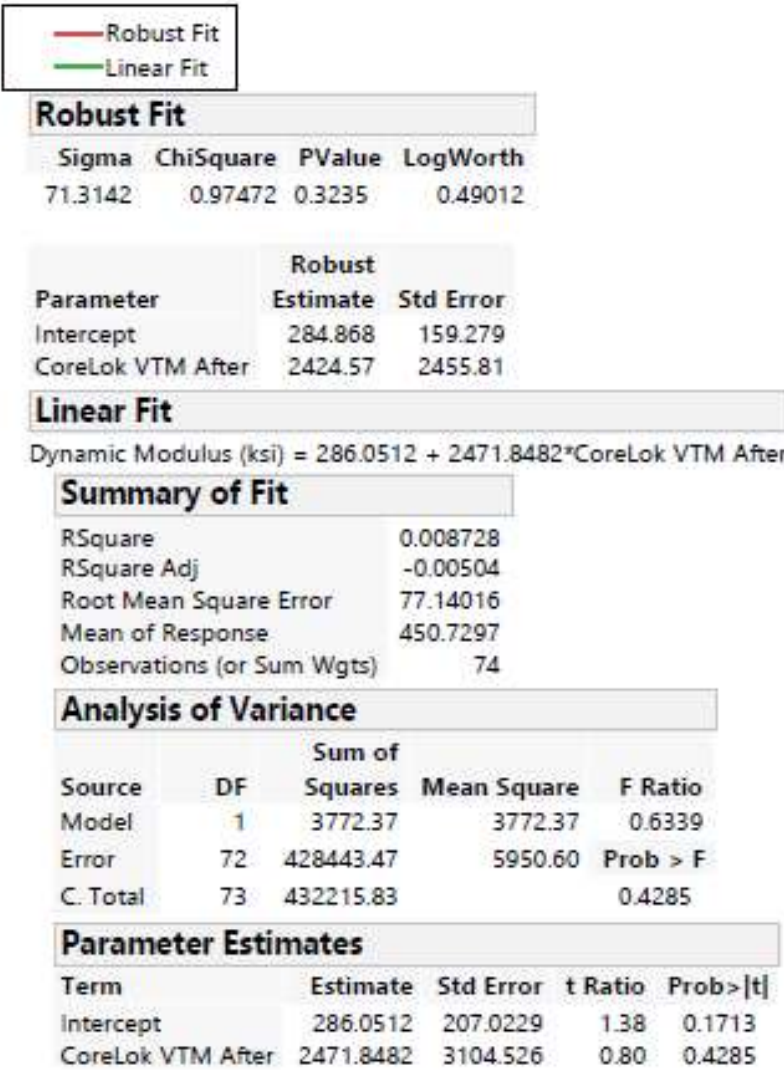




\section{Appendix E - Compaction Data}

\section{PG 70-22 $9.5 \mathrm{~mm}$}

\begin{tabular}{|c|c|c|c|c|c|c|c|c|c|c|c|c|c|}
\hline Gyrations & FT 1A & FT 1B & FT 1C & FT 2A & FT 2B & FT 2C & FT 3A & FT 3B & FT 3C & DM 1 & DM 2 & DM 3 & EXTRA \\
\hline 0 & 224.2 & 223.8 & 225.8 & 226.8 & 223 & 223.3 & 224.4 & 225 & 224.6 & 225.6 & 223.4 & 223.4 & 223.4 \\
\hline 1 & 216.3 & 216.1 & 218 & 218.8 & 215.1 & 215.5 & 216.3 & 216.9 & 216.7 & 217.7 & 215.7 & 215.6 & 215.8 \\
\hline 2 & 211.7 & 211.6 & 213.3 & 214.1 & 210.4 & 211 & 211.6 & 212.3 & 212.2 & 213 & 211.1 & 210.9 & 211.3 \\
\hline 3 & 208.2 & 208.2 & 209.8 & 210.6 & 207 & 207.5 & 208.2 & 208.8 & 208.7 & 209.5 & 207.6 & 207.4 & 207.9 \\
\hline 4 & 205.5 & 205.5 & 207.1 & 207.7 & 204.3 & 204.9 & 205.4 & 206 & 205.9 & 206.8 & 204.9 & 204.7 & 205.3 \\
\hline 5 & 203.3 & 203.3 & 204.8 & 205.4 & 202.1 & 202.7 & 203.2 & 203.7 & 203.7 & 204.5 & 202.7 & 202.4 & 203 \\
\hline \multicolumn{14}{|c|}{ Break } \\
\hline 50 & 180.3 & 180.6 & 181.6 & 181.9 & 179.7 & 180.2 & 180.5 & 180.4 & 180.9 & 181.3 & 180.1 & 179.8 & 180.2 \\
\hline 51 & 180.2 & 180.4 & 181.4 & 181.7 & & 180 & 180.3 & 180.2 & 180.7 & 181.1 & 179.9 & 179.7 & 180 \\
\hline 52 & 180 & 180.3 & 181.2 & 181.5 & & 179.8 & 180.2 & 180 & 180.6 & 181 & 179.8 & & 179.8 \\
\hline 53 & 179.9 & 180.1 & 181.1 & 181.4 & & 179.7 & 180 & 179.9 & 180.4 & 180.8 & & & \\
\hline 54 & 179.7 & 179.9 & 180.9 & 181.2 & & & 179.9 & 179.8 & 180.2 & 180.6 & & & \\
\hline 55 & & 179.8 & 180.7 & 181 & & & & & 180.1 & 180.5 & & & \\
\hline 56 & & & 180.6 & 180.9 & & & & & 179.9 & 180.3 & & & \\
\hline 57 & & & 180.4 & 180.7 & & & & & 179.8 & 180.2 & & & \\
\hline 58 & & & 180.3 & 180.6 & & & & & & 180 & & & \\
\hline 59 & & & 180.1 & 180.5 & & & & & & 179.9 & & & \\
\hline 60 & & & 180 & 180.3 & & & & & & 179.8 & & & \\
\hline 61 & & & 179.9 & 180.2 & & & & & & & & & \\
\hline 62 & & & 179.8 & 180 & & & & & & & & & \\
\hline 63 & & & & 179.9 & & & & & & & & & \\
\hline 64 & & & & 179.8 & & & & & & & & & \\
\hline
\end{tabular}




\section{PG 70-22 PM 9.5 mm}

\begin{tabular}{|c|c|c|c|c|c|c|c|c|c|c|c|c|c|}
\hline Gyrations & FT 1A & FT 1B & FT 1C & FT 2A & FT 2B & FT 2C & FT 3A & FT 3B & FT 3C & DM 1 & DM 2 & DM 3 & EXTRA \\
\hline 0 & 223.3 & 222.8 & 222.8 & 223.7 & 223.5 & 224.4 & 226 & 224 & 224 & 224.4 & 223.4 & 225 & 222.5 \\
\hline 1 & 215.4 & 214.8 & 215 & 216 & 215.7 & 216.4 & 218.1 & 216.1 & 216.2 & 216.4 & 215.6 & 217 & 214.8 \\
\hline 2 & 210.8 & 210.2 & 210.4 & 211.5 & 211.1 & 211.8 & 213.4 & 211.5 & 211.6 & 211.8 & 211 & 212.4 & 210.2 \\
\hline 3 & 207.3 & 206.8 & 206.9 & 208.1 & 207.6 & 208.4 & 209.9 & 207.9 & 208.1 & 208.3 & 207.6 & 208.8 & 206.8 \\
\hline 4 & 204.6 & 204.1 & 204.2 & 205.3 & 204.9 & 205.6 & 207.2 & 205.2 & 205.3 & 205.6 & 204.8 & 206.1 & 204.1 \\
\hline 5 & 202.4 & 201.9 & 202 & 203.1 & 202.7 & 203.4 & 204.9 & 202.9 & 203.2 & 203.3 & 202.6 & 203.8 & 201.9 \\
\hline \multicolumn{14}{|c|}{ Break } \\
\hline 48 & 180.1 & 179.9 & 179.8 & 180.7 & 180.5 & 181 & 182 & 180.4 & 180.9 & 180.8 & 180.3 & 181.2 & 179.7 \\
\hline 49 & 180 & 179.8 & & 180.5 & 180.4 & 180.8 & 181.8 & 180.3 & 180.7 & 180.7 & 180.1 & 181.1 & \\
\hline 50 & 179.8 & & & 180.4 & 180.2 & 180.6 & 181.7 & 180.1 & 180.5 & 180.5 & 179.9 & 180.9 & \\
\hline 51 & & & & 180.2 & 180 & 180.4 & 181.5 & 179.9 & 180.4 & 180.3 & 179.8 & 180.7 & \\
\hline 52 & & & & 180.1 & 179.9 & 180.3 & 181.3 & 179.8 & 180.2 & 180.2 & & 180.6 & \\
\hline 53 & & & & 179.9 & 179.7 & 180.1 & 181.2 & & 180.1 & 180 & & 180.4 & \\
\hline 54 & & & & 179.8 & & 180 & 181 & & 179.9 & 179.9 & & 180.2 & \\
\hline 55 & & & & & & 179.8 & 180.9 & & 179.8 & 179.7 & & 180.1 & \\
\hline 56 & & & & & & & 180.7 & & & & & 179.9 & \\
\hline 57 & & & & & & & 180.6 & & & & & 179.8 & \\
\hline 58 & & & & & & & 180.4 & & & & & & \\
\hline 59 & & & & & & & 180.3 & & & & & & \\
\hline 60 & & & & & & & 180.2 & & & & & & \\
\hline 61 & & & & & & & 180 & & & & & & \\
\hline 62 & & & & & & & 179.9 & & & & & & \\
\hline 63 & & & & & & & 179.8 & & & & & & \\
\hline
\end{tabular}


PG 76-22 PM 9.5 mm

\begin{tabular}{|c|c|c|c|c|c|c|c|c|c|c|c|c|c|c|}
\hline Gyrations & FT 1A & FT 1A2 & FT 1B & FT 1B2 & FT 1C & FT 2A & FT 2B & FT 2C & FT 3A & FT 3B & FT 3C & DM 1 & DM 2 & DM 3 \\
\hline 0 & 224.2 & 222.9 & 223.3 & 223 & 225.2 & 222.9 & 223.9 & 223.8 & 221.3 & 222.7 & 222.8 & 222.6 & 222.8 & 225.2 \\
\hline 1 & 216 & 214.9 & 215.4 & 214.8 & 217.1 & 214.7 & 216 & 216 & 213.5 & 214.8 & 214.9 & 214.5 & 215 & 217.2 \\
\hline 2 & 211.3 & 210.2 & 210.8 & 210.3 & 212.4 & 210.2 & 211.3 & 211.3 & 208.8 & 210.1 & 210.4 & 209.9 & 210.3 & 212.4 \\
\hline 3 & 207.7 & 206.7 & 207.3 & 206.8 & 208.9 & 206.7 & 207.9 & 207.8 & 205.3 & 206.6 & 206.9 & 206.3 & 206.8 & 208.9 \\
\hline 4 & 205 & 204.1 & 204.6 & 204 & 206.1 & 204.1 & 205.1 & 205.1 & 202.6 & 203.9 & 204.1 & 203.5 & 204.1 & 206.1 \\
\hline 5 & 202.7 & 201.8 & 202.4 & 201.8 & 203.9 & 201.9 & 202.8 & 202.8 & 200.4 & 201.7 & 201.9 & 201.3 & 201.8 & 203.8 \\
\hline \multicolumn{15}{|c|}{ Break } \\
\hline 42 & 181.2 & 181 & 181.6 & 180.7 & 182.3 & 181 & 181.4 & 181.4 & 179.7 & 180.7 & 180.8 & 180 & 180.4 & 182.1 \\
\hline 43 & 181 & 180.8 & 181.4 & 180.5 & 182.1 & 180.8 & 181.2 & 181.2 & & 180.5 & 180.6 & 179.8 & 180.2 & 181.9 \\
\hline 44 & 180.8 & 180.6 & 181.2 & 180.3 & 181.9 & 180.6 & 181 & 181 & & 180.3 & 180.4 & & 180 & 181.7 \\
\hline 45 & 180.6 & 180.5 & 181 & 180.1 & 181.7 & 180.4 & 180.8 & 180.8 & & 180.1 & 180.2 & & 179.8 & 181.5 \\
\hline 46 & 180.4 & 180.3 & 180.9 & 179.9 & 181.6 & 180.2 & 180.6 & 180.6 & & 179.9 & 180 & & & 181.3 \\
\hline 47 & 180.3 & 180.1 & 180.7 & 179.8 & 181.4 & 180 & 180.4 & 180.4 & & 179.7 & 179.9 & & & 181.1 \\
\hline 48 & 180.1 & 179.9 & 180.5 & & 181.2 & 179.9 & 180.3 & 180.3 & & & 179.7 & & & 181 \\
\hline 49 & 179.9 & 179.8 & 180.3 & & 181 & 179.7 & 180.1 & 180.1 & & & & & & 180.8 \\
\hline 50 & 179.8 & & 180.2 & & 180.9 & & 179.9 & 179.9 & & & & & & 180.6 \\
\hline 51 & & & 180 & & 180.7 & & 179.8 & 179.8 & & & & & & 180.4 \\
\hline 52 & & & 179.9 & & 180.5 & & & & & & & & & 180.3 \\
\hline 53 & & & 179.8 & & 180.4 & & & & & & & & & 180.1 \\
\hline 54 & & & & & 180.2 & & & & & & & & & 180 \\
\hline 55 & & & & & 180.1 & & & & & & & & & 179.8 \\
\hline 56 & & & & & 179.9 & & & & & & & & & \\
\hline 57 & & & & & 179.8 & & & & & & & & & \\
\hline
\end{tabular}




\section{PG 70-22 $12.5 \mathrm{~mm}$}

\begin{tabular}{|c|c|c|c|c|c|c|c|c|c|c|c|c|c|}
\hline Gyrations & FT 1A & FT 1B & FT 1C & FT 2A & FT 2B & FT 2C & FT 3A & FT 3B & FT 3C & DM 1 & DM 2 & DM 3 & EXTRA \\
\hline 0 & 220.3 & 221.5 & 220.8 & 221 & 224.3 & 223.4 & 222 & 222 & 221.1 & 222.4 & 221.6 & 223.3 & 222.8 \\
\hline 1 & 212.6 & 213.6 & 213.1 & 213.2 & 216.6 & 215.7 & 214.1 & 214 & 213 & 214.4 & 213.7 & 215.5 & 214.9 \\
\hline 2 & 208.1 & 209.1 & 208.4 & 208.8 & 212 & 211.1 & 209.5 & 209.4 & 208.4 & 209.9 & 209.1 & 210.9 & 210.1 \\
\hline 3 & 204.8 & 205.7 & 205 & 205.5 & 208.6 & 207.7 & 206.1 & 206.1 & 204.9 & 206.6 & 205.6 & 207.4 & 206.8 \\
\hline 4 & 202.2 & 203 & 202.3 & 202.8 & 205.9 & 205.1 & 203.4 & 203.4 & 202.2 & 204 & 203 & 204.6 & 204.1 \\
\hline 5 & 200 & 200.9 & 200.2 & 200.7 & 203.7 & 203 & 201.2 & 201.2 & 199.9 & 201.8 & 200.8 & 202.4 & 201.9 \\
\hline \multicolumn{14}{|c|}{ Break } \\
\hline 41 & 179.7 & 180.4 & 180 & 180.4 & 183.6 & 182.9 & 180.8 & 180.6 & 179.6 & 181.5 & 180.4 & 181.6 & 181.9 \\
\hline 42 & & 180.2 & 179.8 & 180.2 & 183.4 & 182.7 & 180.6 & 180.4 & & 181.3 & 180.2 & 181.4 & 181.7 \\
\hline 43 & & 180 & & 180 & 183.2 & 182.5 & 180.4 & 180.2 & & 181.1 & 180 & 181.2 & 181.5 \\
\hline 44 & & 179.8 & & 179.8 & 183 & 182.3 & 180.3 & 180 & & 180.9 & 179.8 & 181.1 & 181.3 \\
\hline 45 & & & & 179.7 & 182.9 & 182.1 & 180.1 & 179.9 & & 180.7 & 179.7 & 180.9 & 181.2 \\
\hline 46 & & & & & 182.7 & 181.9 & 179.9 & 179.7 & & 180.6 & & 180.7 & 181 \\
\hline 47 & & & & & 182.5 & 181.8 & 179.7 & & & 180.4 & & 180.5 & 180.8 \\
\hline 48 & & & & & 182.3 & 181.6 & & & & 180.2 & & 180.3 & 180.7 \\
\hline 49 & & & & & 182.2 & 181.4 & & & & 180 & & 180.2 & 180.5 \\
\hline 50 & & & & & 182 & 181.3 & & & & 179.9 & & 180 & 180.3 \\
\hline 51 & & & & & 181.9 & 181.1 & & & & 179.7 & & 179.8 & 180.2 \\
\hline 52 & & & & & 181.7 & 181 & & & & & & 179.7 & 180 \\
\hline 53 & & & & & 181.6 & 180.8 & & & & & & & 179.9 \\
\hline \multicolumn{14}{|c|}{ Break } \\
\hline 61 & & & & & 180.5 & 179.8 & & & & & & & \\
\hline \multicolumn{14}{|c|}{ Break } \\
\hline 67 & & & & & 179.8 & & & & & & & & \\
\hline
\end{tabular}




\section{PG 70-22 PM 12.5 mm}

\begin{tabular}{|c|c|c|c|c|c|c|c|c|c|c|c|c|c|}
\hline Gyrations & FT 1A & FT 1B & FT 1C & FT 2A & FT 2B & FT 2C & FT 3A & FT 3B & FT 3C & DM 1 & $\mathrm{DM} 2$ & DM 3 & EXTRA \\
\hline 0 & 220.3 & 220.4 & 223.4 & 220.4 & 220.7 & 223.7 & 223.6 & 220.2 & 220.3 & 221 & 220.8 & 220.2 & 221 \\
\hline 1 & 212.7 & 212.7 & 215.6 & 212.7 & 213.1 & 215.9 & 215.7 & 212.5 & 212.6 & 213.1 & 212.8 & 212.5 & 213.2 \\
\hline 2 & 208.2 & 208.2 & 211.2 & 208.1 & 208.5 & 211.3 & 211.2 & 208 & 208.1 & 208.6 & 208.3 & 207.9 & 208.7 \\
\hline 3 & 204.9 & 204.9 & 207.8 & 204.8 & 205.1 & 207.9 & 207.7 & 204.6 & 204.8 & 205.2 & 204.9 & 204.6 & 205.3 \\
\hline 4 & 202.2 & 202.3 & 205.2 & 202 & 202.5 & 205.3 & 205.1 & 202 & 202.2 & 202.6 & 202.3 & 202 & 202.6 \\
\hline 5 & 200 & 200.2 & 203 & 199.9 & 200.3 & 203.2 & 202.9 & 199.8 & 200 & 200.4 & 200.1 & 199.8 & 200.4 \\
\hline \multicolumn{14}{|c|}{ Break } \\
\hline 40 & 180.1 & 180.4 & 183.4 & 179.9 & 180.2 & 183.5 & 183 & 179.8 & 180.4 & 180.6 & 180.3 & 180 & 180.3 \\
\hline 41 & 179.9 & 180.2 & 183.2 & 179.7 & 180 & 183.3 & 182.8 & & 180.2 & 180.4 & 180.1 & 179.8 & 180.1 \\
\hline 42 & 179.7 & 180 & 183 & & 179.8 & 183.1 & 182.6 & & 180 & 180.2 & 179.9 & 179.6 & 179.9 \\
\hline 43 & & 179.8 & 182.9 & & & 182.9 & 182.4 & & 179.8 & 180 & 179.7 & & 179.7 \\
\hline 44 & & & 182.7 & & & 182.7 & 182.2 & & 179.7 & 179.9 & & & \\
\hline 45 & & & 182.5 & & & 182.5 & 182 & & & 179.7 & & & \\
\hline \multicolumn{14}{|c|}{ Break } \\
\hline 55 & & & 181 & & & 181 & 180.5 & & & & & & \\
\hline 56 & & & 180.8 & & & 180.8 & 180.3 & & & & & & \\
\hline 57 & & & 180.7 & & & 180.7 & 180.2 & & & & & & \\
\hline 58 & & & 180.6 & & & 180.6 & 180.1 & & & & & & \\
\hline 59 & & & 180.4 & & & 180.4 & 179.9 & & & & & & \\
\hline 60 & & & 180.3 & & & 180.3 & 179.8 & & & & & & \\
\hline 61 & & & 180.2 & & & 180.2 & & & & & & & \\
\hline 62 & & & 180.1 & & & 180.1 & & & & & & & \\
\hline 63 & & & 179.9 & & & 179.9 & & & & & & & \\
\hline 64 & & & 179.9 & & & 179.8 & & & & & & & \\
\hline
\end{tabular}




\section{PG 76-22 PM 12.5 mm}

\begin{tabular}{|c|c|c|c|c|c|c|c|c|c|c|c|c|c|}
\hline Gyrations & FT 1A & FT 1B & FT 1C & FT 2A & FT 2B & FT 2C & FT 3A & FT 3B & FT 3C & DM 1 & $\mathrm{DM} 2$ & DM 3 & EXTRA \\
\hline 0 & 219.9 & 219.6 & 219.3 & 221.7 & 220.4 & 219.5 & 221.9 & 220.5 & 220.3 & 220.8 & 220.4 & 219.6 & 220.1 \\
\hline 1 & 212.2 & 211.8 & 211.5 & 213.9 & 212.4 & 211.6 & 214 & 212.6 & 212.4 & 212.9 & 212.5 & 211.7 & 212.3 \\
\hline 2 & 207.6 & 207.3 & 206.9 & 209.2 & 207.9 & 206.9 & 209.4 & 208 & 208 & 208.4 & 208 & 207.1 & 207.9 \\
\hline 3 & 204.2 & 204 & 203.6 & 205.8 & 204.4 & 203.6 & 206.2 & 204.5 & 204.6 & 205.1 & 204.5 & 203.7 & 204.5 \\
\hline 4 & 201.6 & 201.4 & 201 & 203.1 & 201.8 & 201 & 203.6 & 201.8 & 201.9 & 202.5 & 201.9 & 201.1 & 201.9 \\
\hline 5 & 199.5 & 199.3 & 198.8 & 200.9 & 199.6 & 198.8 & 201.4 & 199.7 & 199.7 & 200.3 & 199.7 & 198.9 & 199.7 \\
\hline \multicolumn{14}{|c|}{ Break } \\
\hline 37 & 180.6 & 180.1 & 179.6 & 181.4 & 180.3 & 179.8 & 182.7 & 180.3 & 180.2 & 181.2 & 180.5 & 179.8 & 180.6 \\
\hline 38 & 180.3 & 179.9 & & 181.2 & 180.1 & & 182.5 & 180.1 & 180 & 181 & 180.3 & 179.6 & 180.3 \\
\hline 39 & 180.1 & 179.7 & & 181 & 179.9 & & 182.2 & 179.9 & 179.8 & 180.8 & 180.1 & & 180.1 \\
\hline 40 & 179.9 & & & 180.7 & 179.7 & & 182 & 179.7 & 179.6 & 180.6 & 179.9 & & 179.9 \\
\hline 41 & 179.8 & & & 180.5 & & & 181.8 & & & 180.4 & 179.7 & & 179.7 \\
\hline 42 & & & & 180.3 & & & 181.6 & & & 180.2 & & & \\
\hline 43 & & & & 180.1 & & & 181.5 & & & 180 & & & \\
\hline 44 & & & & 180 & & & 181.3 & & & 179.8 & & & \\
\hline 45 & & & & 179.8 & & & 181.1 & & & 179.7 & & & \\
\hline 46 & & & & & & & 180.9 & & & & & & \\
\hline 47 & & & & & & & 180.8 & & & & & & \\
\hline 48 & & & & & & & 180.6 & & & & & & \\
\hline 49 & & & & & & & 180.4 & & & & & & \\
\hline 50 & & & & & & & 180.3 & & & & & & \\
\hline 51 & & & & & & & 180.1 & & & & & & \\
\hline 52 & & & & & & & 180 & & & & & & \\
\hline 53 & & & & & & & 179.9 & & & & & & \\
\hline
\end{tabular}




\section{Appendix F - Dynamic Modulus}

\section{MEPDG Outputs}

PG 70-22 $9.5 \mathrm{~mm}$

\begin{tabular}{|c|c|c|c|c|c|c|}
\hline $\begin{array}{c}\text { Temp } \\
\left({ }^{\circ} \mathbf{C}\right)\end{array}$ & $\begin{array}{c}\text { Temp } \\
\left({ }^{\circ} \mathbf{F}\right)\end{array}$ & $\begin{array}{c}\text { Frequency } \\
(\mathbf{H z})\end{array}$ & $\begin{array}{c}\text { Shift } \\
\text { Factor }\end{array}$ & $\begin{array}{c}\text { Reduced } \\
\text { Frequency }\end{array}$ & $\begin{array}{c}\mathbf{E}^{*} \\
(\mathbf{k s i})\end{array}$ & $\begin{array}{c}\mathbf{E}^{*} \\
(\mathbf{M P a})\end{array}$ \\
\hline-10.0 & 14 & 25 & 3.786929 & 153062.6 & 2618.8 & 18061.7 \\
\hline-10.0 & 14 & 10 & 3.786929 & 61225.04 & 2522.7 & 17399.3 \\
\hline-10.0 & 14 & 5 & 3.786929 & 30612.52 & 2440.0 & 16828.8 \\
\hline-10.0 & 14 & 1 & 3.786929 & 6122.504 & 2212.1 & 15257.0 \\
\hline-10.0 & 14 & 0.5 & 3.786929 & 3061.252 & 2098.2 & 14471.1 \\
\hline-10.0 & 14 & 0.1 & 3.786929 & 612.2504 & 1799.3 & 12410.0 \\
\hline 4.4 & 40 & 25 & 1.861437 & 1817.092 & 2006.3 & 13837.7 \\
\hline 4.4 & 40 & 10 & 1.861437 & 726.8369 & 1833.3 & 12644.0 \\
\hline 4.4 & 40 & 5 & 1.861437 & 363.4185 & 1693.7 & 11681.3 \\
\hline 4.4 & 40 & 1 & 1.861437 & 72.68369 & 1350.9 & 9317.5 \\
\hline 4.4 & 40 & 0.5 & 1.861437 & 36.34185 & 1200.7 & 8281.4 \\
\hline 4.4 & 40 & 0.1 & 1.861437 & 7.268369 & 865.5 & 5969.3 \\
\hline 21.1 & 70 & 25 & -0.12543 & 18.72879 & 1059.2 & 7305.0 \\
\hline 21.1 & 70 & 10 & -0.12543 & 7.491515 & 871.5 & 6010.5 \\
\hline 21.1 & 70 & 5 & -0.12543 & 3.745757 & 739.0 & 5097.1 \\
\hline 21.1 & 70 & 1 & -0.12543 & 0.749151 & 475.7 & 3281.0 \\
\hline 21.1 & 70 & 0.5 & -0.12543 & 0.374576 & 384.3 & 2650.2 \\
\hline 21.1 & 70 & 0.1 & -0.12543 & 0.074915 & 223.4 & 1540.7 \\
\hline 37.8 & 100 & 25 & -1.89933 & 0.315219 & 363.6 & 2507.9 \\
\hline 37.8 & 100 & 10 & -1.89933 & 0.126088 & 267.9 & 1847.7 \\
\hline 37.8 & 100 & 5 & -1.89933 & 0.063044 & 210.1 & 1449.1 \\
\hline 37.8 & 100 & 1 & -1.89933 & 0.012609 & 116.5 & 803.5 \\
\hline 37.8 & 100 & 0.5 & -1.89933 & 0.006304 & 90.0 & 620.7 \\
\hline 37.8 & 100 & 0.1 & -1.89933 & 0.001261 & 50.0 & 344.6 \\
\hline 54.4 & 130 & 25 & -3.49276 & 0.008039 & 98.5 & 679.5 \\
\hline 54.4 & 130 & 10 & -3.49276 & 0.003215 & 70.1 & 483.7 \\
\hline 54.4 & 130 & 5 & -3.49276 & 0.001608 & 54.5 & 375.9 \\
\hline 54.4 & 130 & 1 & -3.49276 & 0.000322 & 31.3 & 216.0 \\
\hline 54.4 & 130 & 0.5 & -3.49276 & 0.000161 & 25.1 & 173.4 \\
\hline 54.4 & 130 & 0.1 & -3.49276 & $3.22 \mathrm{E}-05$ & 15.9 & 109.8 \\
\hline & & & & & & \\
\hline
\end{tabular}




\begin{tabular}{|c|c|c|c|c|c|c|}
\hline $\begin{array}{c}\text { Temp } \\
\left({ }^{\circ} \mathbf{C}\right)\end{array}$ & $\begin{array}{c}\text { Temp } \\
\left({ }^{\circ} \mathbf{F}\right)\end{array}$ & $\begin{array}{c}\text { Frequency } \\
(\mathbf{H z})\end{array}$ & $\begin{array}{c}\text { Shift } \\
\text { Factor }\end{array}$ & $\begin{array}{c}\text { Reduced } \\
\text { Frequency }\end{array}$ & $\begin{array}{c}\mathbf{E}^{*} \\
(\mathbf{k s i})\end{array}$ & $\begin{array}{c}\mathbf{E}^{*} \\
(\mathbf{M P a})\end{array}$ \\
\hline-10.0 & 14 & 25 & 3.936123 & 215805.6 & 2560.3 & 17658.6 \\
\hline-10.0 & 14 & 10 & 3.936123 & 86322.26 & 2452.3 & 16913.4 \\
\hline-10.0 & 14 & 5 & 3.936123 & 43161.13 & 2359.7 & 16275.2 \\
\hline-10.0 & 14 & 1 & 3.936123 & 8632.226 & 2107.6 & 14535.8 \\
\hline-10.0 & 14 & 0.5 & 3.936123 & 4316.113 & 1983.1 & 13677.6 \\
\hline-10.0 & 14 & 0.1 & 3.936123 & 863.2226 & 1662.7 & 11467.7 \\
\hline 4.4 & 40 & 25 & 1.934772 & 2151.355 & 1849.4 & 12755.3 \\
\hline 4.4 & 40 & 10 & 1.934772 & 860.542 & 1662.1 & 11463.2 \\
\hline 4.4 & 40 & 5 & 1.934772 & 430.271 & 1513.9 & 10441.4 \\
\hline 4.4 & 40 & 1 & 1.934772 & 86.0542 & 1162.2 & 8015.9 \\
\hline 4.4 & 40 & 0.5 & 1.934772 & 43.0271 & 1014.0 & 6993.4 \\
\hline 4.4 & 40 & 0.1 & 1.934772 & 8.60542 & 697.7 & 4811.8 \\
\hline 21.1 & 70 & 25 & -0.13037 & 18.51689 & 842.1 & 5807.9 \\
\hline 21.1 & 70 & 10 & -0.13037 & 7.406757 & 671.0 & 4627.7 \\
\hline 21.1 & 70 & 5 & -0.13037 & 3.703378 & 555.2 & 3829.6 \\
\hline 21.1 & 70 & 1 & -0.13037 & 0.740676 & 338.8 & 2336.4 \\
\hline 21.1 & 70 & 0.5 & -0.13037 & 0.370338 & 268.3 & 1850.1 \\
\hline 21.1 & 70 & 0.1 & -0.13037 & 0.074068 & 150.9 & 1040.9 \\
\hline 37.8 & 100 & 25 & -1.97416 & 0.265329 & 238.9 & 1647.7 \\
\hline 37.8 & 100 & 10 & -1.97416 & 0.106132 & 172.1 & 1187.2 \\
\hline 37.8 & 100 & 5 & -1.97416 & 0.053066 & 133.5 & 920.6 \\
\hline 37.8 & 100 & 1 & -1.97416 & 0.010613 & 73.7 & 508.3 \\
\hline 37.8 & 100 & 0.5 & -1.97416 & 0.005307 & 57.4 & 395.8 \\
\hline 37.8 & 100 & 0.1 & -1.97416 & 0.001061 & 33.2 & 228.6 \\
\hline 54.4 & 130 & 25 & -3.63036 & 0.005856 & 59.4 & 409.9 \\
\hline 54.4 & 130 & 10 & -3.63036 & 0.002342 & 43.1 & 297.4 \\
\hline 54.4 & 130 & 5 & -3.63036 & 0.001171 & 34.2 & 236.1 \\
\hline 54.4 & 130 & 1 & -3.63036 & 0.000234 & 21.0 & 144.9 \\
\hline 54.4 & 130 & 0.5 & -3.63036 & 0.000117 & 17.4 & 120.3 \\
\hline 54.4 & 130 & 0.1 & -3.63036 & $2.34 \mathrm{E}-05$ & 12.0 & 82.7 \\
\hline
\end{tabular}


PG 70-22 PM 9.5 mm

\begin{tabular}{|c|c|c|c|c|c|c|}
\hline $\begin{array}{c}\text { Temp } \\
\left({ }^{\circ} \mathbf{C}\right)\end{array}$ & $\begin{array}{c}\text { Temp } \\
\left({ }^{\circ} \mathbf{F}\right)\end{array}$ & $\begin{array}{c}\text { Frequency } \\
(\mathbf{H z})\end{array}$ & $\begin{array}{c}\text { Shift } \\
\text { Factor }\end{array}$ & $\begin{array}{c}\text { Reduced } \\
\text { Frequency }\end{array}$ & $\begin{array}{c}\mathbf{E}^{*} \\
(\mathbf{k s i})\end{array}$ & $\begin{array}{c}\mathbf{E}^{*} \\
(\mathbf{M P a})\end{array}$ \\
\hline-10.0 & 14 & 25 & 4.193196 & 390064.5 & 2535.2 & 17485.6 \\
\hline-10.0 & 14 & 10 & 4.193196 & 156025.8 & 2428.9 & 16752.3 \\
\hline-10.0 & 14 & 5 & 4.193196 & 78012.89 & 2338.6 & 16129.4 \\
\hline-10.0 & 14 & 1 & 4.193196 & 15602.58 & 2095.0 & 14449.4 \\
\hline-10.0 & 14 & 0.5 & 4.193196 & 7801.289 & 1975.9 & 13627.6 \\
\hline-10.0 & 14 & 0.1 & 4.193196 & 1560.258 & 1670.9 & 11524.1 \\
\hline 4.4 & 40 & 25 & 2.061135 & 2877.893 & 1791.0 & 12352.6 \\
\hline 4.4 & 40 & 10 & 2.061135 & 1151.157 & 1609.7 & 11102.2 \\
\hline 4.4 & 40 & 5 & 2.061135 & 575.5787 & 1467.6 & 10121.7 \\
\hline 4.4 & 40 & 1 & 2.061135 & 115.1157 & 1133.2 & 7816.0 \\
\hline 4.4 & 40 & 0.5 & 2.061135 & 57.55787 & 993.2 & 6850.0 \\
\hline 4.4 & 40 & 0.1 & 2.061135 & 11.51157 & 694.6 & 4790.4 \\
\hline 21.1 & 70 & 25 & -0.13889 & 18.15739 & 774.3 & 5340.2 \\
\hline 21.1 & 70 & 10 & -0.13889 & 7.262954 & 618.7 & 4266.9 \\
\hline 21.1 & 70 & 5 & -0.13889 & 3.631477 & 514.1 & 3545.6 \\
\hline 21.1 & 70 & 1 & -0.13889 & 0.726295 & 319.1 & 2200.8 \\
\hline 21.1 & 70 & 0.5 & -0.13889 & 0.363148 & 255.4 & 1761.4 \\
\hline 21.1 & 70 & 0.1 & -0.13889 & 0.07263 & 148.3 & 1022.5 \\
\hline 37.8 & 100 & 25 & -2.10309 & 0.197174 & 208.5 & 1438.1 \\
\hline 37.8 & 100 & 10 & -2.10309 & 0.07887 & 152.5 & 1052.0 \\
\hline 37.8 & 100 & 5 & -2.10309 & 0.039435 & 120.0 & 827.4 \\
\hline 37.8 & 100 & 1 & -2.10309 & 0.007887 & 68.9 & 475.3 \\
\hline 37.8 & 100 & 0.5 & -2.10309 & 0.003943 & 54.7 & 377.0 \\
\hline 37.8 & 100 & 0.1 & -2.10309 & 0.000789 & 33.0 & 227.5 \\
\hline 54.4 & 130 & 25 & -3.86746 & 0.003392 & 52.0 & 358.9 \\
\hline 54.4 & 130 & 10 & -3.86746 & 0.001357 & 38.9 & 268.1 \\
\hline 54.4 & 130 & 5 & -3.86746 & 0.000678 & 31.6 & 217.6 \\
\hline 54.4 & 130 & 1 & -3.86746 & 0.000136 & 20.4 & 140.5 \\
\hline 54.4 & 130 & 0.5 & -3.86746 & $6.78 \mathrm{E}-05$ & 17.2 & 118.9 \\
\hline 54.4 & 130 & 0.1 & -3.86746 & $1.36 \mathrm{E}-05$ & 12.3 & 85.1 \\
\hline & & & & & & \\
\hline
\end{tabular}


PG 70-22 PM $12.5 \mathrm{~mm}$

\begin{tabular}{|c|c|c|c|c|c|c|}
\hline $\begin{array}{c}\text { Temp } \\
\left({ }^{\circ} \mathbf{C}\right)\end{array}$ & $\begin{array}{c}\text { Temp } \\
\left({ }^{\circ} \mathbf{F}\right)\end{array}$ & $\begin{array}{c}\text { Frequency } \\
(\mathbf{H z})\end{array}$ & $\begin{array}{c}\text { Shift } \\
\text { Factor }\end{array}$ & $\begin{array}{c}\text { Reduced } \\
\text { Frequency }\end{array}$ & $\begin{array}{c}\mathbf{E}^{*} \\
(\mathbf{k s i})\end{array}$ & $\begin{array}{c}\mathbf{E}^{*} \\
(\mathbf{M P a})\end{array}$ \\
\hline-10.0 & 14 & 25 & 4.058589 & 286107.2 & 2501.3 & 17251.5 \\
\hline-10.0 & 14 & 10 & 4.058589 & 114442.9 & 2388.0 & 16469.9 \\
\hline-10.0 & 14 & 5 & 4.058589 & 57221.44 & 2291.9 & 15807.4 \\
\hline-10.0 & 14 & 1 & 4.058589 & 11444.29 & 2034.2 & 14029.8 \\
\hline-10.0 & 14 & 0.5 & 4.058589 & 5722.144 & 1909.0 & 13166.2 \\
\hline-10.0 & 14 & 0.1 & 4.058589 & 1144.429 & 1591.6 & 10977.6 \\
\hline 4.4 & 40 & 25 & 1.994969 & 2471.208 & 1747.4 & 12051.9 \\
\hline 4.4 & 40 & 10 & 1.994969 & 988.4833 & 1561.4 & 10768.8 \\
\hline 4.4 & 40 & 5 & 1.994969 & 494.2416 & 1416.4 & 9768.7 \\
\hline 4.4 & 40 & 1 & 1.994969 & 98.84833 & 1079.0 & 7441.7 \\
\hline 4.4 & 40 & 0.5 & 1.994969 & 49.42416 & 939.4 & 6479.2 \\
\hline 4.4 & 40 & 0.1 & 1.994969 & 9.884833 & 646.4 & 4458.5 \\
\hline 21.1 & 70 & 25 & -0.13443 & 18.34475 & 752.8 & 5191.9 \\
\hline 21.1 & 70 & 10 & -0.13443 & 7.3379 & 598.4 & 4127.2 \\
\hline 21.1 & 70 & 5 & -0.13443 & 3.66895 & 495.4 & 3416.7 \\
\hline 21.1 & 70 & 1 & -0.13443 & 0.73379 & 305.2 & 2105.0 \\
\hline 21.1 & 70 & 0.5 & -0.13443 & 0.366895 & 243.8 & 1681.2 \\
\hline 21.1 & 70 & 0.1 & -0.13443 & 0.073379 & 141.3 & 974.6 \\
\hline 37.8 & 100 & 25 & -2.03558 & 0.230336 & 208.7 & 1439.6 \\
\hline 37.8 & 100 & 10 & -2.03558 & 0.092134 & 152.8 & 1054.0 \\
\hline 37.8 & 100 & 5 & -2.03558 & 0.046067 & 120.4 & 830.1 \\
\hline 37.8 & 100 & 1 & -2.03558 & 0.009213 & 69.6 & 479.7 \\
\hline 37.8 & 100 & 0.5 & -2.03558 & 0.004607 & 55.4 & 382.0 \\
\hline 37.8 & 100 & 0.1 & -2.03558 & 0.000921 & 33.8 & 233.3 \\
\hline 54.4 & 130 & 25 & -3.74331 & 0.004515 & 55.0 & 379.6 \\
\hline 54.4 & 130 & 10 & -3.74331 & 0.001806 & 41.3 & 284.7 \\
\hline 54.4 & 130 & 5 & -3.74331 & 0.000903 & 33.6 & 231.9 \\
\hline 54.4 & 130 & 1 & -3.74331 & 0.000181 & 21.9 & 151.1 \\
\hline 54.4 & 130 & 0.5 & -3.74331 & $9.03 \mathrm{E}-05$ & 18.6 & 128.5 \\
\hline 54.4 & 130 & 0.1 & -3.74331 & $1.81 \mathrm{E}-05$ & 13.5 & 92.8 \\
\hline
\end{tabular}


PG 76-22 PM 9.5 mm

\begin{tabular}{|c|c|c|c|c|c|c|}
\hline $\begin{array}{c}\text { Temp } \\
\left({ }^{\circ} \mathbf{C}\right)\end{array}$ & $\begin{array}{c}\text { Temp } \\
\left({ }^{\circ} \mathbf{F}\right)\end{array}$ & $\begin{array}{c}\text { Frequency } \\
(\mathbf{H z})\end{array}$ & $\begin{array}{c}\text { Shift } \\
\text { Factor }\end{array}$ & $\begin{array}{c}\text { Reduced } \\
\text { Frequency }\end{array}$ & $\begin{array}{c}\mathbf{E}^{*} \\
(\mathbf{k s i})\end{array}$ & $\begin{array}{c}\mathbf{E}^{*} \\
(\mathbf{M P a})\end{array}$ \\
\hline-10.0 & 14 & 25 & 3.747481 & 139772.3 & 2490.8 & 17179.0 \\
\hline-10.0 & 14 & 10 & 3.747481 & 55908.92 & 2370.7 & 16350.8 \\
\hline-10.0 & 14 & 5 & 3.747481 & 27954.46 & 2268.4 & 15644.9 \\
\hline-10.0 & 14 & 1 & 3.747481 & 5590.892 & 1992.3 & 13741.1 \\
\hline-10.0 & 14 & 0.5 & 3.747481 & 2795.446 & 1858.1 & 12815.3 \\
\hline-10.0 & 14 & 0.1 & 3.747481 & 559.0892 & 1519.7 & 10481.1 \\
\hline 4.4 & 40 & 25 & 1.842047 & 1737.747 & 1761.5 & 12148.9 \\
\hline 4.4 & 40 & 10 & 1.842047 & 695.0989 & 1567.0 & 10807.9 \\
\hline 4.4 & 40 & 5 & 1.842047 & 347.5495 & 1415.3 & 9761.3 \\
\hline 4.4 & 40 & 1 & 1.842047 & 69.50989 & 1063.4 & 7334.2 \\
\hline 4.4 & 40 & 0.5 & 1.842047 & 34.75495 & 919.1 & 6338.9 \\
\hline 4.4 & 40 & 0.1 & 1.842047 & 6.950989 & 620.6 & 4280.2 \\
\hline 21.1 & 70 & 25 & -0.12412 & 18.78522 & 798.0 & 5503.8 \\
\hline 21.1 & 70 & 10 & -0.12412 & 7.514087 & 633.6 & 4369.8 \\
\hline 21.1 & 70 & 5 & -0.12412 & 3.757044 & 524.0 & 3613.7 \\
\hline 21.1 & 70 & 1 & -0.12412 & 0.751409 & 322.5 & 2224.5 \\
\hline 21.1 & 70 & 0.5 & -0.12412 & 0.375704 & 257.9 & 1779.0 \\
\hline 21.1 & 70 & 0.1 & -0.12412 & 0.075141 & 151.1 & 1042.0 \\
\hline 37.8 & 100 & 25 & -1.87954 & 0.329911 & 247.2 & 1704.8 \\
\hline 37.8 & 100 & 10 & -1.87954 & 0.131965 & 182.4 & 1257.9 \\
\hline 37.8 & 100 & 5 & -1.87954 & 0.065982 & 144.7 & 997.8 \\
\hline 37.8 & 100 & 1 & -1.87954 & 0.013196 & 85.5 & 589.4 \\
\hline 37.8 & 100 & 0.5 & -1.87954 & 0.006598 & 68.9 & 475.2 \\
\hline 37.8 & 100 & 0.1 & -1.87954 & 0.00132 & 43.5 & 300.3 \\
\hline 54.4 & 130 & 25 & -3.45637 & 0.008741 & 75.1 & 518.0 \\
\hline 54.4 & 130 & 10 & -3.45637 & 0.003496 & 57.1 & 393.5 \\
\hline 54.4 & 130 & 5 & -3.45637 & 0.001748 & 47.0 & 323.9 \\
\hline 54.4 & 130 & 1 & -3.45637 & 0.00035 & 31.4 & 216.8 \\
\hline 54.4 & 130 & 0.5 & -3.45637 & 0.000175 & 27.1 & 186.7 \\
\hline 54.4 & 130 & 0.1 & -3.45637 & $3.5 \mathrm{E}-05$ & 20.2 & 139.1 \\
\hline & & & & & & \\
\hline
\end{tabular}


PG 76-22 PM $12.5 \mathrm{~mm}$

\begin{tabular}{|c|c|c|c|c|c|c|}
\hline $\begin{array}{c}\text { Temp } \\
\left({ }^{\circ} \mathbf{C}\right)\end{array}$ & $\begin{array}{c}\text { Temp } \\
\left({ }^{\circ} \mathbf{F}\right)\end{array}$ & $\begin{array}{c}\text { Frequency } \\
(\mathbf{H z})\end{array}$ & $\begin{array}{c}\text { Shift } \\
\text { Factor }\end{array}$ & $\begin{array}{c}\text { Reduced } \\
\text { Frequency }\end{array}$ & $\begin{array}{c}\mathbf{E}^{*} \\
(\mathbf{k s i})\end{array}$ & $\begin{array}{c}\mathbf{E}^{*} \\
(\mathbf{M P a})\end{array}$ \\
\hline-10.0 & 14 & 25 & 3.784247 & 152120.1 & 2460.0 & 16966.3 \\
\hline-10.0 & 14 & 10 & 3.784247 & 60848.04 & 2333.6 & 16094.5 \\
\hline-10.0 & 14 & 5 & 3.784247 & 30424.02 & 2226.2 & 15354.3 \\
\hline-10.0 & 14 & 1 & 3.784247 & 6084.804 & 1938.9 & 13372.9 \\
\hline-10.0 & 14 & 0.5 & 3.784247 & 3042.402 & 1800.4 & 12417.6 \\
\hline-10.0 & 14 & 0.1 & 3.784247 & 608.4804 & 1455.1 & 10035.6 \\
\hline 4.4 & 40 & 25 & 1.860118 & 1811.584 & 1692.1 & 11670.7 \\
\hline 4.4 & 40 & 10 & 1.860118 & 724.6336 & 1493.6 & 10301.4 \\
\hline 4.4 & 40 & 5 & 1.860118 & 362.3168 & 1340.2 & 9243.4 \\
\hline 4.4 & 40 & 1 & 1.860118 & 72.46336 & 990.3 & 6830.0 \\
\hline 4.4 & 40 & 0.5 & 1.860118 & 36.23168 & 849.4 & 5858.3 \\
\hline 4.4 & 40 & 0.1 & 1.860118 & 7.246336 & 563.6 & 3887.0 \\
\hline 21.1 & 70 & 25 & -0.12534 & 18.73262 & 724.4 & 4996.1 \\
\hline 21.1 & 70 & 10 & -0.12534 & 7.493048 & 568.8 & 3923.2 \\
\hline 21.1 & 70 & 5 & -0.12534 & 3.746524 & 466.8 & 3219.3 \\
\hline 21.1 & 70 & 1 & -0.12534 & 0.749305 & 283.2 & 1953.0 \\
\hline 21.1 & 70 & 0.5 & -0.12534 & 0.374652 & 225.5 & 1555.3 \\
\hline 21.1 & 70 & 0.1 & -0.12534 & 0.07493 & 131.6 & 907.7 \\
\hline 37.8 & 100 & 25 & -1.89798 & 0.316197 & 213.1 & 1470.0 \\
\hline 37.8 & 100 & 10 & -1.89798 & 0.126479 & 156.8 & 1081.6 \\
\hline 37.8 & 100 & 5 & -1.89798 & 0.063239 & 124.4 & 857.9 \\
\hline 37.8 & 100 & 1 & -1.89798 & 0.012648 & 74.0 & 510.2 \\
\hline 37.8 & 100 & 0.5 & -1.89798 & 0.006324 & 60.0 & 413.6 \\
\hline 37.8 & 100 & 0.1 & -1.89798 & 0.001265 & 38.5 & 265.8 \\
\hline 54.4 & 130 & 25 & -3.49028 & 0.008085 & 64.5 & 445.0 \\
\hline 54.4 & 130 & 10 & -3.49028 & 0.003234 & 49.5 & 341.1 \\
\hline 54.4 & 130 & 5 & -3.49028 & 0.001617 & 41.0 & 283.1 \\
\hline 54.4 & 130 & 1 & -3.49028 & 0.000323 & 28.1 & 193.5 \\
\hline 54.4 & 130 & 0.5 & -3.49028 & 0.000162 & 24.4 & 168.2 \\
\hline 54.4 & 130 & 0.1 & -3.49028 & $3.23 \mathrm{E}-05$ & 18.5 & 127.9 \\
\hline & & & & & & \\
\hline
\end{tabular}




\section{Appendix G - ALPHA Fatigue Outputs}

\section{PG 70-22 9.5 mm Default Output}

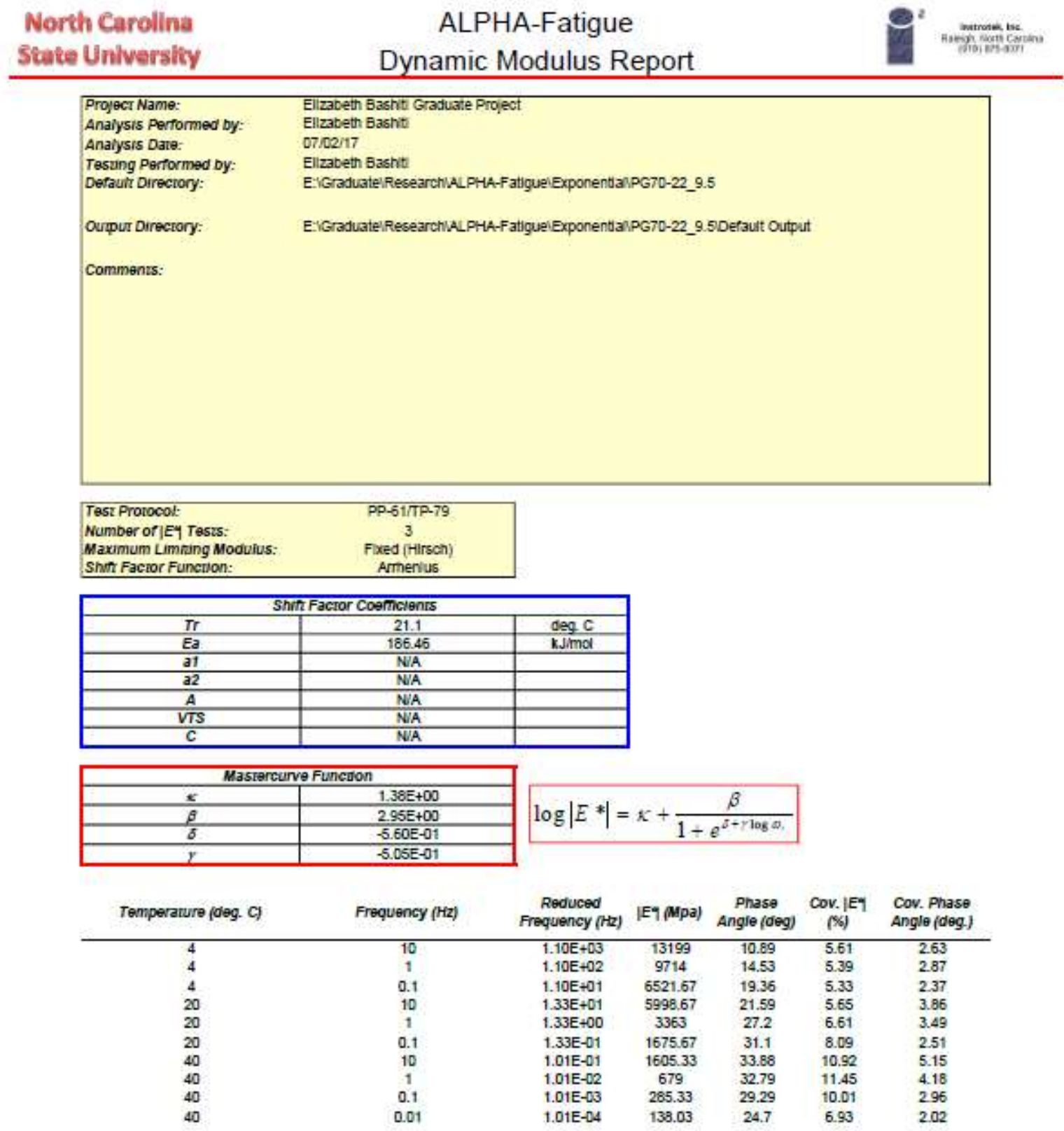




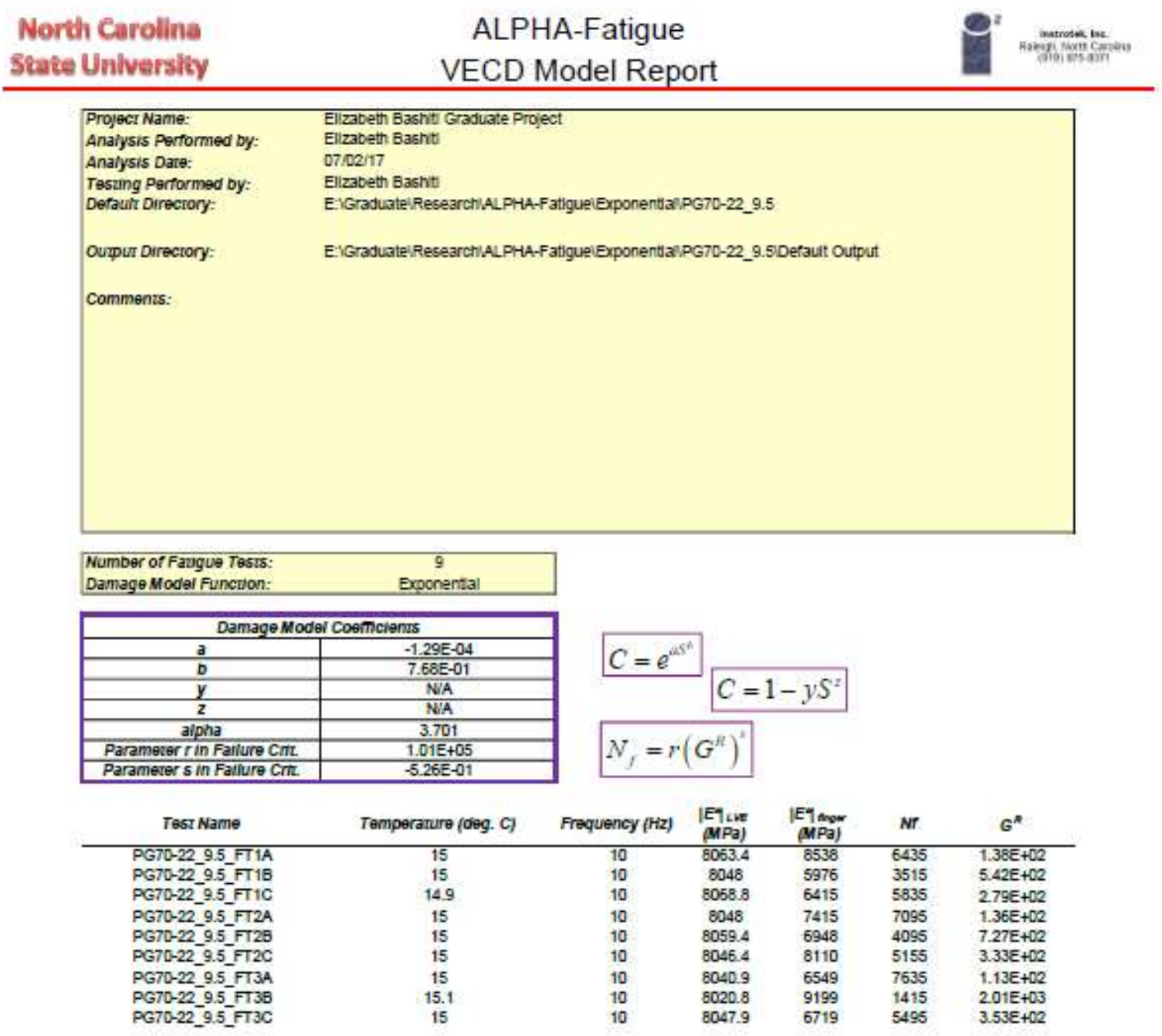


North Carolina State Unlverslity
ALPHA-Fatigue Model Predictions Report

\begin{tabular}{|c|c|}
\hline Project Name: & Elizabeth Bashti Graduate Project \\
\hline Analysis Pertormed by: & Ellzabeth Basht \\
\hline Analysis Dare: & $07 / 02 / 17$ \\
\hline Tesuing Performed by: & Elizabeth Bashit \\
\hline Defauth Direciory: & 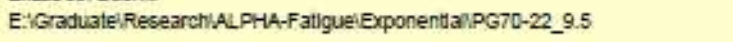 \\
\hline Oumus Directory: & E:Graduate:Research/ALPHA-FatigueiExponentaaPG70-22_9.5Defaut Output \\
\hline
\end{tabular}

Commenzs:

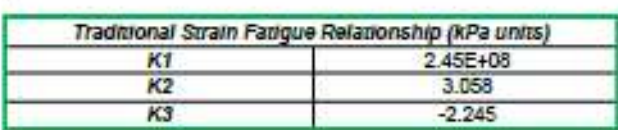

Tradmional Suress Fangue Relazonshyp 1 (KPa unns)

\begin{tabular}{|c|c|}
\hline \multicolumn{2}{|c|}{ Tradmional Suress Fangue Relawonship 1 (KPa unms) } \\
\hline$K 1$ & $3.65 E-02$ \\
\hline$K 2$ & -3.956 \\
\hline$K 3$ & 2.597 \\
\hline
\end{tabular}

Tradmonal Saress Fangue Relavonshyp 2 (kPa unns)

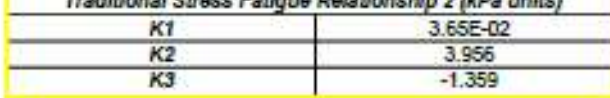

Traokitional Strain Fazigue Relationship (psi unnts)

\begin{tabular}{|c|c|}
\hline$K 1$ & $3.21 E+05$ \\
\hline$K 2$ & 3.058 \\
\hline 3 & -2.245 \\
\hline
\end{tabular}

\begin{tabular}{|c|c|}
\hline \multicolumn{2}{|c|}{ Tradional Suress Fangue Refadonship 1. (psi unis) } \\
\hline$K 1$ & $2.64 E-03$ \\
\hline$K_{2}$ & -3.956 \\
\hline$K 3$ & 2.597 \\
\hline
\end{tabular}

Tradional Suress Fangue Relagonship 2 (ps/ unms)

\begin{tabular}{|c|c|}
\hline$K 1$ & $2.64 E-03$ \\
\hline$K 2$ & 3.956 \\
$K 3$ & -1.359 \\
\hline
\end{tabular}

Endurance Umin (microsurain)

\begin{tabular}{|c|c|}
\hline \multicolumn{2}{|c|}{ Endurance Umin (microsuram) } \\
\hline Temperature (deg. C) & Endurance Limit \\
\hline 5 & 16 \\
\hline 10 & 17 \\
\hline 15 & 20 \\
\hline 20 & 23 \\
\hline 25 & 29 \\
\hline
\end{tabular}

$$
N_{1}=K_{1}\left(\frac{1}{\varepsilon_{l}}\right)^{K_{2}}\left(\left|E^{*}\right|\right)^{K_{1}}
$$

$$
N_{j}=K_{1}\left(\sigma_{i}\right)^{K_{2}}\left(\left|E^{*}\right|\right)^{K_{1}}
$$

$N_{f}=K_{1}\left(\frac{1}{\varepsilon_{i, j i}}\right)^{K_{2}}\left(\left|E^{*}\right|\right)^{K_{3}}$

$$
N_{t}=K_{1}\left(\frac{1}{\varepsilon_{t}}\right)^{K_{2}}(|E *|)^{K_{3}}
$$

$$
N_{i}=K_{1}\left(\sigma_{i}\right)^{K_{2}}\left(\left|E^{*}\right|\right)^{K_{3}}
$$

$$
N_{f}=K_{1}\left(\frac{1}{\varepsilon_{t, i n}}\right)^{K_{3}}\left(\left|E^{*}\right|\right)^{K_{3}}
$$




\section{PG 70-22 9.5 mm Peak Output}

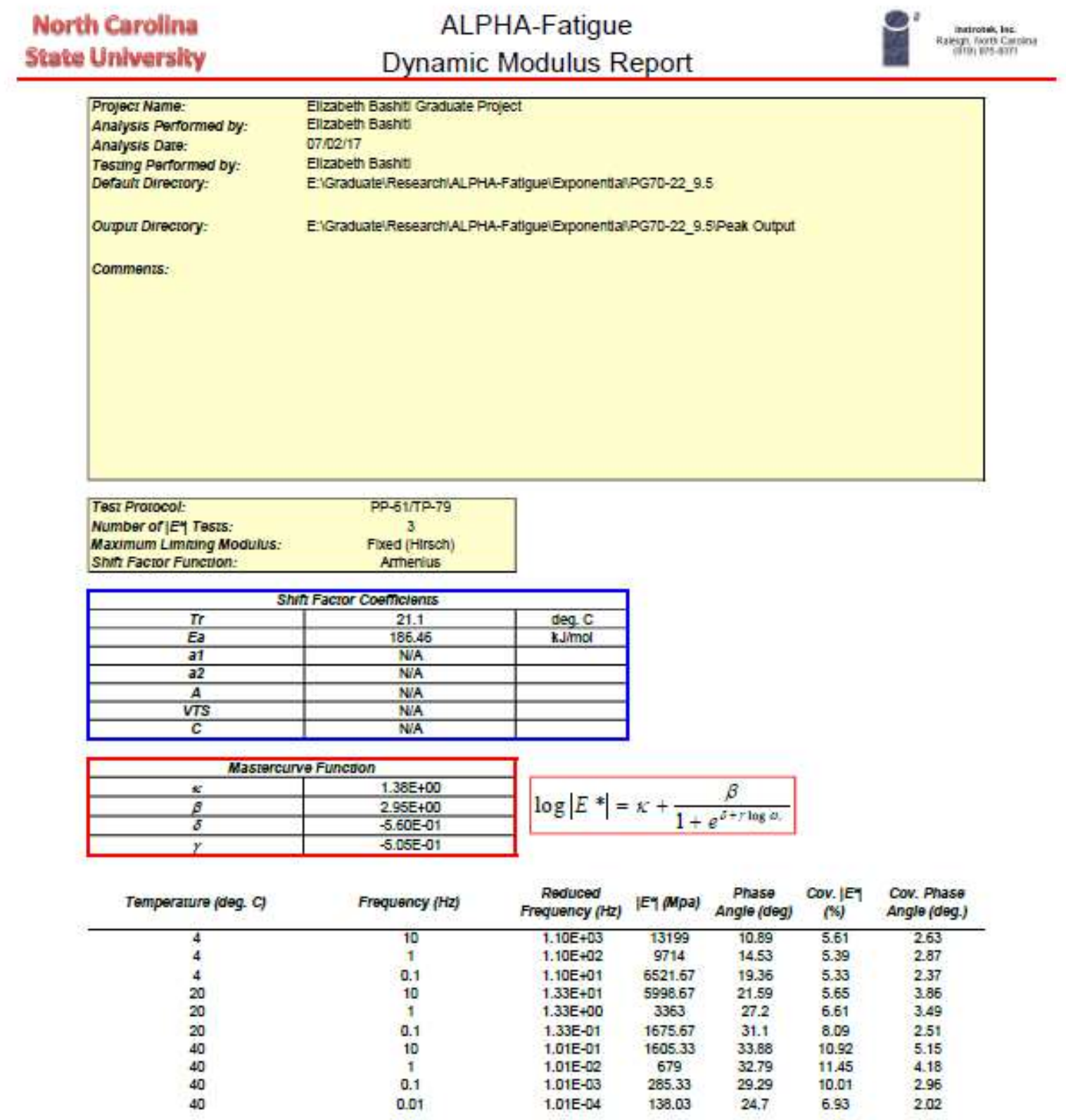




$\begin{array}{cc}\begin{array}{c}\text { North Carollina } \\ \text { State Unlverslty }\end{array} & \text { ALPHA-Fatigue } \\ \text { VECD Model Report }\end{array}$

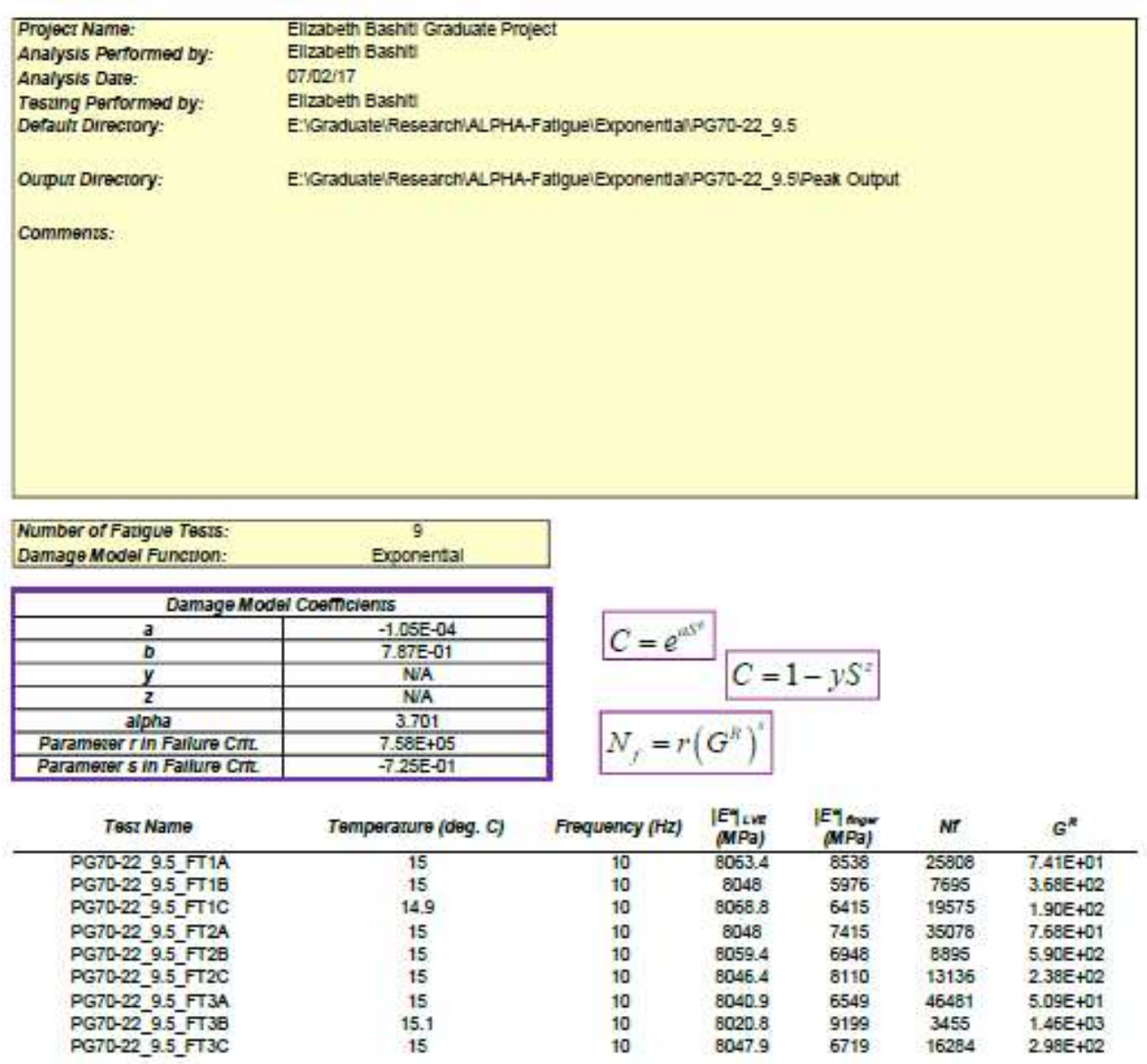


North Carolina State Univershy
ALPHA-Fatigue Model Predictions Report

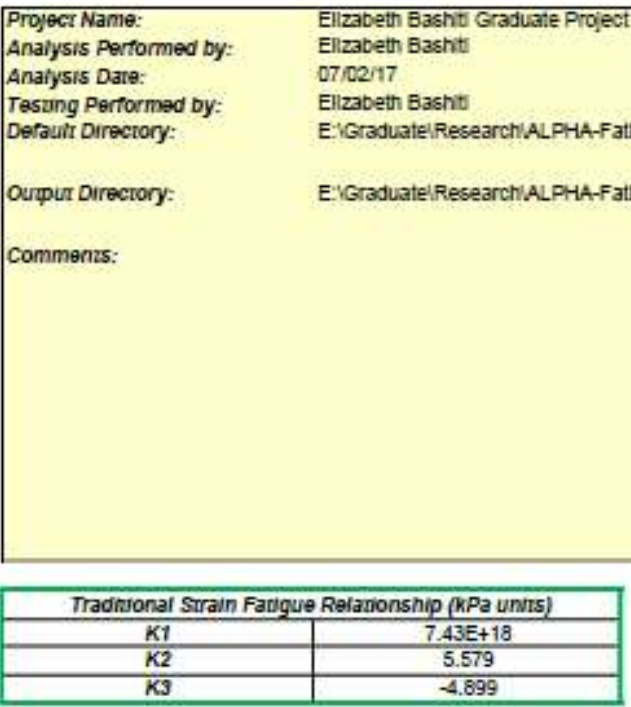

$N_{1}=K_{1}\left(\frac{1}{\varepsilon_{1}}\right)^{K_{2}}(|E *|)^{K_{3}}$

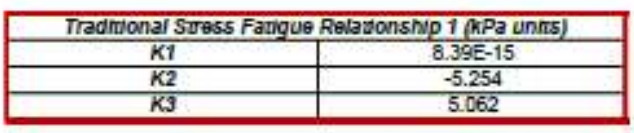

$N_{f}=K_{1}\left(\sigma_{f}\right)^{K_{2}}\left(\left|E^{*}\right|\right)^{K_{3}}$

Tradmional Surss Famigue Relavonship 2 (kPa unms)

\begin{tabular}{l|c}
$K 1$ & $8.39 \mathrm{E}-15$ \\
\hline$K 2$ & 5.254 \\
\hline$K 3$ & -0.191
\end{tabular}

$N_{f}=K_{1}\left(\frac{1}{\varepsilon_{i, i n i}}\right)^{K_{2}}\left(\left|E^{*}\right|\right)^{K_{3}}$

Tradinonal Surain Favgue Relanionship. (psi unnts)

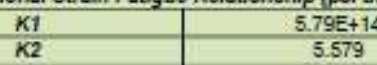

5.579

4.899

$N_{1}=K_{1}\left(\frac{1}{\varepsilon_{1}}\right)^{K_{2}}(|E *|)^{K_{3}}$

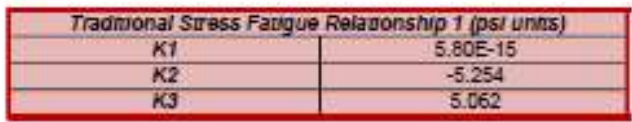

$N_{j}=K_{1}\left(\sigma_{i}\right)^{K_{2}}\left(\left|E^{*}\right|\right)^{K_{3}}$

Tradiuanal Suess Faugue Relamonship 2 (pst unus)

\begin{tabular}{c|c}
\hline$K 1$ & $5.80 \mathrm{E}-15$ \\
\hline$K 2$ & 5.254 \\
\hline$K 3$ & -0.191 \\
\hline
\end{tabular}

$N_{f}=K_{1}\left(\frac{1}{\varepsilon_{i, j}}\right)^{K_{2}}\left(\left|E^{*}\right|\right)^{k_{1}}$

\begin{tabular}{|c|c|}
\hline \multicolumn{2}{|c|}{ Enourance Limin (mucrosuratn) } \\
\hline Temperature (deg. C) & Endurance Limit \\
\hline 5 & 66 \\
\hline 10 & 73 \\
\hline 15 & 89 \\
\hline 20 & 107 \\
\hline 25 & 146 \\
\hline
\end{tabular}




\section{PG 70-22 12.5 mm Default Output}

\section{North Carolina \\ State University}

\author{
ALPHA-Fatigue \\ Dynamic Modulus Report
}

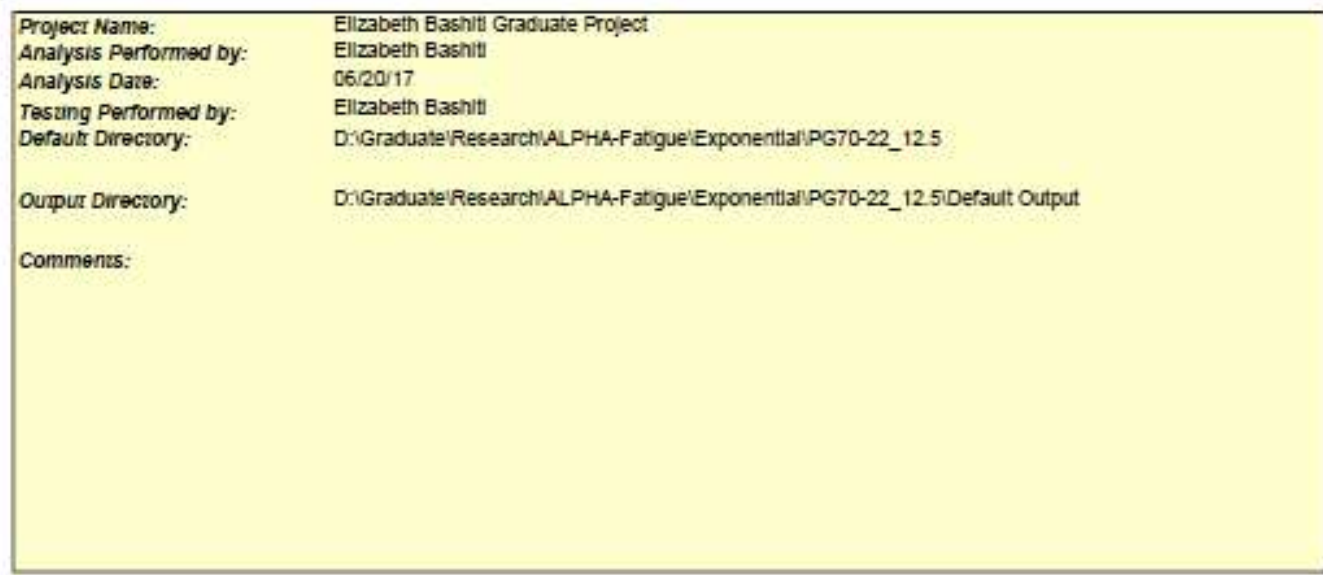

\begin{tabular}{lc|}
\hline Test Prozocol: & PP-61/TP-79 \\
Number of |E4 Tesis: & 3 \\
Maximum Limming Modulus: & Flued (Hirsch) \\
Shit Facror Function: & Amthenlus \\
\hline
\end{tabular}

\begin{tabular}{|c|c|c|}
\hline \multicolumn{3}{|c|}{ Shin Factor Coentients } \\
\hline$\pi r$ & 21.1 & deg. C \\
\hline Ea & 193.8 & $\mathrm{k} \cdot \mathrm{J} / \mathrm{mol}$ \\
\hline af & NA & \\
\hline a2 & N/A & \\
\hline A & N/A & \\
\hline VTS & NA & \\
\hline C & N/A & \\
\hline
\end{tabular}

\begin{tabular}{|c|c|}
\hline \multicolumn{2}{|c|}{ Mastercurve Funceon } \\
\hline$\kappa$ & $1.43 \mathrm{E}+D 0$ \\
\hline$\beta$ & $2.91 \mathrm{E}+00$ \\
\hline$\delta$ & $-2.92 \mathrm{E}-01$ \\
\hline$\gamma$ & $-5.10 \mathrm{E}-01$ \\
\hline
\end{tabular}

$$
\log |E *|=x+\frac{\beta}{1+e^{\delta+y \log \theta}}
$$

Temperazure (deg. C)

\begin{tabular}{r} 
Temperaure \\
\hline 4 \\
4 \\
4 \\
20 \\
20 \\
20 \\
40 \\
40 \\
40 \\
40
\end{tabular}

Frequen
10
1
0.1
10
1
0.1
10
1
0.1
0.01

\begin{tabular}{ccccc}
$\begin{array}{c}\text { Reduced } \\
\text { Frequency (Hz) }\end{array}$ & IEY (Mpa) & $\begin{array}{c}\text { Phase } \\
\text { Angle (deg) }\end{array}$ & $\begin{array}{c}\text { Cov. JEY } \\
\text { (N) }\end{array}$ & $\begin{array}{c}\text { Cov. Phase } \\
\text { Angle (deg.) }\end{array}$ \\
\hline $1.33 E+03$ & 12043.33 & 11.83 & 5.13 & 4.82 \\
$1.33 E+02$ & 8590.67 & 15.75 & 6.18 & 5.54 \\
$1.33 E+01$ & 5589.67 & 20.73 & 7.98 & 5.05 \\
$1.35 E+01$ & 4441.67 & 25.35 & 15.63 & 6.97 \\
$1.35 E+00$ & 2316.33 & 30.31 & 18.9 & 5.43 \\
$1.35 E-01$ & 1113.6 & 32.41 & 20.98 & 3.48 \\
$8.39 E-02$ & 1059.33 & 35.51 & 11.24 & 1.8 \\
$8.39 E-03$ & 437.7 & 32.92 & 14.15 & 0.58 \\
$8.39 E-04$ & 189.57 & 28.45 & 14.86 & 2.11 \\
$8.39 E-05$ & 102 & 23.31 & 9.25 & 5.21
\end{tabular}


North Carolina State Unlversilty
ALPHA-Fatigue VECD Model Report

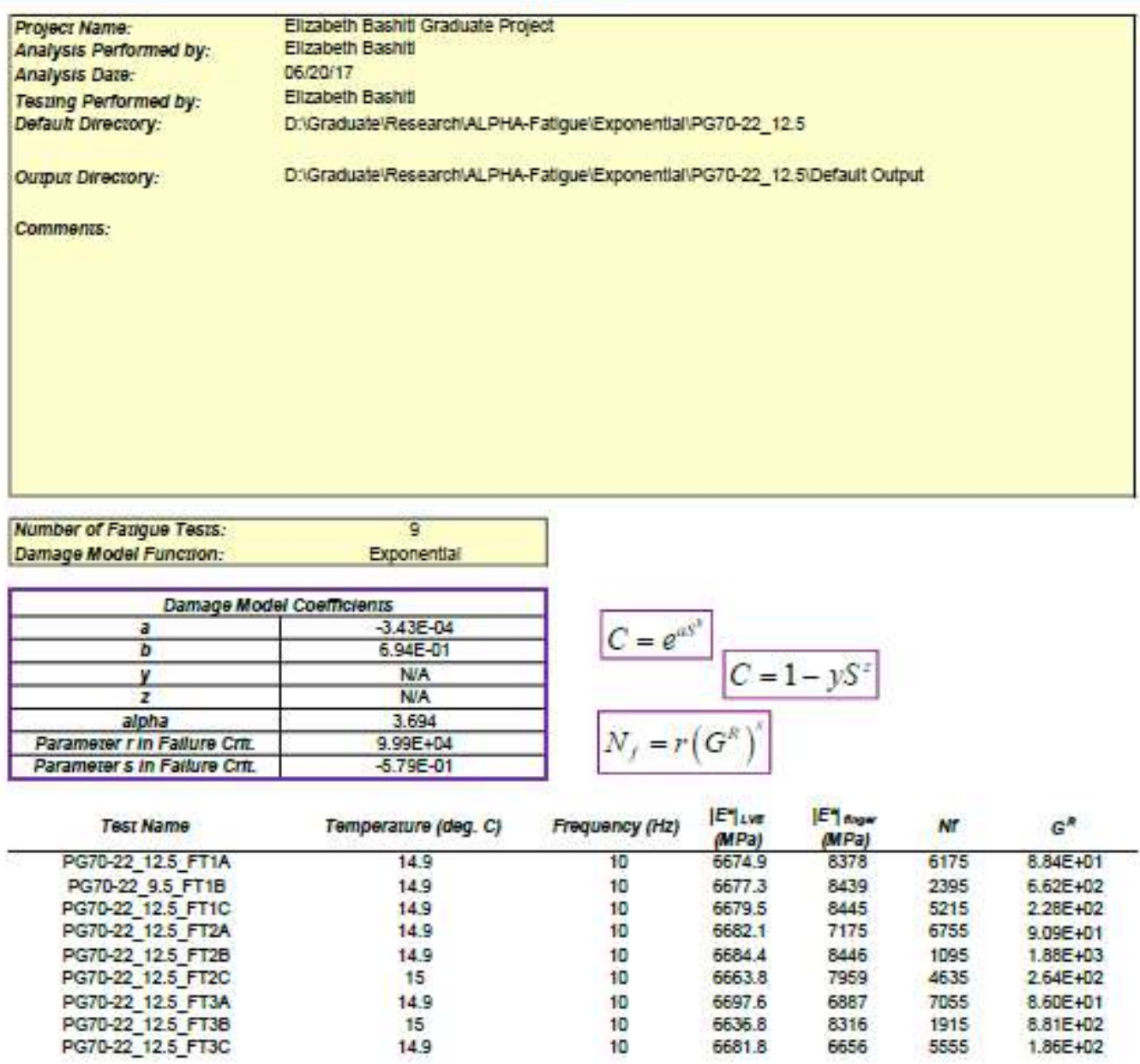


North Carolina State Universthy
ALPHA-Fatigue Model Predictions Report

\begin{tabular}{|c|c|}
\hline $\begin{array}{l}\text { Project Name: } \\
\text { Analysis Performed Dy: }\end{array}$ & $\begin{array}{l}\text { Elizabeth Eashiti Graduate Project } \\
\text { Ellzabeth Bashiti }\end{array}$ \\
\hline Anafysis Dave: & $06 / 20 / 17$ \\
\hline Tesung Pertormed by: & Elizabeth Eashitt \\
\hline Defauth Direcrary: & D:GraduatelResearch/ALPHA-Fatigue'ExponentlailPG70-22_12.5 \\
\hline Oumpur Direczory: & DiGraduateresearchiALPHA-Fatigue'Exponential:PG70-22_12.50efault output \\
\hline
\end{tabular}

Commenes:

\begin{tabular}{|c|c|}
\hline \multicolumn{2}{|c|}{ Traoinional Suain Fangue Relamionship (kPa univs) } \\
\hline$K 1$ & $4.46 \mathrm{E}+10$ \\
\hline$K 2$ & 3.591 \\
\hline$K 3$ & -2.886 \\
\hline
\end{tabular}

$$
N_{f}=K_{1}\left(\frac{1}{\varepsilon_{t}}\right)^{K_{2}}(|E *|)^{K_{3}}
$$

\begin{tabular}{|c|c|}
\hline$K 1$ & $120 \mathrm{~F}+01$ \\
\hline K2 & -4.28 \\
\hline K3 & 2.361 \\
\hline
\end{tabular}

$$
N_{i}=K_{1}\left(\sigma_{i}\right)^{K_{2}}(|E *|)^{K_{1}}
$$

Tradional Stress Faggue Relavonship 2 (kPa unms)

\begin{tabular}{c|c}
\hline Tradivonal Stress Faggue Relavonship 2( KPa uniss) \\
\hline K1 & $1.20 \mathrm{E}+01$ \\
\hline $\mathrm{K} 2$ & 4.28 \\
\hline $\mathrm{K} 3$ & -1.919 \\
\hline
\end{tabular}

$$
N_{l}=K_{1}\left(\frac{1}{\varepsilon_{1, \mathrm{mit}}}\right)^{K_{2}}\left(\left|E^{*}\right|\right)^{K_{3}}
$$

Tradinonal Surain faugue Relanonship (p5l unirs)

\begin{tabular}{c|c} 
KI & $1.69 \mathrm{E}+08$ \\
\hline $\mathrm{K} 2$ & 3.591
\end{tabular}

\begin{tabular}{l|r}
$\mathrm{K} 2$ & 3.591 \\
\hline $\mathrm{K} 3$ & -2.896
\end{tabular}

-2.886 .

$N_{1}=K_{1}\left(\frac{1}{\varepsilon_{f}}\right)^{K_{2}}(|E *|)^{K_{3}}$

\begin{tabular}{|c|c|}
\hline \multicolumn{2}{|c|}{ Tradmional Suress Fangue Re/awionship T (psi unnas) } \\
\hline$K 1$ & $2.95 \mathrm{E}-\mathrm{D1}$ \\
\hline $\mathrm{K} 2$ & -4.28 \\
\hline $\mathrm{K} 3$ & 2.361 \\
\hline
\end{tabular}

\begin{tabular}{|c|c|}
\hline $\mathrm{KI}$ & $2.95 E-01$ \\
\hline$K 2$ & 4.28 \\
\hline K3 & -1.919 \\
\hline \multicolumn{2}{|c|}{ Endurance Limn (microsurain) } \\
\hline Temperature $\{$ deg $\mathrm{C}$ ) & Endurance Limit \\
\hline 5 & 19 \\
\hline 10 & 21 \\
\hline 15 & 26 \\
\hline 20 & 31 \\
\hline 25 & 43 \\
\hline
\end{tabular}

$$
N_{f}=K_{1}\left(\sigma_{1}\right)^{K_{2}}\left(\left|E^{*}\right|\right)^{K_{1}}
$$

Tradmonal Suress Fanigue Reiamonshup 2 (p5i unns)

$N_{f}=K_{1}\left(\frac{1}{\varepsilon_{\text {, w in }}}\right)^{K_{2}}(|E *|)^{K_{3}}$ 


\section{PG 70-22 12.5 mm Peak Output}

\begin{tabular}{cc}
$\begin{array}{c}\text { North Carolina } \\
\text { Stake Unlversity }\end{array}$ & ALPHA-Fatigue \\
\hline
\end{tabular}

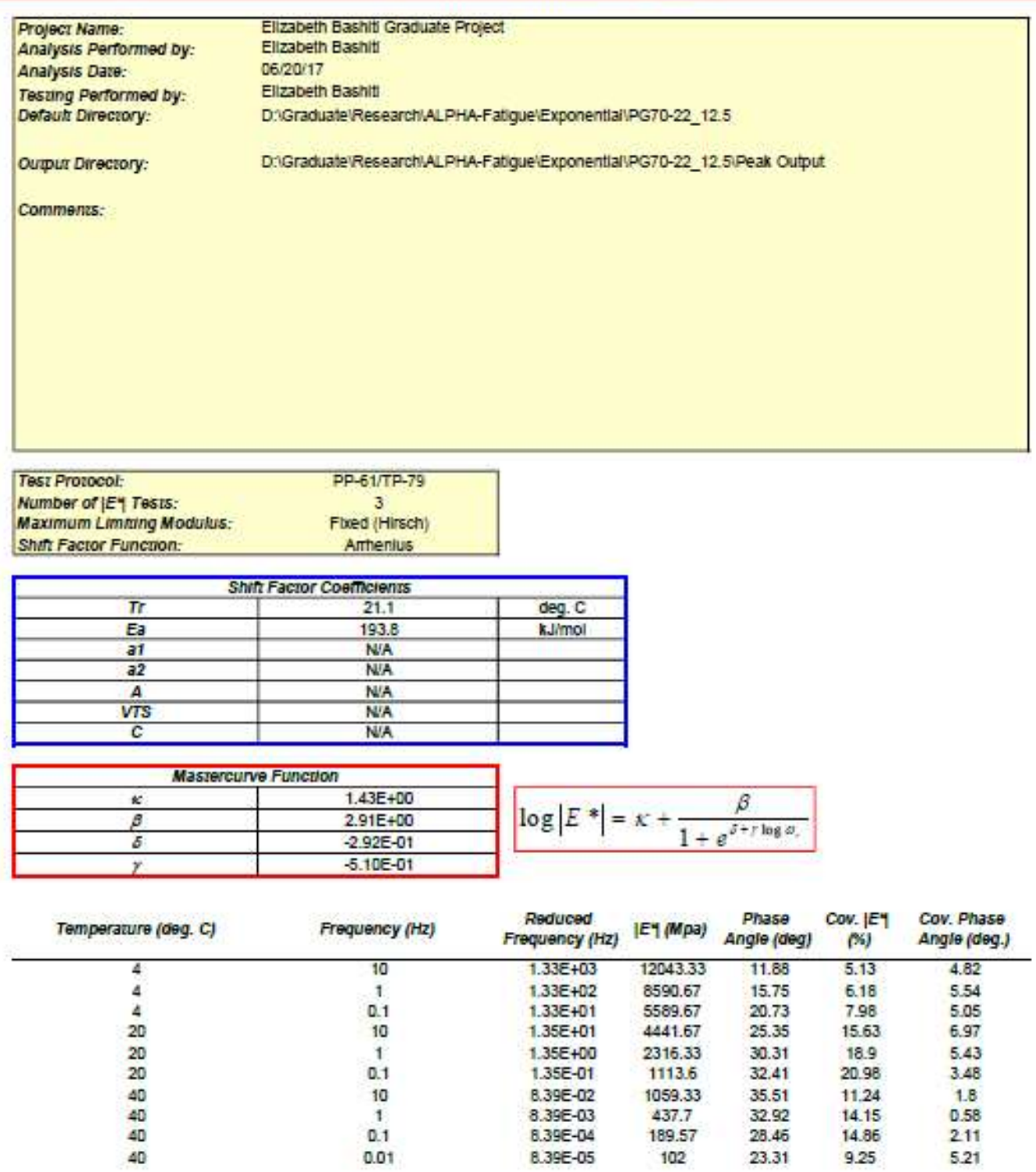




\begin{tabular}{|c|c|}
\hline $\begin{array}{l}\text { Project Name: } \\
\text { Analysis Performed by: }\end{array}$ & $\begin{array}{l}\text { Ellzabeth Bashiti Graduate Project } \\
\text { Elizabeth Bashitl }\end{array}$ \\
\hline Anaiysis Daze: & $06 / 20 / 17$ \\
\hline Tesung Performed by: & Ellzabeth Bashiti \\
\hline Defauh Direczory: & D.Graduate'ResearchiALPHA-Fatgue'Exponentlal|PG70-22_12.5 \\
\hline Quxpur Direcrory: & D.GradiatelResearch/ALPHA-Fatgue'Exponentian:PG70-22_12.51Peak Output. \\
\hline
\end{tabular}

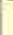

Number of Fanigue Tesis: Damage Model Funcuon:

Exponentia:

\begin{tabular}{|c|c|}
\hline \multicolumn{2}{|c|}{ Damage Model Coemcients } \\
\hline$a$ & $-2.28 \mathrm{E}-04$ \\
\hline$b$ & $7.35 \mathrm{E}-01$ \\
\hline$y$ & NA \\
\hline$z$ & NA \\
\hline alpha & 3.694 \\
\hline Paramerer r in Fallure Crm. & $5.65 \mathrm{E}+05$ \\
\hline Parameter s in Failure Crit. & $-7.49 \mathrm{E}-01$ \\
\hline
\end{tabular}

$$
\begin{aligned}
& C=e^{a x^{8}} \text { C } \\
& N_{f}=r\left(G^{k}\right)^{n}
\end{aligned}
$$

\begin{tabular}{c} 
Test Name \\
\hline PG70-22_12.5_FT1A \\
PG70-22_9.5_FT1B \\
PG70-22_12.5_FT1C \\
PG70-22_12.5_FT2A \\
PG7D-22_12.5_FT28 \\
PG70-22_12.5_FT2C \\
PG70-22_12.5_FT3A \\
PG7D-22_12.5_FT38 \\
PG70-22_12.5_FT3C
\end{tabular}

Temperature (deg. C)

\begin{tabular}{c} 
Frequency $(\mathrm{Hz})$ \\
\hline 10 \\
10 \\
10 \\
10 \\
10 \\
10 \\
10 \\
10 \\
10
\end{tabular}

EYlue |EY) \begin{tabular}{lrcc} 
MPa) & (MPa) & Ni & $G^{*}$ \\
\hline 6674.9 & 8378 & 23902 & $4.72 E+01$
\end{tabular} $\begin{array}{llll}6677.3 & 8439 & 5475 & 4.67 E+02\end{array}$ $\begin{array}{llll}6679.5 & 8445 & 13407 & 1.61 E+02\end{array}$

$\begin{array}{llll}6682.1 & 7175 & 31827 & 5.19 E+01\end{array}$

$6684.4 \quad 8446 \quad 2855 \quad 1.24 E+03$

$\begin{array}{llll}6663.8 & 7959 & 9976 & 2.04 E+02\end{array}$

$\begin{array}{llll}6697.6 & 6887 & 35733 & 4.73 E+01\end{array}$

$\begin{array}{llll}6636.8 & 8316 & 4275 & 6.26 E+02\end{array}$ $\begin{array}{llll}6681.8 & 6656 & 16285 & 1.26 E+02\end{array}$ 
North Carolina State Universilty

\section{ALPHA-Fatigue Model Predictions Report}
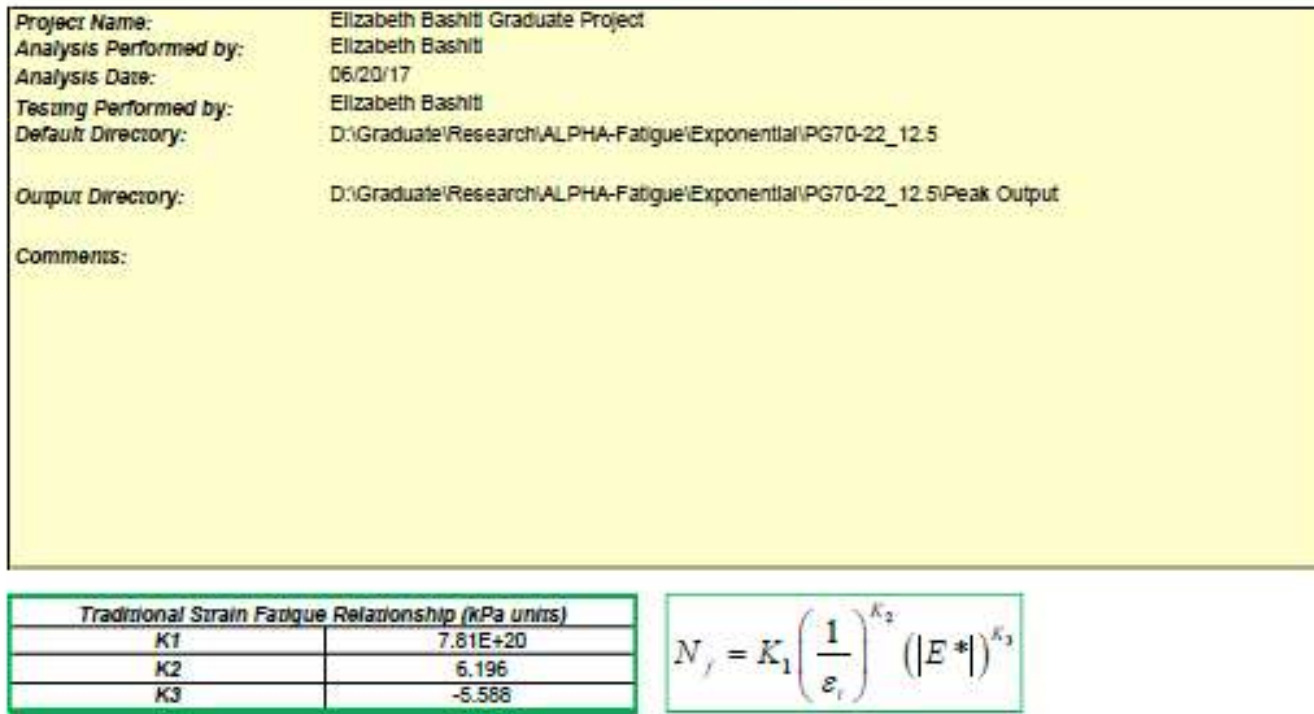

$$
N_{,}=K_{1}\left(\frac{1}{\varepsilon_{i}}\right)^{K_{2}}\left(\left|E^{*}\right|\right)^{K_{3}}
$$

\begin{tabular}{|c|c|}
\hline \multicolumn{2}{|c|}{ 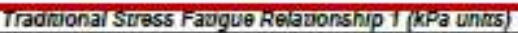 } \\
\hline K1 & $1.64 E-08$ \\
\hline K2 & -5.433 \\
\hline K3 & 4.227 \\
\hline
\end{tabular}

$$
N_{f}=K_{1}\left(\sigma_{4}\right)^{K_{2}}\left(\left|E^{*}\right|\right)^{K_{3}}
$$

Tradiuonal Stress Faugue Relavonship 2 (kPa units)

\begin{tabular}{c|c}
\hline$K 1$ & $1.64 \mathrm{E}-08$ \\
\hline$K 2$ & 5.433 \\
\hline$K 3$ & -1.206
\end{tabular}

$$
N_{i}=K_{1}\left(\frac{1}{\varepsilon_{t, \text { nit }}}\right)^{K_{2}}\left(\left|E^{*}\right|\right)^{K_{3}}
$$

\begin{tabular}{|c|c|}
\hline \multicolumn{2}{|c|}{ Tradinional Suain Fangue Relanonship (psi unins) } \\
\hline K1 & $1.61 \mathrm{E}+16$ \\
\hline K2 & 6.196 \\
\hline K3 & -5.568 \\
\hline
\end{tabular}

$$
N_{,}=K_{1}\left(\frac{1}{\varepsilon_{i}}\right)^{K_{2}}(|E *|)^{K_{2}}
$$

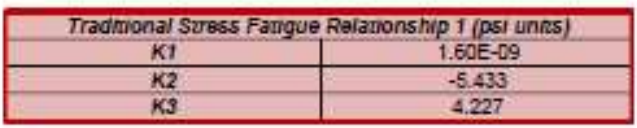

$$
N_{f}=K_{1}\left(\sigma_{j}\right)^{K_{2}}\left(\left|E^{*}\right|\right)^{K_{3}}
$$

Tradmional Suess Fangue Relamionship 2 (psi unns)

\begin{tabular}{|c|c|}
\hline$K 1$ & $1.60 \mathrm{E}-09$ \\
\hline$K 2$ & 5.433 \\
\hline$K 3$ & -1.206 \\
\hline \multicolumn{2}{|c|}{} \\
\hline Endurance Limin (microstrain) \\
\hline Temperature (deg. C) & Endurance Limit \\
\hline 5 & 65 \\
\hline 10 & 77 \\
\hline 15 & 96 \\
\hline 20 & 123 \\
\hline 25 & 179 \\
\hline
\end{tabular}

$N_{f}=K_{1}\left(\frac{1}{\varepsilon_{i, \mathrm{mii}}}\right)^{K_{2}}\left(\left|E^{*}\right|\right)^{K_{3}}$ 


\section{PG 70-22 PM 9.5 mm Default Output}

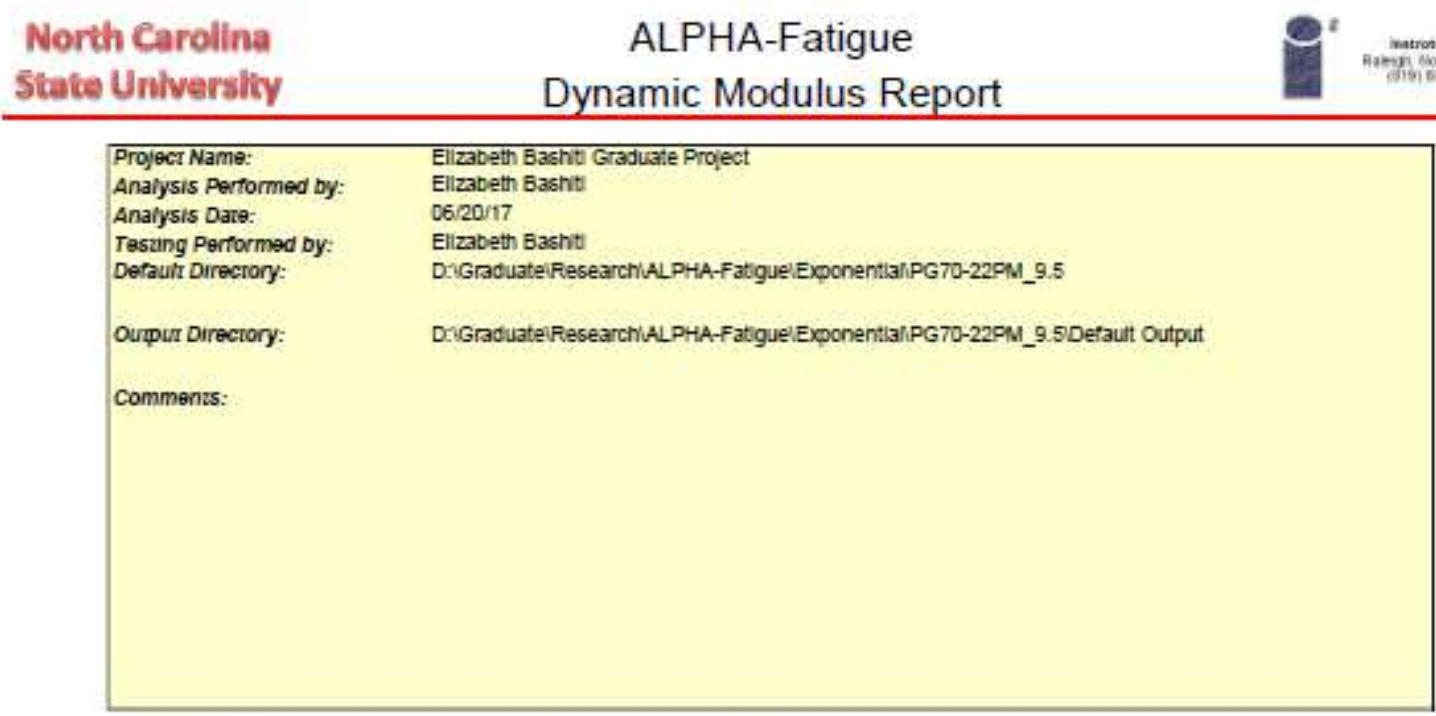

\begin{tabular}{lc}
\hline Test Protocol: & PP-61/TR-79 \\
Number of |Ey Tesis: & 3 \\
Maximum Limning Modulus: & Fixed (Hilrsch) \\
\hline Shut Facior Funcuon: & Armentus \\
\hline
\end{tabular}

Shut Facior Funcuon: Artherivs

\begin{tabular}{|c|c|c|}
\hline \multicolumn{3}{|c|}{ Shiff Factor Coencients } \\
\hline Tr & 21.1 & deg C \\
\hline Ea & 206.45 & kJimol \\
\hline$a t$ & N/A & \\
\hline$a 2$ & N/A & \\
\hline A & N/A & \\
\hline VTS & N/A & \\
\hline C & N/A & \\
\hline
\end{tabular}

\begin{tabular}{|c|c|}
\hline \multicolumn{2}{|c|}{ Mastercurve Funculon } \\
\hline$\varepsilon$ & $1.47 \mathrm{E}+00$ \\
\hline$\beta$ & $2.86 \mathrm{E}+00$ \\
\hline$\delta$ & $-2.47 \mathrm{E}-01$ \\
\hline$\gamma$ & $-4.86 \mathrm{E}-01$ \\
\hline
\end{tabular}

$$
\log |E *|=x+\frac{\beta}{1+e^{\delta+\gamma \log \alpha,}}
$$

\begin{tabular}{|c|c|c|c|c|c|c|}
\hline Temperarure (deg. C) & Frequency $(\mathrm{Hz})$ & $\begin{array}{c}\text { Reduced } \\
\text { Frequency }(\mathrm{Hz})\end{array}$ & [E丩 (Mpa) & $\begin{array}{c}\text { Phase } \\
\text { Angle (dieg) }\end{array}$ & $\begin{array}{c}\text { COV. IEY } \\
\text { (\%) }\end{array}$ & $\begin{array}{l}\text { Cov. Phase } \\
\text { Angle (deg.) }\end{array}$ \\
\hline 4 & 10 & $1.82 E+03$ & 11187.33 & 12.28 & 9.26 & 1.65 \\
\hline 4 & 1 & $1.82 \mathrm{E}+02$ & 7988 & 16.07 & 8.4 & 1.2 \\
\hline 4 & 0.1 & $1.82 \mathrm{E}+01$ & 5200.33 & 20.85 & 7.59 & 1.18 \\
\hline 20 & 10 & $1.37 E+01$ & 4462 & 24.58 & 5.74 & 0.51 \\
\hline 20 & 1 & $1.37 E=00$ & 2363.33 & 29.15 & 5.52 & 0.34 \\
\hline 20 & 0.1 & $1.37 \mathrm{E}-01$ & 1138.67 & 31.14 & 5.99 & 0.5 \\
\hline 40 & 10 & $6.14 E-02$ & 915.63 & 34.78 & 4.17 & 0.36 \\
\hline 40 & 1 & $6.14 \mathrm{E}-03$ & 388.03 & 31.52 & 5.4 & 0.65 \\
\hline 40 & 0.1 & 6. $14 \mathrm{E}-04$ & 184.03 & 26.79 & 6.29 & 0.66 \\
\hline 40 & 0.01 & 6.14E-DS & 111.47 & 22.31 & 8.04 & 2.1 \\
\hline
\end{tabular}




North Carolina
State Unlversity
VECD Model Report

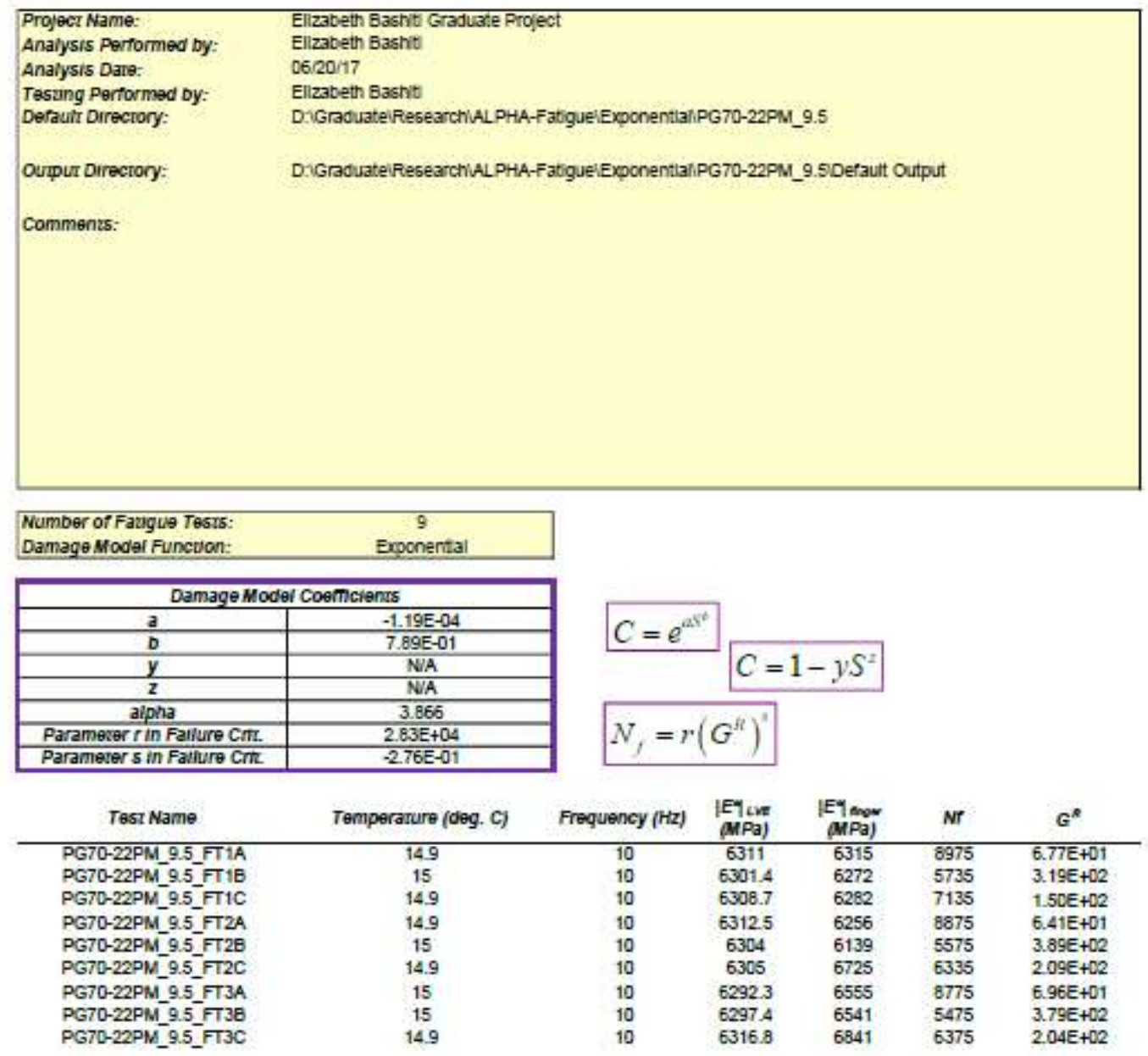


North Carolina State Unlverslity

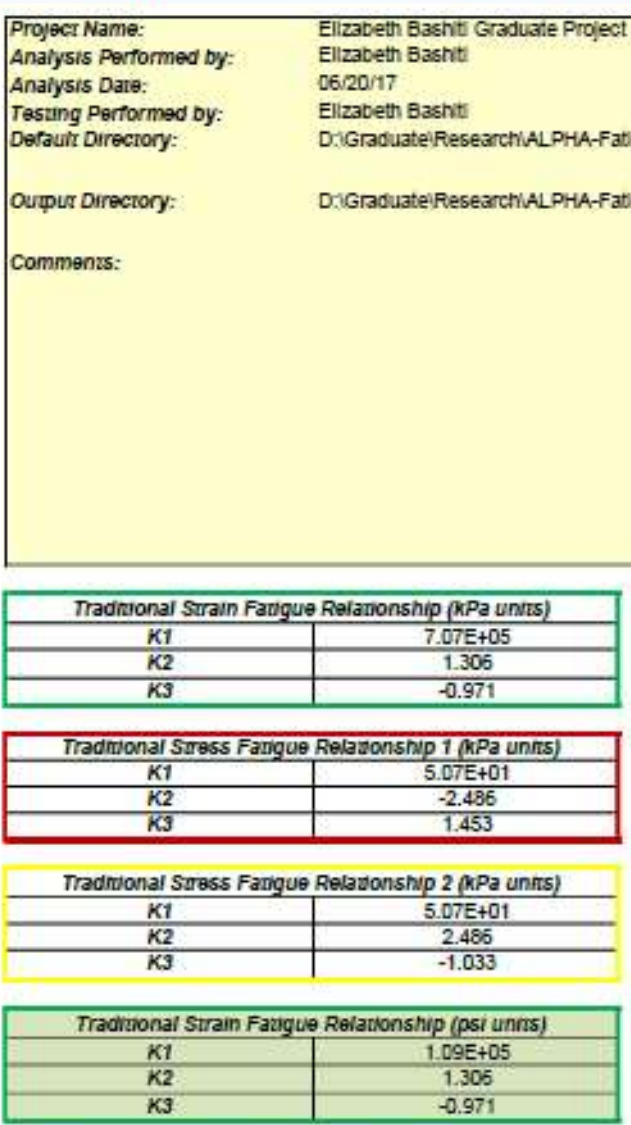

\begin{tabular}{|c|c|}
\hline \multicolumn{2}{|c|}{ Tradional Suress Fangue Reiadonship 1. (psi unns) } \\
\hline$K 1$ & $6.91 \mathrm{E}+00$ \\
\hline$K 2$ & -2.486 \\
\hline$K 3$ & 1.453 \\
\hline
\end{tabular}

Tradiuonal Suress Fangue Relagonship 2 (psi unms)

\begin{tabular}{|c|c|}
\hline$K 1$ & $6.91 \mathrm{E}+00$ \\
\hline$K 2$ & 2.486 \\
\hline $\mathrm{K} 3$ & -1.033 \\
\hline
\end{tabular}

\begin{tabular}{|c|c|}
\hline \multicolumn{2}{|c|}{ Endurance Limin (microsurain) } \\
\hline Temperature (deg. C) & Endurance Limit \\
\hline 5 & 5 \\
\hline 10 & 5 \\
\hline 15 & 6 \\
\hline 20 & 7 \\
\hline 25 & 9 \\
\hline
\end{tabular}

$$
N_{f}=K_{1}\left(\frac{1}{\varepsilon_{i}}\right)^{K_{2}}\left(\left|E^{*}\right|\right)^{x_{3}}
$$

$N_{j}=K_{1}\left(\sigma_{i}\right)^{K_{2}}(|E *|)^{K_{3}}$

$$
\begin{aligned}
& N_{f}=K_{1}\left(\frac{1}{\varepsilon_{r, i}}\right)^{K_{2}}\left(\left|E^{*}\right|\right)^{K_{3}} \\
& N_{1}=K_{1}\left(\frac{1}{\varepsilon_{2}}\right)^{K_{2}}(|E *|)^{K_{3}}
\end{aligned}
$$

$N_{j}=K_{1}\left(\sigma_{i}\right)^{K_{2}}\left(\left|E^{*}\right|\right)^{K_{3}}$

$$
N_{f}=K_{1}\left(\frac{1}{\varepsilon_{c, i w 1}}\right)^{K_{3}}\left(\left|E^{*}\right|\right)^{K_{3}}
$$




\section{PG 70-22 PM 9.5 mm Peak Output}

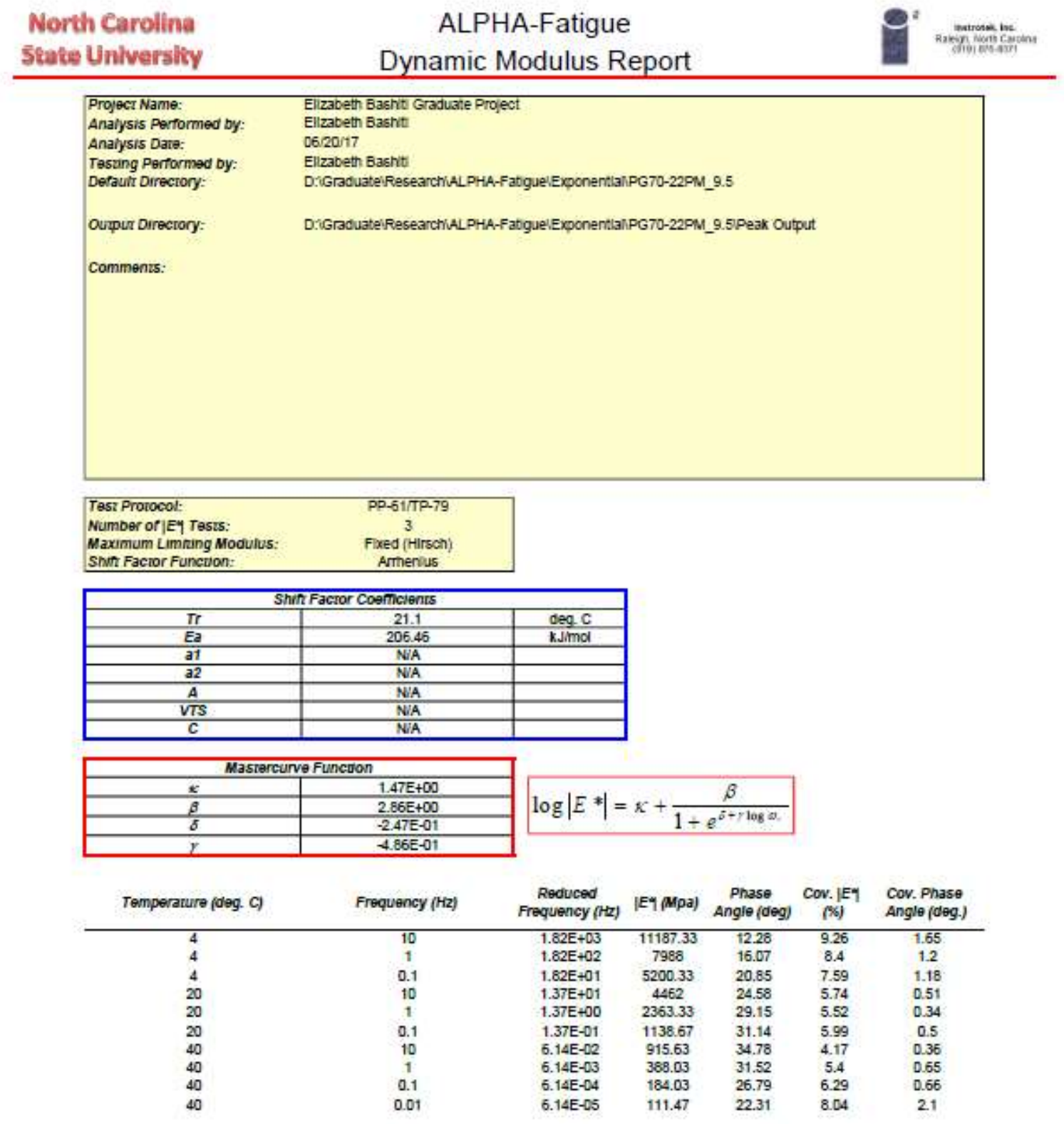




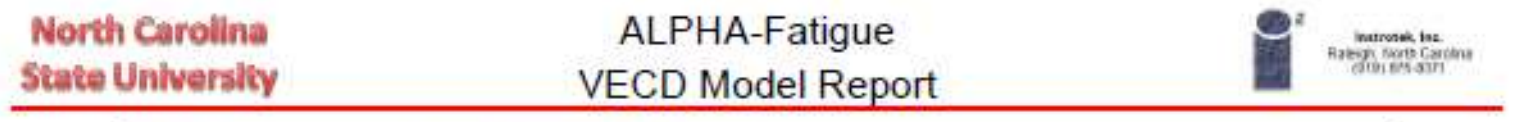

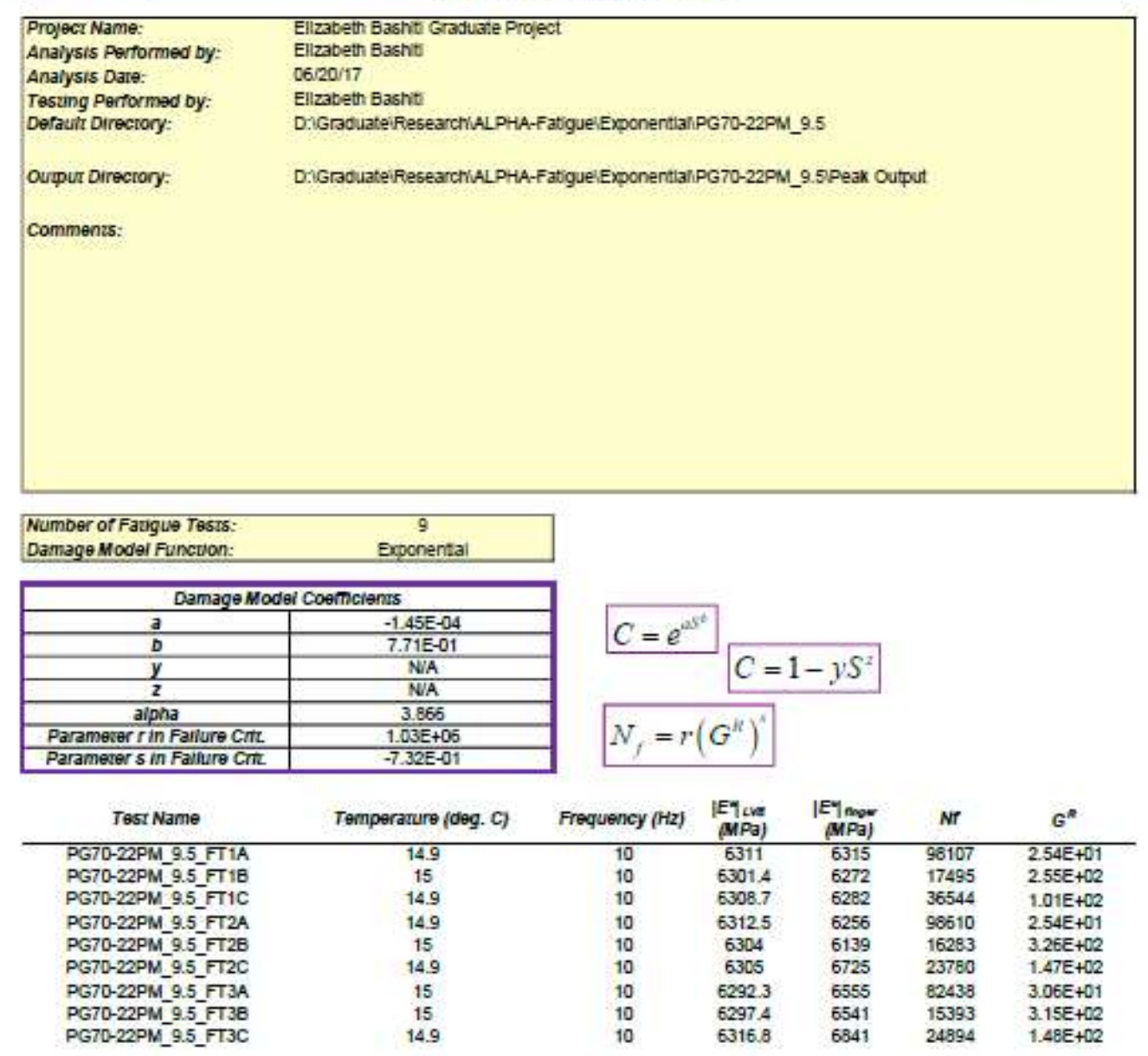


North Carolina State Unlverslty

ALPHA-Fatigue
VECD Model Report

Project Name:

Elizabeth Basht Graduate Project

Analysis Dare:

Tesang Performed by: Ellzabeth Basht:

Derauh Directory:

Elizabeth Basht

D.GGaduateiResearchiLLPHA-FatguelExponential:PG70-22.9M_9.5

Quџur Direcrory:

D.GraduateiResearchiALPHA-FatguelExponentialPG70-22PM_9.51Peak Output

Commenis:

Commonis:

\author{
.
}




\section{PG 70-22 PM 12.5 mm Default Output}

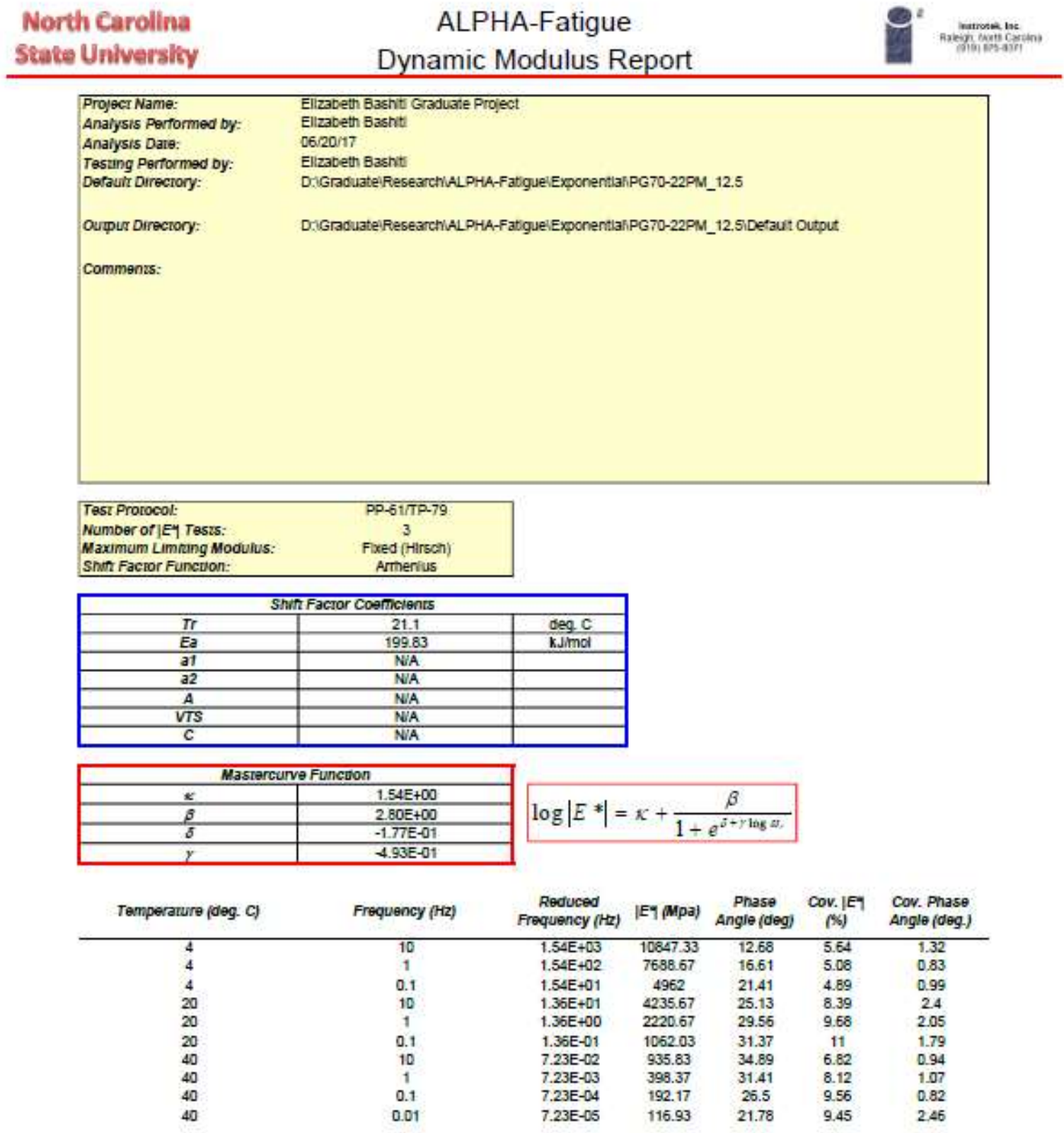




North Carolina
ALPHA-Fatigue
SECate Unlverslty

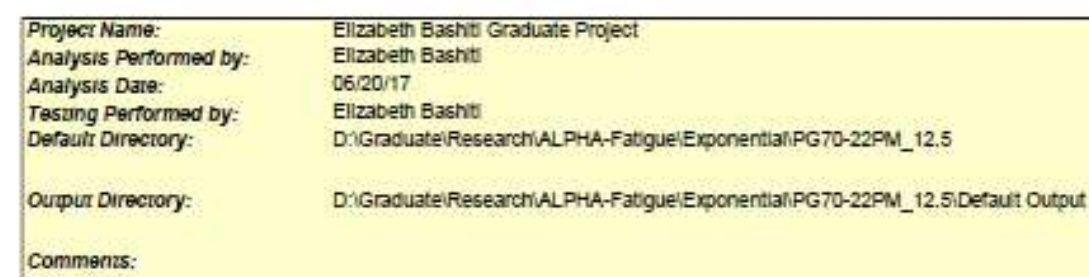

Number of Faugue Tesis: 9

Damage Model Funcuon: Brocnental

\begin{tabular}{|c|c|}
\hline \multicolumn{2}{|c|}{ Damage Model Coemcienrs } \\
\hline$a$ & $-1.62 E-04$ \\
\hline D & $7.62 \mathrm{E}-01$ \\
\hline$y$ & N/A \\
\hline$z$ & N/A \\
\hline alpha & 3.883 \\
\hline Paramever $r$ in Fallure $\mathrm{Cm}$. & $2.80 E+04$ \\
\hline Paramerer 5 in Fallure Criz. & $-2.77 E-01$ \\
\hline
\end{tabular}

$$
\begin{aligned}
& C=e^{a s^{t}} \\
& C=1-y S^{2} \\
& N_{f}=r\left(G^{R}\right)^{n}
\end{aligned}
$$

\begin{tabular}{c} 
Test Name \\
\hline PG70-22PM_12.5_FT1A \\
PG70-22PM_12.5_FT1B \\
PG70-22PM_12.5_FT1C \\
PG70-22PM_12.5_FT2A \\
PG70-22PM_12.5_FT28 \\
PG70-22PM_12.5_FT2C \\
PG70-22PM_12.5_FT3A \\
PG70-22PM_12.5_FT38 \\
PG70-22PM_12.5_FTC
\end{tabular}

Temperaxure (deg. C)

Frequency $(\mathrm{Hz})$

\begin{tabular}{cccc}
$\begin{array}{c}\text { [EY } \\
\text { MMe } \\
\text { MPa) }\end{array}$ & $\begin{array}{c}\text { [E } \\
\text { (MPa) }\end{array}$ & Nr & $G^{R}$ \\
\hline 6059.6 & 6127 & 8975 & $6.20 E+01$ \\
6056.1 & 6276 & 5775 & $2.87 E+02$ \\
6072.7 & 6513 & 6735 & $1.68 E+02$ \\
6056.8 & 5996 & 8735 & $6.53 E+01$ \\
6053.9 & 6434 & 5775 & $2.82 E+02$ \\
6058.9 & 5489 & 8175 & $1.02 E+02$ \\
6036.1 & 6025 & 8715 & $6.22 E+01$ \\
6072.9 & 6491 & 5475 & $3.86 E+02$ \\
6079 & 6053 & 6755 & $1.55 E+02$
\end{tabular}


North Carolina State Universily
ALPHA-Fatigue Model Predictions Report

\begin{tabular}{|c|c|}
\hline $\begin{array}{l}\text { Projecr Name: } \\
\text { Analysis Performed by: } \\
\text { Anafysis Dare: } \\
\text { Tesung Performed by: } \\
\text { Defauth Direciory: }\end{array}$ & $\begin{array}{l}\text { Elizabeth Basht Graduate Project } \\
\text { Elizabeth Basht! } \\
\text { 06/20/17 } \\
\text { Elizabeth Basht } \\
\text { DiGraduateiResearch/ALPHA-FatiguelExponentlal:PGTO-22PM_12.5 }\end{array}$ \\
\hline Oumu Directory: & DiGraduatelResearch(AL PHA-FatiguelExponentialPG70-22PM_12.51 Defaut Outout \\
\hline
\end{tabular}

Comments:

\begin{tabular}{|c|c|}
\hline \multicolumn{2}{|c|}{ Tradional Sualn Favgure Relationship (KPa units) } \\
\hline$K 1$ & $8.93 \mathrm{E}+05$ \\
\hline$K 2$ & 1.291 \\
\hline$K 3$ & -0.978 \\
\hline
\end{tabular}

$N_{i}=K_{1}\left(\frac{1}{\varepsilon_{l}}\right)^{K_{2}}(|E *|)^{K_{3}}$

\begin{tabular}{|c|c|}
\hline \multicolumn{2}{|c|}{ Tradmional Suress Fangue Relavonship 1 (KPa unms) } \\
\hline$K 1$ & $2.21 \mathrm{E}+02$ \\
\hline$K 2$ & -2.35 \\
\hline$K 3$ & 1.302 \\
\hline
\end{tabular}

$N_{f}=K_{1}\left(\sigma_{i}\right)^{K_{2}}\left(\left|E^{*}\right|\right)^{K_{3}}$

Tradmonaf Suress Fangue Relavonship 2 (kPa unns)

\begin{tabular}{c|c}
\hline$K 1$ & $2.21 \mathrm{E}+02$ \\
\hline$K 2$ & 2.36 \\
\hline$K 3$ & -1.058
\end{tabular}

$N_{f}=K_{\mathrm{I}}\left(\frac{1}{\varepsilon_{t, j i n}}\right)^{K_{4}}(|E *|)^{K_{3}}$

Tradruonal Suain Faugue Relanionship (psi units)

\begin{tabular}{r|r}
\hline$K 1$ & $1.35 E+0$ \\
\hline$K 2$ & 1.291
\end{tabular}

1.291

KS

$-0.978$

$N_{1}=K_{1}\left(\frac{1}{\varepsilon_{2}}\right)^{K_{2}}(|E *|)^{K_{3}}$

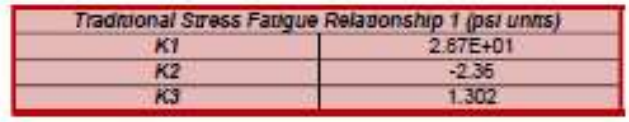

$N_{f}=K_{1}\left(\sigma_{t}\right)^{K_{2}}\left(\left|E^{*}\right|\right)^{K_{3}}$

Tradiuonal Suress Fangue Relamonship 2 (psi unns)

K1

$2.87 \mathrm{E}+\mathrm{O}$

2.36
-1.056

$N_{f}=K_{1}\left(\frac{1}{\varepsilon_{i, i w /}}\right)^{K_{3}}(|E *|)^{K_{3}}$

\begin{tabular}{|c|c|}
\hline \multicolumn{2}{|c|}{ Endurance Limn (microsurain) } \\
\hline Temperature (deg. C) & Endurance Limi \\
\hline 5 & 5 \\
\hline 10 & 5 \\
\hline 15 & 6 \\
\hline 20 & 6 \\
\hline 25 & 8 \\
\hline
\end{tabular}




\section{PG 70-22 PM 12.5 mm Peak Output}

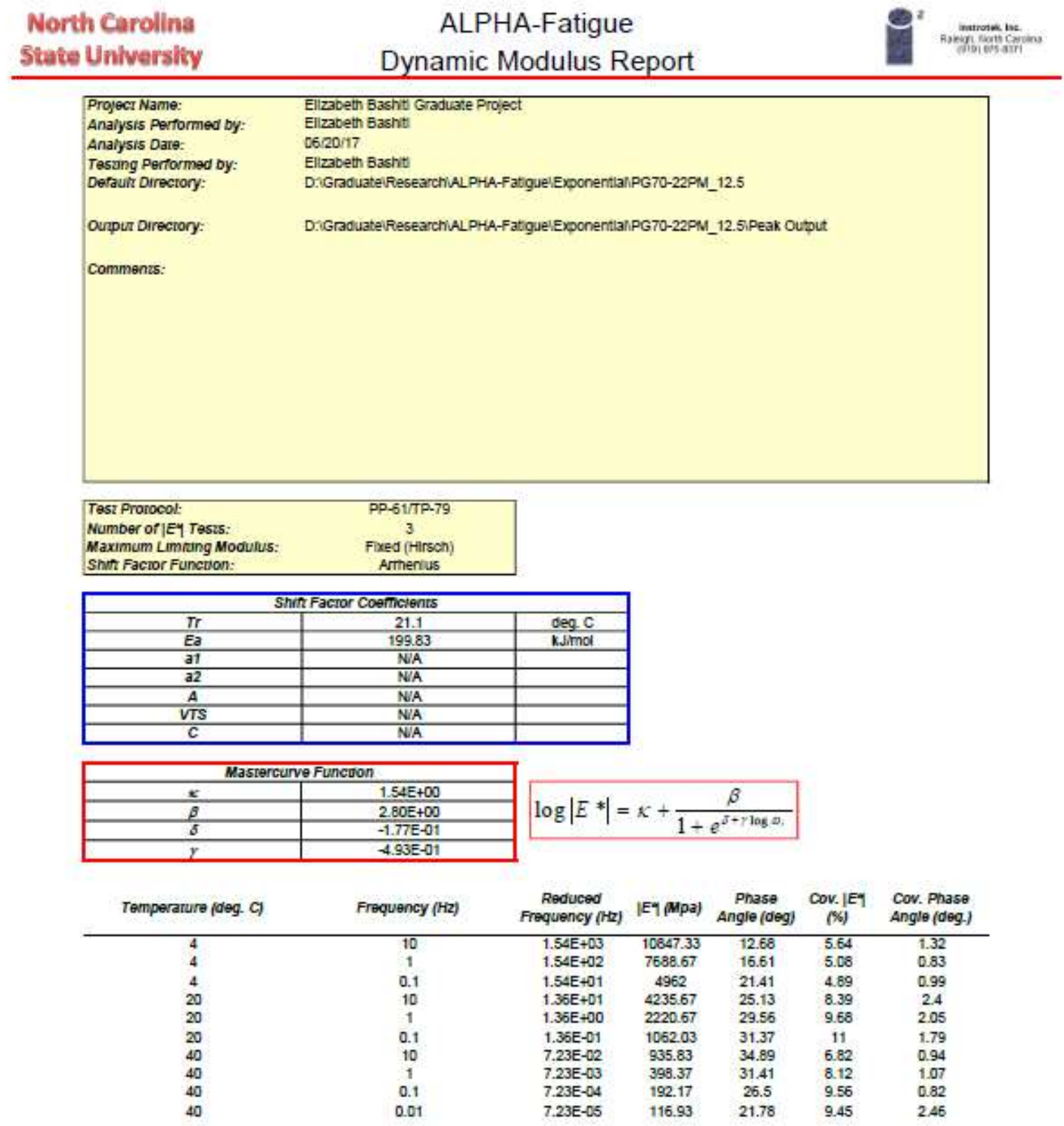




North Carolina
State University
VECD Model Report

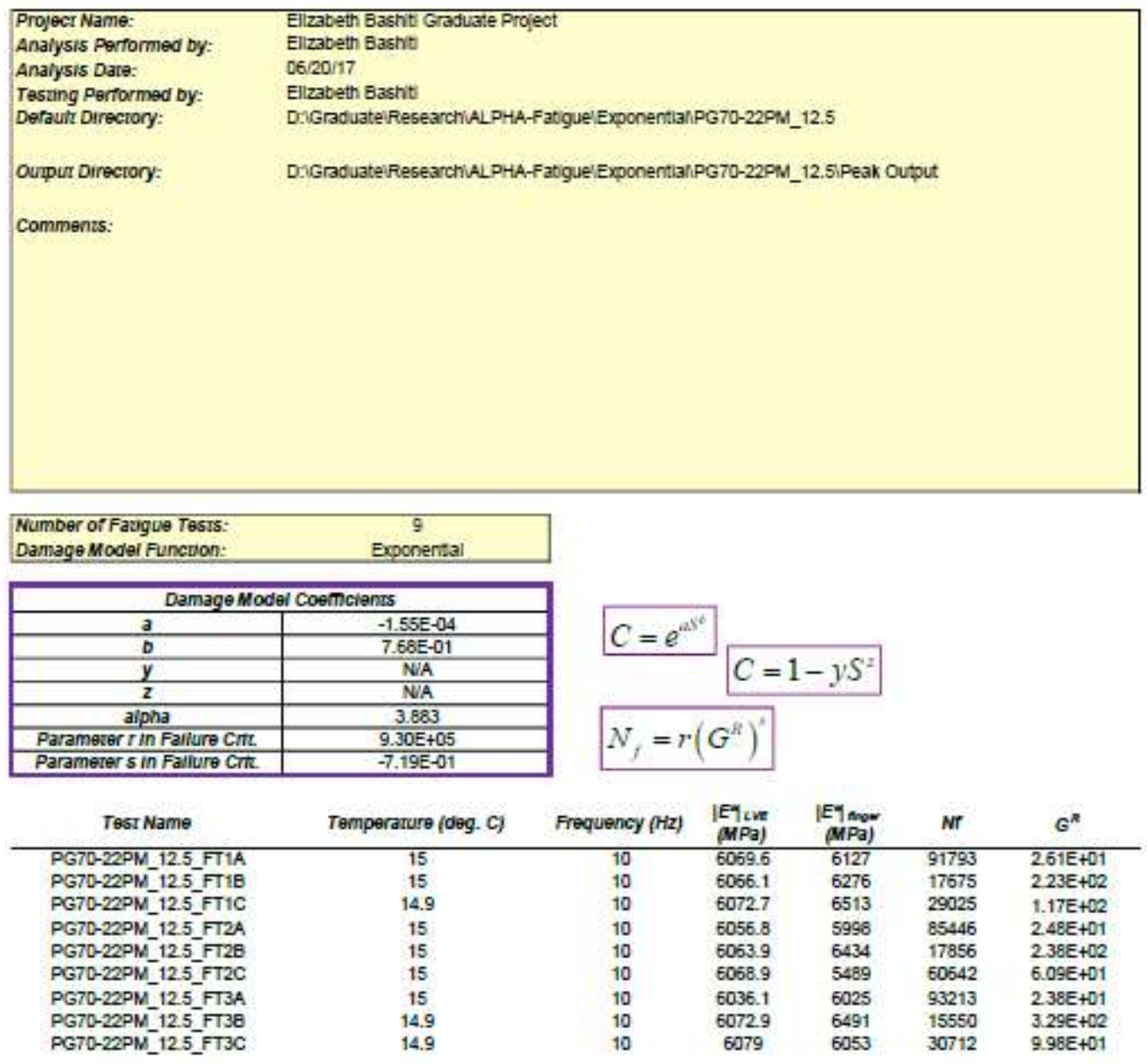


North Carolina State Unlversily
ALPHA-Fatigue Model Predictions Report

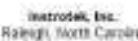

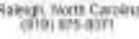

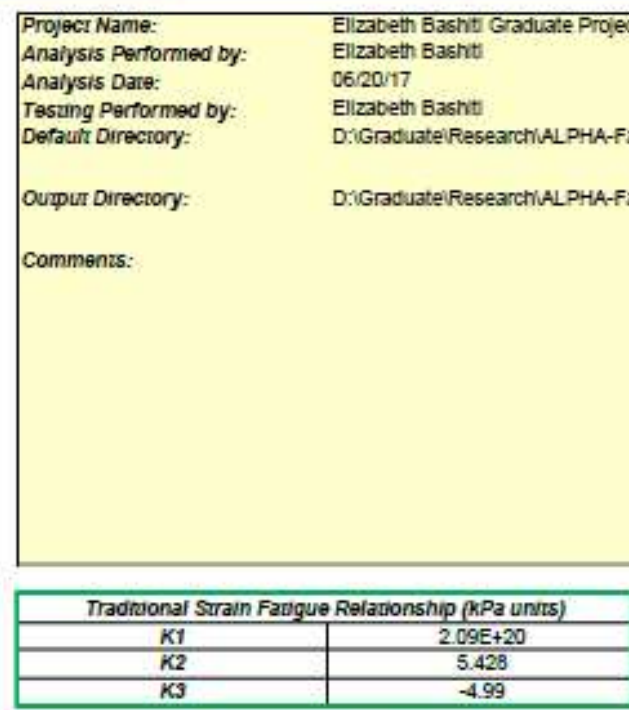

Tradimional Suress Fanigue Relavonship 1 (KPa unms)

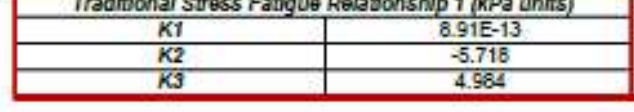

$N_{i}=K_{1}\left(\frac{1}{\varepsilon_{1}}\right)^{K_{2}}(|E *|)^{K_{1}}$

$N_{1}=K_{1}\left(\sigma_{i}\right)^{K_{2}}(|E *|)^{K_{3}}$

Tradmonaf Suress Fangue Relavonshup 2 (kPa unns

\begin{tabular}{c|c}
\hline$K 1$ & $8.91 \mathrm{E}-13$ \\
\hline$K_{2}$ & 5.718 \\
\hline$K_{3}$ & -0.734 \\
\hline
\end{tabular}

$N_{,}=K_{1}\left(\frac{1}{\varepsilon_{i, j \omega}}\right)^{K_{2}}(|E *|)^{K_{3}}$

Traditional Surain Faugue Relanionship (psi unnts)

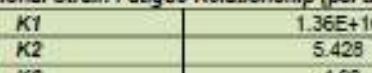

5.428

$N_{1}=K_{1}\left(\frac{1}{\varepsilon_{2}}\right)^{K_{2}}(|E *|)^{K_{3}}$

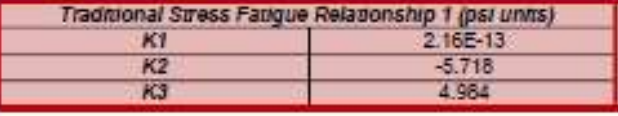

$N_{i}=K_{1}\left(\sigma_{i}\right)^{K_{2}}\left(\left|E^{*}\right|\right)^{K_{3}}$

Tradmonal Suress Fangue Relamonship 2 (psi unns)

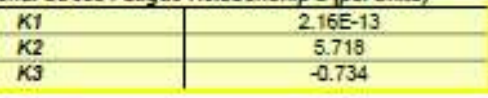

$N_{f}=K_{1}\left(\frac{1}{\varepsilon_{t, i w i}}\right)^{K_{2}}(|E *|)^{K_{3}}$

Endurance Lime (microstraln)

Temperature (deg. C)

ture (deg. C) $\quad$ Endurance Limit

\begin{tabular}{c|c}
\hline 5 & 80 \\
10 & 97 \\
\hline 15 & 125 \\
\hline 20 & 163 \\
\hline
\end{tabular}

\begin{tabular}{l|r}
163 \\
\hline 25 & 162 \\
\hline
\end{tabular}

242 


\section{PG 76-22 PM 9.5 mm Default Output}

$\begin{array}{cc}\text { North Carollna } & \text { ALPHA-Fatigue } \\ \text { State Universliy } & \text { Dynamic Modulus Report }\end{array}$

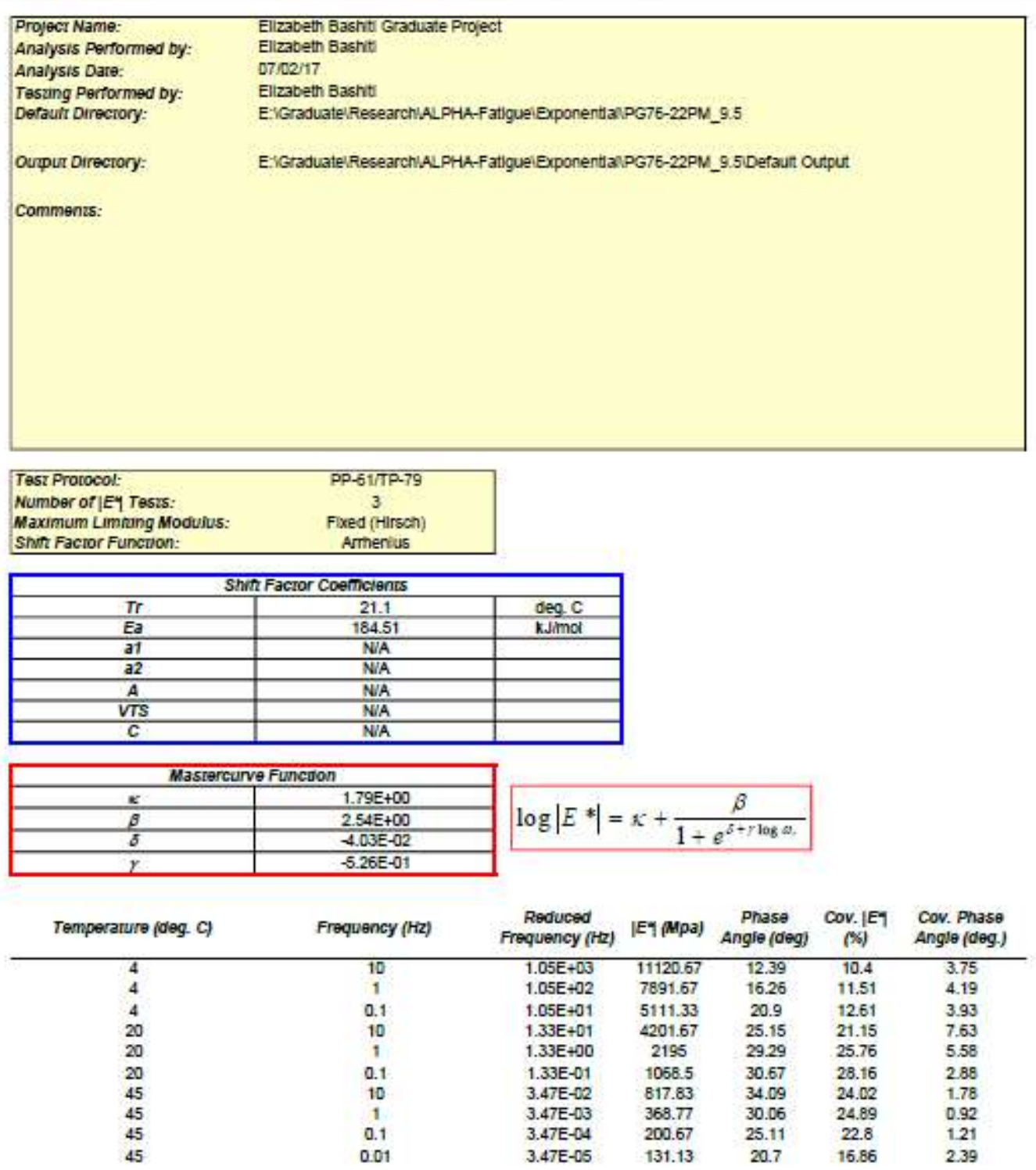




North Carollina
State Universlity
VECD Model Report

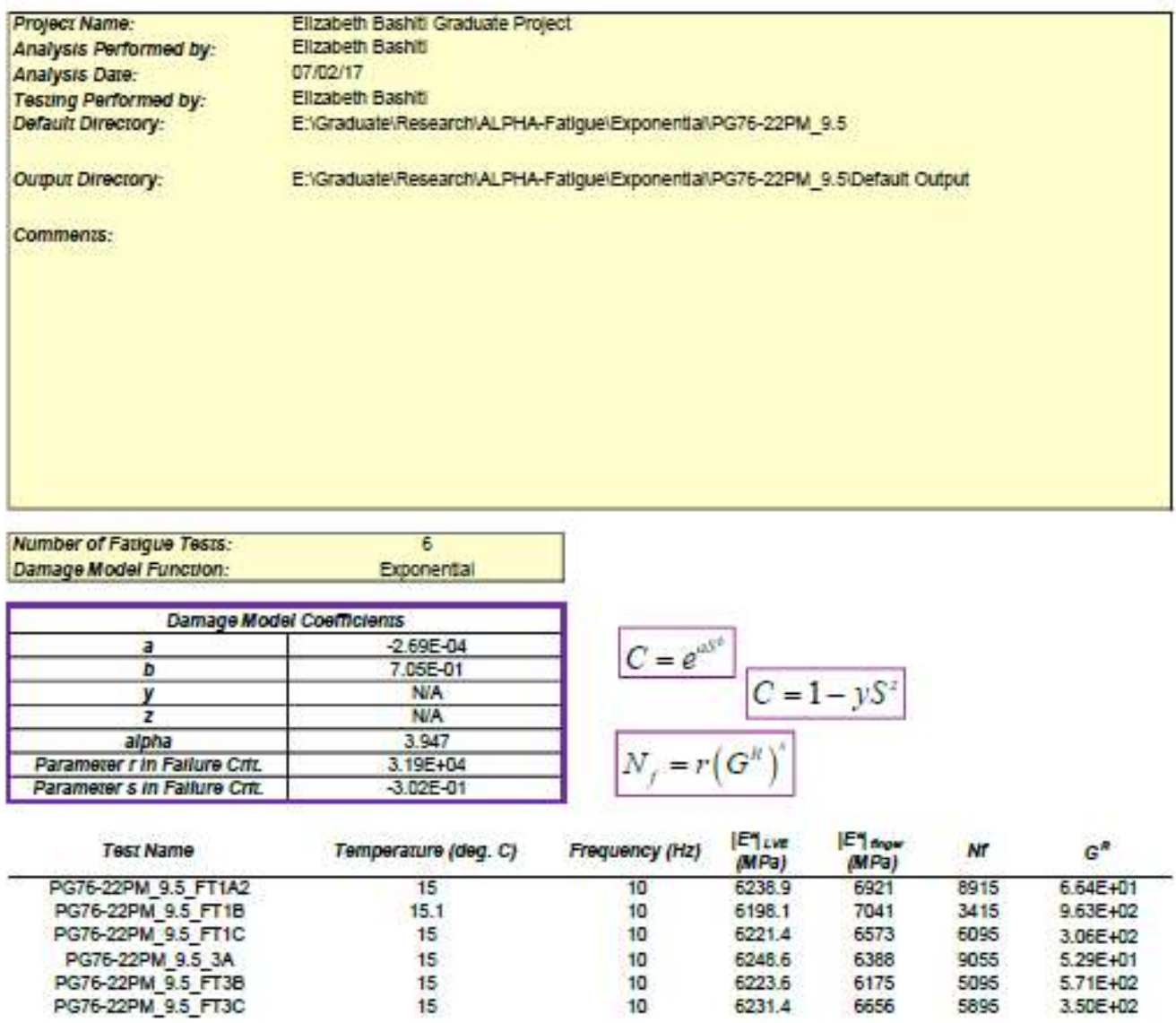


North Carolina State Unlversity
ALPHA-Fatigue Model Predictions Report

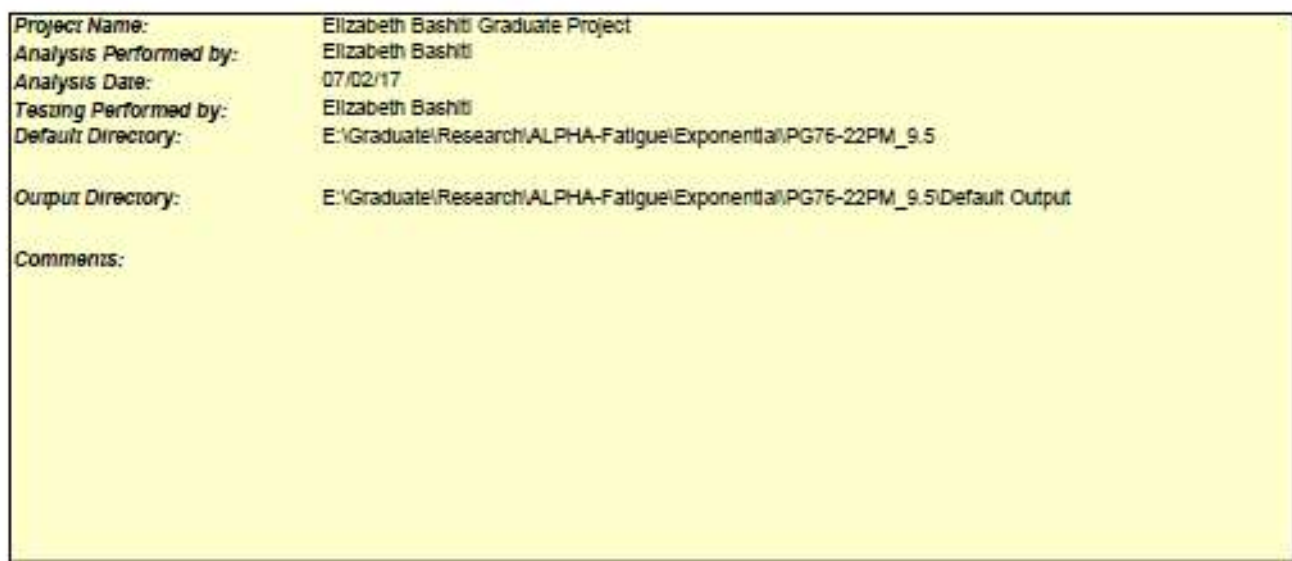

\begin{tabular}{|c|c|}
\hline \multicolumn{2}{|c|}{ Tradivonal Strain Favguie Relanionship (kPa unirs) } \\
\hline$K 1$ & $2.15 E+05$ \\
\hline$K 2$ & 1.391 \\
\hline$K 3$ & -1.083 \\
\hline
\end{tabular}

$$
N_{1}=K_{1}\left(\frac{1}{\varepsilon_{1}}\right)^{K_{2}}(|E *|)^{K_{3}}
$$

Tradmional Suess Faugue Reladonship 1 (kPa untis)

$$
\begin{aligned}
& K 1 \\
& K 2 \\
& K 3
\end{aligned}
$$
$59 E+03$ $-2.264$

$$
N_{f}=K_{1}\left(\sigma_{i}\right)^{K_{2}}\left(\left|E^{*}\right|\right)^{K_{3}}
$$

Tradmional Suress Fawigue Relawonshtp 2 (kPa unns)

\begin{tabular}{c|c|}
\hline$K 1$ & $1.59 \mathrm{E}+03$ \\
\hline$K 2$ & 2.264 \\
\hline$K 9$ & -1.125
\end{tabular}

$$
N_{f}=K_{1}\left(\frac{1}{\varepsilon_{i, i n l}}\right)^{K_{2}}\left(\left|E^{*}\right|\right)^{K_{3}}
$$

Tradironal Suran Favgue Relanonship (PSi unns)

\begin{tabular}{r|r}
\hline$K 1$ & $2.66 E+05$ \\
\hline$K 2$ & $1.39 t$ \\
$K 9$ & -1.083
\end{tabular}

$\frac{1.39 t}{-1.083}$

$$
N_{1}=K_{1}\left(\frac{1}{\varepsilon_{1}}\right)^{K_{2}}(|E *|)^{K_{3}}
$$

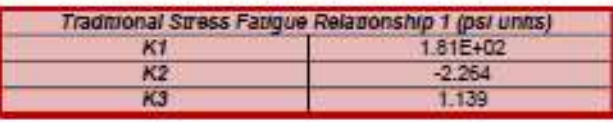

$$
N_{j}=K_{1}\left(\sigma_{i}\right)^{K_{2}}\left(\left|E^{*}\right|\right)^{K_{3}}
$$

Tradiuanal Suress Faugue Relazonship 2 (psi unus)

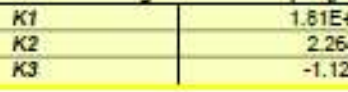

264

$-1.125$

$$
N_{f}=K_{1}\left(\frac{1}{\varepsilon_{i, j w i}}\right)^{K_{2}}\left(\left|E^{*}\right|\right)^{K_{3}}
$$

\begin{tabular}{|c|c|}
\hline \multicolumn{2}{|c|}{ Endurance Limi (mucrosurain) } \\
\hline Temperature (deg. C) & Endurance Limit \\
\hline 5 & 4 \\
\hline 10 & 4 \\
\hline 15 & 4 \\
\hline 20 & 5 \\
\hline 25 & 6 \\
\hline
\end{tabular}




\section{PG 76-22 PM 9.5 mm Peak Output}

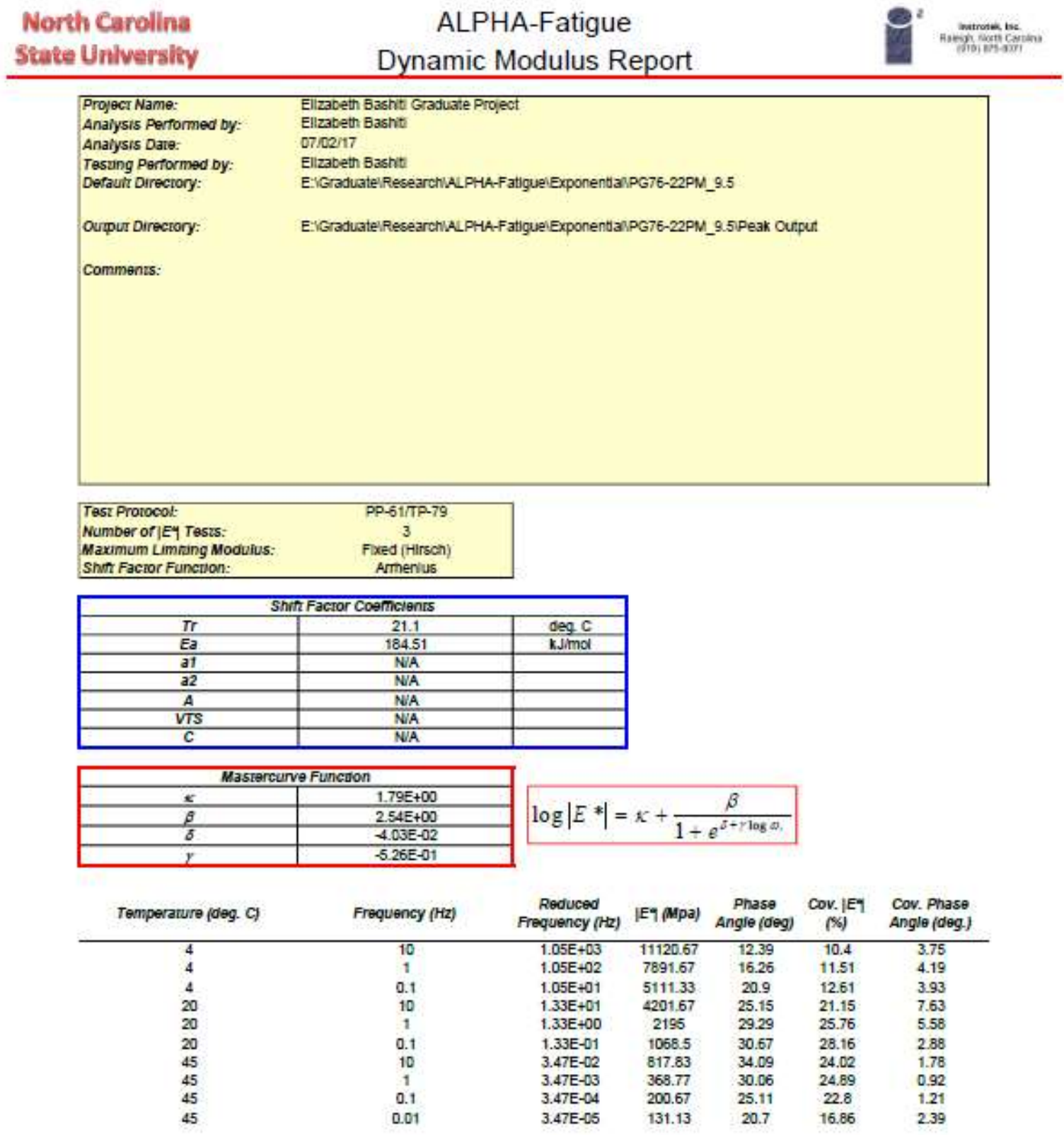




\section{North Carolina}

State Universilty

\section{ALPHA-Fatigue \\ VECD Model Report}

\begin{tabular}{|c|c|}
\hline Project Name: & Ellzabeth Bastit Graduate Project \\
\hline Analysis Pertormed by: & Ellzabeth Basht \\
\hline Analysis Date: & $07 / 02 / 17$ \\
\hline Tesung Performed by: & Ellzabeth Bashto \\
\hline Defauth Direciory: & E:IGraduatelResearchIALPHA-FatigueiExponentia:PG76-22PM_9.5 \\
\hline Oupur Directory: & ElGraduatelResearchWALPHA-FatiguelExponentalPG76-22PM_9.5Peak Output \\
\hline
\end{tabular}

Comments:

\begin{tabular}{lc|}
\hline Number of Faugue Tests: & 6 \\
Damage Model Functuon: & Exponental
\end{tabular}

\begin{tabular}{|c|c|}
\hline \multicolumn{2}{|c|}{ Damage Model Coemcienrs } \\
\hline$a$ & $-2.36 E-04$ \\
\hline$D$ & $7.19 E-01$ \\
\hline$y$ & NEA \\
\hline$z$ & N/A \\
\hline alpha & 3.947 \\
\hline Paramever r in Fallure Clt. & $6.79 E+05$ \\
\hline Parameser s in Failure Crt. & $-6.43 E-01$ \\
\hline
\end{tabular}

$$
\begin{aligned}
& C=e^{a S^{2}} \quad C=1-y S^{2} \\
& N_{f}=r\left(G^{R}\right)^{\prime}
\end{aligned}
$$

\begin{tabular}{|c|c|c|c|c|c|c|}
\hline Test Name & Temperanure (deg. C) & Frequency $(\mathrm{Hz})$ & $\begin{array}{l}\text { [E'cue } \\
(\mathrm{MPa} \text { ) }\end{array}$ & $\begin{array}{c}\text { [E } \text { (Enow }_{\text {mow }} \\
\text { (MPa) }\end{array}$ & Nr & $G^{*}$ \\
\hline PG76-22PM_9.5_FT1A2 & 15 & 10 & 6236.9 & 6921 & 98610 & $237 E+01$ \\
\hline PG76-22PM_9.5_FT1B & 15.1 & 10 & 6198.1 & 7041 & 7535 & $8.56 E+02$ \\
\hline PG76-22PM_9.5_FT1C & 15 & 10 & 6221.4 & 6573 & 21139 & $2.50 E+02$ \\
\hline PG76-22PM_9.5_3A & 15 & 10 & 6248.6 & 6388 & 98510 & $1.61 E+01$ \\
\hline PG76-22PM_9.5_FT38 & 15 & 10 & 6223.6 & 6175 & 12673 & $5.36 E+02$ \\
\hline PG76-22PM_9.5_FT3C & 15 & 10 & 6231.4 & 6656 & 18888 & $2.89 E+02$ \\
\hline
\end{tabular}


North Carolina State Unlvershty
ALPHA-Fatigue Model Predictions Report

\begin{tabular}{|c|c|}
\hline Project Name: & Ellzabeth Basht Graduate Prolect \\
\hline Analysis Performed by: & Ellzabeth Basht \\
\hline Analysis Dare: & $07 / 2217$ \\
\hline Tesang Pertormed by: & Ellzabeth Basht: \\
\hline Defauh Directory: & E:GraduatelResearchiLLPHA-FatigueiExponentla:PG76-22PM_9.5 \\
\hline Oumpur Directory: & E:Graduate ResearchiALPHA-FatigueiExponentla:PG76-22PM_9.5Peak Output \\
\hline
\end{tabular}

Comments:

\begin{tabular}{|c|c|}
\hline \multicolumn{2}{|c|}{ Tradicional Surain Fangue Relanionship (KPa unirs) } \\
\hline$K 1$ & $4.27 \mathrm{E}+15$ \\
\hline$K 2$ & 4.179 \\
\hline$K 3$ & -3.681 \\
\hline
\end{tabular}

\begin{tabular}{|c|c|}
\hline Tradmional Sur 65 . Fanigue Relawonship 1 (kPa unnis) \\
\hline$K 1$ & $1.30 \mathrm{E}-05$ \\
\hline$K 2$ & -5.72 \\
\hline$K 3$ & 3.963 \\
\hline
\end{tabular}

Tradruonal Su6ss Faugue Relavonshup 2 (kPa untrs)

\begin{tabular}{c|c|}
\multicolumn{2}{c}{ Tradmonal Subss Faugue Relawonship 2 (KPa unms) } \\
\hline K1 & $1.30 E-05$ \\
\hline K2 & 5.72 \\
\hline K3 & -1.757
\end{tabular}

Tradiuonal Surain Favgue Relanionship (psi unnts)

\begin{tabular}{|c|c|}
\hline$K t$ & $3.49 \mathrm{E}+12$ \\
\hline K2 & 4.179 \\
\hline KS & -3.681 \\
\hline
\end{tabular}

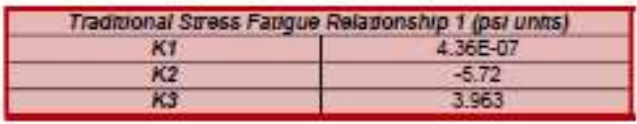

3.963

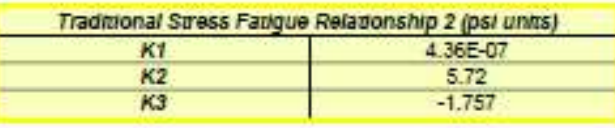

\begin{tabular}{|c|c|}
\hline \multicolumn{2}{|c|}{ Endurance Limn (microstrain) } \\
\hline Temperature (deg. C) & Endurance Linit \\
\hline 5 & 58 \\
\hline 10 & 67 \\
\hline 15 & 85 \\
\hline 20 & 106 \\
\hline 25 & 149 \\
\hline
\end{tabular}

$$
N_{1}=K_{1}\left(\frac{1}{\varepsilon_{1}}\right)^{K_{2}}(|E *|)^{K_{3}}
$$

$$
N_{f}=K_{1}\left(\sigma_{i}\right)^{K_{2}}(|E *|)^{K_{3}}
$$

$N_{f}=K_{1}\left(\frac{1}{\varepsilon_{i, j i}}\right)^{K_{2}}(|E *|)^{K_{3}}$

$N_{i}=K_{1}\left(\frac{1}{\varepsilon_{l}}\right)^{K_{2}}(|E *|)^{K_{3}}$

$N_{f}=K_{1}\left(\sigma_{i}\right)^{K_{2}}\left(\left|E^{*}\right|\right)^{K_{1}}$

$N_{j}=K_{1}\left(\frac{1}{\varepsilon_{i, i w j}}\right)^{K_{2}}\left(\left|E^{*}\right|\right)^{K_{3}}$ 


\section{PG 76-22 PM 12.5 mm Default Output}

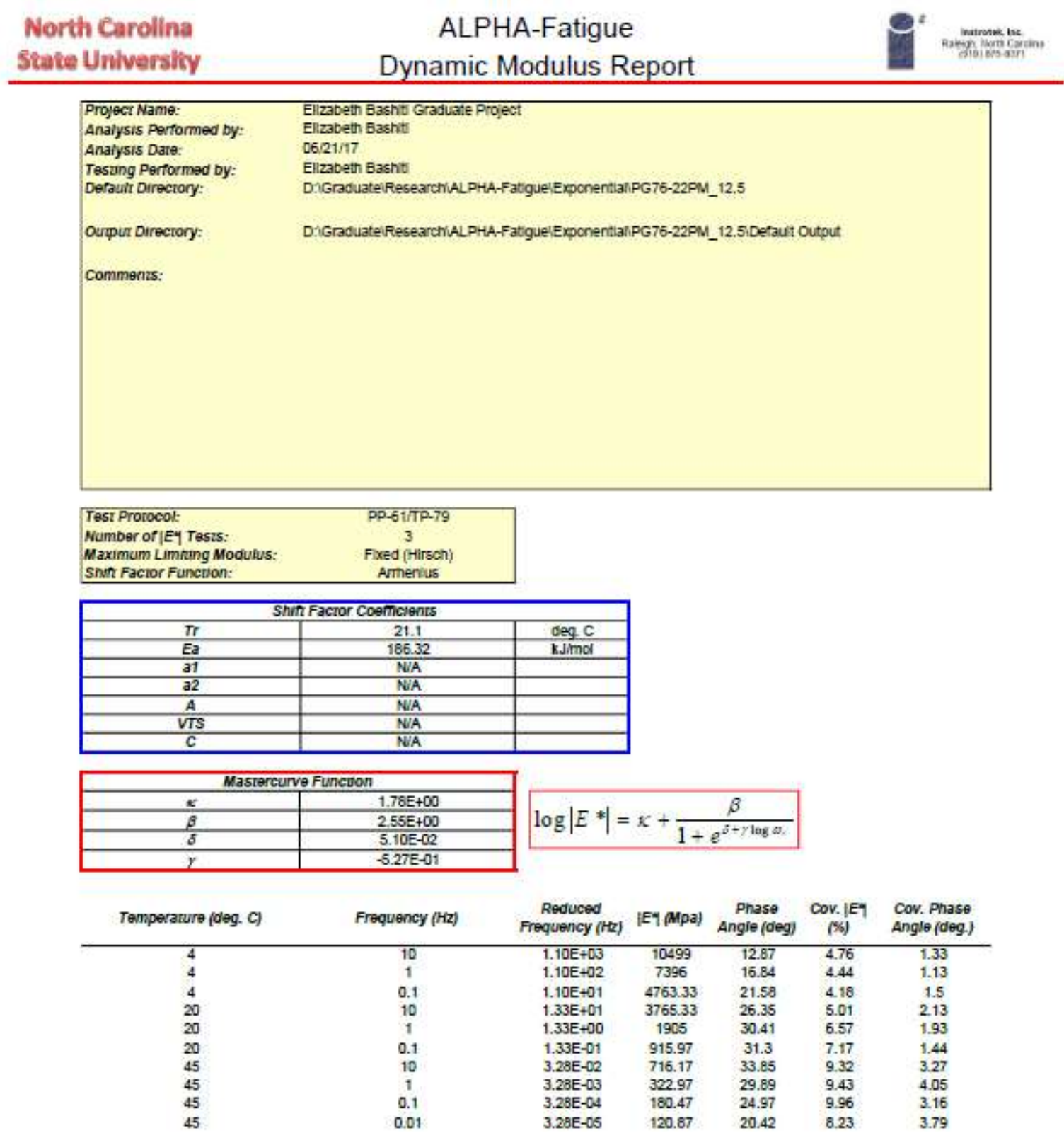


North Carolina

State Univeralty
ALPHA-Fatigue
VECD Model Report

Projecr Name:

Analysis Performed by:

Analysis Date:

Tesung Performed by:

Defauth Direciory:

Oupur Directory:

Comments:
Ellzabeth Bashit Graduate Project

Ellzabeth Basht:

$06 / 21 / 17$

Ellzabeth Basht

D.lGracuateiResearchiLLPHA-FatiguelExponential:PG76-22PM_12.5

DigracuateiResearch/ALPHA-FatguelExponentlah:PG76-22PM_12.51Defaut Output

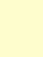


North Carolina State Unlversiky
ALPHA-Fatigue Model Predictions Report

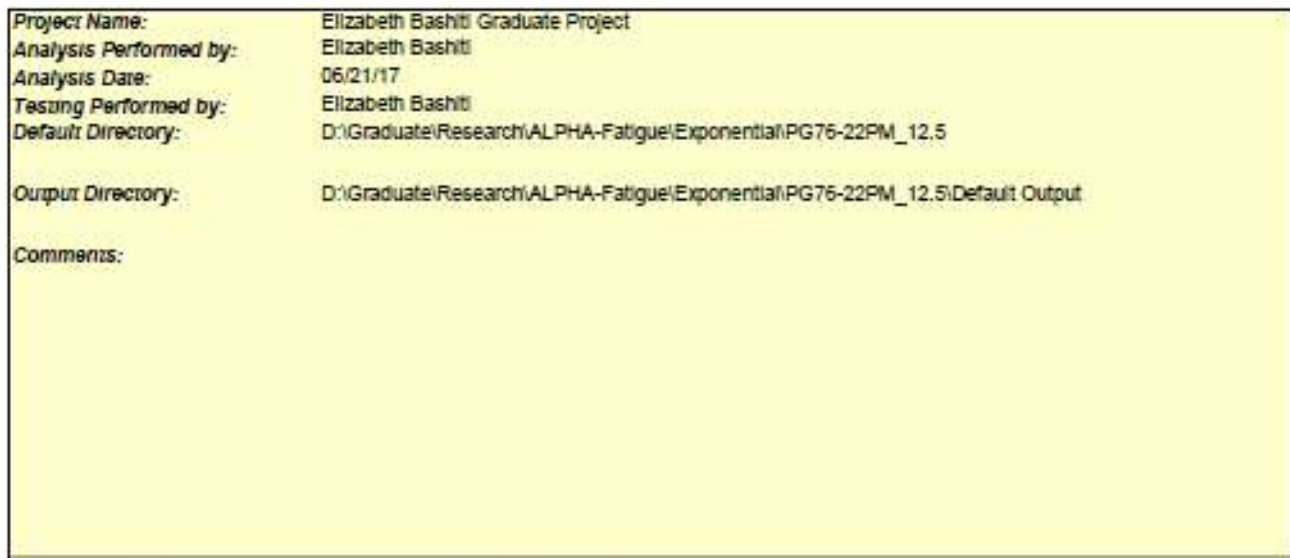

\begin{tabular}{|c|c|}
\hline \multicolumn{2}{|c|}{ Tradivonal Strain Favgue Relasionship (kPa unirs) } \\
\hline$K 1$ & $4.92 E+05$ \\
\hline$K 2$ & 1.054 \\
\hline$K 3$ & -0.816 \\
\hline
\end{tabular}

$$
N_{1}=K_{1}\left(\frac{1}{\varepsilon_{1}}\right)^{K_{2}}(|E *|)^{K_{3}}
$$

Tradmional Suess Faugue Reladonship 1 (KPa unns)

$$
\begin{aligned}
& K 1 \\
& K 2 \\
& K 3
\end{aligned}
$$
$87 \mathrm{C}+0.3$ $-1.901$

$$
N_{f}=K_{1}\left(\sigma_{i}\right)^{K_{2}}\left(\left|E^{*}\right|\right)^{K_{3}}
$$

Tradmional Stress Fawigue Relawonshtp 2 (kPa unns)

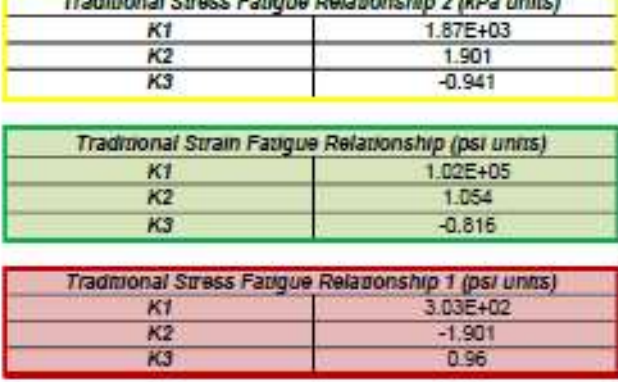

$$
N_{f}=K_{1}\left(\frac{1}{\varepsilon_{i, i n \mid}}\right)^{K_{2}}(|E *|)^{K_{3}}
$$

Tradruanal Suress Fangue Relagonship 2 (pst unns)

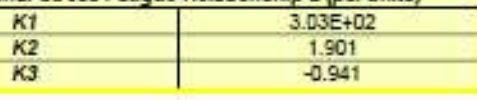

$$
N_{1}=K_{1}\left(\frac{1}{\varepsilon_{1}}\right)^{K_{2}}(|E *|)^{K_{3}}
$$

$$
N_{j}=K_{1}\left(\sigma_{i}\right)^{K_{2}}\left(\left|E^{*}\right|\right)^{K_{1}}
$$

\begin{tabular}{|c|c|}
\hline$K 1$ & $3.03 E+02$ \\
\hline$K 2$ & 1.901 \\
\hline$K 3$ & -0.941 \\
\hline \multicolumn{2}{|c|}{} \\
\hline Endurance Limn (mucrosuratin) \\
\hline Temperature (deg. C) & Endurance Limit \\
\hline 5 & 4 \\
\hline 10 & 4 \\
\hline 15 & 5 \\
\hline 20 & 6 \\
\hline 25 & 7 \\
\hline
\end{tabular}

$$
N_{f}=K_{1}\left(\frac{1}{\varepsilon_{i, j i}}\right)^{K_{2}}(|E *|)^{K_{3}}
$$




\section{PG 76-22 PM 12.5 mm Peak Output}

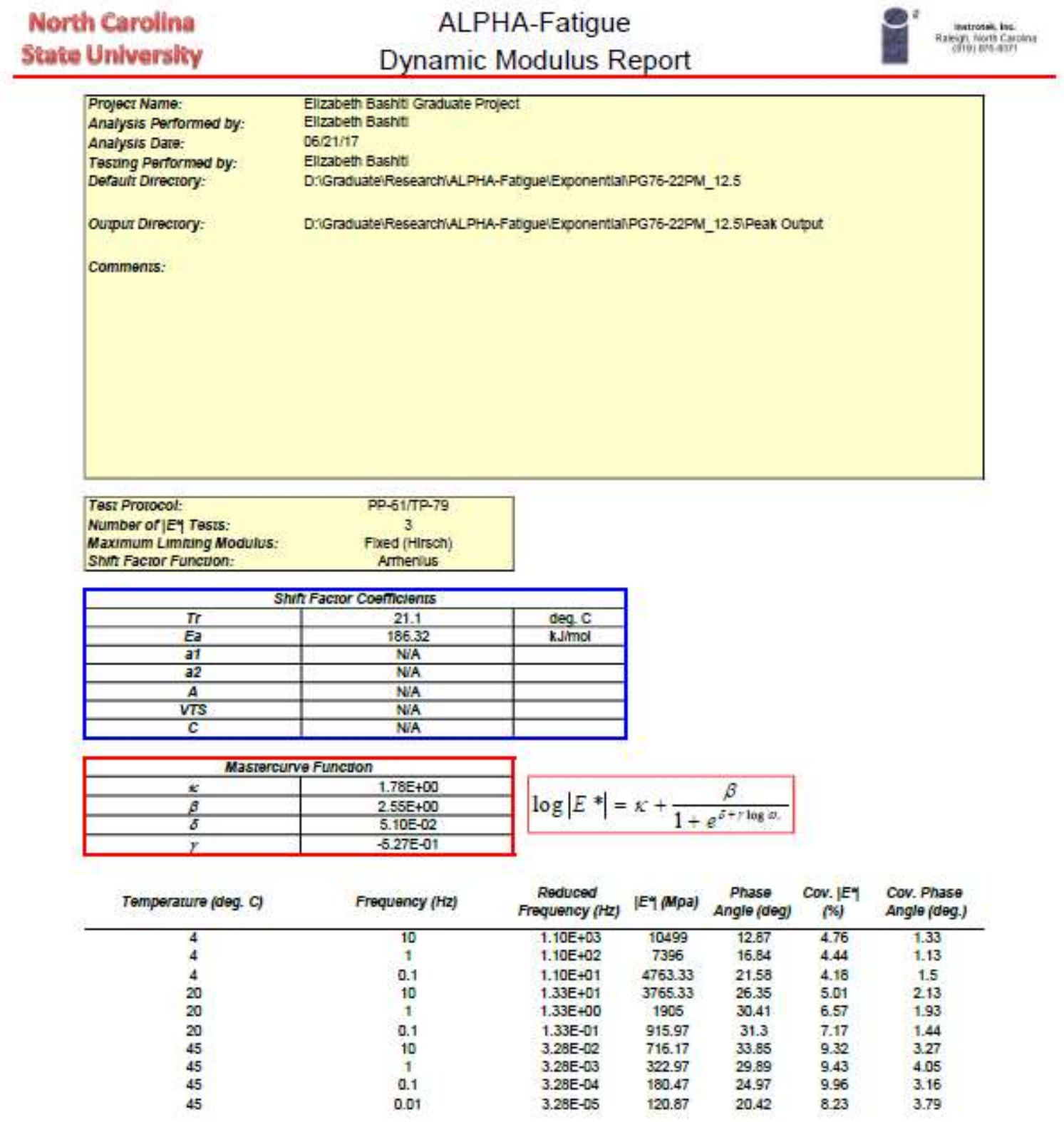




\begin{tabular}{c} 
North Carollina \\
State Universlity \\
\hline
\end{tabular}

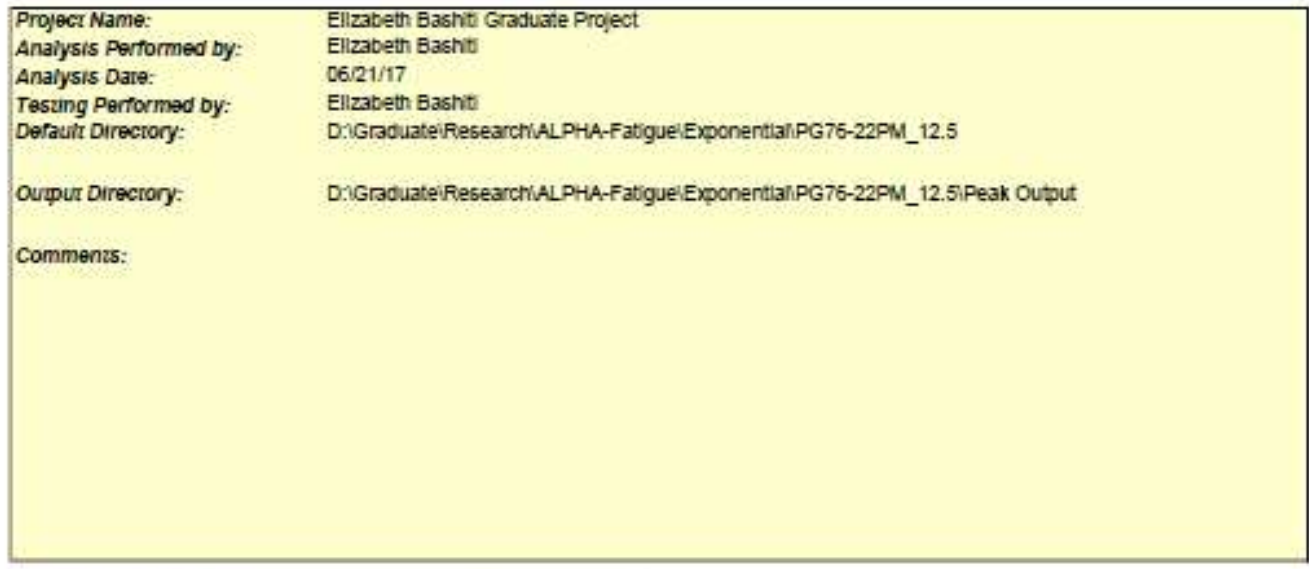

\begin{tabular}{lc|}
\hline Number of Fazigue Tests: & 9 \\
Damage Model Funcuon: & Exponental
\end{tabular}

\begin{tabular}{|c|c|}
\hline \multicolumn{2}{|c|}{ Damage Model Coemcienus } \\
\hline$a$ & $-225 E-04$ \\
\hline$D$ & $7.28 E-01$ \\
\hline$y$ & N/A \\
\hline$z$ & N/A \\
\hline alpha & 3.929 \\
\hline Paramerer $r$ in Fallure Cric. & $4.52 E+05$ \\
\hline Parameser s in Faifure Crit. & S.6SE-01 \\
\hline
\end{tabular}

$$
\begin{aligned}
& C=e^{\omega S^{b}} \\
& C=1-y S^{2} \\
& N_{f}=r\left(G^{h}\right)^{t}
\end{aligned}
$$

\begin{tabular}{|c|c|c|c|c|c|c|}
\hline Test Name & Temperamure (deg. C) & Frequency $(\mathrm{Hz})$ & $\begin{array}{l}\text { [EYcue } \\
\text { (MPa) }\end{array}$ & $\begin{array}{c}\mid E Y_{\text {mow }} \\
\text { (MPa) }\end{array}$ & NF & $G^{n}$ \\
\hline PG76-22PM_12.5_FT1A & 15 & 10 & 5746.4 & 6154 & 98610 & $1.4 D E+D 1$ \\
\hline PG76-22PM_12.5_FT1B & 15 & 10 & 5731.4 & 6429 & 11152 & $6.56 E+02$ \\
\hline PG76-22PM_12.5_FT1C & 15 & 10 & 5753.8 & 6771 & 20086 & $2.93 \varepsilon+02$ \\
\hline PG76-22PM_12.5_FT2A & 15 & 10 & 5745.1 & 6917 & 98510 & $241 E+01$ \\
\hline PG76-22PM_125_FT28 & 14.9 & 10 & 5761.6 & 5759 & 19377 & $2.49 E+02$ \\
\hline PG76-22PM_12.5_FT2C & 14.9 & 10 & 5767.2 & 6521 & 22244 & $1.83 E+02$ \\
\hline PG76-22PM_12.5_FT3A & 15 & 10 & 5744.1 & 5911 & 97606 & $1.02 E+01$ \\
\hline PG76-22PM_12.5_FT38 & 15 & 10 & 5743.5 & 6428 & 11383 & $5.28 \varepsilon+02$ \\
\hline PG76-22PM_12.5_FT3C & 15 & 10 & 5738.6 & 6014 & 26887 & $1.94 E+02$ \\
\hline
\end{tabular}


North Carolina Scate Untversily
ALPHA-Fatigue Model Predictions Report

\begin{tabular}{|c|c|}
\hline Projecr Name: & Elizabeth Basht Graduate Project \\
\hline Analysis Pertormed by: & Elzabeth Basht \\
\hline Anafiysis Dare: & $06 / 21 / 17$ \\
\hline Tesung Performed by: & Elizabeth Basht \\
\hline Defauk Direcrory: & D:GraduateiResearch(ALPHA-FatiguelExponentian:PG76-22PM_12.5 \\
\hline Oumpun Directory: & 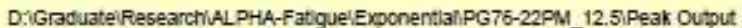 \\
\hline
\end{tabular}

comments:

Tradrional STrain Favgue Relationship (kPa units)

\begin{tabular}{|c|c|}
\hline$K 1$ & $4.58 \mathrm{E}+12$ \\
\hline$K 2$ & 3.287 \\
\hline$K 3$ & -2.821 \\
\hline
\end{tabular}

\begin{tabular}{|c|c|}
\hline \multicolumn{2}{|c|}{ Tradmonal Swess Fangue Relavonship 1 (KPa unns) } \\
\hline$K 1$ & $9.67 \mathrm{E}-04$ \\
\hline$K 2$ & -5.632 \\
\hline$K 3$ & 3.645 \\
\hline
\end{tabular}

Tradmonal Suress Fangue Reladonshyp 2 (KPa unms)

\begin{tabular}{|c|c|}
\hline Tradmonaf Suress Fanigue Relavonship 2 (KPa unns) \\
\hline K1 & $9.67 \mathrm{E}-04$ \\
\hline K2 & 5.632 \\
\hline$K 3$ & -1.986
\end{tabular}

Tradiuonal Suain Faugue Relanionship ( $\mathrm{psi}$ unnts)

\begin{tabular}{|c|c|}
\hline \multicolumn{2}{|c|}{ Tradiuonal Suan Favgue Relanionship (psi units) } \\
\hline K1 & $1.97 \mathrm{E}+10$ \\
\hline$K 2$ & 3.287 \\
\hline$K 3$ & -2.821 \\
\hline
\end{tabular}

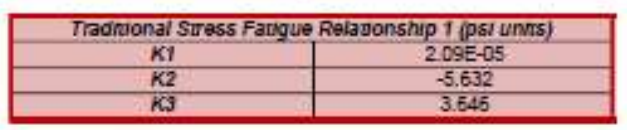

Tradiuonal Suress Fangue Relamonship 2 (psi unms)

\begin{tabular}{|c|c|}
\hline$K 1$ & $2.09 E-05$ \\
\hline$K 2$ & 5.632 \\
\hline$K 3$ & -1.986 \\
\hline
\end{tabular}

\begin{tabular}{|c|c|}
\hline \multicolumn{2}{|c|}{ Endurance Limn (microsurain) } \\
\hline Temperature (deg. C) & Endurance Limit \\
\hline 5 & 39 \\
\hline 10 & 45 \\
\hline 15 & 57 \\
\hline 20 & 71 \\
\hline 25 & 99 \\
\hline
\end{tabular}

$$
N_{i}=K_{1}\left(\frac{1}{\varepsilon_{i}}\right)^{K_{2}}(|E *|)^{K_{3}}
$$

$N_{f}=K_{1}\left(\sigma_{i}\right)^{K_{2}}\left(\left|E^{*}\right|\right)^{K_{3}}$

$N_{f}=K_{1}\left(\frac{1}{\varepsilon_{t, j a n}}\right)^{K_{4}}\left(\left|E^{*}\right|\right)^{K_{3}}$ $N_{f}=K_{1}\left(\frac{1}{\varepsilon_{i}}\right)^{K_{2}}(|E *|)^{K_{3}}$

$$
N_{j}=K_{1}\left(\sigma_{t}\right)^{K_{2}}\left(\left|E^{*}\right|\right)^{K_{3}}
$$

$N_{f}=K_{1}\left(\frac{1}{\varepsilon_{l, w}}\right)^{K_{3}}\left(\left|E^{*}\right|\right)^{K_{3}}$ 